\title{
Recent Developments in Yugoslav Archaeology
}

\author{
edited by \\ J. C. Chapman, J. Bintliff, \\ V. Gaffney and B. Slapšak
}

BAR International Series 431

1988 


\title{
B.A.R.
}

5, Centremead, Osney Mead, Oxford OX2 0DQ, England.

\author{
GENERAL EDITORS
}

A.R. Hands, B.Sc., M.A., D.Phil.

D.R. Walker, M.A.

BAR -S431, 1988: 'Recent Developments in Yugoslav Archaeology'

Price $£ 16.00$ post free throughout the world. Payments made in dollars must be calculated at the current rate of exchange and $\$ 8.00$ added to cover exchange charges. Cheques should be made payable to B.A.R. and sent to the above address.

(C) The Individual Authors, 1988

\section{ISBN 0860545563}

For details of all new B.A.R. publications in print please write to the above address. Information on new titles is sent regularly on request, with no obligation to purchase.

Volumes are distributed from the publisher. All B.A.R. prices are inclusive of postage by surface mail anywhere in the world.

\section{Printed in Great Britain}


This volume is dedicated to those great landimprovers - the first farmers who introduced

stone clearance and the art of cairn- and terrace-

building to the karstlands of Yugoslavia. 
TABLE OF CONTENTS

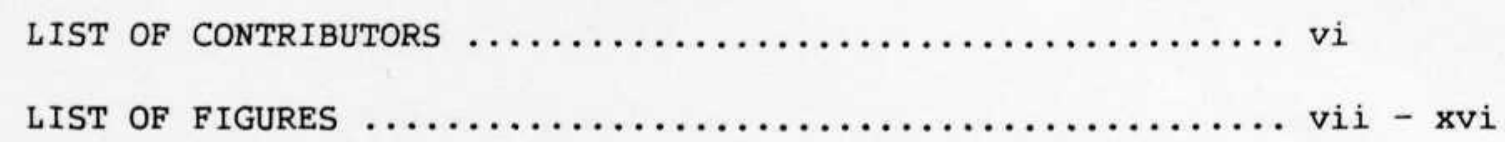

INTRODUCTION ...............John Chapman \& John Bintliff xvii - xix

PART ONE : THE NEOTHERMAL DALMATIA PROJECT

CHAPTER 1 The Neothermal Dalmatia Project - Archaeological survey results ........John Chapman \& Robert Shiel $001-030$

CHAPTER 2 The extent of change in the agricultural landscape of Dalmatia, Yugoslavia, as a result

of 7,000 years of land management $\ldots \ldots \ldots \ldots \ldots$

............................ Shiel \& John Chapman $031-044$

CHAPTER 3 The Neolithic animal husbandry of Smilëić and Nin ....................................... Schwartz 045 - 075

CHAPTER 4 Dalmatian pottery : spots before the eyes $\ldots . .$.

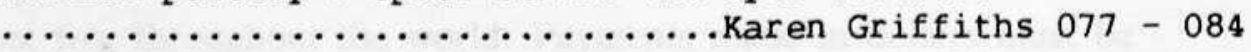

CHAPTER 5 The potential for the analysis of Early Medieval pottery in Dalmatia ...................... Evans 085 - 099

CHAPTER 6 An ethno-archaeological study of pottery production on the Dalmatian island of $\mathrm{I} \overline{\mathbf{z}} \ldots \ldots \ldots$

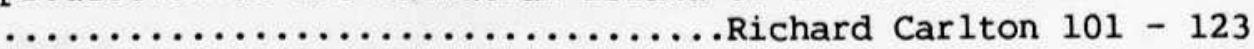

CHAPTER 7 Ethnoarchaeology and Latinity in the mountains of the southern Velebit ..................... Nandris 125 - 143 
PART TWO : HVAR

CHAPTER 8 The 1982-1986 Ager Pharensis survey. Potentials and limitations of 'wall survey' in karstic environments ................. Boz̄idar Slaps̄ak 145 - 149

CHAPTER 9 The Ager Pharensis / Hvar Project 1987 .........

................. John Bintliff \& Vince Gaffney 151 - 175

CHAPTER 10 Maslinovik : a Greek watchtower in the Chora of

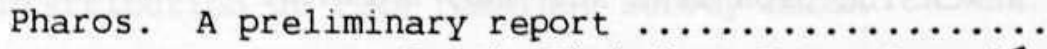

............... Branko Kirigin \& Petar Popović 177 - 189

CHAPTER 11 A modular analysis of the field system of pharos.

................ Zoran Stanc̄ić \& Boz̄idar Slaps̄ak 191 - 199

PART THREE : SLOVENIA

CHAPTER 12 Mineralogical research on the Neolithic ceramic assemblage from Moverna Vas ........ Igor Klopc̄ič 201 - 209

CHAPTER 13 The social context of the introduction of iron in

the Early Iron Age of Slovenia .........Phil Mason 211 - 223

CHAPTER 14 An interim report of survey work carried out at Sveti Jakob, a multi-period hilltop settlement above Dovsko (Senovo), Slovenia ........Uros Bavec 225 - 238

CHAPTER 15 Coming down from the hills. A preliminary report on the intensive surface collection of a lowland Iron Age activity area in Slovenia ....Phil Mason $239-245$ 


\section{LIST OF CONTRIBUTORS}

Uros Bavec, University of Ljubljana, Filozofski Fakultet, Arheološki Odeljenje, 61000 LJUBLJANA, Aškerc̄eva 12, YUGOSLAVIA.

John Bintliff, University of Bradford, Schools of Studies in Archaeological Sciences, BRADFORD, West Yorkshire, BD7 1DP, BRITAIN.

Richard Carlton, University of Newcastle upon Tyne, Department of ArchaeologY, NEWCASTLE UPON TYNE NE1 7RU, BRITAIN.

John Chapman, University of Newcastle upon Tyne, Department of ArchaeologY, NEWCASTLE UPON TYNE NE1 7RU, BRITAIN.

Huw Evans, University of Newcastle upon Tyne, Department of Archaeology, NEWCASTLE UPON TYNE NEI 7RU, BRITAIN.

Vince Gaffney, University of Bradford, Schools of Studies in Archaeological Sciences, BRADFORD, West Yorkshire, BD7 1DP, BRITAIN.

Karen Griffiths, University of Newcastle upon Tyne, Department of Archaeology, NEWCASTLE UPON TYNE NE1 7RU, BRITAIN.

Branko Kirigin, Arheoloski Muzej, 58000 SPLIT, Frankopansa 25, YUGOSLAVIA.

Igor Klopc̄ić, University of Ljubljana, Filozofski Fakultet, Arheolos̄ki Odeljenje, 61000 LJUBLJANA, As̄kerc̄eva 12, YUGOSLAVIA.

Phil Mason, University of Ljubljana, Filozofski Fakultet, Arheolos̄ki Odeljenje, 61000 LJUBLJANA, As̄kerc̄eva 12, YUGOSLAVIA.

John Nandris, University College London, Institute of Archaeology, 31-34, Gordon Square, LONDON WCIH OPY, BRITAIN.

Petar Popović, Arheološki Institut, 11000 BEOGRAD, Knez Mihailova 35, YUGOSLAVIA.

Charles Schwartz, 8227, Norton Avenue/No. 1, LOS ANGELES, CA 90046, USA.

Robert Shiel, University of Newcastle upon Tyne, Department of Agricultural and Environmental Sciences; NEWCASTLE UPON TYNE NE1 7RU, BRITAIN.

Boz̄idar Slaps̄ak, University of Ljubljana, Filozofski Fakultet, Arheolos̄ki Odeljenje, 61000 LJUBLJANA, As̄kerc̄eva 12, YUGOSLAVIA.

Zoran Stanc̄ić, University of Ljubljana, Filozofski Fakultet, Arheolos̄ki Odeljenje, 61000 LJUBLJANA, As̄kerc̄eva 12, YUGOSLAVIA. 
Figure 1.1 Location map of project study area, survey transects and survey block.

Figure 1.2 Distribution of Neolithic/Eneolithic remains.

Figure 1.3 Distribution of Bronze Age remains.

Figure 1.4 Distribution of Iron Age remains.

Figure 1.5 Distribution of Roman remains.

Figure 1.6 Distribution of Medieval remains.

Figure 1.7 Distribution of Iska remains, survey block

Figure 1.8 Distribution of modern settlement remains.

Figure 1.9 Distribution of later chipped stone remains.

Figure 1.10 Distribution of cairns.

Figure 1.11 Distribution of linear features.

Figure 1.12 Distribution of later settlement remains.

Figure 2.1 Block diagram of the landscape units, study area.

Figure 2.2 Changes since the Neolithic period in (a) land type and (b) land-use suitability.

Figure 2.3 Distribution of modern land classes in the survey block (key as in Figure 2.1).

Figure 3.1 Variation in sheep metacarpals : Obre, Tinj, Nin reports on excavations and fieldwork which appear in 'Arheoloski Pregled' testify to the wide-ranging archaeological activities in all republics. and Smilcic.

Figure 3.2 Variation in goat metacarpals : Obre, Tinj, Nin and Smilcic.

Plate 3.1 1. Cut marks. Cattle phalange III; Early Neolithic, Bag 44, 40-60 cm. 2. Cut marks. Cattle phalange III: a. dorsal view b. lateral view. Early Neo. Sonda 13, 60-70 cm. 3. Cut marks. Cattle phalange III. a. medial view b. dorsal view. Early Neo. Sonda 15, 100-120 cm.

Plate 3.2 1. Cut marks. Cattle phalange III, dorsal view. Early Neolithic Sonda 13, 60-70 cm. 2. Cut marks. Cattle phalange III, lateral view. Early Neolithic Bag 44, $94 \mathrm{~cm}$. 3. Cut marks. Cattle phalange III, ventral-lateral view; Middle Neolithic. Sonda $12,30-40 \mathrm{~cm}$. 4 . Cut marks. Cattle phalange III. a. ventral-lateral view b. medial view. Early Neolithic. Bag 44, $94 \mathrm{~cm}$.

Plate 3.3 1. Gnawing. Domestic dog radius. a. dorsal view b. ventral 
view. Middle Neolithic Sonda 9, 160-180 cm. 2. Gnawing. Caprovine ulna, dorsal view. No location. 3. Gnawing. Goat distal humerus, ventral view. Middle Neolithic Sonda 1, 160-170 cm. 4. Cut marks. Sheep horncore; Middle Neolithic, Sonda 1, 80-130 cm.

Plate 3.4 1. Premolar alignment (straight). Domestic dog mandible. a. lateral view b. dorsal view; Early Neolithic, Sonda 15, 150-160 cm. 2 . Hornless sheep skull fragment. Early Neolithic, Sonda 14, 100-120 cm. 3 . Premolar alignment (unaligned). Domestic dog mandible, medial view. Middle Neolithic, Sonda 9, 160-180 cm. 4. Modified. Caprovine acetabulum. Early Neolithic, Bag 44, 110-120 cm.

Plate 3.5 Pathology. Healed break, left metatarsal, Red Deer. a. dorsal view b. dorsal-lateral view c. ventral view.

Plate 3.6 1. Hornless sheep, Nin: skull fragment. a. ventral medial view b. dorsal lateral view. Early Neolithic, Unit 2. 2. Wild horse, Nin. dorsal view. Early Neolithic, Unit 2.

Figure 4.1 Plan of Nadin-Gradina, with location of 1986 sondas.

Figure 4.2 Cooking wares, Nadin-Gradina 1986 excavations.

Figure 4.3 Distribution of cooking wares, Sondas 1 and 3 , Nadin.

Figure 4.4 Distribution of cooking wares, Sondas 1 and 3, Nadin.

Figure 4.5 Sources of pottery imported into Nadin.

Figure 5.1 Distribution of findspots of Early Croatian pottery in north Dalmatia.

Figure 5.2 a. A model of economic costs and returns of pottery production. Source: Arnold 1986. b. Travel distance for potting clay (solid line) and temper (dashed line). Source: Arnold 1986.

Figure 5.3 Vessel height vs. waist diameter/widest body diameter: Stankovci and Materiza. Figure 5.4 Vessel height vs. basal diameter: Stankovci and Materiza.

Figure 5.5 Rim height vs. rim weight: all pots.

Figure 5.6 Vessel height vs. widest body diameter: Materiza.

Plate 6.1 Romano VLAKHOV, Potter, using a quernstone mill to grind calcite for use as temper. Veli İ̃, Dalmatia.

Plate 6.2 Mato GAVRAN, Potter, with his hand-wheel and a newly-thrown pot. Doboj, Bosnia.

Plates $6.3-6.8$ Stages in the manufacture of a large bread-oven, or crpnja, by Marijan and Libero SUTLOVIC. Veli Iz, Dalmatia. 
Plate 6.3 Forming a base for the vessel sides.

Plate 6.4 Adding the last coil prior to smoothing and shaping.

Plate 6.5 Adding the handles. Note the complete range of wooden tools to the right of the potter. The clay used by both potters in the workshop is behind the water container.

Plate 6.6 Pots being positioned ready for firing, after being pre-heated in the sun.

Plate 6.7 Crpnje in place ready for firing. Note the use of large stones and a broken sherd in stacking the pots.

Plate 6.8 Burning dried grass and olive cuttings on top of the pots. Note the rubbish tip (top right), which slightly overlaps with the firing area.

Figure 7.1 Map of southern Velebit Mountains, Yugoslavia.

Figure 9.1 The island of Hvar

Figure 9.2 The Ager Pharensis land division system with known Roman sites.

Figure 9.3 Area of field system surveyed in the 1987 season.

Figure 9.4 Results from part of the extensive survey showing site and offsite pottery distributions. The Roman villa site of Cerevac is represented by the dense pottery concentrations at the top of the area shown.

Figure 9.5a Site Pl (delimited by dashed area) within the context of results from extensive survey in its vicinity. Darker numbers denote finds on field walls; continuous line delimits area of artefact densities over 5 .

Figure 9.5b Site P1, intensive survey results, contour at 9 sherds; shaded strip inaccessible,

Figure 9.5c Site Pl, extensive survey results after correction for visibility

Figure 9.6a Site P2 (delimited by dashed area) within the context of the extensive survey results. For key, see figure $5 a$.

Figure 9.6b Site P2, intensive survey results, raw data

Figure 9.6C Site P2, intensive survey results after correction for visibility

Figure 9.7a Site P4 within the context of the extensive survey results. For key, see figure 9.5a. 
Figure 9.7b Site P4, intensive survey results. For key, see figure 9.5a. Figure 9.8 The situation of the Villa Jeze (left) and modern Vrboska (right).

Figure 9.9 The relationship of the surface and sub-surface collection grids used at Jeze.

Figure 9.10 The distribution of artefacts at Jeze as determined by extensive surface collection (hard data).

Figure 9.11 The distribution of artefacts at Jeze as determined by intensive surface collection.

Figure 9.12 A volumetrically corrected sub-surface distribution of all artefacts at Jeze.

Figure 9.13 The distribution of sub-surface tesserae/mortar at Jeze

Figure 10.1 Elevation of tower, Maslinovik

Figure 10.2 Pottery from Maslinovik

Figure 10.3 Map of the Starigrad plain, showing location of Maslinovik, Tor and Pharos, and lines of sight.

Plate 10.1 Excavations in progress at Maslinovik. North to top.

Plate 10.2 Excavations in progress at Maslinovik. North to top.

Plate 10.3 Excavations in progress at Maslinovik. North to top.

Plate 10.4 View of tower from South west.

Plate 10.5 Interior of the tower from North.

Plate 10.6 Tor : view of the South East corner. Upper part reconstructed.

Figure 11.1 Frequency distribution of all measurements, Pharos centuriation system.

Figure 11.2 Distribution of measurements by direction (solid bars = E - $\mathrm{W}$; stippled bars $=\mathbf{N}-\mathrm{S})$.

Figure 11.3 Standard deviation of road widths

Figure 11.4 Adjusted frequency distributions of standard deviations of road width (key as in Fig. 11.2).

Figure 13.1 Comparative chronology in the South East Alpine region in the early first millennium BC (after Dobiat 1980 and Dular 1982). 
Figure 13.2 Geographical background of Slovenia

Figure 13.3 Prehistoric communications showing major Late Bronze Age and Early Iron Age sites.

Figure 14.1 Slovenia and the position of Sveti Jakob

Figure 14.2 Finds from Sveti Jakob: 1 - worked cores 2 - serpentine axe 3-4 - Eneolithic pottery

Figure 14.3 The location of the extensive surface collection grid.

Figure 14.4 The distribution of all flints collected within the extensive collection grid.

Figure 14.5 Flint implement and core distribution.

Figure 14.6 Flint artifact types : densities per square metre.

Figure 14.7 The distribution of all prehistoric pottery within the extensive collection grid.

Figure 14.8 Prehistoric pottery densities per square metre.

Plate 14.1 View of surveyed area below Sveti Jakob. North to top.

Figure 15.1 The location of the survey area in Slovenia

Figure 15.2 Site locations in the survey area: (1) Magdalenska gora; (2)

Cikava. Stippled areas above $400 \mathrm{~m}$ asl.

Figure 15.3 Sherd densities, surface survey of Cikava. 
The history of Yugoslav archaeology is the story of the domination of archaeological survey by site excavation. From the 19th. century researches into Classical cities such as Salona and Pula to the modern international excavation projects at, inter alia, Obre, Anza, Divostin, Selevac and Gomolava, major resources have been devoted to efforts to answer site-based questions by intensive, if destructive, site-based investigations. There is a long history of archaeological reconnaissance in Yugoslav fieldwork but the goals of this research were related more often to the discovery of sites to excavate rather than to the recovery of information with its own inherent value (Chapman, in press). In its own way, this volume is a record of alternative lines of research which now complement the site-based approach to Yugoslav archaeology.

This volume is an extended conference report of a meeting of the same name, organized by one of us (J. B.) at the University of Bradford in December 1987. The meeting was attended by a large delegation from Yugoslavia, consisting of both scholars and research students, as well as a representative sample of British sclmolars specializing in Eastern European archaeological studies. The nature of the conference programme inevitably laid stress on the results of institutional collaboration between Yugoslav and British universities and museums, several of which currently bear fruit in fieldwork partnerships. The main chains in the present links between Yugoslavia and Britain are, on the Yugoslav side, Zadar, Ljubljana and Split and, on the British side, Newcastle upon Tyne and Bradford. It is a result of these connections and associated fieldwork that the three focus areas of the volume - Neothermal Dalmatia, Hvar and Slovenia - have been chosen. It should not, however, be concluded from the range of research presented here that other important archaeological studies are not being carried out in all other parts of the country. The annual reports on excavations and fieldwork which appear in 'Arheolos̄ki Pregled' testify to the wide-ranging archaeological activities in all republics.

The range of new approaches formulated to the common problems of prehistoric and historic archaeological research can be encompassed within six ideas, two theoretical and four methodological. First, the importance of explanation of cultural change, at whatever scale, provides a leitmotif for these investigations. The processualist notion of covering-law theory and law-like, predictable change has been rejected in favour of a probabilistic attempt to relate variables, whether couched in systemic or non-systemic terms, in more complex causal chains (see papers by Chapman \& Shiel, Mason). The role of ethno-science, whether in studies of land use or technology, has become central to the generation of structured analogies and homologies (see papers by Shiel \& Chapman, Nandris, Carlton). 
A second theoretical insight is the importance of the contrasting effects of studying short-term versus long-term phenomena, whether in a Braudelian framework (Bintliff (ed), in press) or as part of analyses of social power (Mann 1986). The common and contrastive effects of settlement and social change in karstic landscapes require analysis in relation to shorter-term cycles of economic progress and decline. Aspects of these cyclical processes are touched on as a way of relating the study areas in question to a wider arena in both spatial as well as temporal terms (see papers by Chapman \& Shiel, Bintliff \& Gaffney).

It is not surprising that such theoretical perspectives should generate new methodologies for application both in the field and in the laboratory. Four approaches have been developed in an attempt to investigate hypotheses generated from these theories - landscape archaeology, ethno-archaeology, intensive field survey and scientific archaeology.

The clearest link between the Braudelian view of the past and recent Yugoslav developments concerns the approach of landscape archaeology. This field attempts to document the evolution of the countryside from the earliest times and define the principal constraints and opportunities offered to any given mode of production. This approach is based on the notion of a landscape context for every site/non-site, in which the significance of a site/non-site can be partially assessed by its effect on future landscapes. The stone monuments of the karst are particularly amenable to such an approach, since, once built, rarely removed - hence the dedication of this volume. This cumulative development of the countryside is, perhaps paradoxically, best approached through a retrogressive analysis of the terrain, starting from the best-known period of today and working backwards in time.

It is precisely this aspect of making the maximum use of present-day information in support of building models of past behaviour that characterizes the second methodological approach - that of ethnoarchaeology. While accepting the limitations of applying knowledge about the present to different periods in the past, the ethnoarchaeologist may counter by stating that this is indeed a strategy that characterizes all archaeological work. The range of relationships between modern behaviour and the generation of material remains can be very wide; this variability enforces a more reflexive approach to the interpretation of past behavioural residues. Likewise, in land use studies, the identification of modern patterns of agriculture and pastoralism provide but a starting point for the modelling of past economic systems (see Shiel \& Chapman).

Perhaps the feature which most characterizes this volume is the application of techniques of intensive, systematic survey, geophysical survey and analytical field survey at the regional level in different parts of Yugoslavia. In each of the three focus areas - the Zadar lowlands, Hvar and Slovenia - major investment in intensive survey has yielded the basis for settlement archaeology and hence the potential for the interpretation of long-term social change. Selection of specific survey methodologies varies with the aims of different projects - more 
intensive, site-based geophysical and surface pick-up surveys on Hvar and in Slovenia (papers by Bintliff \& Gaffney, Slaps̄ak, Bavec, Mason), more regional in cover with selected analytical survey and trial excavation in the Zadar lowlands (see papers by Chapman \& Shiel, Griffiths). At a higher level, these differences reflect the scale at which researchers are attempting to characterize and explain human behaviour through the interpretation of surface remains.

Finally, the injection of scientific techniques of analysis into archaeology is beginning to yield impressive results. The application of characterization studies to ceramics (see paper by Klopéić) is parallelled by research on sourcing of stone artifacts in Yugoslavia (e.(en>g., the work of $K$. Bíró). Similarly, the value of subsistence information from earlier excavations is demonstrated in the faunal analyses of the important Neolithic sites of Smilc̈ić and Nin (see paper by Schwartz). And the integration of scientific studies of soil and settlement pattern data lies at the heart of the research strategy for the Neothermal Dalmatia project (see paper by Shiel \& Chapman).

The development and refinement of these new theoretical concepts and the existence of a range of appropriate methodologies provides an important boost for Yugoslav archaeological research. If the diffusion of such ideas and techniques is extended and enhanced by the appearance of this volume, then its purpose will have been well served. Further concrete results of these recent developments are to be presented at symposia to be held at regular intervals in future years. 
PART ONE : NEOTHERMAL DALMATIA 



\title{
CHAPTER ONE
}

\section{THE NEOTHERMAL DALMATIA PROJECT - ARCHAEOLOGICAL SURVEY RESULTS}

\author{
JOHN CHAPMAN \& ROBERT SHIEL
}

\subsection{INTRODUCTION}

The Neothermal Dalmatia Project (henceforth NDP) is an Anglo-Yugoslav co-operative project whose aim is to define and explain changes in environment, settlement pattern and social structure in the Zadar lowlands of north Dalmatia over the last 12,000 years. The inter-disciplinary nature of NDP is reflected in the papers in this volume relating to soil science and ethno-archaeology (see papers by Shiel and Chapman, Nandris, and Carlton, this volume); other disciplines with a full part to play in NDP include zoology, botany, history and geomorphology. Many of these subjects have not been fully integrated into Yugoslav archaeology until now and the results of NDP indicate the enormous potential for such inter-disciplinary studies.

In this paper, the results of five seasons of intensive, systematic survey in the Zadar Lowlands are presented. From 1982 to 1986, NDP teams completed archaeological field survey of c. $116 \mathrm{sq}$. $\mathrm{km}$. of predominantly limestone terrain. In the period 1984 - 1986, soil scientists from the University of Newcastle upon Tyne made a map of modern land use in the same area to provide an environmental data base with which to understand past geomorphological change and model past human subsistence and social behaviour. The current model for landscape evolution is presented below (Shiel \& Chapman, this volume). The constant interplay between archaeological distributions and land use change will be readily apparent; this dialectical relationship is one of the most important aspects of settlement studies.

\subsection{SURVEY METHODOLOGY}

The NDP survey was predicated on the selection of a study area of 2,400 sq. $\mathrm{km}$. , which encompassed the full range of environmental variation from sea-level to the peak of the Velebit Mountains, at 1,758 m. Because of topographical and geomorphological factors (viz., the widespread evidence for erosion on the higher karst), intensive systematic survey was restricted to the lowland parts of the zone, or Ravni Kotari (Fig. 1.1). Fieldwork was organised in two stages :-

1. an extensive transect survey across the grain of the countryside, in order to define the main environmental zones in the coastal plain and relate the distribution of monuments and surface finds to these zones.

2. an intensive block survey covering examples of each of the main lowland environmental zones, in order to define a representative set of settlement patterns through time for the lowland zone. 
The transect survey was completed in 1982 - 1983. Some $50 \mathrm{sq}$. km were covered, to include two transects north-east of Zadar and a longer transect south-east of the city. The 1-km width of the transect is a compromise between the normally narrower transects designed to maximise cover of environmentally varied areas and wider strips permitting the recovery of some elements of settlement pattern data which could reasonably be interpreted in relation to the environmental zonation. On the basis of the finds in this phase of survey, a $7 \times 11 \mathrm{~km}$ block was defined which included segments of three lowland valleys and two intervening limestone ridges. The inclusion of one of the major monuments in the Ravni Kotari - the multiperiod site of Nadin - near the edge of the survey block enabled us to pose questions about the relationships between major Iron Age hillforts / Roman municipia and the surrounding rural settlement in the respective periods.

The fieldwalking strategies for both transect and block survey phases were essentially similar except for the closer spacing of walkers across the countryside in the latter phase (Batovic \& Chapman 1985). Teams of ten walkers walked in parallel on fixed compass bearings ( 42 degrees/222 degrees) across the grain of the terrain. In the transect phase, spacings between walkers were more frequently $50 \mathrm{~m}$ than $25 \mathrm{~m}$; the reverse is true of the block survey. Each fieldwalker recorded archaeological remains on their own on individual bilingual recording forms, as well as on the available $1: 25,000$ base maps and collected surface material for dating and functional analysis. As soon as archaeological remains were discovered, an assessment of the total size of the scatter or monument was made and the number of collection units was determined according to that size. For sites of up to $30 \times 30 \mathrm{~m}$, one collection unit was used, located centrally in that distribution; two units were used for sites up to $50 \times 50 \mathrm{~m}$, three for sites up to $100 \times 100 \mathrm{~m}$ and four for larger sites. The standard collecting policy was to retrieve all visible material within a 5-metre square. This standardisation of collection policy enables the comparison of surface densities in areas of different environmental conditions in all areas of the survey.

Archaeological remains were classified into three categories for the purposes of fieldwork :-

1. single finds locations with between 1 and 3 artifacts in a collection unit

2. findspot locations with four or more artifacts in a collection unit

3. monuments locations with upstanding remains (e. g., clearance cairns, burial cairns or barrows, cists, enclosed sites, hill-forts, linear features, deserted Medieval villages, chapels, etc.).

The strategy of coverage of the landscape at 25 - or $50-\mathrm{m}$ spacings enables the comparison of large-scale spatial patterning of the survey remains in order to produce meaningful settlement patterns at the regional scale. 
The survey has not attempted to characterize intra-site patterning in any detail (cf. chapter by Bintliff \& Gaffney, this volume). Instead, medium-intensity survey permits the definition of zones of discard around and between nodes of settlement in the lowland zone.

\subsection{PROBLEMS IN THE INTERPRETATION OF ARCHAEOLOGICAL SURVEY DATA}

The interpretation of archaeological survey results falls into two overlapping stages:- (1) the validation of the apparent pattern of results, and (2) the establishment of the behavioural meaning of whatever pattern is validated. By 'validation', we address the question to what extent the survey data is a complete and representative sample of past residues of human activities; by 'meaning', we address the question of the classes of activity which have produced those material residues. Because past landscapes are irretrievable, being transformed continuously, the only available strategy for us is to proceed backwards in time, starting from the present and moving deeper and deeper into what L. P. Hartley called "the past (as) a foreign country", a place where "they do things differently there" (Hartley: quoted by Lowenthal 1985:1). This procedure of moving backwards from the partially known to the largely unknown is what I take to characterize ethnoarchaeology and all sciences which rely on the principle of uniformitarianism.

\section{3 .1 Survival}

The quantity of material collected in a typical Mediterranean zone survey is so great that it can sometimes blind us to the material remains which have not survived or been discovered. Do these gaps on survey maps constitute evidence of absence or the converse ?

Many human activities leave no by-product of material remains at all. The basis of all approaches to the study of the material culture that survives is that there is some systematic relationship between the behaviour and the material residue. Much attention has been devoted to identifying the transformations of these residues from the time of deposition to the time of discovery (Schiffer 1975: Binford 1982). Three processes are particularly important in altering the original pattern of material remains :- burial of remains through soil erosion, burial of sites through earthworm action, and destruction of remains exposed by soil erosion.

Geomorphological change can be apprehended at two different spatial scales - the regional (cf. Vita-Finzi 1969) and the local (cf. van Andel \& Runnels 1986). Major episodes of climatically-induced sedimentation can affect landscapes in many parts of the Mediterranean; local processes of sedimentation can often be related to human land use or misuse in specific landscapes. In the NDP, it has been possible to identify at least three episodes of local erosion and deposition consequent upon initial cultivation, with attendant deforestation, of an area. Downslope of such zones of destabilisation, erosion products are likely to have masked remains of previous periods. Comparison of settlement remains of a certain period with those of previous phases has revealed potentially 
interesting 'gaps' in distributions of earlier periods (Chapman \& Shiel, forthcoming).

The relationship of microfaunal activity to survey discovery lies in the often substantial quantities of earth moved to the surface in non-ploughed, mainly acidic areas (Darwin 1881). Earthworm activity will have occurred mainly on slopes and ridges where soil depth is sufficient to provide material for transport. Hence differential burial of some artifacts and perhaps even monuments is possible away from intensively cultivated areas.

A final factor which is difficult to quantify is the significance of modern land use differences, which permit varying degrees of visibility of presumed finds (see paper by Bintliff \& Gaffney, this volume). Recent practice focusses on areas which are extensively ploughed, rather than mixed areas of grassland and arable, with consequent visibility bias (Haselgrove 1985).

\section{3 .2 Meaning}

Human behaviour which produces material residues occurs both within and outside habitation sites (Gaffney et al. 1985). Survey archaeologists recognize that the often greater densities of surface remains on or near habitation sites are a reflection of the spatial concentration of activities (Thomas 1975). The continuous mapping of finds densities across the countryside has produced estimates of discard rates, currently divided into 'background noise' and 'site' patterning (Gallant 1982). The finds density at which 'background noise' becomes 'site' is not only region-specific but also varies through time within a region (e. g., the Ager Tarraconensis survey: Millett, n. d.; Keay, n. d.). Such diachronic variation in finds densities has been interpreted both as a reflection of the size of population (the 'pots = people' assumption) and as an indication of varying levels of artifact production independent of population sizes (the 'pots $=$ economy' assumption)(Millett 1985: n. d.). Millett (1985) proposes an independent test through quantifying the discard of sherds on excavated sites to provide a calibration for survey finds densities. However, the number of intervening variables between human activity and recovery of evidence is so great that it is hard to provide comparable units of observation and large enough samples for comparison. The definition of mean and higher-than-average levels of finds discard for each period has been attempted for NDP; this procedure enables not only a more objective definition of 'sites' and 'non-sites', but also indicates variations in discard through time.

There are a wide variety of mechanisms by which artifacts can appear in the countryside surrounding habitation sites. Most of these mechanisms contribute to a stochastic discard pattern through the palimpsest effect. The incorporation of artifacts into settlement middens which are then recycled as manure into nearby areas produces spatial patterning of off-site finds which is heavily-distance-dependent and of ten blurred by frequent changes in land use during and after the occupation. Systematic deposition of broken pots around rural huts used seasonally over a long 
period is another common mechanism for non-random off-site discard in Mediterranean survey areas.

\subsubsection{General}

This survey of the problems of interpretation of the activities which produce the surface finds distribution found during survey reveals the multiple calibrations of 'raw' survey data necessary to produce an accurate picture of past behaviours. Since each successive calibration introduces its own error factor into the study, there is a danger of the build-up of cumulative error scores of over $100 \%$. Two solutions to this dilemma seem possible:-

1. increasingly detailed surveys of progressively smaller areas, in which multiple regression analyses provide a mathematical basis for adjustments to increasingly 'cooked' survey data.

2. regional level survey which attempts to deal with broader questions of settlement pattern change at a higher level of generality, taking into account the transformations of the data base as far as possible.

Because no intensive, systematic survey had been completed in Dalmatia before the start of this project, NDP felt that a broad definition of settlement change was a priority, leaving the more detailed approach to a second phase of operations. Hence, NDP has selected the second strategY, building in checks on the interpretation of the survey data at each possible stage of interpretation.

\subsection{THE SURVEY DATA}

The NDP survey data fall into two categories : transect data and the results of the block survey. In this review, block survey data will be presented through a series of maps, while data from both transect and block survey will form the basis of the statistical treatment of the results. Initial consideration will be given to the density of finds in collection units, as a preliminary aspect of quantification.

Because the density of surface finds was mapped within 5 x $5 \mathrm{~m}$ collection quadrats, it has proved difficult to provide estimates of overall densities of classes of finds per sq. km. (as, e. g., the Ager Tarraconensis project; cf. the East Hants survey: Shennan 1985). However, analysis of finds densities in the collection units provides a comparable picture of discard by period and enables a clear distinction between 'sites' from 'non-sites'. The technique of calculating means, quartiles and octiles of finds density per collection unit gives a conservative estimate of surface distributions, while at the same time highlighting period-by-period differences in surface finds density (Table 1). 
Table 1 Density of surface finds per collection unit

\begin{tabular}{|c|c|c|c|c|c|c|c|c|}
\hline PERIOD & $\begin{array}{l}\text { PALAEO- } \\
\text { LITHIC }\end{array}$ & $\begin{array}{l}\text { NEOL ITHIC/ } \\
\text { ENEOLITHIC }\end{array}$ & $\begin{array}{c}\text { BRONZE } \\
\text { AGE }\end{array}$ & $\begin{array}{r}\text { IRON } \\
\text { AGE }\end{array}$ & ROMAN & $\begin{array}{l}\text { MEDI - } \\
\text { EVAL }\end{array}$ & IS̄KA & $\begin{array}{c}\text { LATER } \\
\text { CS }\end{array}$ \\
\hline N & 44 & 42 & 283 & 109 & 226 & 70 & 119 & 207 \\
\hline $\begin{array}{l}\text { UPPER } \\
\text { OCTILE }\end{array}$ & 12 & 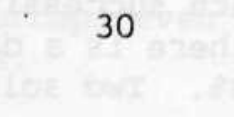 & 47 & 20 & 11 & 7 & $3-x+2 y=$ & 15 \\
\hline $\begin{array}{l}\text { UPPER } \\
\text { QUARTILI }\end{array}$ & 6 & 16 & 17 & 11 & 7 & 5 & 4 & 8 \\
\hline MEDIAN & 5 & 5 & 5 & 5 & 4 & 4 & 3 & 4 \\
\hline $\begin{array}{l}\text { LOWER } \\
\text { QUARTILI }\end{array}$ & 3 & 3 & 3 & 3 & $376=$ & $x_{619}$ & 2 & 2 \\
\hline $\begin{array}{l}\text { LOWER } \\
\text { OCTILE }\end{array}$ & 1 & 1 & 1 & 1 & 1 & 1 & 1 & 1 \\
\hline
\end{tabular}

The results of this analysis indicate that, in all periods, there is a low level of artifact density across parts of the landscape which corresponds partly to our category of 'single finds', partly to 'findspots'. In even larger parts of the surveyed area, no surface finds were recovered at all. Given the pragmatic need to classify surface remains into those areas which reflect habitation and those which do not, it is proposed here to define as residential sites those scatters whose value exceeds the mean value in the relevant time period (cf. Millett 1985).

The interesting and partly counterfactual pattern of finds densities amongst the 'sites' is the general trend to lower densities with time. Both Bintliff (1985) and Rutter (1983) have illustrated with Greek data the tendency for cumulative destruction of sites and ceramics the further back one goes in time; here, the pattern is for nucleated artifactual discard in the earlier prehistoric periods, followed by a greater dispersion of discard across more of the landscape from the Roman period onwards. What is impossible to calculate is tra percentage survival of individual classes of pottery; nevertheless, it seems likely that overall larger quantities of later material survive but in a more dispersed way. The peak of collection unit densities in the Neolithic/Eneolithic and Bronze Ages may also reflect high artifact recovery/visibility in soils that have recently been ploughed (Neolithic/Eneolithic) or eroded (Bronze Age). No data are yet available from NDP excavations for a multi-period comparison of the quantities of pottery production. The low values for even upper octiles in the Medieval and Is̄ka periods are perhaps only one of several reasons for the relative lack of abundance of such scatters in the survey. 
Using these results, it will be possible to comment briefly on the distribution maps which are presented for the 11 x $7 \mathrm{~km}$ survey block. Eleven maps are presented for the following distributions :Neolithic/Eneolithic (Fig. 1.2), Bronze Age (Fig. 1.3), Iron Age (Fig. 1.4), Roman (Fig. 1.5), Medieval (Fig. 1.6), Is̄ka (Fig. 1.7), modern (Fig. 1.8), later lithics (Fig. 1.9), cairns (Fig. 1.10), linear features (Fig. 1.11) and other settlements (Fig. 1.12). It should be noted that no traces of Palaeolithic settlement are known from the survey block /1/. In the following commentary, the archaeological significance of the distributions will be discussed; interpretation of the land use associated with the settlement patterns is reserved for a later section.

\section{Neolithic/Eneolithic $(6000-2000$ bc) (Fig. 1.2)}

Finds of this period can be dated with relative ease to one of the main subdivisions of the Neolithic (Early, Middle and Late) or Eneolithic (=Copper Age). Although finds were made in 42 separate collection units, the density and clustering of finds suggests only six main habitation groups in the entire 4,000-year period. The most dispersed group lies in the neighbourhood of Miljovici, with 14 separate collection units yielding Late Neolithic and Copper Age material. This appears to represent a series of shorter-term occupations with periodic relocation of settlement or, conceivably, an Extended Village pattern of the type identified in northern France (Howell 1983). A similar group of low-density Early Neolithic finds occurs near Jagodnja, although the finds are more widely spaced than at Miljovići. The other four sites represent more nucleated remains covering, in the case of Tinj, not more than 1.25 ha (Chapman \& Batović 1985). An important discovery concerns the site at Kula Atlagić, located in the geomorphological 'window' of a well-section buried $1.5 \mathrm{~m}$ beneath hillwash in the Benkovac trough. This chance recovery underlines the dangers of assuming nil environmental change in the valleys of the Ravni Kotari and also warns against over-enthusiastic attempts to estimate population from survey data.

Two general points can be made about the Neo/Eneo distributions: (1) remains are relatively scanty, with no sign of population increase consequent upon the adoption of farming and (2) there are far more Early Neolithic sites and findspots than for the Middle or Late Neolithic phases and indeed than for the Copper Age. On the basis of wider considerations than the NDP survey, it may be argued that a weak tendency to settlement nucleation in Dalmatia can be dated to the late 5 th. and 4 th. millennia bc (Chapman 1981; 1982).

\section{Bronze Age (2000 - 800 bc) (Fig. 1.3)}

The pattern of Bronze Age sites and monuments presents a dramatic increase in the quantity of discard and size of area exploited over the preceding periods. The highest upper octile and quartile values for the whole survey define Bronze Age discard and find recovery. Though this may be partly explained by the density of finds in enclosures and hill-forts not since disturbed, there does seem to be an increase in the quantity of artifactual discard in this period. 
The major defining characteristic of the Bronze Age in Dalmatia is the first recorded use of dry-stone walls for the construction of linear features, field systems, cairns, enclosures and hill-forts. Eighteen foci of major occupation can be detected in this period (compare 6 for the 4000-year period of the Neo/Eneo). Of this total, nine are defined by higher-than-average densities of finds. The remaining nine are dry-stone walled monuments : six hill-forts, two field systems and a cairnfield. The sites range from a single artifact scatter with one or two single finds within a $1 / 2-\mathrm{km}$ radius to scatters with partially surviving linear features, cairns and up to a dozen single finds within a 1/2-km radius. Similar variation occurs within the 'territories' of the monuments; there are no visible finds in the $1 / 2-\mathrm{km}$ radius around the small hill-fort of Muvača, over twenty cairns and scatters in the area surrounding Kruglas and Strkovac̄a. Since there is currently no method of assessing the contemporaneity or otherwise of these scatters with the monuments, no attempt has been to model land use on the basis of off-site patterning; instead, the conservative assumption has been made that finds within a l/2-km radius of major sites and monuments are likely to have been associated with the activities of residents at such sites.

Between the areas of major occupation lie large areas of often fertile land, with relatively low densities of finds and monuments. It is often not clear whether isolated cairns have burial as well as stone clearance functions. Higher-than-average density pottery scatters may indicate short-term residence or the cumulative use of short-term rural huts. There is, however, no question of a full use of the landscape in this period and any notions of pressure on land by population would be entirely fallacious. Instead, there is a moderate degree of settlement nucleation, with clusters of several occupation sites in preferred segments of the landscape.

$$
\text { Iron Age ( } 800 \text { - } 100 \text { bc) (Fig. 1.4) }
$$

The Iron Age in Dalmatia has traditionally been viewed as the 'time of the hill-forts', a period when all settlement was concentrated into the large number of hill-top defended sites (Batovic 1977; Suic 1974). The NDP survey provided an opportunity to test this hypothesis by examination of low-lying areas between the ridges where the hill-forts are clustered. Perhaps unsurprisingly, a number of 'lowland' scatters were found and interpreted as dispersed farmsteads which were presumably integrated in some way with the hill-forts. Hence, the Iron Age distribution displays the first clear indications of settlement hierarchy in Dalmatia. A two-level system of hill-forts and farmsteads in the earlier Iron Age was replaced at some time in the last 300 years BC by a three-level hierarchy, with the addition of an extra level of major hill-forts above the minor hill-forts. The precise dating of this social change and its explanation remain a research task for the future.

The number of sites and monuments dated to the Iron Age is broadly similar to that of the Bronze Age: a total of 19, with ten hill-forts and nine farmsteads. The major change between the two periods is that the Iron Age off-site discard is much reduced, with more than 5 scatters 
within a $1 / 2-\mathrm{km}$ radius at only one site (Nadin-Gradina). Similarly, off-site discard between the settlement 'territories' is very low indeed; this decline may reflect a shrinking use of the landscape or merely a different set of discard practices in the Iron Age. The absence of field systems datable to the Iron Age is a curious anomaly, given the labour-intensive creation of terracing by the Iron Age occupants of Nadin-Gradina (Chapman, Shiel \& Batovic 1987:129 \& Fig. 5).

On the basis of the NDP survey, the model of strongly clustered Iron Age settlement in hill-forts can be replaced by another where 'lowland' settlement modules are important in the structure of an Iron Age society in which elite residences are firmly located in the hill-forts. It seems likely that a smaller proportion of the productive potential of the survey area was exploited in this period than in the Bronze Age.

\section{The Roman period (100 BC - AD 600) (Fig. 1.5)}

The incorporation of the Ravni Kotari into the province of Dalmatia in the late 1st. century BC stimulated many changes in the settlement pattern and land use strategies of the region. While the innovations introduced by the Roman authorities are important, the elements of continuity with what went before are particularly striking in settlement, social structure and land use (Chapman \& Shiel, forthcoming).

The most striking change in the settlement pattern is the expansion of the extensive use of the lowland landscape that had not previously been matched. What may be important about the Roman economy is that settled areas were more widely occupied than before, not that the Roman economy was more efficient or more intensive than anything prior (personal communication, K. Griffiths). This more extensive exploitation was achieved through a hierarchical settlement pattern which, in the Zadar lowlands at least, resembled the three tiers of the late PRIA structure with the addition of Iader (Zadar) as an administrative and market centre or colonia. In the survey area, the major hill-fort of Nadin-Gradina was granted the title of municipium with the name Nedinum in the Claudian or Tiberian period (Wilkes 1969:212-214), while the occupation of four minor hill-forts continued into at least the 1st. century $\mathrm{AD}$. The major Roman settlement expansion was in the low-lying areas, where the number of lowland farms increased from nine in the PRIA to at least 15 in the RIA. In addition to these major farm occupations, there is artifactual or structural evidence for farming activity at a further 20 lowland sites in the Roman period. Outside the $1 / 2-\mathrm{km}$ radius 'territories' of the lowland farms, there is abundant evidence of artifact discard, suggesting either widespread manuring practices or frequent part-time use of rural structures. The sizeable number of clearance cairns dated to the Roman period can be interpreted as evidence for the deliberate improvement of soil resources in the area.

In summary, the Roman occupation of the Ravni Kotari displays a combination of increasing nucleation of population at municipia with the highest level of dispersal of rural land use seen at any period in the survey area. The on- and off-site totals of artifacts indicate the 
highest absolute discard rates over the whole survey area in the last ten millennia, although Bronze Age discard rates were locally higher in certain hill-forts. The precise relationship between discard rates and agricultural intensification is still under investigation.

Medieval (AD $600-1700)$ (Fig. 1.6)

A massive decline in the discovery rate of Medieval sites and monuments in comparison with the Roman period can hardly be interpreted as other than a major economic and population dislocation. A reduction in his staff in the Audio Visual Centre of the University of Newcastle upon Tyne for their conversion of all the diagrams for Neothermal Dalmatia Project articles into finished artowrk. occupations from over 40 to eight is combined with a low level of artifact discard between site 'territories'. of the major occupations, one is the hill-fort at Nadin, and three others represent artifact clusters centred around Medieval chapels or churches. While it may be argued that some Medieval settlements have been incorporated into, or are masked by, modern rural settlements (e. g., Tinj), it should be pointed out that a large number of villages was destroyed in the course of the Venetian - Turkish wars in the Ravni Kotari (Bracewell, n. d.) and thus may not survive on the ground. Occasional re-use by pastoralists of the hill-fort of Vinculja presents a rare opportunity to discover domestic settlement traces.

Outside the coastal strip of the Zadar lowlands, where Byzantine and Venetian urban settlement continued through much of this period, the picture painted by Medieval artifactual remains is one of rural decline and stagnation. It is only in the 14 th. and 15 th. centuries that rural economies begin to expand in this part of Dalmatia (Raukar 1977).

\section{IS̄ka pottery (A. D. 1700 - present) (Fig. 1.7)}

The production of coarse, carbonate-tempered wares on the island of veli I $\bar{z}$ is documented from the 18th. century up to the present day (Carlton, this volume). This pottery was once widely exported from Iz to the mainland and it is consequently one of the less ambiguous signs of pottery use in the Modern period. Its distribution in the Zadar lowlands is less common than the ceramics from any other period, with upper octile values of only 5 sherds per collection unit. Most of the finds were discovered within a 1/2-km radius of Post-Medieval or Modern villages and hamlets ; the almost total absence of association with other monuments is striking. The mechanisms by which Iska pottery reaches the fields are unknown; manuring or the carrying of vessels to rural workplaces seem the most likely.

\section{The Contemporary period (Fig. 1.8)}

The distribution of existing villages and hamlets is taken from the $1: 25,000$ maps used for the survey. The absence of any central place in the survey area is characteristic of the last two centuries, when the Zadar plain fell firmly within the purview of the city of zadar. The nearest town to the survey area is Benkovac, itself an 18th. century 
A. D. foundation. This dispersed pattern is redolent of much of the settlement patterning in the prehistoric and Medieval period in the survey zone.

\section{Later chipped stone (Fig. 1.9)}

The designation 'Later chipped stone' refers to lithic artifacts which are not demonstrably Palaeolithic in technology nor type and are therefore to be dated to some phase of the Neothermal period. There is a strong contrast between the dense clustering of LCS in the 1982 survey transects around hills capped with flint-bearing Miocene sands and gravels (Batovic \& Chapman 1985:181-182) and the low density of lithic finds in the survey block. This is perhaps related to the absence of any significant lithic raw material source in the block. In any case, the dispersed nature of lithics distribution documents either low production or low discard/high curation rates for the contemporary settlements. Although some lithics are found with datable pottery in 28 collection units, there is no proof of chronological association between pot and lithics. By contrast, lithics on the Mataci-Stojici ridge (1982 transect) were found with nothing but Bronze Age pottery in over 80 collection units. As may be expected, the Mataci-Stojici assemblages are characterized by a higher proportion of debitage and cores and a lower proportion of retouched pieces than the lithics from the survey block.

Cairns (Fig. 1.10)

By far the most frequent single monument class in the survey areas is the stone cairn. Constructed of either limestone boulders or boulders with earthern infilling, cairns display an impressive variety of sizes, shapes and topographic locations. The number of cairns found together ranges from two to over $250 / 2 /$. Further evidence notwithstanding, cairns are interpreted as primarily a sign of land clearance from arable fields and only secondarily as betokening a burial monument (Chapman, Shiel \& Batović 1987:128-9). The placement of sherds in the interstices, or on top, of cairns provides a terminus ante quem for the construction of the monument (ibid. :128). Data from local excavations indicate that the date range of cairns is Bronze Age to Roman; however, stone clearance cairns are still created today, so no facile assumptions about dating can usually be made.

The distribution of cairns in the survey block is moderately dispersed, with occasional large clusters, such as in the Kakma - Mitrovici cairnfield. Some groups of cairns occur in areas lacking Bronze Age, Iron Age or Roman foci (e. g., in the eastern corner of the survey block). Otherwise, most major cairn groups lie within a $1 \mathrm{~km}$ radius of Bronze Age or Iron Age occupation sites.

\section{Linear features (Fig. 1.11)}

The term 'linear feature' is preferred as a neutral descriptor for such field monument classes as 'walls', 'field boundaries', territorial boundaries', etc. The main characteristic of linear features is their construction in dry-stone technique and in a style recognizably different 
highest absolute discard rates over the whole survey area in the last ten millennia, although Bronze Age discard rates were locally higher in certain hill-forts. The precise relationship between discard rates and agricultural intensification is still under investigation.

Medieval (AD $600-1700)$ (Fig. 1.6)

A massive decline in the discovery rate of Medieval sites and monuments in comparison with the Roman period can hardly be interpreted as other than a major economic and population dislocation. A reduction in his staff in the Auctio Visual Centre of the University of Newcastle upon Tyne for their conversion of all the diagrams for Neothermal Dalmatia Project articles into finished artowrk. occupations from over 40 to eight is combined with a low level of artifact discard between site 'territories'. of the major occupations, one is the hill-fort at Nadin, and three others represent artifact clusters centred around Medieval chapels or churches. While it may be argued that some Medieval settlements have been incorporated into, or are masked by, modern rural settlements (e. g., Tinj), it should be pointed out that a large number of villages was destroyed in the course of the Venetian - Turkish wars in the Ravni Kotari (Bracewell, n. d.) and thus may not survive on the ground. Occasional re-use by pastoralists of the hill-fort of Vinculja presents a rare opportunity to discover domestic settlement traces.

Outside the coastal strip of the Zadar lowlands, where Byzantine and Venetian urban settlement continued through much of this period, the picture painted by Medieval artifactual remains is one of rural decline and stagnation. It is only in the 14 th. and 15th. centuries that rural economies begin to expand in this part of Dalmatia (Raukar 1977).

Iška pottery (A. D. 1700 - present) (Fig. 1.7)

The production of coarse, carbonate-tempered wares on the island of veli $I \overline{\mathbf{z}}$ is documented from the 18th. century up to the present day (Carlton, this volume). This pottery was once widely exported from Iz to the mainland and it is consequently one of the less ambiguous signs of pottery use in the Modern period. Its distribution in the Zadar lowlands is less common than the ceramics from any other period, with upper octile values of only 5 sherds per collection unit. Most of the finds were discovered within a $1 / 2-\mathrm{km}$ radius of Post-Medieval or Modern villages and hamlets ; the almost total absence of association with other monuments is striking. The mechanisms by which Iska pottery reaches the fields are unknown; manuring or the carrying of vessels to rural workplaces seem the most likely.

\section{The Contemporary period (Fig. 1.8)}

The distribution of existing villages and hamlets is taken from the $1: 25,000$ maps used for the survey. The absence of any central place in the survey area is characteristic of the last two centuries, when the Zadar plain fell firmly within the purview of the city of Zadar. The nearest town to the survey area is Benkovac, itself an 18th. century 
A. D. foundation. This dispersed pattern is redolent of much of the settlement patterning in the prehistoric and Medieval period in the survey zone.

Later chipped stone (Fig. 1.9)

The designation 'Later chipped stone' refers to lithic artifacts which are not demonstrably Palaeolithic in technology nor type and are therefore to be dated to some phase of the Neothermal period. There is a strong contrast between the dense clustering of LCS in the 1982 survey transects around hills capped with flint-bearing Miocene sands and gravels (Batovic \& Chapman 1985:181-182) and the low density of lithic finds in the survey block. This is perhaps related to the absence of any significant lithic raw material source in the block. In any case, the dispersed nature of lithics distribution documents either low production or low discard/high curation rates for the contemporary settlements. Although some lithics are found with datable pottery in 28 collection units, there is no proof of chronological association between pot and lithics. By contrast, lithics on the Mataci-Stojici ridge (1982 transect) were found with nothing but Bronze Age pottery in over 80 collection units. As may be expected, the Mataci-Stojici assemblages are characterized by a higher proportion of debitage and cores and a lower proportion of retouched pieces than the lithics from the survey block.

\section{Cairns (Fig. 1.10)}

By far the most frequent single monument class in the survey areas is the stone cairn. Constructed of either limestone boulders or boulders with earthern infilling, cairns display an impressive variety of sizes, shapes and topographic locations. The number of cairns found together ranges from two to over $250 / 2 /$. Further evidence notwithstanding, cairns are interpreted as primarily a sign of land clearance from arable fields and only secondarily as betokening a burial monument (Chapman, Shiel \& Batovic 1987:128-9). The placement of sherds in the interstices, or on top, of cairns provides a terminus ante quem for the construction of the monument (ibid. :128). Data from local excavations indicate that the date range of cairns is Bronze Age to Roman; however, stone clearance cairns are still created today, so no facile assumptions about dating can usually be made.

The distribution of cairns in the survey block is moderately dispersed, with occasional large clusters, such as in the Kakma - Mitrovici cairnfield. Some groups of cairns occur in areas lacking Bronze Age, Iron Age or Roman foci (e. g., in the eastern corner of the survey block). Otherwise, most major cairn groups lie within a $1 \mathrm{~km}$ radius of Bronze Age or Iron Age occupation sites.

\section{Linear features (Fig. 1.11)}

The term 'linear feature' is preferred as a neutral descriptor for such field monument classes as 'walls', 'field boundaries', territorial boundaries', etc. The main characteristic of linear features is their construction in dry-stone technique and in a style recognizably different 
from those of recent field walls. Criteria for dating these features are similar for those used to date cairns (see above).

Because of the destruction of field monuments during agriculture and construction work, the distribution of linear features is not only a palimpsest and his staff in the Audio Visual Centre of the University of Neweastle upon Tyne for their conversion of all the diagrams for Neothermal Dalmatia Project articles into finished artowrk but a partial and fragmentary palimpsest covering construction over the last 4,000 years. Current dating evidence for the earliest linear features comes from the Pridraga cairnfield, where cairns with Bronze Age pottery in their fill overlay a linear feature some $250 \mathrm{~m}$ in length (Chapman, Shiel \& Batović 1987:128 \& Fig. 4). Dating evidence from survey block linear features indicates an apparent peak in their frequency in the Roman period.

\section{Other settlements (Fig. 1.12)}

A diverse set of usually undated monuments is included in this category . Monument classes include enclosures, post-Medieval settlements, house platforms, stone huts, terracing, lime-pits and ridge-and-furrow cultivation. Of these, only the lime-kilns can be approximately dated to the 15 th. century A. D. or later. No dated examples of ridge-and-furrow cultivation from Yugoslavia are currently known to the author.

\section{General comments}

Several interesting long-term trends emerge from the results of the NDP survey. The first point is the relative under-use of the land use potential for the survey block over most of the last 8 millennia. At no period, even during Roman provincial administration, was the terrain of this part of the Ravni Kotari used to the full. While detailed soil studies may contradict this view, the distributional evidence is clear that there was always spare arable capacity in this area, so that any notional model attempting to use population pressure to account for settlement and economic change would run into severe, if not insurmountable problems.

The second theme linking much of past settlement on the plain is the predominance of small-scale, dispersed settlement units. On the rare occasions when kinship groups unite to form more nucleated residential units, it is rare to find site sizes consonant with population levels of more than a hundred individuals. The nucleation evident in the Roman municipium of Nadin-Gradina represents the largest settlement known from eight millennia of plains occupation. The surviving Medieval and post-Medieval historical data suggest that small population size characterized much of the plains settlement from the 13th. century onwards (Bracewell, n. d.). Hence, site nucleation stands out as a break from the norm, a pattern which requires explanation as much as the overall tendency towards dispersion. 
A third long-term trend is defined by the apparent cyclicity in the sequence of settlement expansion and contraction in the survey block. In three periods (the Neolithic, the Iron Age and the Medieval), large areas of the fertile lowlands appear to remain under-utilized if not completely uncultivated. In the intervening periods (Bronze Age, Roman and Modern), greater proportions of the contemporary landscape are occupied and major attempts are made at land improvements and agrarian management. While the periodicity of these cycles may be too long to relate to the shorter-term cyclical patterns of soil change (loss of fertility - recovery of fertility) (see Shiel \& Chapman, forthcoming), this pattern is more likely to relate to the long-term social changes affecting the region and neighbouring areas of the Mediterranean basin. The interaction between local, regional and inter-regional factors will be the subject of future investigations.

\subsection{LAND USE STRATEGIES IN THE ZADAR LOWLANDS}

The land use classification developed for the study area is fully discussed in the next paper (see Shiel \& Chapman, this volume). Shiel defines five classes of land on the basis of modern land use rather than precise pedological principles:- arable, stony, terrace, karst and bottomland. The modern distribution of these classes is discussed below (see Shiel \& Chapman, Fig. 2.3). In his model of and use changes in the survey area, Shiel proposes a series of modifications to the land use potential of the area which make it dangerous to use the modern land use map as a surrogate for past land use distributions. In this section, I shall combine Shiel's model with excavation data on buried soils and sediments to propose a sequence of land use change over the past eight millennia.

The absence of closely datable Mesolithic lithics in the survey block makes concrete discussion of the transition from foragers to farmers almost impossible. As in other periods of low sea-level (e. g., the Upper Palaeolithic), it is likely that the main areas of Mesolithic settlement would be the coastal plains, now submerged beneath the Adriatic. The discovery of Palaeolithic material in the Lika valley (Malez 1975) and finds of Mesolithic flints in the Velebit Mountains (Forenbaher \& Vranjićan 1982) indicate occasional exploitation of the mountain zone. It is unlikely that the open woodlands of the Ravni Kotari with their herds of deer, aurochs, pig and possibly sheep would have been ignored by foraging populations. Evidence of the burial of bottomland such as at Kula Atlagic suggests one mechanism for the loss of Mesolithic sites; lack of recognition of Mesolithic toolkits in the generalized lithics discard found on survey hinders the quest still further. The hypothesis for future exploration is that foraging populations selected valley edge and bottom areas rather than hill-slopes and karst ridges. If this notion is correct, there would be a substantial degree of settlement continuity between the last foragers and the earliest farming groups in the area.

The excavated remains of the only Early Neolithic site in the area to yield a reasonable sample of palaeo-economic data demonstrate that, contrary to current orthodoxy (Tringham 1971:103; Whittle 1985:98), the 
farmers in the plain cultivated a wide range of cereals and domesticated the five main farmyard animals from as early as the 6th. millennium bc. A high percentage of domestic animals, predominantly ovicaprines, was recovered in a sample of nearly 4,000 bones (pers. comm., C. Schwartz). In a wide range of crop remains, four varieties of wheat ((?) wild einkorn, domestic einkorn, emmer and possibly spelt), barley and oats were identified along with a range of crop weeds and several legumes (pers. comm., J. Huntley). The molluscan data from Tinj indicate use of several contrasting eco-zones:- such use of coastal resources perhaps explains the evidence for short-term occupation in coastal caves such as the Buta Jama (Ilakovac 1965). If Tinj is typical of Neolithic economies in the area, it is no surprise to find a strong correlation between Neolithic locations and the arable land class. Almost all Neolithic and Eneolithic clusters are located on the land which provides not only the most fertile arable but also the highest-quality pasture. The main exception in the survey block - Prtenjaça - occupies a narrow karst ridge flanked by rich arable soils on each side.

The palaeoeconomic evidence from the only excavated open air Eneolithic site in the Ravni Kotari - Bukovič-Lastvine (Batovic \& Chapman 1986)confirms the importance to the inhabitants of mixed farming. The dominance of domesticated animals in the faunal spectrum rivals that of Tinj, while an increase in the importance of cattle relative to ovicaprines may signal the impact of secondary products innovations (Sherratt 1979). The range of plant remains recovered was narrower than at Tinj; nevertheless, local cultivation of wheat (probably einkorn and emmer), and probably oats, millet and barley is suggested. Charcoal from juniper, olive and oak was also found at Buković. Use of local and marine molluscs indicates the use of a narrower range of ecological zones and species than at Tinj (identifications by C. Schwartz). In summary, population levels in the Neo/Eneo appear so low that all subsistence activities could be effected on the arable soils. This suggests a small-scale economy, with specialized site location combined with generalized land use.

The location of Bronze Age sites off as well as on the arable class prompts the question of why such an expansion in range of location was necessary given the absence of population pressure. The obvious alternative is the hypothesis of productive specialization, in which certain crops offered higher yields if cultivated on the karst ridges and slopes. Unfortunately, none of the three test excavations at Bronze Age sites (Mataci, Cauševica and Grabar) has yielded much in the way of palaeobotanical information. Plant remains from Čaus̄evica included juniper pips, olive stones and seeds of millet. It should be noted that there are severe criteria for accepting the domestication of tree crops like the olive and other fruit, not to mention the vine (Runnels \& Hansen 1986); hence, there is little chance of determining the question of local domestication one way or other from such small floral samples. Nevertheless, increased interest in even wild vines and olives may well have prompted the establishment of settlements off the arable. The use of multi-cropping strategies in lowland arable fields would be but one benefit from the domestication of tree crops and the vine. 
The location of several major Bronze Age foci of settlement on what is now karst land should be put in perspective. On each excavated Bronze Age site, we have found evidence for soil erosion beginning in, and continuing after, the Bronze Age occupation. On this basis, much of what is now karst had a deeper soil profile in the 2nd. millennium bc, such as would now be classed as 'stony'. On this re-interpretation of land use change, most of the Bronze Age sites would occur on arable or stony land, with the onset of karst conditions on flat limestone ridges representing a degradation of the soil cover partly caused by Bronze Age agriculture.

In the Iron Age, a stronger preference for hill-top and ridge sites indicates settlement in just those areas which have been, or are in the process of being, degraded through human intervention. Excavations of Iron Age features at Nadin-Gradina revealed evidence of the construction of terraces and subsidiary enclosures in the late 1st. millennium BC, a sign that land management was being taken seriously in the late PRIA. However, since no Early Iron Age enclosures have been excavated, it is difficult to judge whether degradation of the karst ridges was continuing into the 1st. MBC or constituted a primarily Bronze Age phenomenon. The current hypothesis is that, given the scale of Iron Age use of the limestone ridges, vegetatión and soil loss would continue to be an important factor throughout this period.

The only direct palaeoeconomic evidence from the Iron Age derives from the NDP excavations at Nadin-Gradina (Batovic \& Chapman 1987). The faunal sample from the late PRIA indicates a predominance of caprines over cattle, pigs and horses in a sample dominated by domestic animals (identifications by $C$. Schwartz). Botanical identifications document the local cultivation of emmer and spelt wheat, six-row barley and millet and the use of the olive and the vine. The charcoal samples imply the proximity of broad-leaved associations (oak, hazel, willow) as well as some Mediterranean evergreen vegetation (Quercus ilex).

In the Roman period, major and proportionate use of all land use classes is attested, with the location of low-lying farms on all soil classes except bottomland. Without excavation of several such farms, it would be difficult to test the current hypothesis that generalized site location is the counterpart of specialized land use. The palaeoeconomic data from Nadin-Gradina is the only direct subsistence evidence for the area. The clear predominance of domestic caprines over any other food animal shows continuity from Iron Age husbandry. The list of locally cultivated plant species includes spelt, six-row barley, two species of millet, legumes, the grape and the olive. Charcoal identifications reveal a similar balance of broad-leaved and evergreen species to that found in the pre-Roman Iron Age. The 1-km territory of Nadin includes land of all classes except bottomland; the potential for specialized cultivation is very great. The construction of what in Britain would be called a 'banjo' enclosure (Perry 1969) with its neck facing Nadinsko Blato, the largest area of summer grazing in the plain, reinforces the importance of stock-raising at Roman Nadin. The stimulus of cash crops such as sheep, olives and grapes to the regional economy is one reason for the expanded areas of arable and non-arable taken into cultivation or pasture; the 
ready availability of Zadar as a harbour both for Italy and, later, for Greece and Byzantium ensured that transport facilities kept pace with economic growth.

There is no direct subsistence information for the Medieval economy in the Ravni Kotari from archaeological excavations. Syntheses of the historical sources (for the 12th. to the 14th. centuries, Klaic 1976; for the 15th. century, Raukar 1977) provide indirect data which could be taken to mean that caprine husbandry was pre-eminent in stock raising, but information on crops is too general to be of much use (viz. cultivation of cereals, olives and the vine). What few predictions can be made from the attenuated settlement pattern data from this period concern the possible beginnings of a trend found in modern villages to-day - namely a preference for locations at the junction of several land use classes.

In the modern period, there is a dominance of animal products over plant products in most peasant villages in the survey area. The many varieties of meat and dairy foods are the principal products of the large flocks of sheep and the smaller numbers of pigs and cattle. Since the Second World War, the introduction of cash crops such as tobacco, peppers, tomatoes and melons has meant a diversification of plant products away from the traditional maize, wheat, barley, oats, millet and legumes. Vines and olives are still important and possession of high-quality groves and vineyards is often closely related to the holding of status positions in the village.

The predominant locational strategy of the modern village is in an ecotone position, with three or sometimes four land use classes in a 1-km radius. Productive specialization across the full altitudinal range of village land is normal for mixed farming communities in the Zadar lowlands.

Three general conclusions can be drawn from these land use studies:-

1. In a landscape with a mosaic of land use classes, efficient land use strategies would necessitate some combination of mixed farming. It would be possible but hardly very productive to specialize in wholly arable farming or purely pastoralism.

2. There is a long-term tendency to shift from specialized site location to more generalized locations; whether or not this tendency is balanced by a second, namely a shift from generalized to more specialized land use cannot yet be tested because of paucity of direct subsistence evidence from the proto- and historic periods.

3. The highly localized land class distribution, with its small patch sizes, would favour a subsistence strategy based on dispersed settlement patterns, where each settlement unit controlled access to and utilized the full range of available land use classes. 


\subsection{CONCLUSIONS}

The results of the first phase of the Neothermal Dalmatia Project impinge on many fields of scientific activity. In this paper, the main results of intensive, systematic field survey have been integrated with land use and subsistence information from soil survey and trial excavations. A long-term pattern emerges of a predominantly dispersed pattern of settlement based on increasingly generalized locations, with access to a progressively wider range of land use classes. Superimposed on the basic dispersed pattern is a tendency towards population nucleation in the Roman and Modern periods and, to a lesser extent, in the Iron Age. The main peaks in population of the city of Zadar coincide with the development of economic expansion and the provision of wider markets. The impact of the incorporation of the rural hinterland of the Ravni Kotari into a wider economic network remains a subject for future study.

\subsection{ACKNOWLEDGEMENTS}

We acknowledge with thanks the financial support for the Neothermal Dalmatia Project provided by : The British Academy, National Geographic Society, the Society of Antiquaries of London and the University of Newcastle upon Tyne. It is a pleasure to acknowledge the ready support for the project of Professors John Evans, Colin Renfrew, Peter Fowler, Rosemary Cramp, Martin Harrison, James Griffin, Greg Johnson, Bernard Wailes, Henry Wright and Ronnie Tylecote. Thanks are also due to the co-editors of this volume for their usually creative encouragement. It is a pleasure to acknowledge the help of the entire staff of the Arheolos̄ki Muzej Zadar and the Narodni Muzej (Etnografski Odjel) Zadar, and especially the Director of the AMZ, Professor R. Jurić. We are also indebted to our palaeoeconomic specialists, Drs. Charles Schwartz, Judith Turner, Jackie Huntley and Sandra Nye, for their faunal and botanical reports. It is a special pleasure to thank Ian Munro and his staff in the Audio Visual Centre of the University of Newcastle upon Tyne for their conversion of all the diagrams for Neothermal Dalmatia Project articles into finished artowrk. Our final debt of gratitude is to all those fieldwalkers who contributed to the success of the NDP survey.

\subsection{FOOTNOTES}

1. Clusters of Middle Palaeolithic chipping debris were found on the Mataci - Stojići ridge in the course of the 1982 season (Batovic \& Chapman 1985:181-2).

2. The largest group in the survey area was the cairnfield of Pridraga, with some 245 cairns (Chapman, Shiel \& Batović 1987:127 \& Fig. 4). 


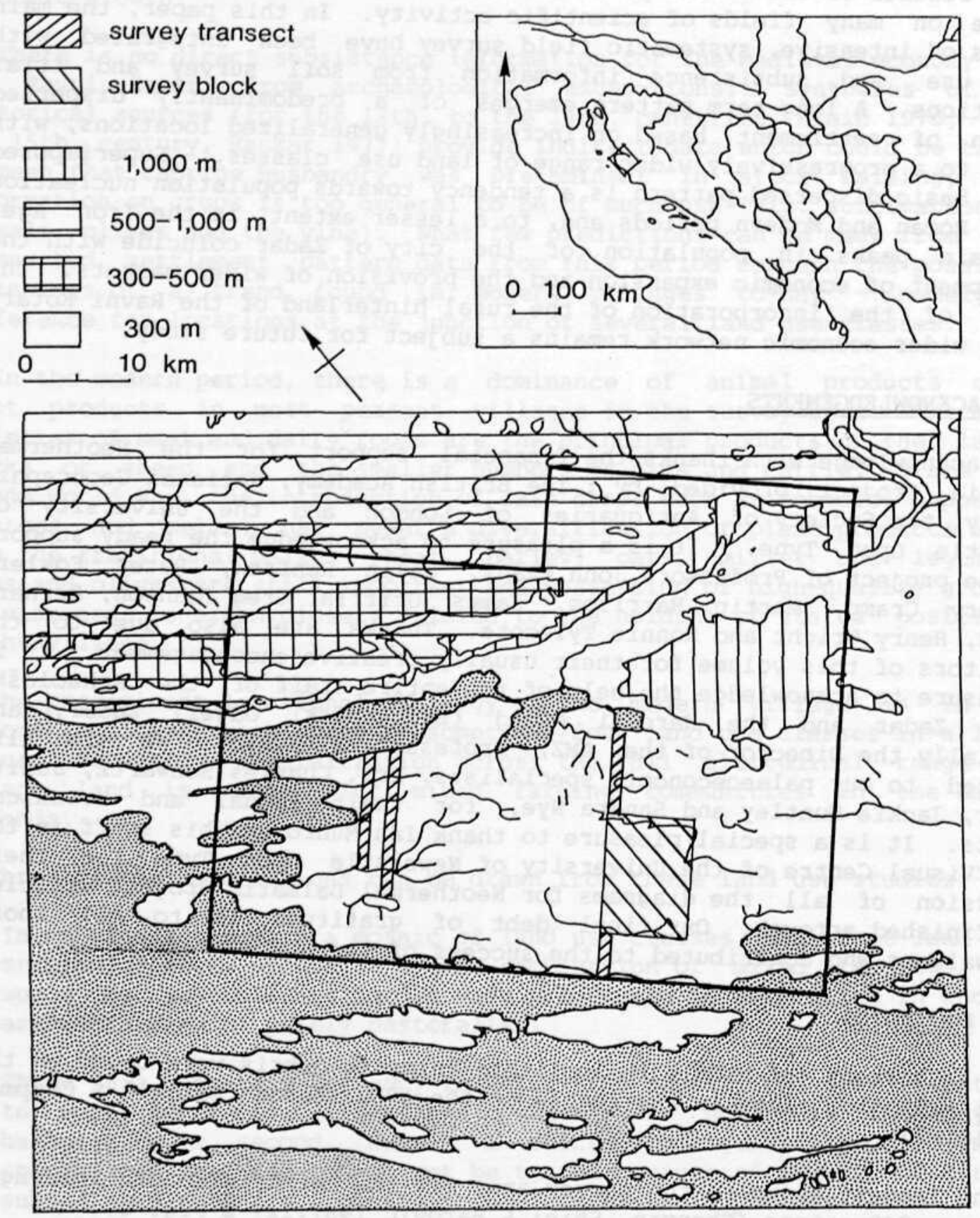

Figure 1.1 Location map of project study area, survey transects and survey block. 


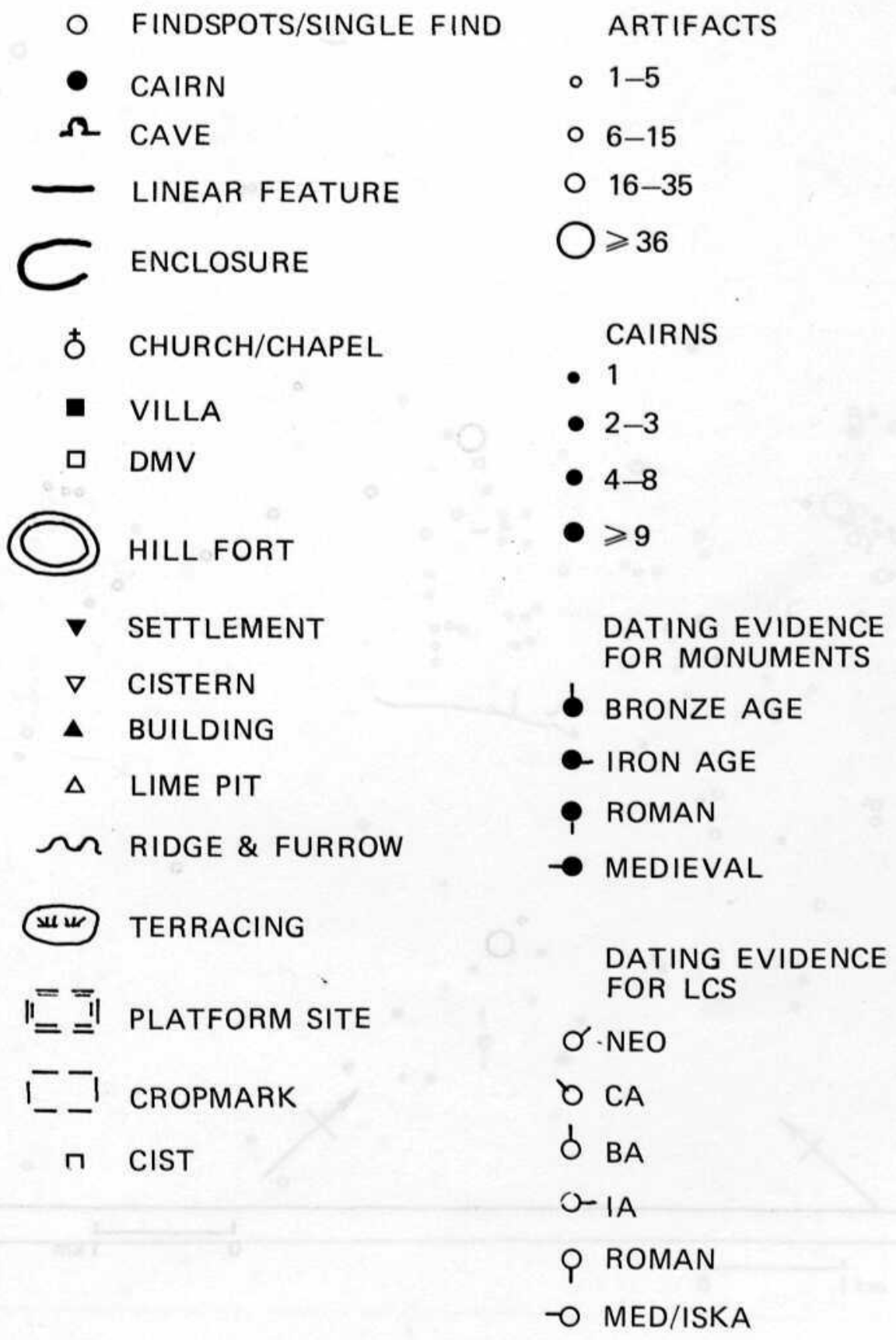




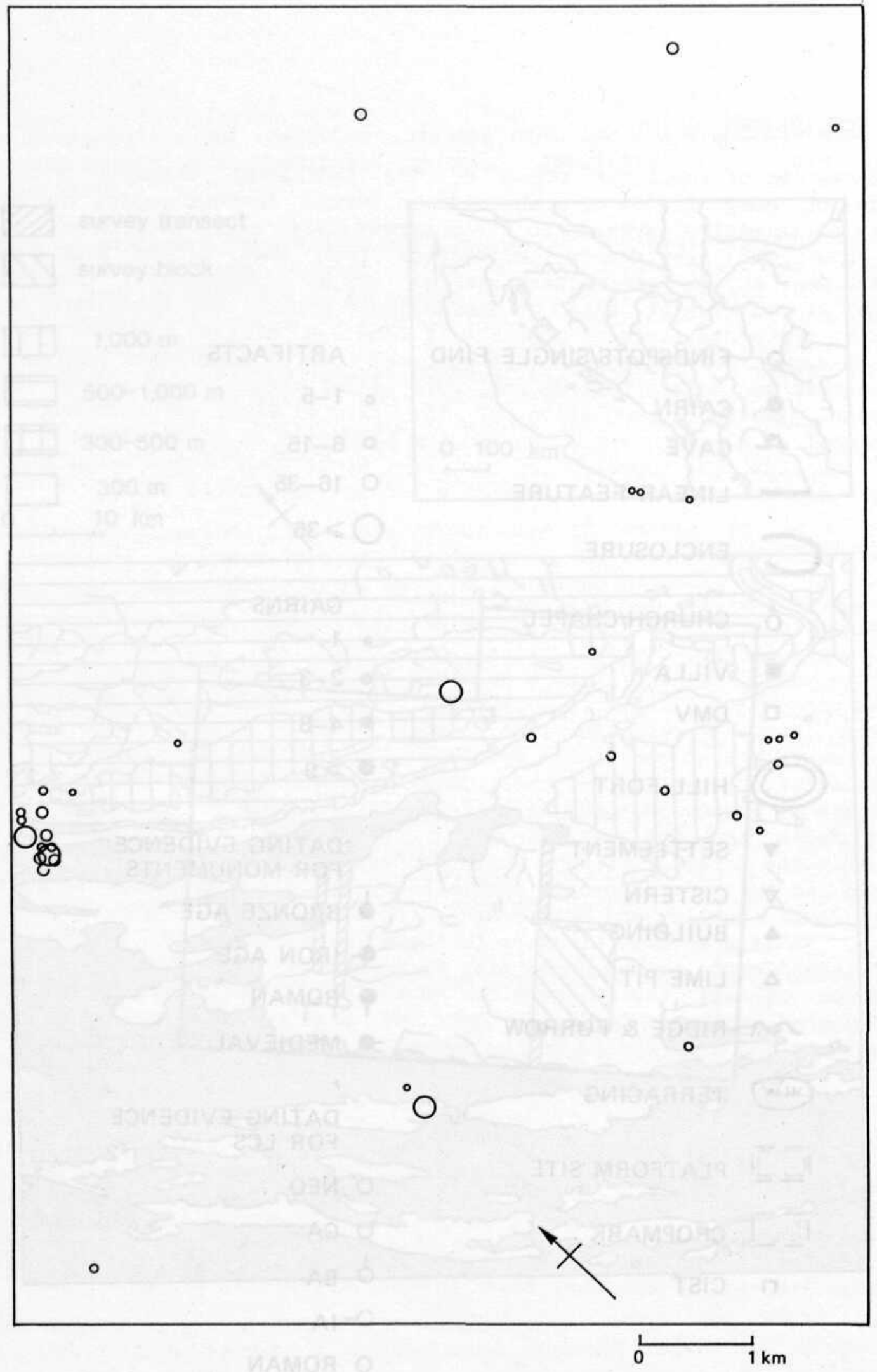

Figure 1.2 Distribution of Neolithic/Eneolithic remairs. 


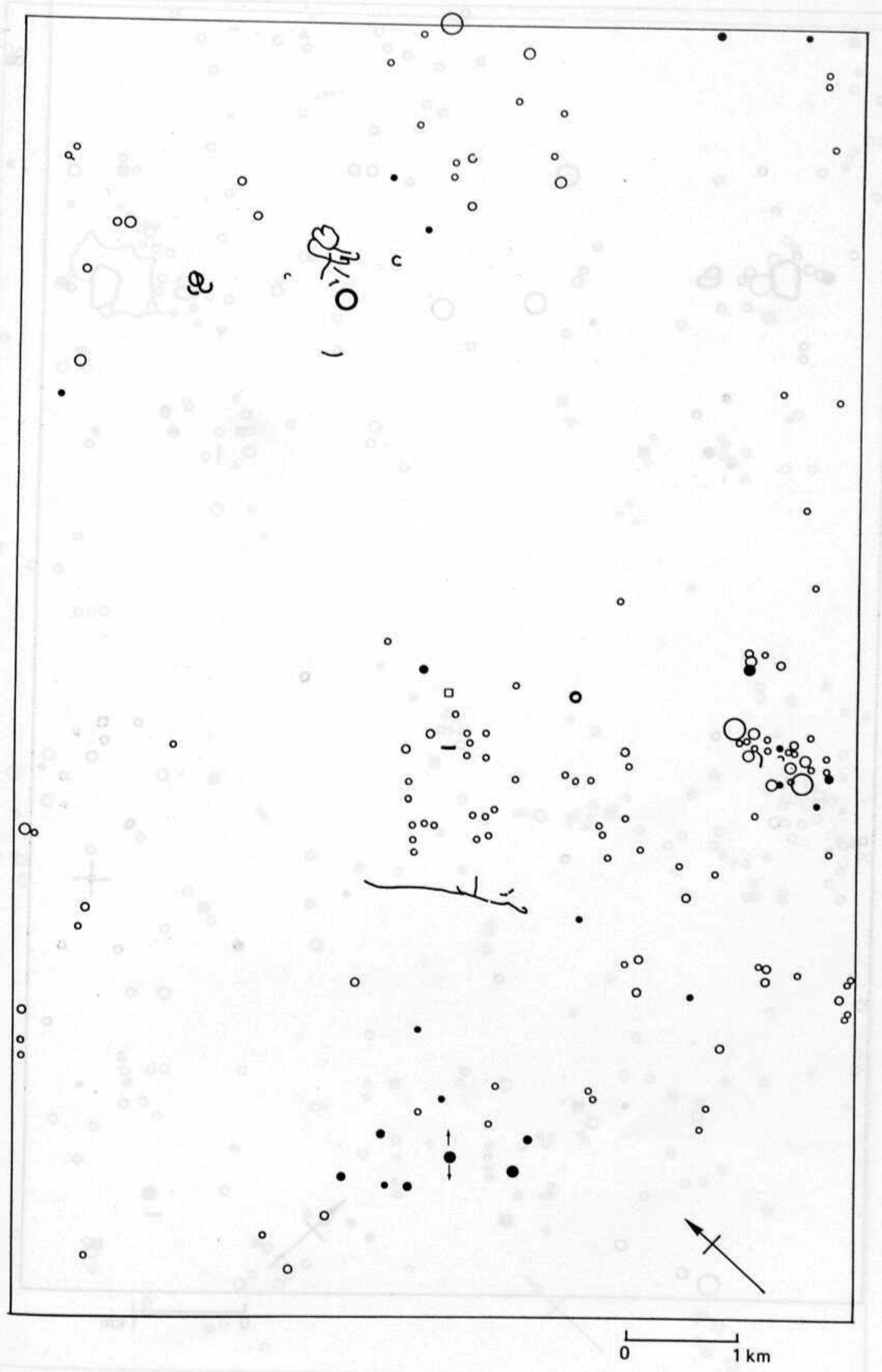

Figure 1.3 Distribution of Bronze Age remains. 


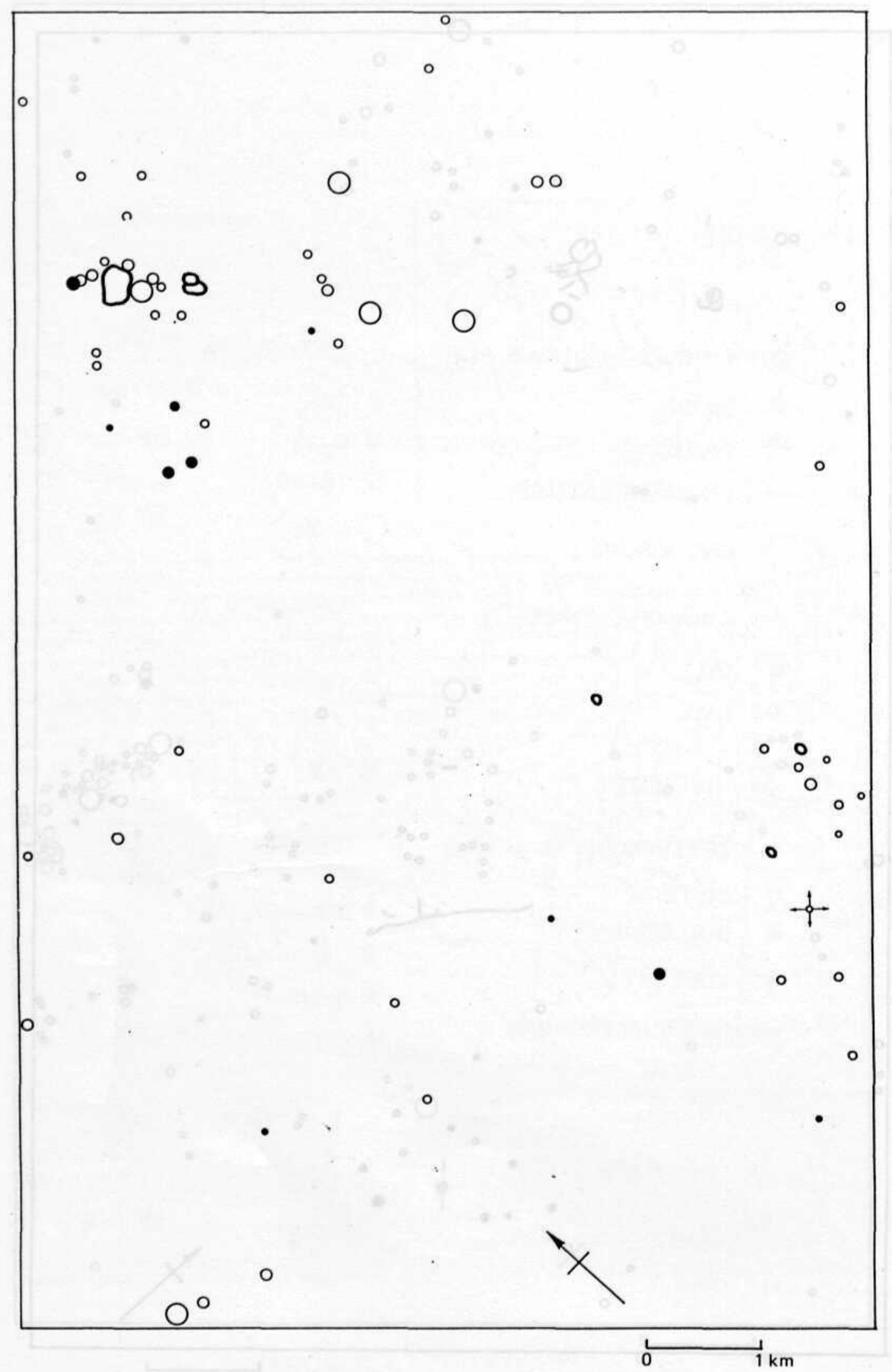

rigure 1.4 Distribution of Iron Age remains. 


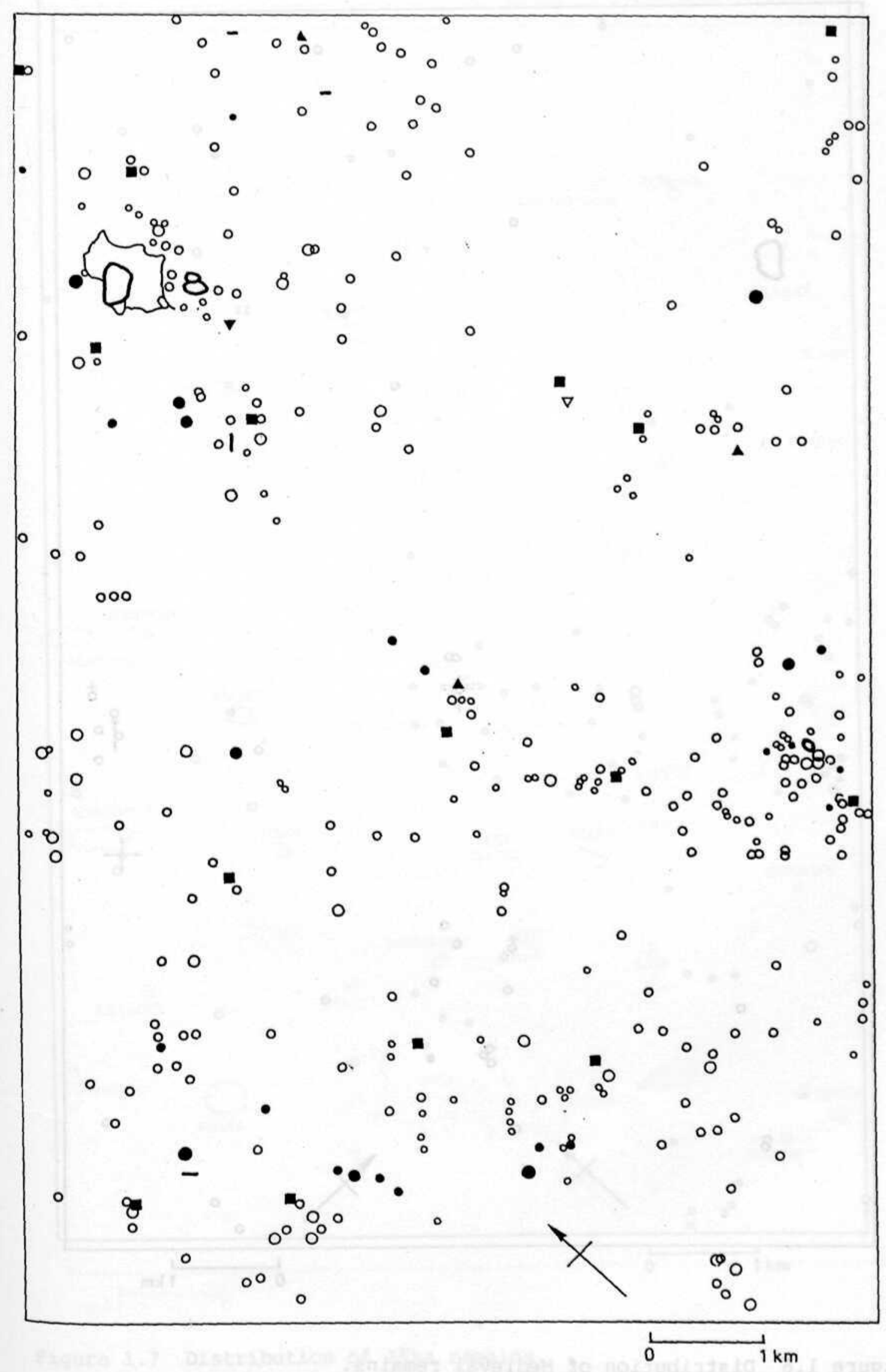

Figure 1.5 Distribution of Roman remains. 


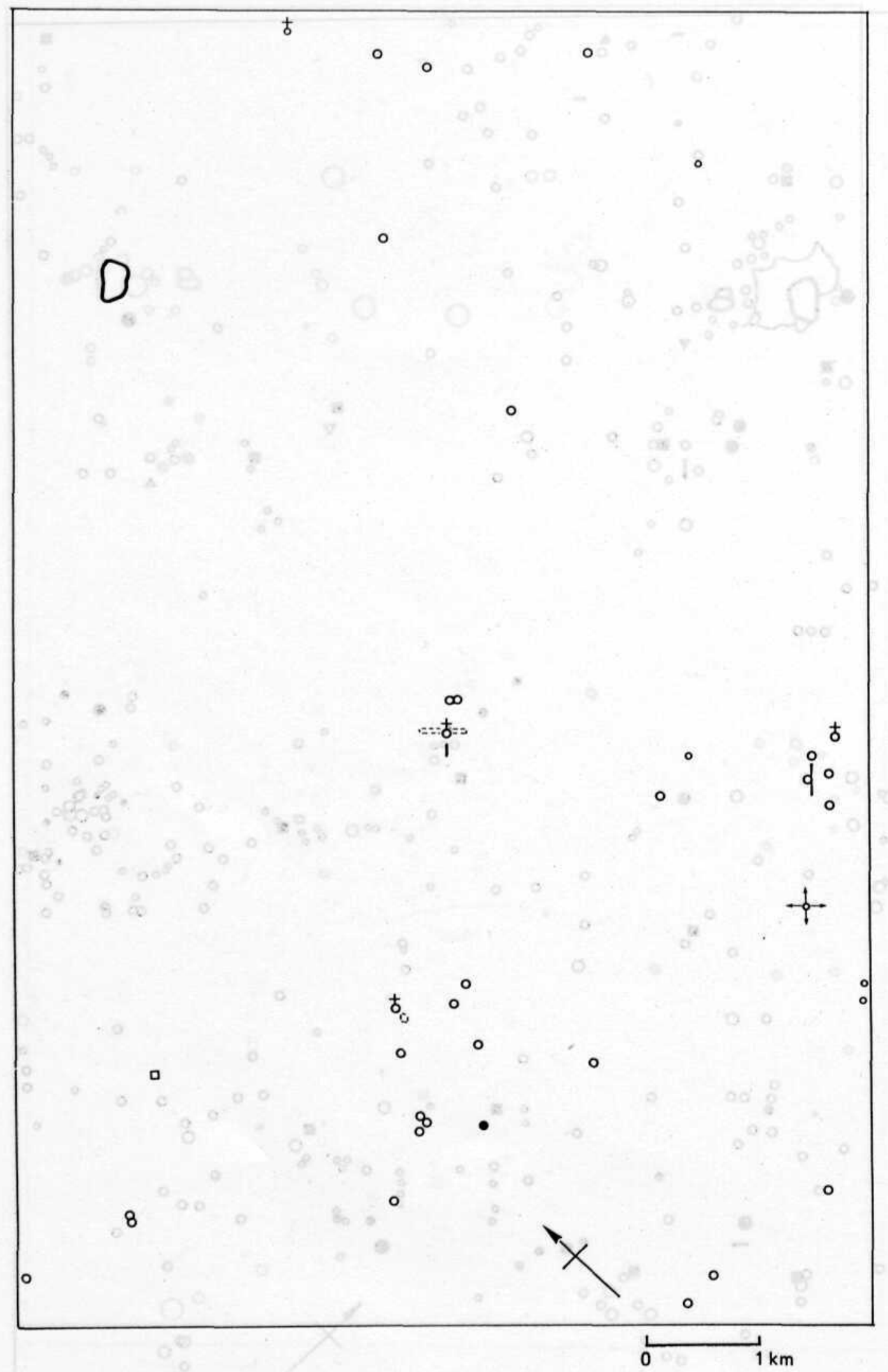

Figure 1.6 Distribution of Medieval remains. 


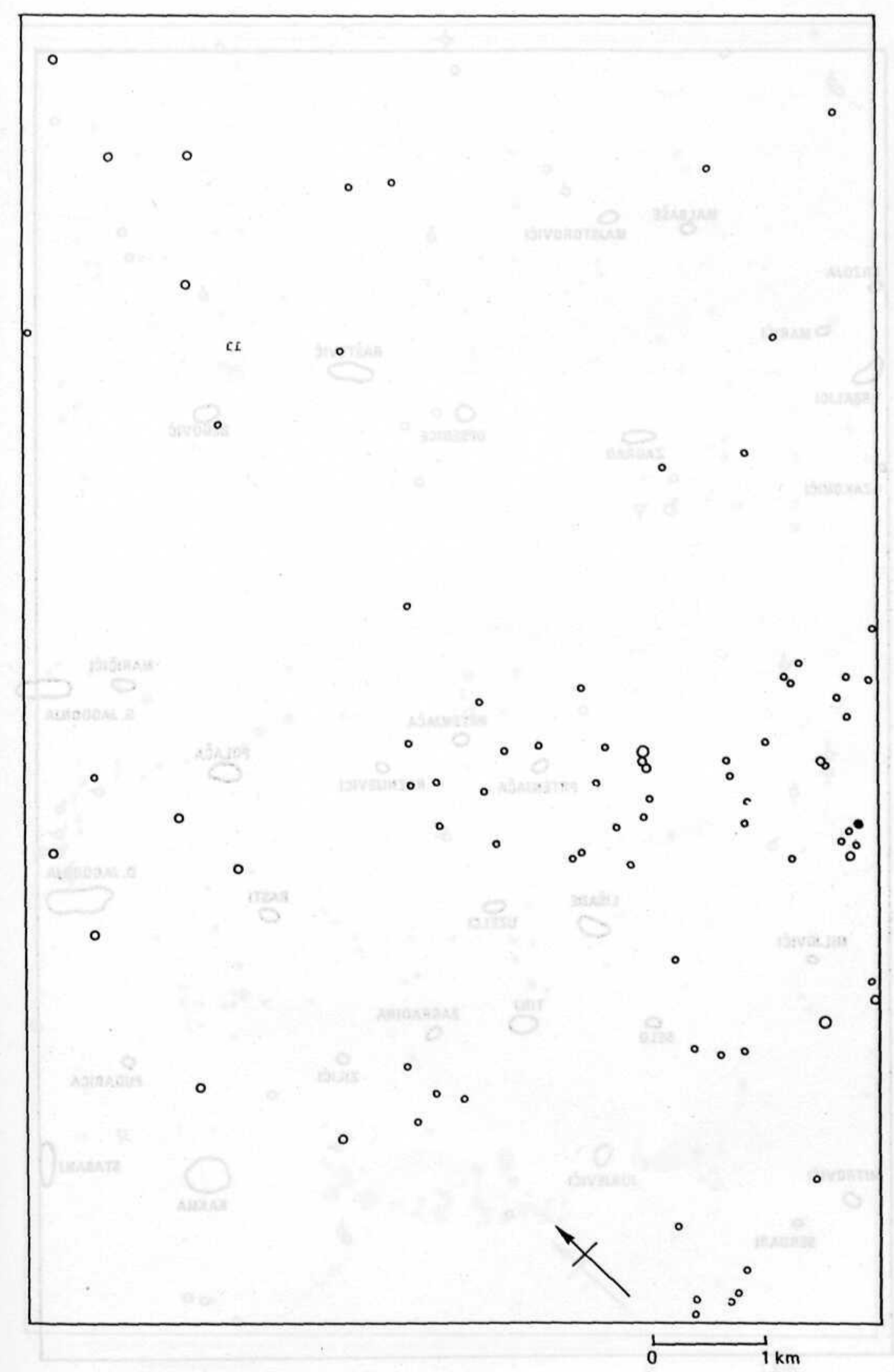

Figure 1.7 Distribution of Is̄ka remains. 


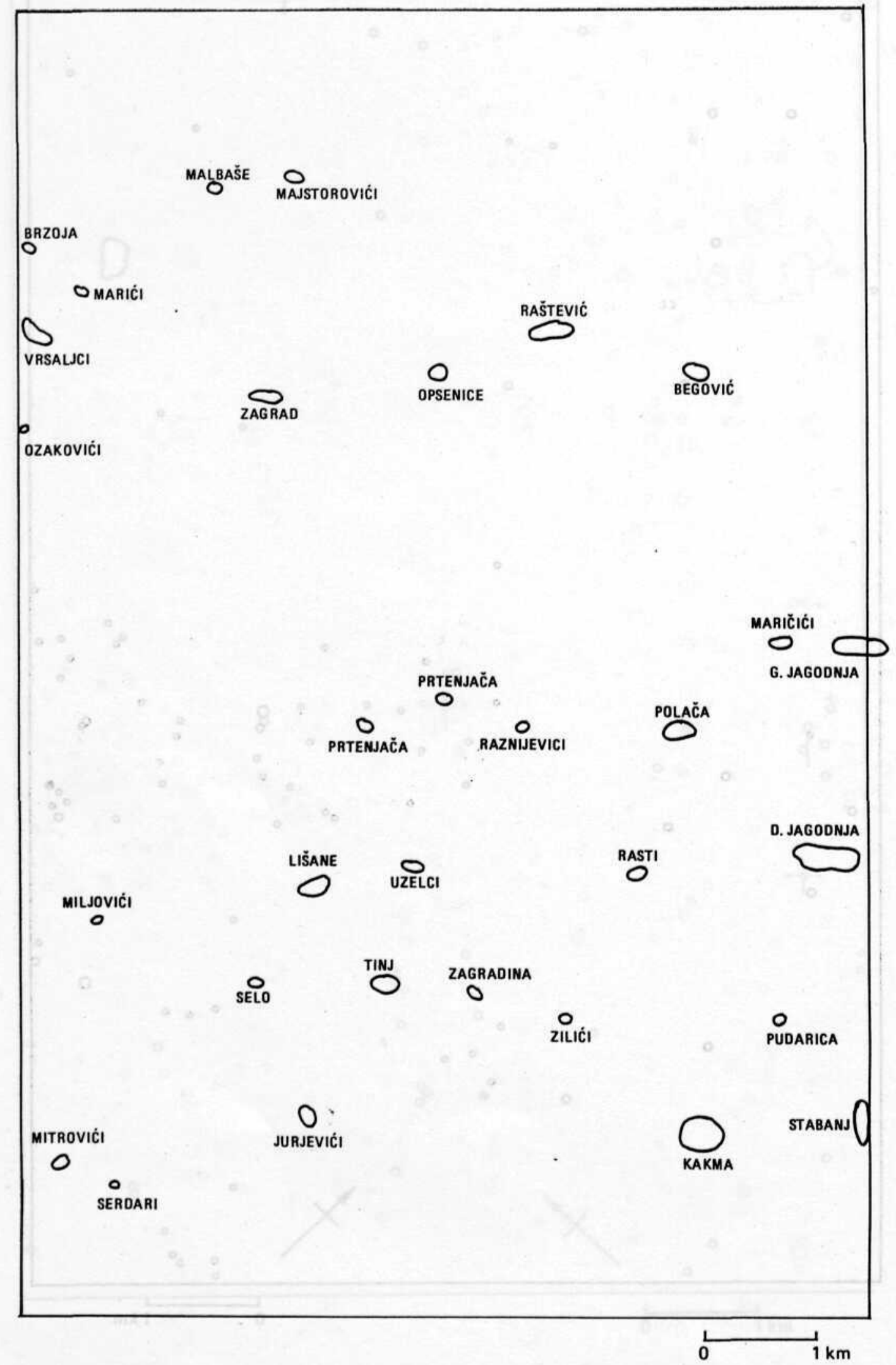

Figure 1.8 Distribution of modern settlement remains. 


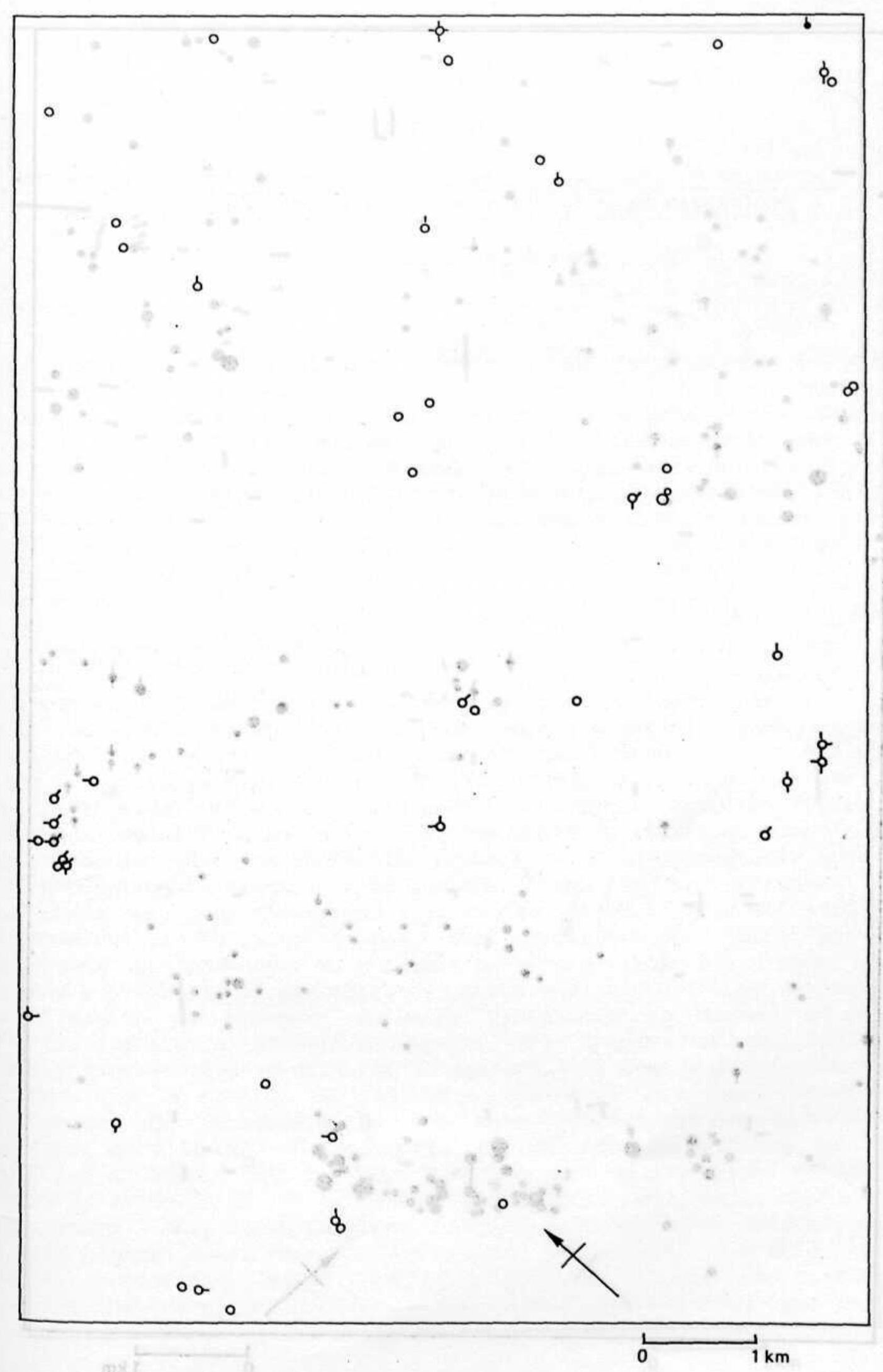

Figure 1.9 Distribution of later chipped stone remains. 


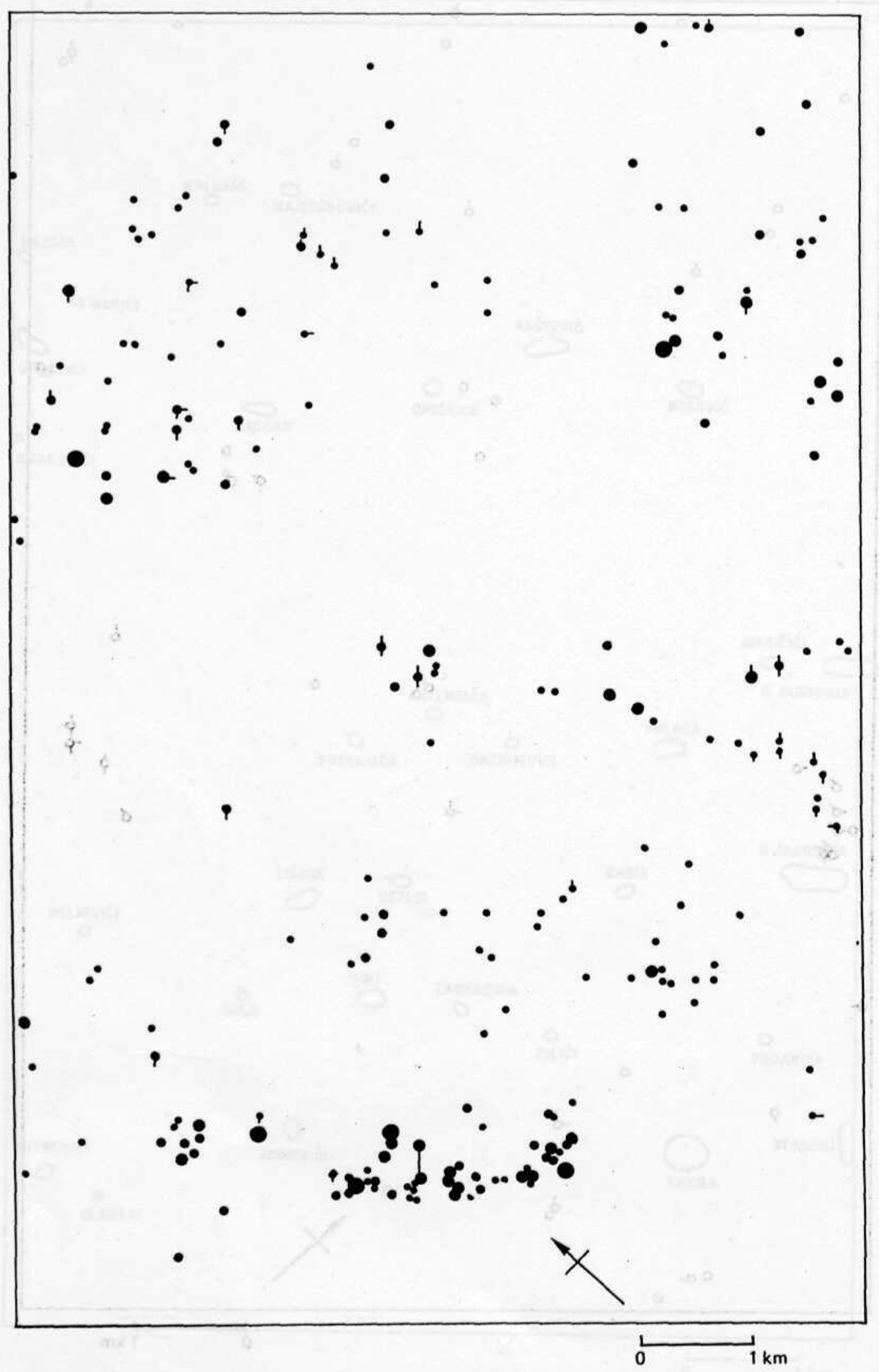

Figure 1.10 Distribution of cairns. 


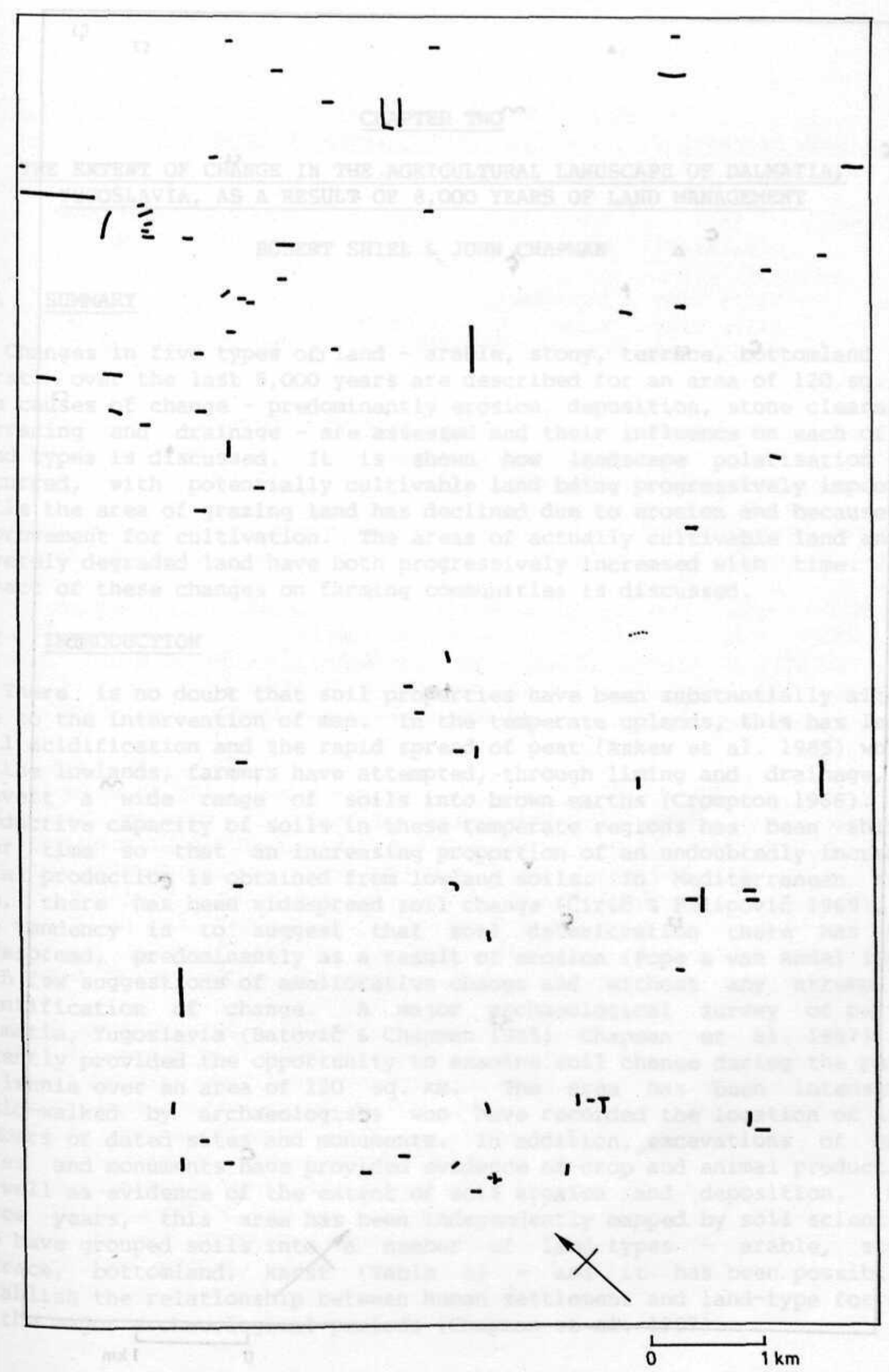

Figure 1.11 Distribution of linear features. 


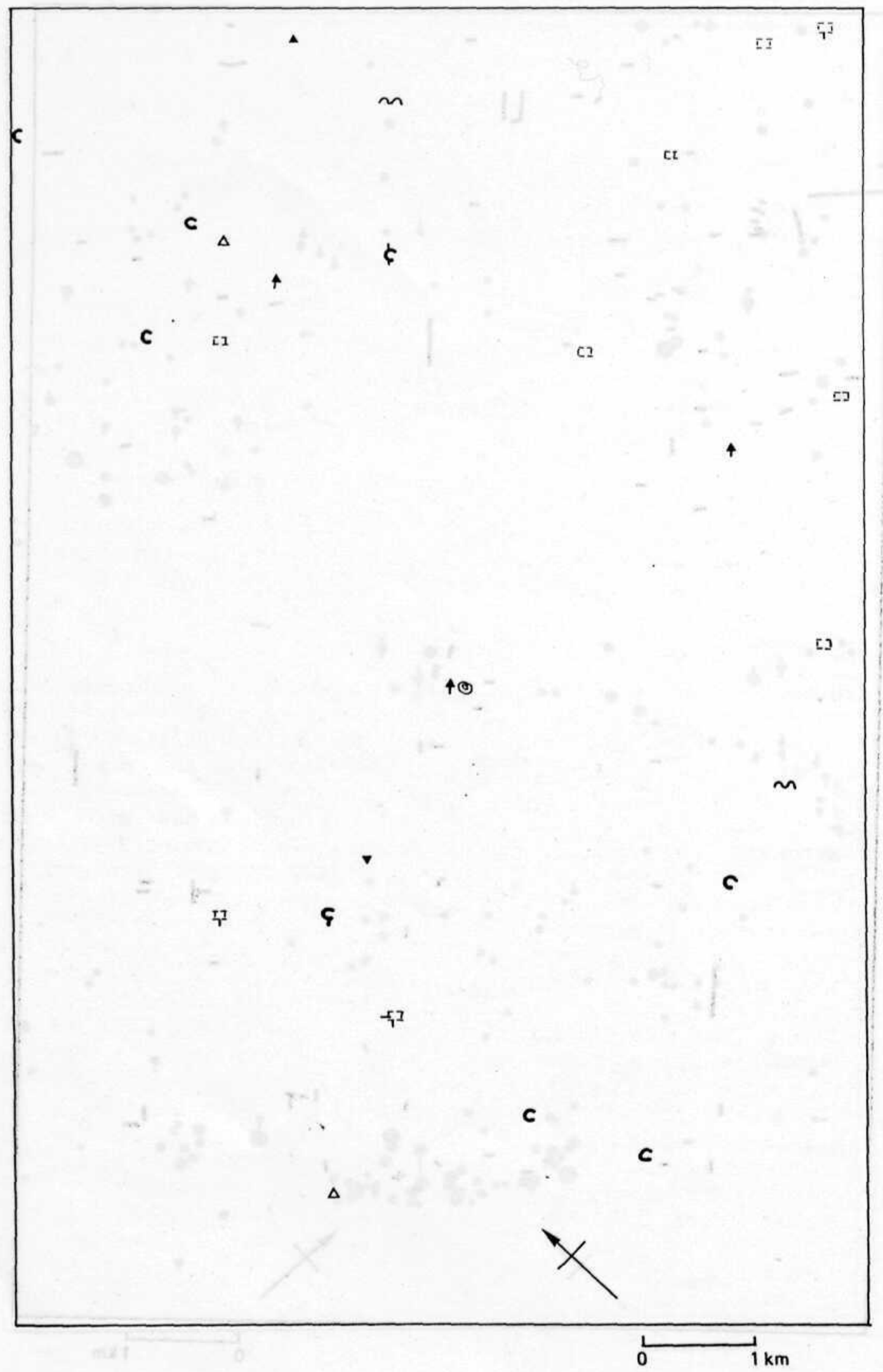

Figure 1.12 Distribution of later settlement remains. 


\section{CHAPTER TWO}

THE EXTENT OF CHANGE IN THE AGRICULTURAL LANDSCAPE OF DALMATIA, YUGOSLAVIA, AS A RESULT OF 8,000 YEARS OF LAND MANAGEMENT

ROBERT SHIEL \& JOHN CHAPMAN

\subsection{SUMMARY}

Changes in five types of land - arable, stony, terrace, bottomland and karst - over the last 8,000 years are described for an area of $120 \mathrm{sq.} \mathrm{km.}$ The causes of change - predominantly erosion, deposition, stone clearance, terracing and drainage - are assessed and their influence on each of the land types is discussed. It is shown how landscape polarisation has occurred, with potentially cultivable land being progressively improved, while the area of grazing land has declined due to erosion and because of improvement for cultivation. The areas of actually cultivable land and of severely degraded land have both progressively increased with time. The impact of these changes on farming communities is discussed.

\subsection{INTRODUCTION}

There is no doubt that soil properties have been substantially altered due to the intervention of man. In the temperate uplands, this has led to soil acidification and the rapid spread of peat (Askew et al. 1985) while, in the lowlands, farmers have attempted, through liming and drainage, to convert a wide range of soils into brown earths (Crompton 1966). The productive capacity of soils in these temperate regions has been shifted over time so that an increasing proportion of an undoubtedly increased total production is obtained from lowland soils. In Mediterranean areas too, there has been widespread soil change (Cirić \& Filipović 1969), but the tendency is to suggest that soil deterioration there has been widespread, predominantly as a result of erosion (Pope \& van Andel 1984), with few suggestions of ameliorative change and without any attempt at quantification of change. A major archaeological survey of part of Dalmatia, Yugoslavia (Batović \& Chapman 1985; Chapman et al. 1987) has recently provided the opportunity to examine soil change during the past 8 millennia over an area of $120 \mathrm{sq} . \mathrm{km}$. The area has been intensively field-walked by archaeologists who have recorded the location of large numbers of dated sites and monuments. In addition, excavations of major sites and monuments have provided evidence of crop and animal production, as well as evidence of the extent of soil erosion and deposition. Over three years, this area has been independently mapped by soil scientists who have grouped soils into a number of land-types - arable, stony, terrace, bottomland, karst (Table 1) - and it has been possible to establish the relationship between human settlement and land-type for each of the major archaeological periods (Chapman et al. 1987). 
Table 1 Some properties of the main land classes found in the Ravni Kotari, Yugoslavia

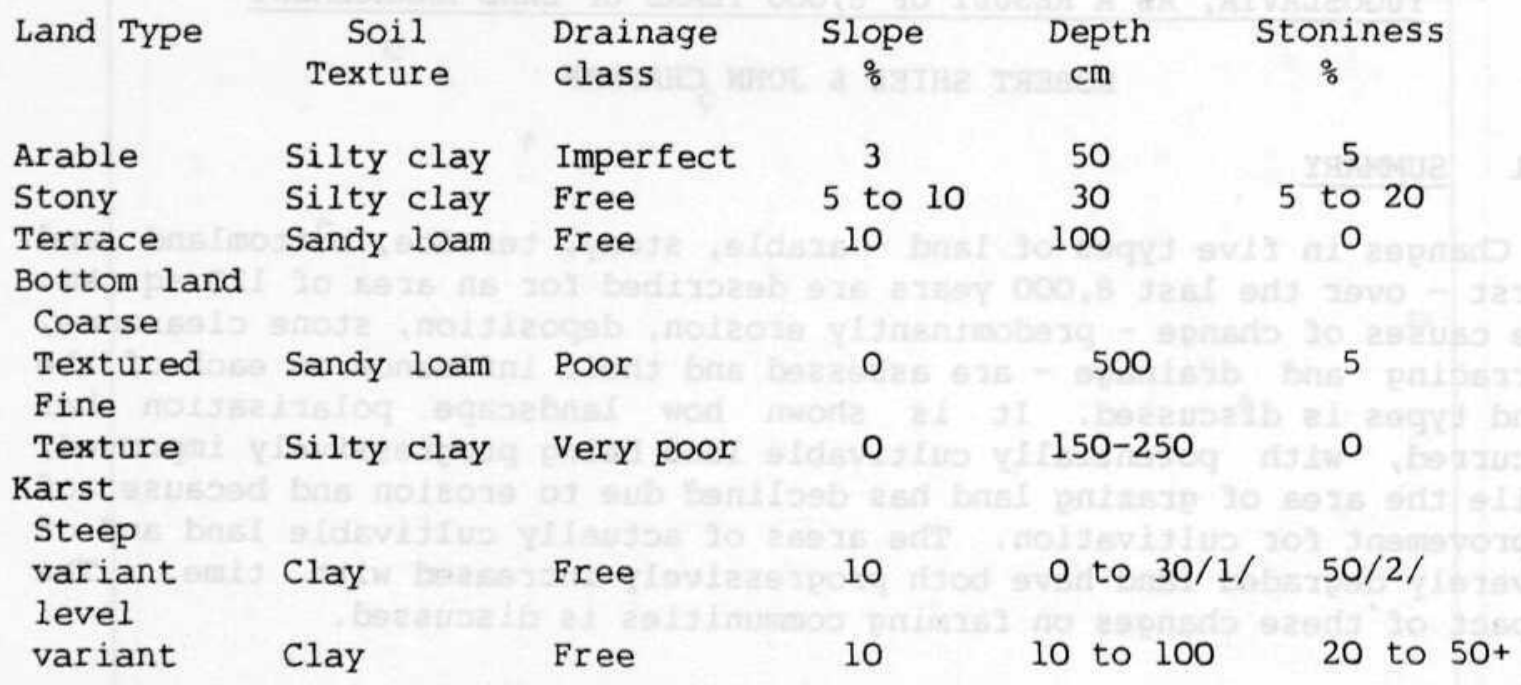

/1/ varies within this range over a distance of less than $10 \mathrm{~m}$

/2/ includes outcropping solid limestone

For a full description of land use types, see Chapman et al. 1987.

This major investigation provides a unique opportunity to examine the change in soil over time in a large block of land, most of which has been intensively used throughout the period. In this paper, an attempt is made to reconstruct the soil environment of 8,000 years ago and demonstrate how soil has changed since that time.

\subsection{THE PHYSICAL ENVIRONMENT}

The survey block is situated near the town of Zadar and extends from the Adriatic coast inland for $22 \mathrm{~km}$ to Karinsko More (see Chapman \& Shiel, above, Figure 1.1). Cretaceous Limestone underlies much of the area together with interbedded calcareous sands and marls. The limestone forms a series of low hog-backed ridges reaching $300 \mathrm{~m}$ elevation, which are aligned parallel to the strike and to the Adriatic coast (Fig. 2.1). These ridges rarely extend for more than $10 \mathrm{~km}$ along the strike and are spaced 3 to $8 \mathrm{~km}$ apart, forming a complex network. The valleys are low-lying ( 50 to $100 \mathrm{~m}$ elevation) and, because outlet to the Adriatic and to Karinsko More is interrupted by the ridges, some of the valleys are flooded seasonally. The flooding occurs at very definite rainfall peaks in spring and autumn (Table 2). 
Table 2 Monthly rainfall and potential transpiration

for coastal Dalmatia, Yugoslavia

$\begin{array}{lllllllllllllll}\text { MONTH } & 1 & 2 & 3 & 4 & 5 & 6 & 7 & 8 & 9 & 10 & 11 & 12 \\ \begin{array}{l}\text { RAIN- } \\ \text { FALL } / 1 / \text { mm }\end{array} & 53 & 56 & 69 & 53 & 94 & 66 & 43 & 30 & 89 & 114 & 109 & 79 \\ \begin{array}{l}\text { POTENTIAL } \\ \text { TRANSP- } \\ \text { IRATION } / 2 /\end{array} & 18 & 23 & 44 & 70 & 110 & 140 & 160 & 153 & 100 & 50 & 25 & 15\end{array}$

/1/ Source : British Admiralty Handbook 1944

/2/ Source : Lockwood 1974

During summer, however, there is a very substantial soil moisture deficit. The land types are closely related to this ridge and valley structure (cf. Figs. 2.1 and 2.3) with karst occupying the summits of the main limestone ridges. On the lower slopes are terrace and stony land types, with arable land in level situations, and bottomland in the flood-risk sections of the valleys. As the ridges are not continuous, this pattern becomes blurred, with karst occurring occasionally in valley bottoms, and terrace soils being found near ridge summits.

\subsection{LAND DEGRADATION}

Although erosion is the most obvious degradational force in the area, the deposition of erosion products may degrade land if they constitute a less productive soil than that buried. Water is the most obvious agent of erosion, but wind erosion may be substantial in an area with such a dry summer. Also, soil deposition in basins may increase the risk of flooding and lead to a deterioration in soil drainage; this problem may be compounded by changes in sea level.

\subsubsection{Erosion}

Water erosion is potentially severe in autumn, when heavy rain follows a dry summer in which vegetation may have been destroyed, consumed or withered. Such erosion will be most likely on the steeper slopes and on soils which are less well drained, or less permeable. On this basis, Soils of the karst and stony types combine steep slope and fine texture, and so may be considered at risk. Terrace soils are more steeply sloping but have a much coarser texture. Evidence of recent erosion comes from observation of plants - usually thorny types (e. g.,Euphorbia spp) - which protect an area of soil some $10 \mathrm{~cm}$ deeper than the surrounding land, where there is frequently no vegetation cover and a soil surface consisting of $50 \%$ stones. Such situations are also common where conifers seem to offer comparable protection from rain, and are presumably equally unpalatable to animals. Erosion in the last century is held responsible for degradation of pasture leading to locally-lamented loss of carrying capacity on the karst. Similarly, substantial well-built sheep housing is known in areas 
which could not now offer grazing proportional to the housing capacity provided.

More remote in time, there are substantial field systems of Mediaeval date, situated near modern settlements, where substantial field walls enclose areas consisting of over 50\% solid limestone. Presumably these walls enclosed soil when built, but the postulated erosion of such soil presents problems. The walls would prevent both wind and sheet erosion but, as the underlying rock is limestone, soil may be lost into an ever-expanding network of grykes. Walls of the larger fields - and of prehistoric ramparts - do stop soil moving laterally and have led to lynchetting, indicating in some areas that soil was more extensive and that sheet erosion does occur. Ramparts from the Bronze and Iron Age have been excavated and substantially thicker soil is found under them than is present in the surrounding land. The difference in soil thickness is frequently $20 \mathrm{~cm}$, an important difference as the surrounding land can often be karst with no continuous soil cover. Finally, Bronze Age cairnfields are found in extensive areas which today are karst. This indicates that, by the Bronze Age, erosion had already progressed to the extent that stones were exposed. There is dispute over the purpose of the cairns (Chapman et al. 1987) but if they constitute clearance, then there must have been substantially more soil than today to justify the effort.

The erosion described so far has been sheet erosion but, in valleys, gully erosion is clear. The limestone itself is being eroded and the steep-sided gullies can be $10 \mathrm{~m}$ deep in solid limestone. Downcutting in these gullies increases slopes on the valley sides, which have, in most cases, lost all their soil. However, the total area affected by this more catastrophic erosion is small as a result of the limited size of catchments.

Wind erosion was investigated by examining the texture of local lacustrine/marine deposits. Although much of the material had a clay texture, there were substantial deposits of fine sand and silt which may indicate wind-blown material. Any such wind erosion is not likely to have occurred within the study area, as the dominant soil texture in the area is clay, and there is no widespread evidence of locally-derived silt or fine sand being trapped in vegetation or behind man-made structures.

\subsubsection{Deposition}

Much of the eroded material has been deposited in low-lying areas with a high flood risk and, as such, has not led to deterioration. Where coarse fluvial deposits have been deposited at higher levels - on stony or arable soils - then degradation does result, but the area affected is small (less than $1 \%$ ). Erosion of the terrace soils appears to result in local downhill movement, and the overlain material (most usually stony land) may have had greater potential than the terrace soils but the affected area again is small - terrace only occupies $3 \%$ in total. Erosion of soil, from what is now karst, onto stony land or arable land does not lead to a marked deterioration as all of the soil involved is of similar quality. 
In general, therefore, deposition of eroded material has had little deleterious effect on overall soil quality. Datable deposition events provide further evidence of the chronology of erosion and may indicate from archaeological evidence whether the land buried was better or worse than it is today. However, although some sites have been found buried deep in deposits, their number is small because of the effort required to locate them.

\subsubsection{Drainage}

Postglacial rise in sea level may have substantially increased the area of bottomland with a high flood risk. This change would affect land near present sea level most seriously, and clearly there has been a substantial loss of land, which is now submerged by the Adriatic. Coring through sediments and examination of fill in bottomlands suggest that land levels in the inland bottomlands have risen by several metres, balancing to a large extent the effect of sea level rise. In bottomlands which are higher above sea level, the deposition will have a beneficial effect by raising land levels but, in parts of a bottomland where there has been less deposition, conditions may have become wetter. As there is usually an abrupt vertical transition of several metres at the edge of bottomlands, these changes are most likely to have influenced only the extent of waterlogging within the bottomlands. Until artificial drainage was carried out this century, waterlogging was extensive and persistent in the bottomlands. Archaeological evidence suggests low intensity use with infrequent attempts at settlement. These settlements may have coincided with climatic variation, but this is believed to have had a minor impact on the Mediterranean environment (Barker 1985; Bintliff \& van Zeist 1982). The risk of flooding will have increased over time due to soil loss from the surrounding ridges, which has reduced the water-holding capacity of the profile and increased runoff rate and volume.

\subsection{LAND ENHANCEMENT}

The most obvious form of land enhancement has been stone clearance. The cleared stones have frequently been built into walls which, on sloping sites, has led to lynchet development. An extreme form of this is terracing of land on the steeper slopes. In addition, deposition of soil eroded from elsewhere has, led to widespread soil deepening. This deepening may have reduced soil wetness. Water tables have also been lowered by major arterial drainage schemes.

\subsubsection{Stone Clearance}

The first evidence of large-scale stone clearance comes from the Bronze Age, when stone was cleared into cairns on land which has subsequently been downgraded to karst. Other areas, already referred to, have substantial walls forming field systems enclosing karst. Elsewhere, stone clearance has had a more permanently beneficial effect, although clearly stone continues to be removed from fields, possibly due to deeper cultivation, soil movement or soil loss. Field boundaries remain modest in scale over much of the area and only in rare situations reach the 
gigantic proportions that they do on other stony areas (Glentworth \& Muir 1963). They nevertheless represent a substantial progressive investment of labour. In a few areas, now classified as arable, stone removal has proceeded to the point of changing the land class. Although much of the land which it was practical to clear has been cleared, in geographically isolated areas there is both unreclaimed land and land which has reverted to wilderness after abandonment.

\subsubsection{Terracing and lynchetting}

The field walls have led to substantial lynchet development with frequently more than $1 \mathrm{~m}$ difference in level between top and bottom of adjoining fields. The fields are therefore more level and easier to manage, while soil erosion is effectively checked. The system has been effective in soil stabilisation, as the density of Bronze Age surface finds (0.97 per sq. km (Chapman et al. 1987) is highest in the stony land type. As lynchetting would presumably develop relatively quickly with cultivation and clearance, the walls will have effectively 'fixed' the landscape from an early date. Terracing on steeper land, which appears to have originated in the late Iron Age period, would require more organisation as the terrace has to be built as a unit. Much of the terrace land is at high elevations - in some cases it occurs at levels above the surrounding limestone summits. There is erosion of the soils found on terraces but in no case was this seen to be associated with breakdown of terrace walls. Like the lynchets, the terraces stabilise the landscape.

\subsubsection{Soil deposition}

The terraces and lynchets have trapped soil within fields but in flatter areas - in particular on the arable and bottomland - deposition from higher land has led to soil thickening. In some areas, eroded terrace soils - those which have no artificial terraces - cover arable land but the area affected is small. Elsewhere, the deposits vary in texture. The fine textured silty clay bottomland deposits are frequently thin (less than $2 \mathrm{~m}$ ) but the coarser deposits which are thicker (more than $5 \mathrm{~m})$, have a high water table. Some of the coarse textured materials are stony and have been cleared as with stony soils. These deposited materials therefore have either deepened a similar fine textured pre-existing soil or provided a new soil with low available water capacity but a good ground water source.

\subsubsection{Drainage}

It has already been indicated that soil drainage has varied with time due to a range of processes, some of which fortuitously have led to drainage improvement. The only evidence of attempts at artificial drainage before this century occurs in parts of the study area with a direct outlet to the Adriatic, as the other areas of badly drained land require arterial drainage. During this century, the attraction of these large blocks of level, homogeneous soil has encouraged improvers and most of the bottomlands are now at least partially drained. The most 
enterprising of these schemes - the drainage of Nadinsko Blato - involved cutting a $2 \mathrm{~km}$ tunnel through hard limestone, but led to the reclamation of $5 \mathrm{sq} . \mathrm{km}$.

\subsection{EFFECTS OF CHANGE ON EACH LAND TYPE}

\subsubsection{Arable}

There is no evidence for any substantial change in this land type over time. The Neolithic settlers preferentially selected arable land and their almost complete absence from other land types suggests that arable has not degraded to any of the other types. The arable land is formed on softer rocks which are unlikely to become karstified and also is in level situations where there is no evidence of soil loss by erosion. Deposition of erosion products of karst and stony land would deepen the soil and this may have substantially improved soil drainage. Erosion products from gullies and terrace soils would, however, make the land excessively stony and coarse-textured respectively. There is no evidence for widespread degradation due to stone deposition as the majority of the fluvial materials have reached bottomland without being deposited on arable land. The coarse textured deposits do restrict the range of crops but, as terrace is the preferred soil type for vines, any land affected in this way therefore remains productive. Changes in drainage, or area, of arable land have not been significantly affected by alterations to the bottomlands.

\subsubsection{Karst}

This is today the most extensive land type, and has increased substantially in area with time. The first use of what is today karst began in the Bronze Age, and may be a reflection of the small area of arable land available but, even at that date, there was clearly a great deal of stone loose near the soil surface. The absence of settlement from the more steeply sloping karst at higher elevations - until defended sites were necessary - may be because the soil was already seriously degraded, possibly without human intervention, by the Bronze Age (Bintliff 1977). The more seriously eroded form of karst has certainly increased substantially over time. There appears to have been a steady loss of stony land to karst throughout the study period, as is attested by the field systems from several periods which have a deeper soil under walls but severely eroded karst within the field systems. This continuing degradation is seen today in the deeper soil under bushes. Present-day soil on the karst only exceeds $20 \mathrm{~cm}$ in depth over small areas and, if this had been relatively continuous in the past, good grazing would have been available, and localised cultivation between the outcrops of solid limestone would have been possible. On a small Adriatic island such as Ugljan, this form of karst is cultivated as the best available, in spite of the extent of limestone outcrop. It appears likely that, with the exception of steep ridges, all of present-day karst was stony in the Bronze Age, though it may have contained some localised limestone outcrops. That which has not been so severely eroded we see today still as stony. This land has progressively deteriorated to its present state, 
having been suitable initially for cultivation, then for intensive grazing and finally, in recent times, over a large part of the present-day karst, only for extensive grazing.

\section{6 .3 Stony}

As described above, this land type has been severely reduced in area due to erosion and loss is continuing where the soil overlies hard limestone. The remaining land is similar in productive potential to arable land but was initially only suitable for grazing. The ease of management of this land type has been very substantially improved by stone clearance and lynchet development, which have made the land suitable for arable crop production. The area of stony land does not appear to have increased through erosion of other land types but the degree of stoniness may have increased due to progressive soil loss. At least some of the soil loss appears to have been vertical loss into grykes in the underlying limestone. These frequently constitute c. $10 \%$ of the area and can be $1 \mathrm{~m}$ deep; they may therefore contain an amount equivalent to $10 \mathrm{~cm}$ of soil. However, the date of gryke development is not known so that this soil, and grykes, may have originated before the period under consideration. The more stable areas of stony land appear to overlie softer limestone or sandstone, in which gryke development is less pronounced.

\subsubsection{Terrace}

Prior to the erection of stone terracing walls, the terrace land was suitable merely for grazing. The development of the terraces may have coincided with the introduction of grape vines, which are successful on the freely drained soil. The origin of the terrace soils is unclear but, as they do appear in some places to be associated with erosion of limestone in gullies, the total area may in fact have increased with time. Much of the soil has moved downhill, exposing a karst limestone surface at higher elevations. Where the eroded terrace soils now overlie stony or arable land, this results in a net loss of cultivable land. In most cases, however, the terrace soil is eroded onto what is today karst, so producing no net loss.

\subsubsection{Bottomland}

This area has been used for seasonal grazing and, in drier climatic periods, may have been used for crop production. The coarse-textured material which has deepened some bottomland soils appears to have come from erosion of solid limestone. The fine-textured sediments are almost certainly from local soils but are relatively thin and indicate a soil loss equivalent to $20 \mathrm{~cm}$ over the surrounding area. This loss of soil is much smaller than 40 to $100 \mathrm{~cm}$ suggested by Van Andel et al (1986) for the Southern Argolid area in Greece. The modern reclamation of bottomland has increased the area of cultivable land substantially but has led to a consequent reduction in summer pastures. In the past this grazing constituted an important part of the rural economy. 


\subsection{DISCUSSION}

Prior to the Neolithic period, man appears to have made little impact on the landscape of the study area. At the outset of the Neolithic, the land can be divided into a small area of easily cultivated land (that which could be cultivated without need for physical improvement) but which would also provide good grazing, a large area of good grazing capable of supporting a continuous crop cover but which, for one or more reasons, could not be used for cultivation without modification, and a small area of poorer grazing land which had already been eroded by natural events possibly during the Pleistocene (van Andel et al. 1986) and where soil cover was below 100\% (Figure 2.2a). Seasonally flooded land could already have been important in terms of providing summer grazing for substantial flocks. From the Neolithic to the 19th century A.D. three main trends were at work in the landscape

4. The area of cultivable land increased sharply due to "improvement" of what had formerly been good grazing land.

5. The area of good pasture shrank both in compensation for this loss and because of soil erosion.

6. The area of poor quality grazing increased inexorably due to the erosion of good pasture.

Although there was a net increase of cultivable land during this period, some formerly-stony land was degraded to karst, but this was more than compensated for by improvement. The area of cultivable terrace land almost certainly increased, at least in the Roman period (Figure 2.2b).

By the late 19th century, it appears that, due to-over grazing, the unimproved stony land over hard limestone was being rapidly degraded to karst and, during the 20th century, this led to a collapse in flock size. There have been earlier, historic-period, fluctuations in flock size and land use intensity, all of which may have been triggered as much by political as by ecological change. The reduction of grazing resulted in the spread of forestry on the karst ridges, while summer grazing was further reduced by the reclamation of bottomlands in the post-war period. The reclaimed bottomlands have been used for industrialised farming of a small number of crops separate from the traditional mixed farming village system.

The villager has, therefore, witnessed loss of grazing land on the karst and bottomland, with a compensatory increase in cultivable land (Figure 2.2). There has been a move away from a farming system based on sheep towards a more crop-oriented economy. This has been associated with a declining rural population (Vadnal, personal communication) but the decline appears to be related equally to an increasing unwillingness by children to work on family farms. The effect has been to concentrate 
labour on the more profitable cash cropping, while outlying fields have been allowed to revert to wilderness. There has also been an increase in part-time farming.

In summary, the main trend has been that land suitable for growing one or more crops (other than grass) has increased in area with time while the area of good grazing land has declined, and the area of poor grazing has increased (Figure 2.2). The polarisation of land use is startingly similar to that in Britain, with an increase in output from the more easily managed lowland soils capable of growing a wide range of crops, and a decline in output from the uplands. Although the climate and factors limiting yield are very different from those in Britain, the similar response of agriculture to variations in productive potential is very enlightening. It appears that the current trends in land use are not geographically restricted, and are outgrowths of a trend which originates, in Yugoslavia, in the Neolithic. Unless current trends are altered, the logical conclusion of this process will be that all land capable of conversion to arable farming will be 'improved' and the remaining land will be 'abandoned' to some low intensity use, which may not be a conventional form of agriculture. In Yugoslavia, this process now appears to be near a conclusion, with an already serious reduction in the role of livestock. It can be argued that the role of livestock is now uneconomic, and as fewer people become willing to look after livestock, there will be a progressive withdrawal from use of the less productive soils. 

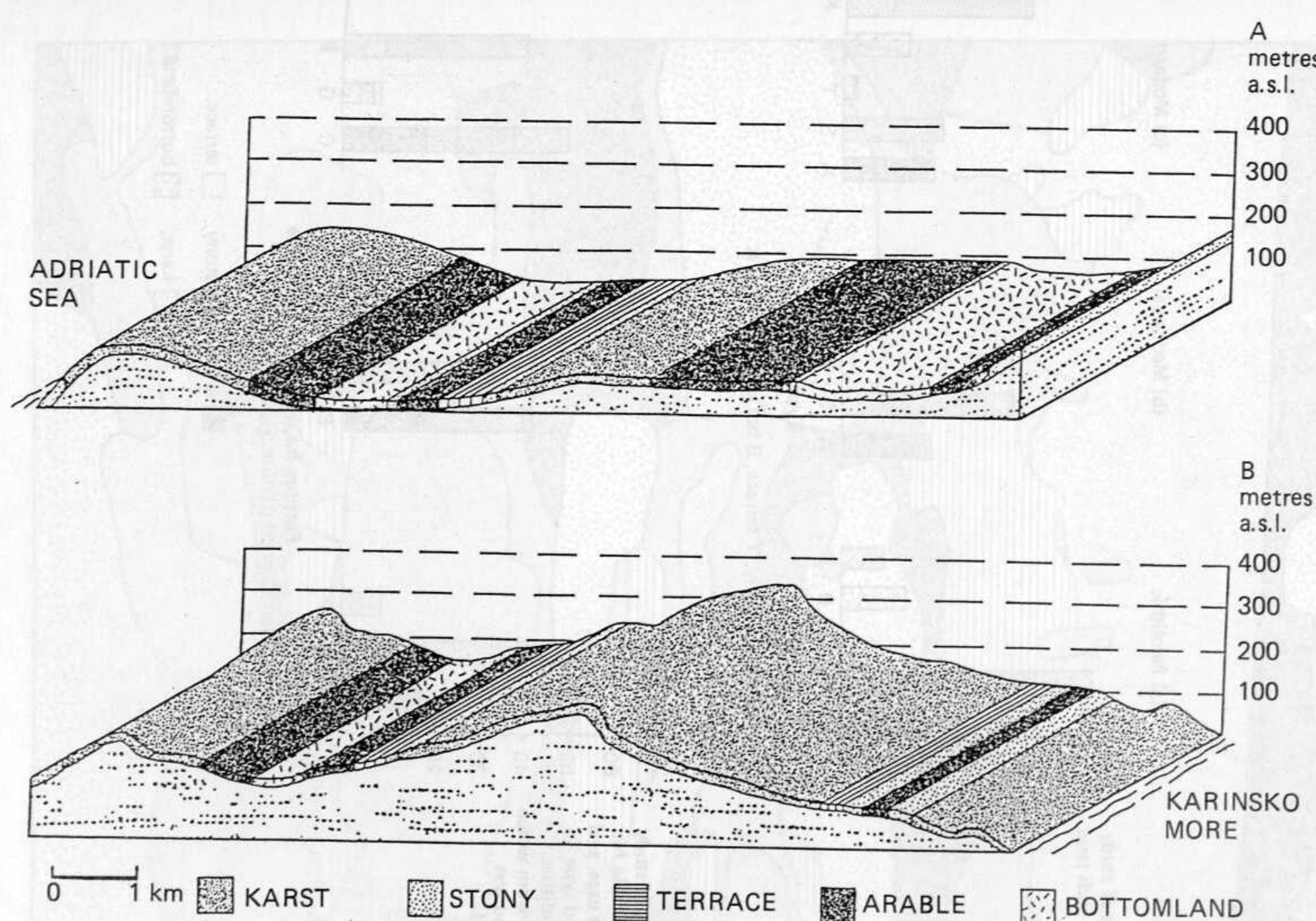
(a) Neolithic

\begin{abstract}
Percent of study area in each land

type
\end{abstract}

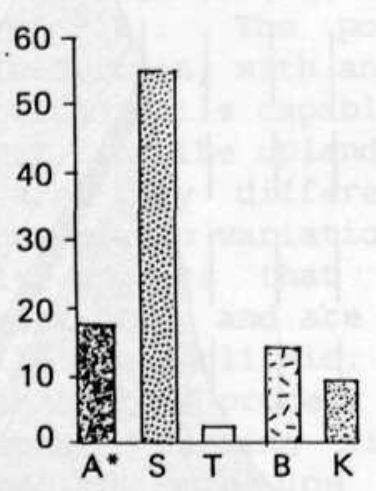

(b) Mediaeval

(c) Modern

*A arable, S stony, $\mathrm{T}$ terrace, B bottomland, $\mathrm{K}$ karst

\section{Percent of study area suitable for various uses, and the land type in the Neolithic Period from which the land was derived}

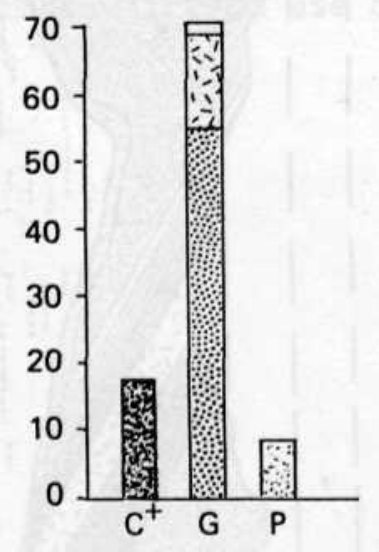

Purpose for which land is suitable ${ }^{+} \mathrm{C}$ cultivation, $\mathrm{G}$ good pasture, $\mathrm{P}$ poor pasture

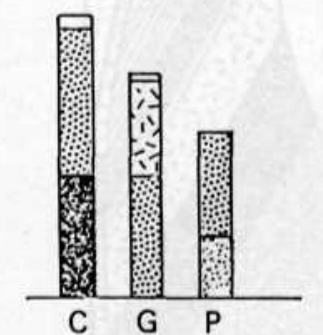

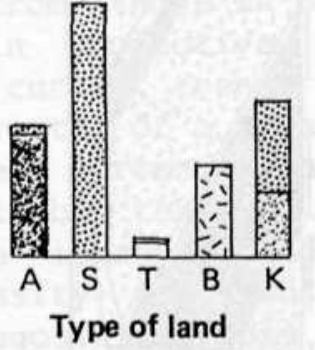

arable，留 stony， $\square$ terrace,

karst, $\mathrm{E}$.

Figure 2.2 Changes since the Neolithic period in (a) land type and (b) land-use suitability. 


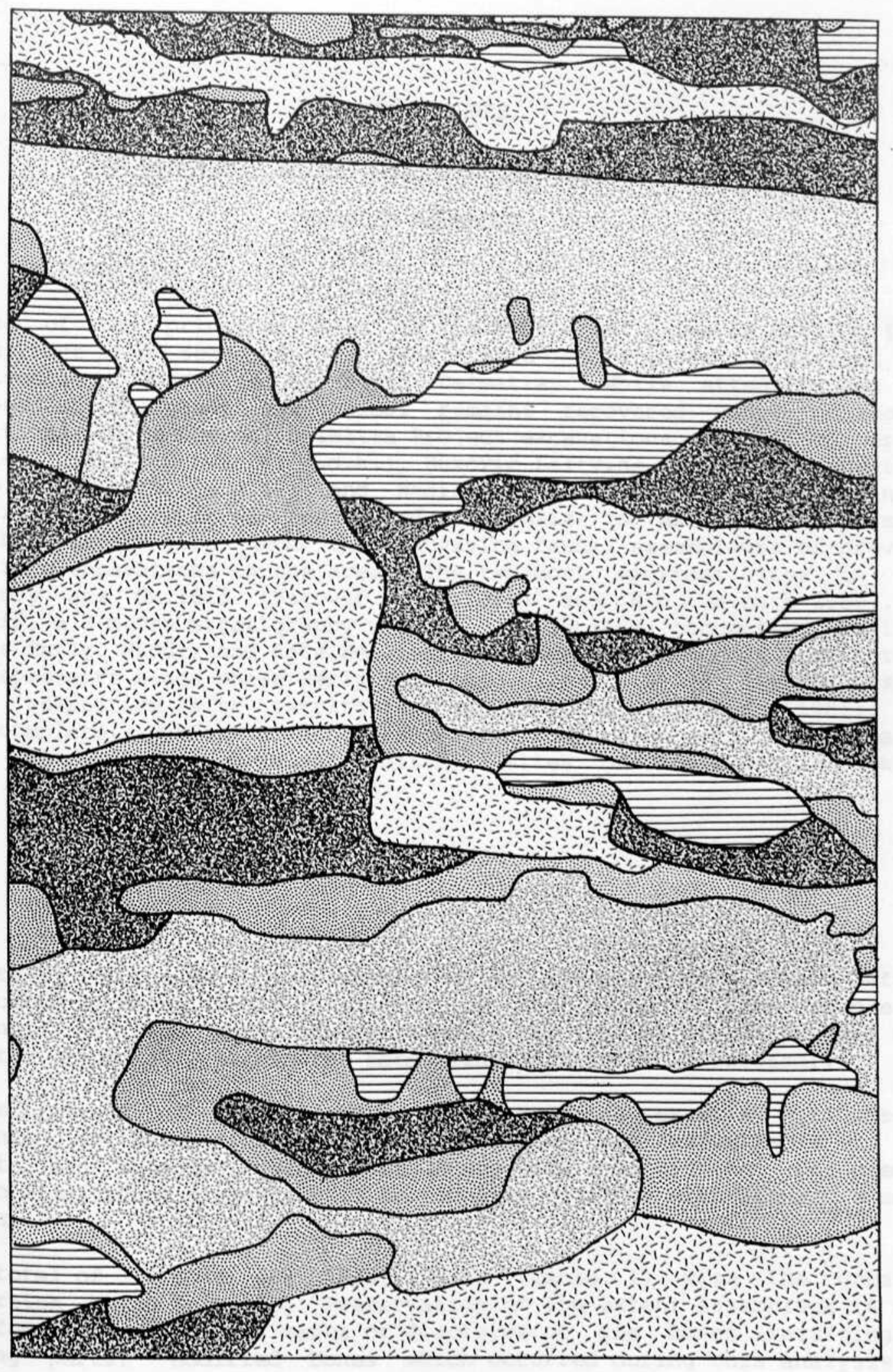

Figure 2.3 Distribution of modern land classes in the survey block (key as in Figure 2.1). 


\section{CHAPTER THREE}

\section{THE NEOLITHIC ANIMAL HUSBANDRY OF SMILC̄IĆ AND NIN}

\section{CHARLES SCHWARTZ}

\subsection{INTRODUCTION}

One of the principal aims of the Neothermal Dalmatia Project is to reconstruct the sequence of subsistence strategies practised by prehistoric communities in North Dalmatia. While attention has been focussed on the plant and animal remains recovered under controlled conditions in Neothermal Dalmatia Project excavations at Tinj (Turner and Huntley, n.d.a.; Schwartz, n.d.a.), Buković-Lastvine (Turner and Huntley, n.d.b.; Schwartz, n.d.b.) and Nadin-Gradina (Turner and Nye, n.d.; Schwartz, n.d.c.), it was considered worthwhile to extract the maximum possible information from the surviving faunal assemblages of previous Neolithic excavations in the area. The two most important sites in this category are Smilểić (Batovié 1963,1966) and Nin (Batovié 1968). At Smilc̈ic, a 3-metre stratigraphy was found to include occupation horizons of the Early, Middle and Late Neolithic periods. By contrast, the site of Nin represents a one-phase Early Neolithic site. Brief discussions of their respective site territories can be found in Chapman (1981). The most completely published faunal report for comparison with the Dalmatian sites concerns the Bosnian Neolithic sites of Obre I and II (Bökönyi 1974).

\subsection{SMILCIC}

\subsubsection{The Sample}

Totals for the vertebrate sample reflect the pre-sorted sample left in the museum by Malez (Table 1); most of the unidentifiable sample is missing. Modified bones are included in the species discussion and will be noted accordingly within the butchering techniques if necessary.

Descriptions of morphological or pathological examples will also be presented, yet butchering and hunting practices are unavailable to all intents and purposes, since part of the sample is missing. Measurement data of individual elements will be supplied together with actual element counts.

A total of 378 bones are identifiable (Table 1) with the greatest proportion being domestic. Preservation of the extant assemblage is good with few postdepositional marks or fractures of the bones resulting in missing parts. Modified bones which occurred during this anaiysis are included for analysis here as well as in the modified bone report (Schwartz 1987).

All bones are measured on the basis of Duerst (1926) and Bökönyi (1974). The osteological material is stored in the Archaeological Museum, 
Zadar, Yugoslavia.

Table 1 Bone Distribution Totals

SPECIES EN EN/MN MN MN/LN LN totals

domestic

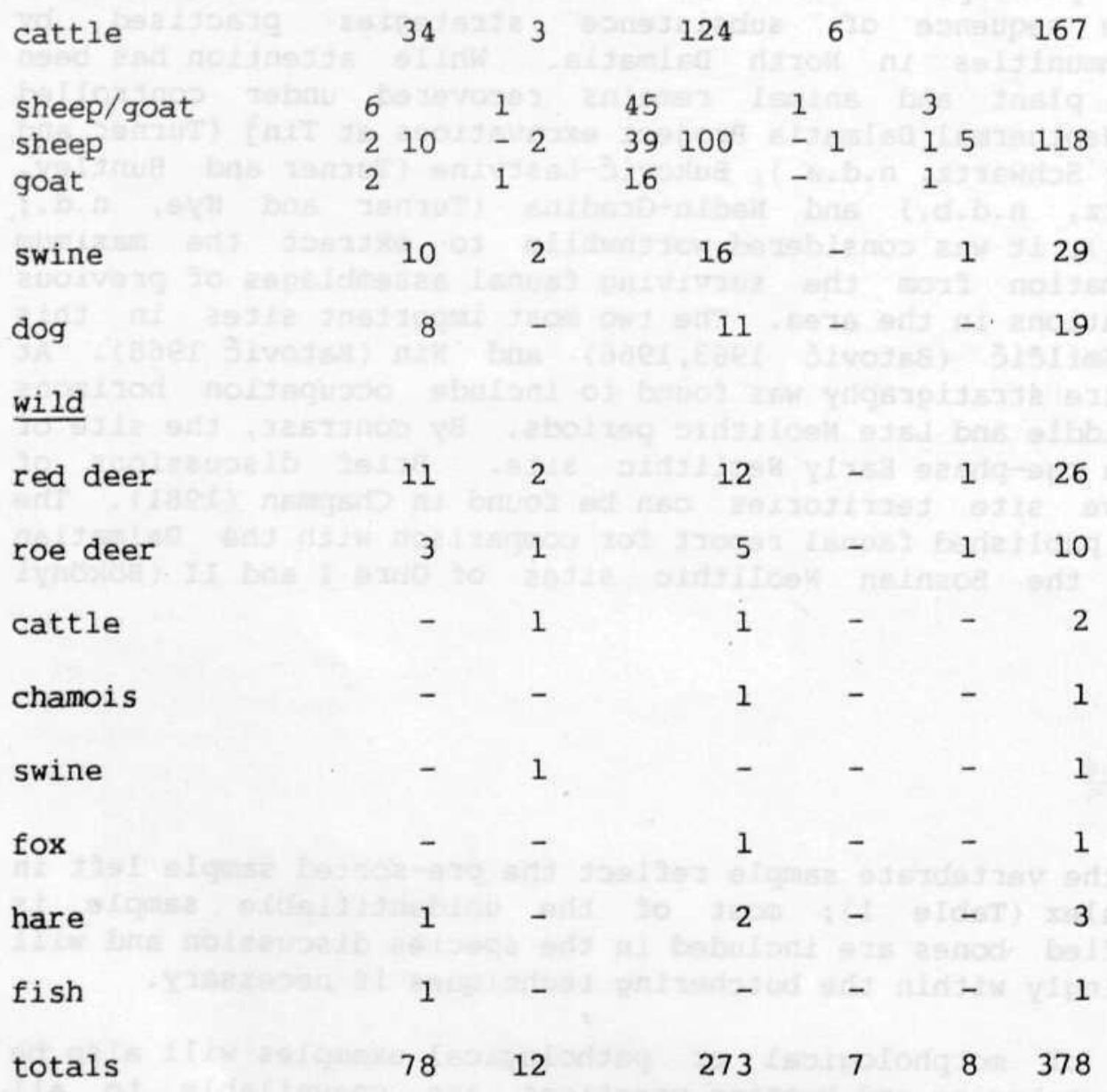

\subsubsection{Species}

Bos primigenius Boj., wild cattle

Bos taurus L., domestic cattle

Much of the bone material from cattle (Tables $2 \& 3$ ) consists of skull elements (including teeth and mandibles), metatarsals, and phalanges. The latter are interesting considering the transverse cuts (Plates $3.1 \& 3.2$ ) which appear, not as a method of butchering, but for some other purpose. There appears to be no ridged pattern of the cuts other than their transverse nature. In most instances, there is more than one cut per phalange whether it is proximal or distal, dorsal or ventral. There is 
only one instance recorded where the bone is severed completely (Plate 3.1.1). Measurements of the 3 rd phalange are given in Table 4. Size comparison with other prehistoric sites such as Tinj (Schwartz 1985), Bukovic-Lastvine (Schwartz 1987), and Obre II (Bökönyi 1974) show close similarities.

A low frequency of cattle bones is identified from the transitional periods EN - MN and MN - LN; none from the Late Neolithic (Table 1). From the EN - MN category, a right mandible (P2 - ascending ramus), a proximal metacarpal, and three phalanges III are identified. From MN - LN, a proximal radius is identified.

A horncore body fragment and a worked distal tibia shaft are possibly from wild cattle. The tibia shaft had been used as a pottery burnisher and could not be measured. However, its overall size is larger than domestic forms and the bone is denser and thicker, suggesting that it may be 'wild'.

Comparison of Smilcic cattle with the contemporary site, Tinj, appears to show differences. At the former site, there are more modified bones, more measurable bone fragments, and higher frequencies of particular elements. The latter consists of horncores and lower hind leg elements. Some of this variation could be due to sampling error and the slightly larger sample from Smilc̈ić. Despite this, there is a real difference in the butchered condition of the bone together with the types and frequencies of the other species recovered.

Size comparison of Smilc̄ić cattle is limited because of few measurable bones. The proximal radius measurements of $77 \mathrm{~mm}$. breadth and $42 \mathrm{~mm}$. width fall in the lower range of variation with those from Obre II (Bökönyi 1974:101-02). An astragalus length measurement, $67.3 \mathrm{~mm}$., from Bukovic-Lastvine (Schwartz 1987) occurs within the range of variation of those from Smilčcić, $65.5 \mathrm{~mm} ., 71.3 \mathrm{~mm}$., and $72.5 \mathrm{~mm}$. No comparison can be made from Tinj. 
Table 2 Distribution of Cattle Bones - Early Neolithic

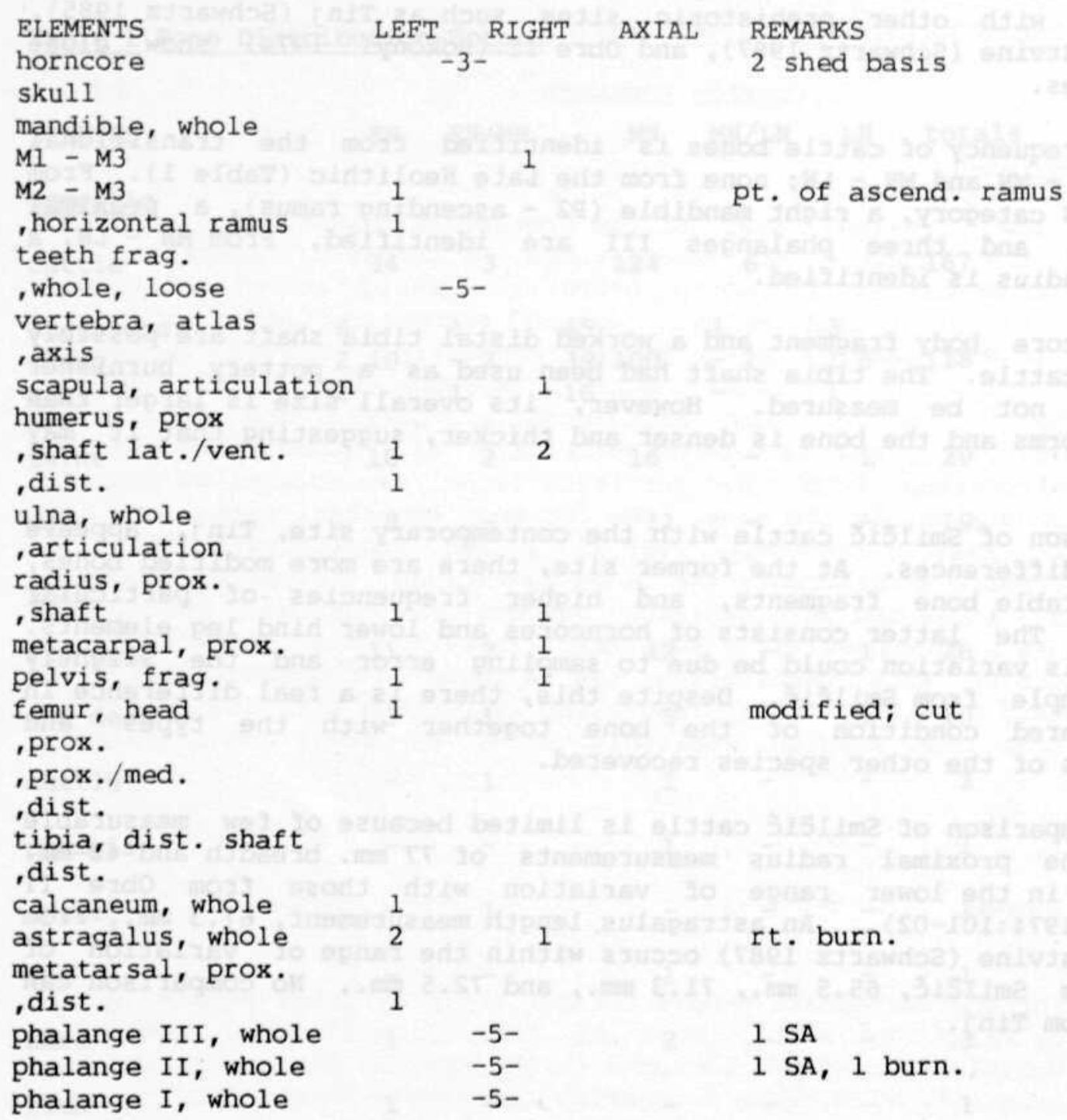

Abbreviations * $\mathrm{SA}=$ sub-adult; burn.= burned

Bone element names preceded by a comma relate to the last main bone name in the list. 


\section{Table 3 Distribution of Cattle Bone - Middle Neolithic}

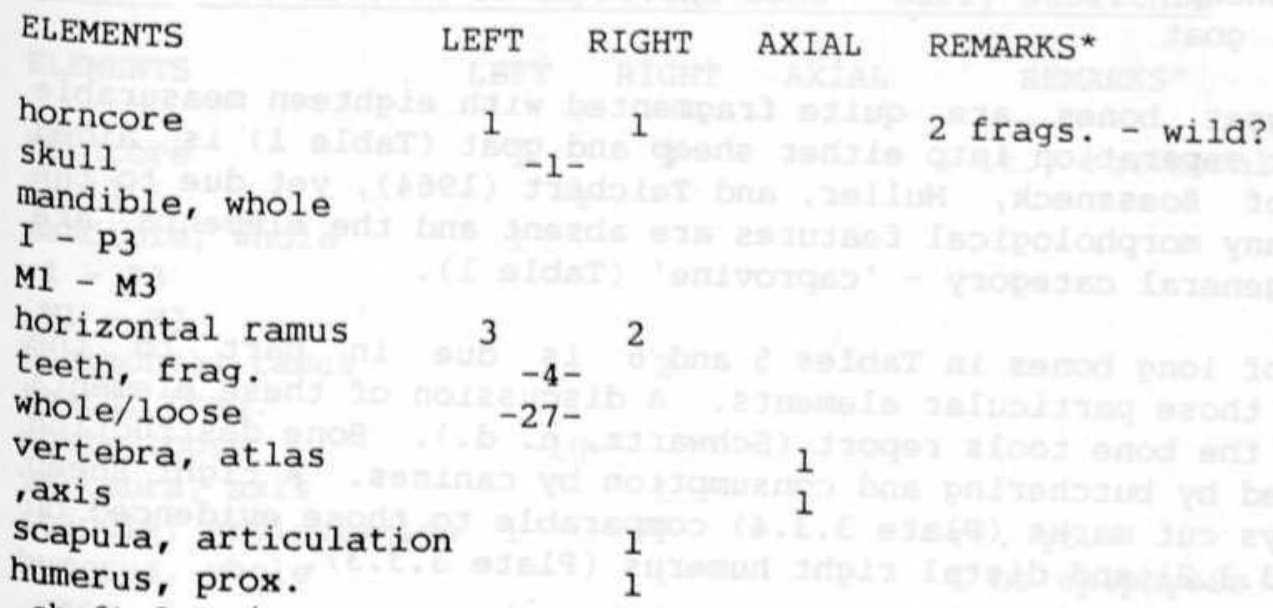

*abbreviations same as for Table 2

\section{Table 4 Measurements of Cattle Third Phalanges}

\section{LENGTH BREADTH MAX. WIDTH}

$\begin{array}{lll}64.1 \mathrm{~mm} . & 28.2 & 34 \\ 66.5 & 29 & 31.2 \\ 73.5 & 33.8 & 34 \\ 65.3 & 31.9 & 34.3 \\ 65 & 28 & 31.3\end{array}$


Ovis aries L., sheep

Capra hircus L., goat

Sheep and goat bones are quite fragmented with eighteen measurable elements. Their separation into either sheep and goat (Table 1) is aided by the work of Boessneck, Muller, and Teichert (1964), yet due to the fragmentation many morphological features are absent and the elements are grouped in the general category - 'caprovine' (Table 1).

The paucity of long bones in Tables 5 and 6 is due in part to the modification of those particular elements. A discussion of these elements can be found in the bone tools report (Schwartz, n. d.). Bone destruction is also evidenced by butchering and consumption by canines. A right sheep horncore displays cut marks (Plate 3.3.4) comparable to those evidenced on an ulna (Plate 3.3.2) and distal right humerus (Plate 3.3.3).

From the transitional periods and Late Neolithic (Table 1) the following bones are identified: Sheep horncore, left \& right horizontal ramus fragments, two goat proximal radii, proximal femur, and two distal tibia.

Two hornless sheep are identified (Plate 3.4.2). If it is correct that, in the early stages of domestication, the females were all hornless (Sandor Bökónyi, personal communication 1986), the sheep from Smilcic are some of the earliest on the Adriatic coast and from the Early Neolithic in Yugoslavia.

Sheep and goat metacarpal measurements fall within the range of variation of those from Obre, Nin, and Tinj (Figures $3.1 \& 3.2$ ). Other measurement comparisons are limited.

Bone modification is depicted by a right pelvic fragment. The top edge of the acetabulum had been smoothed down and a hole made in its depression (Plate 3.4.4).

No pathological specimens are identified. 


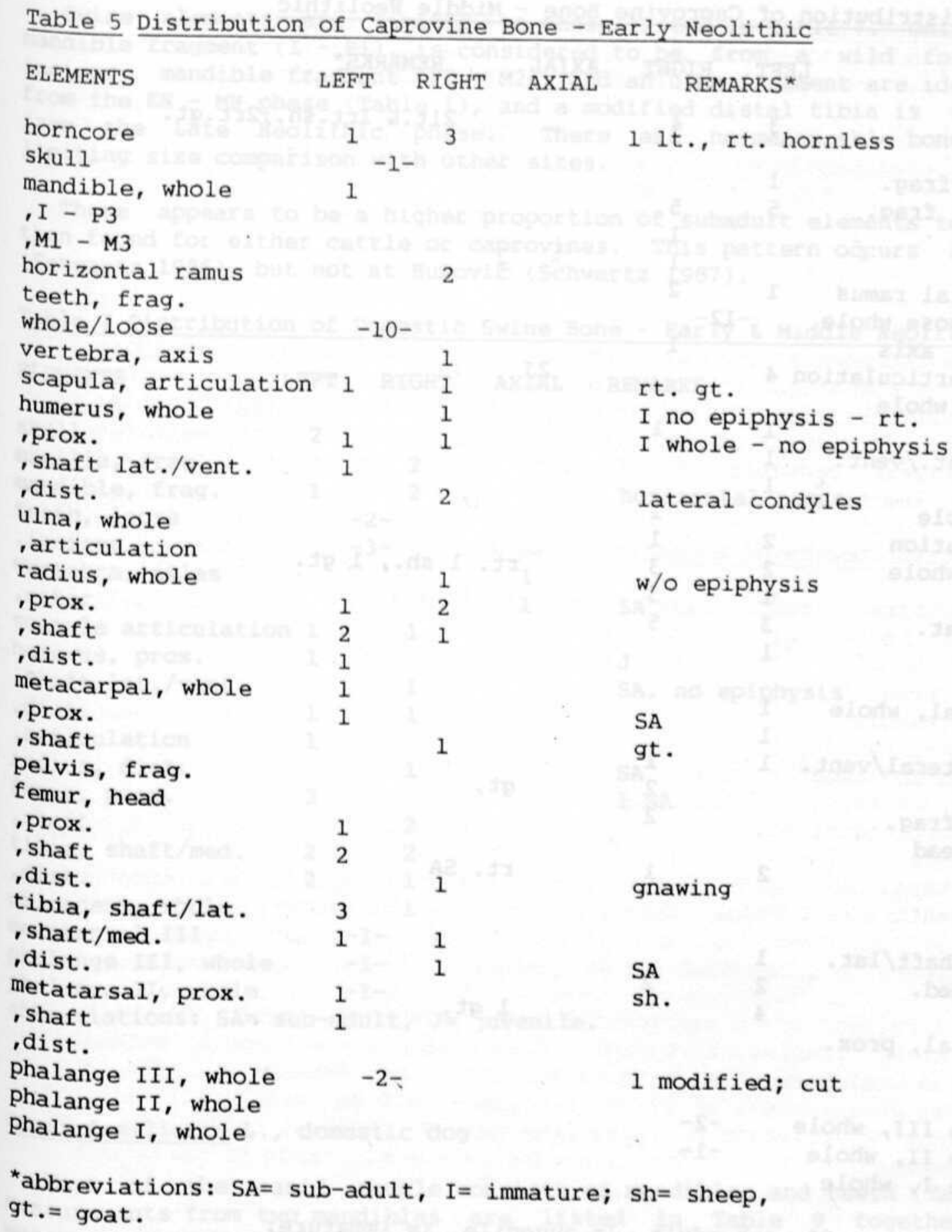

*abbreviations: $\mathrm{SA}=$ sub-adult, $\mathrm{I}=$ immature; $\mathrm{sh}=$ sheep, gt. $=$ goat . 


\section{Table 6 Distribution of Caprovine Bone - Middle Neolithic}

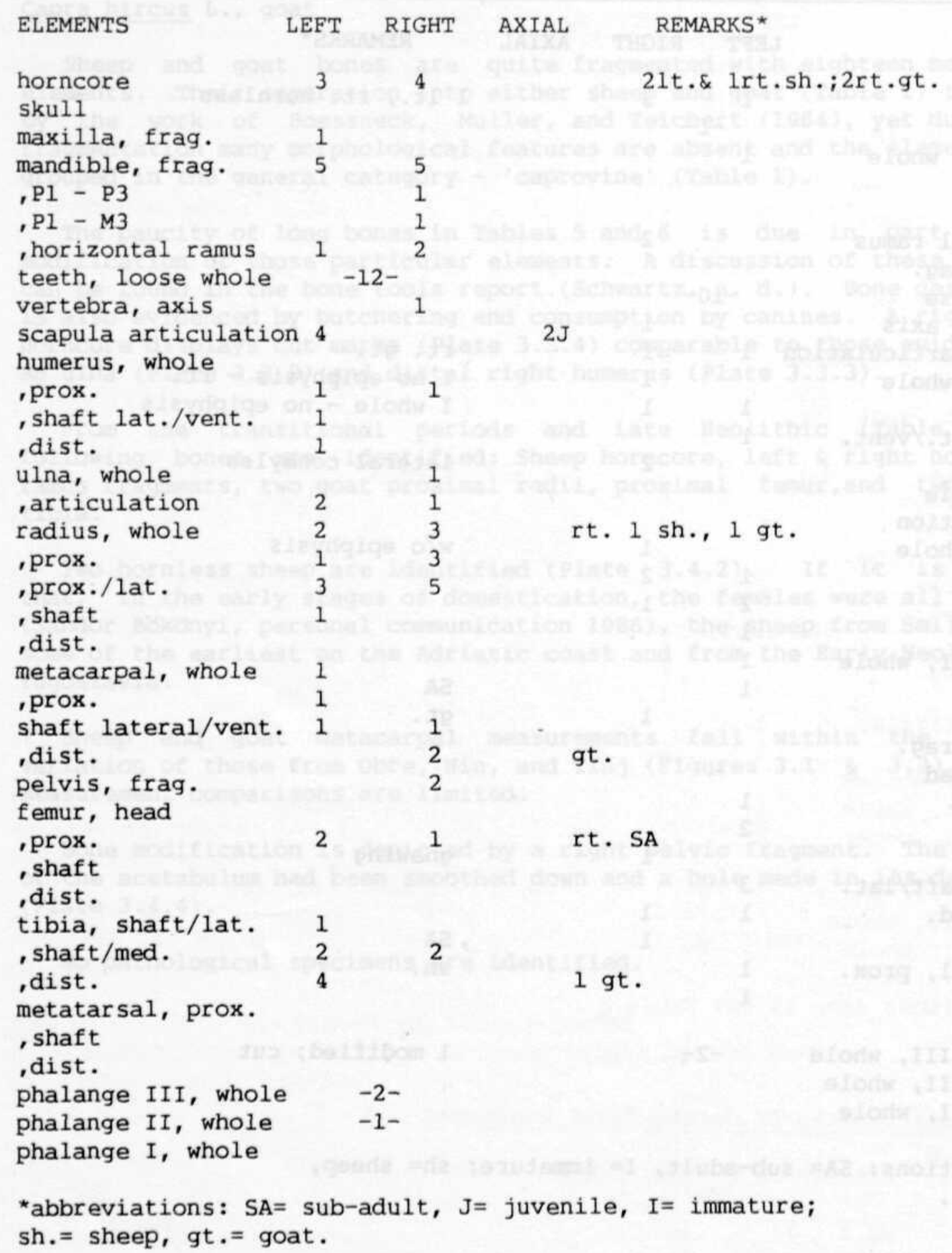


Swine elements are limited to those listed in Table 7. Only one, a mandible fragment ( $I$ - Pl), is considered to be from a wild form. An incisor, mandible fragment (P2 - M2), and an ulna fragment are identified from the EN - MN phase (Table 1), and a modified distal tibia is recorded from the Late Neolithic phase. There are no measurable bones, thus limiting size comparison with other sites.

There appears to be a higher proportion of subadult elements to adults than found for either cattle or caprovines. This pattern occurs in Tinj (Schwartz 1986), but not at Buković (Schwartz 1987).

Table 7 Distribution of Domestic Swine Bone - Early \& Middle Neolithic

ELEMENTS LEFT RIGHT AXIAL REMARKS

skull

maxilla, frag.

mandible, frag.

teeth, loose

, incisor

vertebra, atlas

, other

scapula articulation 1

humerus, prox.

, shaft lat./vent.

, dist.

, articulation

radius, dist.

femur, prox.

, shaft

tibia, shaft/med.

, dist.

calcaneum, whole

metatarsal III

phalange III, whole

phalange II, whole

abbreviations: $\mathrm{SA}=$ sub-adult, $J=$ juvenile. horizontal ramus

$-3-$

1

$1 \quad$ SA

1

$\mathrm{J}$

SA, no epiphysis

SA

$1 \mathrm{SA}$

\section{Canis familiaris L., domestic dog}

Most of the canid sample consists of mandibles and teeth (Table 9). Measurements from two mandibles are listed in Table 9 together with measurements from Obre II (Bókönyi 1974:139-140). 
Table 8 Comparative Lower Tooth Row Measurements

$\begin{array}{llll}\text { SITE } & \text { P1-P4 } & \text { M1-M3 } & \text { LENGTH M } \\ \text { Smilcic } & 33.5 \mathrm{~mm} . & 34 & 18.5 \\ \text { Obre II } & 33 & 32 & 18 \\ & 35 & 32.5 & 19.5 \\ & 32.5 & 30.5 & 19 \\ & 31 & 35 & 20 \\ & 35.5 & 32.5 & 18.5\end{array}$

The measurements from Smilëic fall within the variation of those from Obre II. A comparison of the Obre material to that from Hungary and Greece (Bökönyi 1974:80-1) established that most of the mandibles came from small individuals of gracile to strong stature. One mandible has characteristic crowding of premolars caused by domestication (Bökönyi $1974: 82$ - see Plate 3.4.3)

Table 9 Distribution of Domestic Dog Bones

ELEMENTS LEFT RIGHT AXIAL REMARKS

$\begin{array}{lll}\text { skull } & 1 & 2 \\ \text { maxilla, frag. } & 1 & \\ \text { mandible, whole } & & 2 \\ \text {, horizontal ramus } & 1 & 3 \\ \text { teeth, whole lower } & -1- & \\ \text {, incisor } & -2- & \\ \text { scapula articulation } & & 2 \\ \text { ulna, whole } & & 1 \\ \text { pelvis, frag. } & 1 \\ \text { femur, shaft } & 2\end{array}$

Cervus elephas L., red deer

This large cervid is represented by 25 elements, most of which are antler tines (Tables $1 \&$ 10). Five elements - a scapula, metacarpal, astragalus, calcaneum, and a third phalange - are measurable. The distal metacarpal measurements of $47 \mathrm{~mm}$. breadth $-28.9 \mathrm{~mm}$. width fall within the upper range of variation of those from Obre I (Bokonyi 1974:144), while the calcaneum length, $131.5 \mathrm{~mm}$, occurs in the mid-range of variation from Obre I.

Five of the eleven antler tines recovered exhibited modifications other than polished tips; usually the base of the broken tine had a depression in it large enough to hold a piece of flint or obsidian.

One antler is identified; it is an unshed specimen.

An adult metacarpal (Plate 3.5) exhibited a healed injury; possibly a fracture which occurred while the animal was either an adult or sub-adult 
since the replaced bone covered nearly the total length of the lateral and ventral portions of the bone. It is doubtful whether this healed injury contributed to the animal's demise; more likely there were other contributing factors.

Table 10 Distribution of Red Deer Bone: Early, Middle, and Late Neolithic

ELEMENTS LEFT RIGHT AXIAL REMARKS

antler, tine

, basis

$-1-$

,horizontal ramus

1

teeth, loose

, incisor

scapula articulation

humerus, dist.

ulna, whole

radius, dist.

metacarpal, dist.

calcaneum, whole

astragalus, whole

metatarsal, whole

metatarsal, prox.

, shaft

, dist.

phalange II, whole

11

1
1

1

M2

1

1 rt scap.

1

1

1

1

1

1

1

1

2

1

$-1-$ pathological;partly

fragmented (Plate 5)

\section{Capreolus capreolus L., roe deer}

The bone remains from this small cervid number only ten (Tables 1 \& 11). All are fragmented with two bones measurable; a distal metacarpal and a calcaneum. The former bone has a $22.8 \mathrm{~mm}$. breadth $-16.2 \mathrm{~mm}$. width, which compares well with the example from obre I, $21.7 \mathrm{~mm}$. breadth -14.8 mm. width (Bökönyi 1974:149). 
Table 11 Distribution of Roe Deer Bone : Early, Middle, and Late Neolithic

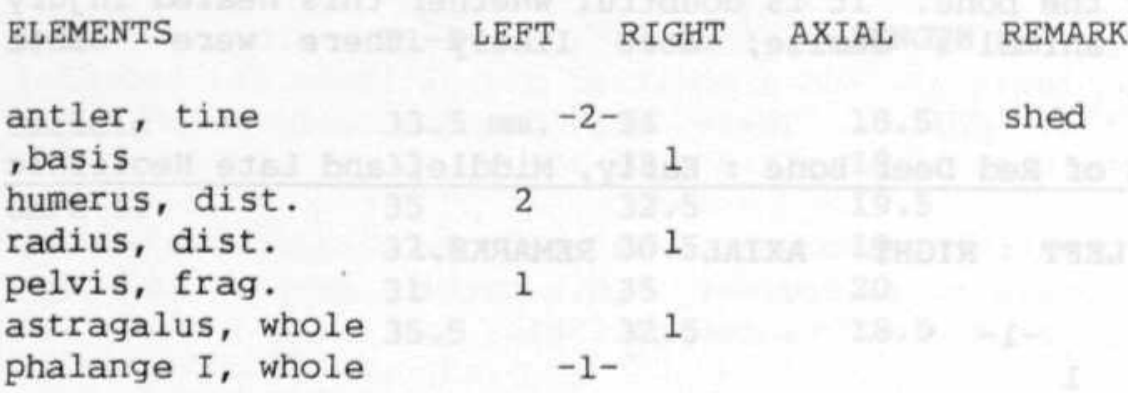

\section{Rupicapra rupicapra L., chamois}

One bone, a horncore with its base partly missing, represents this species. It is recovered from the Middle Neolithic phase at depth of 120 - 140 centimeters. The size of the basis (65 plus) is only an approximation. The examples identified at Obre II (Bökönyi 1974), Lepenski Vir (Bökönyi 1970), and at Sitagroi (Bర̈könyi 1987) measure 70, 71 , and $77 \mathrm{~mm}$. as the circumference of their basis, respectively.

This horncore is distinctive as it is straight, forward leaning, with an almost circular cross-section at its basis. It is possible that some chamois remains are among the fragmented caprovine material.

Chamois' habitat is characteristically the high mountains although during prehistoric times it lived in medium-range mountains. This adaptation resembles its Pleistocene habitat, suggesting in more recent time it has retreated as a result of man's presence (Bökönyi 1987). The most intensive use of chamois in the Dinaric zone was at the Mesolithic site of Odmut (Srejović 1974).

\section{Vulpes vulpes L., fox}

Only one bone, a right mandible (P1 - P3), represents this species. It is an adult.

\section{Lepus europeaus L., brown hare}

Six bones are represented from this animal; two maxilla fragments, a proximal humerus, a proximal and distal tibia, and a metatarsal $I$. None are measurable. This species also occurs at the contemporary neolithic site, Tinj (Schwartz 1986).

Pisces L., fish 
One unidentified vertebra is recovered from fish.

\subsubsection{Summary and Conclusions}

The Smilc̈ić vertebrate remains represent a broader animal base than do the vertebrate species from either Tinj, Nin, or Buković-Lastvine. Significant additions are the wild animals with characteristically different habitats from the faunas of the latter two sites, thus signifying an extension of the resource base at Smilcicic (see also the modified bone analysis, Schwartz 1987). Had the molluscan fauna been of a frequency equal to Tinj, then one could assume that it played an important role in the subsistence base.

The amount of modified bone found at Smilcicic (see also the modified bone analysis, Schwartz 1977) is also significant, being larger in frequency and variety than those from Tinj, Buković-Lastvine, or even Nin.

Both the above characteristics are even more significant given the small amount of bone material identified. However, in comparison to Obre I, with a larger bone sample and different ecological setting, the qualitative differences noted above for the other two Adriatic habitations are set into perspective.

What distinguishes Smilc̈ic from all three of the sites with molluscan remains is its variety. At least seventeen species are recorded, while at Tinj only thirteen are identified. Moreover, probably more significant is thet the subsistence base supported by the Tinj molluscan fauna centered on gathering from rocks and other hard substrata while the species from Smilcic constitute an assemblage based principally on mud and sand.

Consequently, with both these sites having similar geographical locations (within 15 kilometers of each other) and corresponding occupation periods (Early Neolithic), one can infer that the inhabitants of the two occupations utilized different exploitation territories, at least as far as collection of wild resources was concerned. It can also be stated that different hunting patterns existed between the two based on the differences in their wild faunas.

\subsection{THE MOLLUSCAN FAUNA FROM SMILC̈IĆ}

The molluscan remains from Smilc̄ic are minimal yet exhibit a wide variety of species (Table 12). Since this sample exemplifies only a small portion of the original amount recovered, a species presence is recorded for the different phases together with a brief description of each species. Where possible, measurement ranges are noted.

Nomenclature is based on the works of Locard (1892), Riedl (1963), and Garms and Borm (1981). 
Within the species discussion, specific reference is made to habitat. All species recovered from Smilc̈ić are either from the land or from the littoral zone along the seashore. The latter zone is divided into three parts (Sabelli 1979): supralittoral, mesolittoral, and infralittoral. The latter two are of interest here. The middle area, the mesolittoral, covers the zone to the lowest depths at which a family of plants called Zosteraceae can survive.

Table 12 Molluscan Species Occurring at Smilc̈ić

CLASS GASTRAPODA

Gibbula adriatica L.

Gibbula sp.?

Turitella communis Risso

Turret shell

Murex truncularis L., Murex

Euthria cornea L., Horn welk $\mathrm{x}$ terrestrial

Valvata cristata Muller

Spiralina vortex L.

Helix aspersus L., Land snail, class Bivalva

Mytilius galloprovincialis $\mathrm{x}$ Lam., Common mussel

Chlamys opercularis L., $\mathrm{x}$ Scallop

Spondylus gaederopus L., Donkies feet

Pecten Jacobaeus L., St. James' shell

Anomia ephippium L., Jingle shel1

Ostrea edulis lamellosa L., x Edible oyster

Ostrea edulis adriatica L., x Edible oyster

Cardium edule L., Common cockle

Acropagia balustina L.

\subsubsection{Species}

Gibbula adriatica L., Top shell Gibbula sp.?

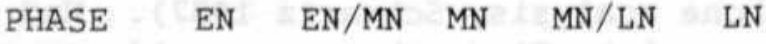

\section{$\mathrm{x}$}

$\mathrm{x}$

$\mathrm{x}$

$x$

$\mathrm{x}$

x

x $\quad x$ 
Its habitat is the tops of stones or rocks in the infralittoral; sometimes the circalittoral. It is quite commmon in the Mediterranean and could be confused with another species, Fanulum L. (Sabelli 1980:168).

Turitella communis Risso, Turret shell

This species is usually found on the fine sands of the infralittoral. Height range from Smilēić is $9 \mathrm{~mm}$. to $33.5 \mathrm{~mm}$.; larger than the $12.5 \mathrm{~mm}$. to $31.5 \mathrm{~mm}$. from Buković (see above, p. xxx).

\section{Murex truncularis L., Murex}

Located usually on detrital bottoms, sand, or muds this edible species appears only in the Middle Neolithic phase. All shells are fragmented with sections of the columnar missing below the operculum.

Eutheria cornea L., Horn welk

This species is found hidden beneath stones or sometimes found on detrital substrate in the circalittoral.

\section{Valvata cristata Muller}

A small snail which lives on plants in area where the water is stagnant.

\section{Spiralina vortex L.}

Also in the general category as Valvata, this small snail lives on plants in stagnant water.

\section{Helix aspersus L.}

A very common land snail found in the Adriatic and similar to the English garden snail. One measurable example, $25 \mathrm{~mm}$. height, compared well with one example from Tinj (Schwartz, in press).

\section{Mytilus galloprovincialis Lam., Common mussel}

One of the few species identified from Smilëic which is found on hard substrate. Its habitat is the mesolittoral and infralittoral zones which would provide easy access for gathering.

Chlamy opercularis L., Scallop 
This species is quite common to the Mediterranean living at ten meters depth (Garms and Borm 1981) on the sandy bottom in the infralittoral. It is smaller that its cousin, St James' Shell.

Spondylus gaederopus L., Donkies feet

Spondylus inhabits depths below two meters and is found attached to hard substrate on the ocean bottom (Shackleton 1968). Several pieces had been worked into bracelets.

Pecten Jacobaeus L., St. James' Shell

A larger species than Chlamy which inhabits the sandy bottom of the infralittoral at a depth around 15 meters (Garms and Borm 1981).

Anomia ephippium L., Jingle shell

This species gets its name because of its fragile nature and natural hole in its right valve making it easy to make into a necklace or bracelet. It inhabits rigid substrate such as rocks found in the infralittoral and circalittoral.

\section{Ostrea edulis ariatica L., Edible oyster} Ostrea edulis lamellosa L., Edible oyster

Both varieties have similar habitats living more commonly on soft sand and mud than on hard substrate in the mesolittoral and infralittoral. Both species are 3 edible and easy to gather especially during the non-summer months.

Cardium edule L., Common cockle

This species is common to the Adriatic and can be found in the sand of the circalittoral and sometimes the infralittoral.

Acropagia balustina L .

Its habitat are the sands of the infralittoral.

\subsubsection{Summary}

The majority of the species from the Smilčic sample are bottom dwellers usually found in the sand or mud. All are edible and would have contributed considerably to the subsistence base had they occurred in a frequency comparable to that of Tinj. 
Because of the varied spectrum of molluscs and narrow ecological base this site is very different from either Bukovic-Lastvine or Tinj. This is especially so of the case of Tinj since both sites are contemporary and are from the same geographical area.

\subsection{NEOLITHIC NIN}

\subsubsection{The Sample}

From the 453 bones recovered, only 85 (18 percent) are unidentified. There are 35 measurable bones mostly from sheep or goat, which reflects their high frequency in the sample (Table 13). Preservation of the sample is good, with little postdepositional destruction. There is little or no burned bone. (1974).

All bones are measured on the basis of Duerst (1926) and Bökönyi

The osteological material is stored in the Archaeological Museum, Zadar, Yugoslavia.

\section{Table 13 Distribution of the Identified Species Elements}

DOMESTIC SPECIES

Bos taurus L., cattle

Caprovines

Ovis aries L., sheep

Capra hircus L., goat

Sus scrofa dom. L.,

domestic swine

Canis familiaris L., dog

WILD SPECIES

Equus caballus L. ,

wild horse

Cervus elephas L., red deer

Capreolus capreolus L.,

roe deer

total

31

$16 \quad 347$

5

2

1
8 300
10

10

\section{NUMBER OF ELEMENTS}

\subsubsection{Species}

Bos taurus L., cattle

Domestic cattle remains are limited to five loose teeth and a phalange II. They are all from adult forms. 
Ovis aries L., sheep

Capra hircus L., goat

Over 87 percent of the total bone sample from Nin consists of bones from these two species. Separation of elements (Tables 12 \& 14) is aided by the work of Boessneck, Muller, and Teichert (1964); however, due to fragmentation, many morphological features are absent and the elements are thus grouped in the general category, 'caprovine'.

Three hornless sheep are identified (Table 14; Plate 3.2). This reinforces the Smilc̈ic evidence for Early Neolithic caprovine domestication on the Adriatic coast (see above).

Sheep and goat metacarpal measurements fall within the lower size range of those from Tinj, Smilēić, and Obre (Figures 3.1-3.2).

Based on the element distribution, butchering appears to have destroyed the brain case yet saved the mandibles. This practice suggests the removal of the tongue. Vertebra and ribs are virtually non-existent except for an identified axis and lumbar element. Except for a sole complete adult long bone, all-metapodial elements are fragmented. This could be the result of breaking the bones for their marrow and possibly their use for tools. The high proportion of pelvic fragments versus femur fragments indicates that separation of the hindleg from the body occurred by smashing the femur head. Lower femur and tibia elements have low frequencies also, possibly indicating their use for sources of marrow. Phalanges III are the only examples present; others may have been destroyed by carnivores, yet there is no evidence substantiating this statement.

No pathological speciments are identified. 


\section{Table 14 Distribution of Caprovine Bone : Early Neolithic}

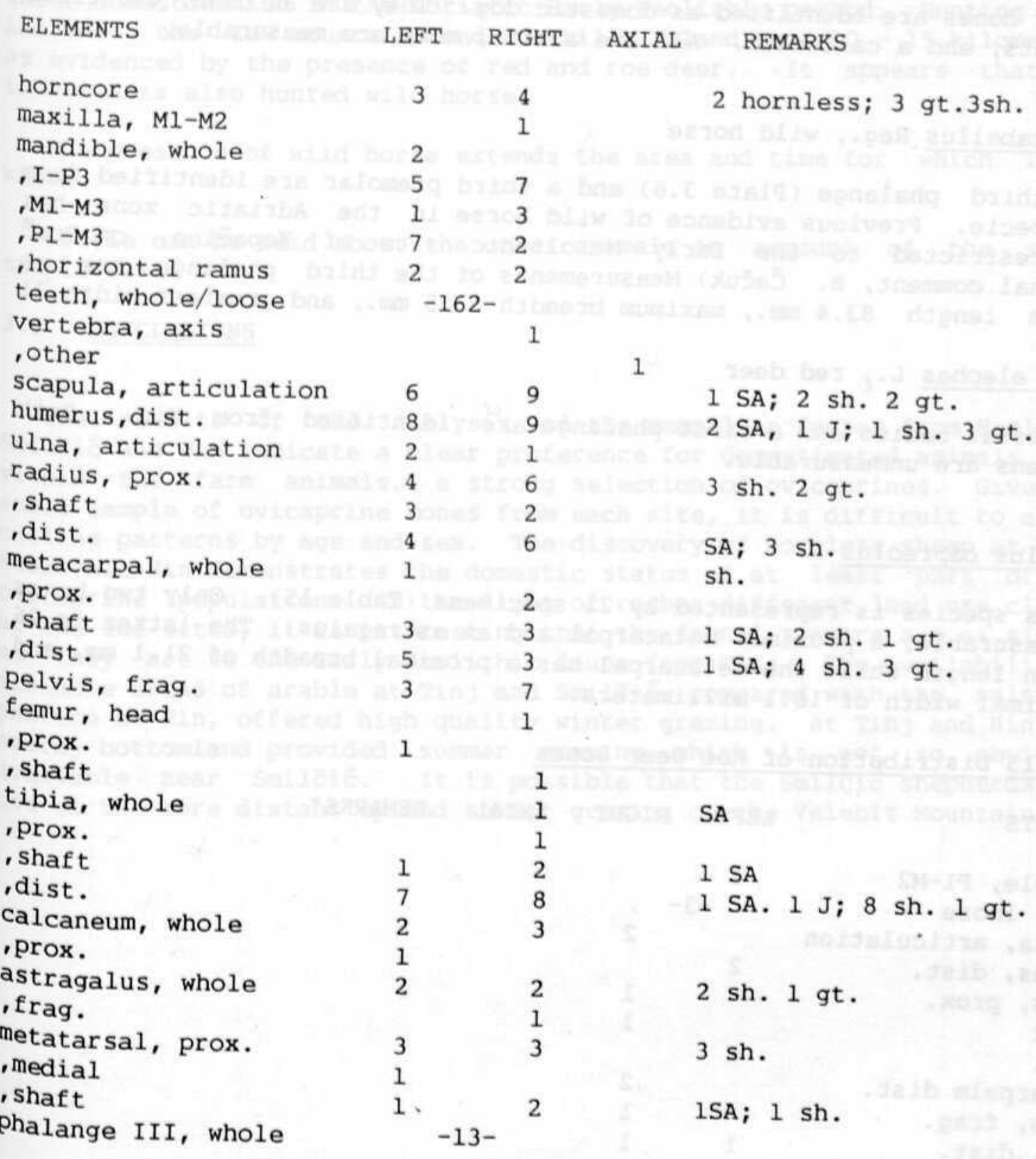

*abbreviations: $S A=$ sub-adult, $J=$ juvenile;

$\mathrm{Sh} .=$ sheep, gt. $=$ goat .

Sus scrofa dom., domestic swine

Five bones represented this species: a mandible fragment; two distal humeri; one a subadult; a proximal radius; and a phalange II. All except the humerus are from adults; none are measurable. 
Canis familiaris L., dog

Four bones are identified as domestic dog. They are an ulna, two tibia fragments, and a calcaneum. All are adults; none are measurable.

\section{Equus caballus Reg., wild horse}

A third phalange (Plate 3.6) and a third premolar are identified from this specie. Previous evidence of wild horse in the Adriatic zone has been restricted to the Early Mesolithic site of Kopac̄ina, on Brac̄ (personal comment, B. Cecüuk) Measurements of the third phalange are at maximum length $83.4 \mathrm{~mm}$. , maximum breadth $53.5 \mathrm{~mm}$., and greatest width 31 $\mathrm{mm}$. .

Cervus elephas L., red deer

A distal radius and a first phalange are identified from Nin. Both specimens are unmeasurable.

\section{Capreolus capreolus L.}

This species is represented by 21 specimens (Table 15). Only two bones are measurable; a proximal metacarpal and an astragalus. The latter is 26 $\mathrm{mm}$. in length while the metacarpal has a proximal breadth of $21.1 \mathrm{~mm}$. and a proximal width of 16.1 millimeters.

\section{Table 15 Distribution of Roe Deer Bones}

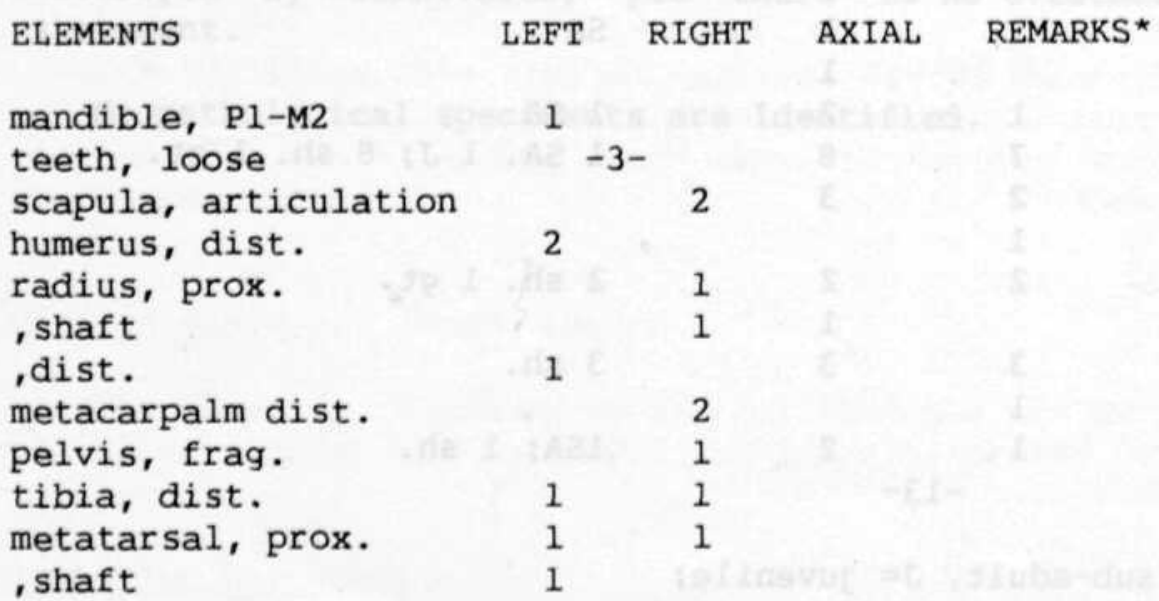

\section{4 .3 Summary}

The osteological remains identified derive from only a small portion of the total neolithic site at Nin. The largest group, the 'caprovines', represents nearly 90 percent of the total sample, and most of the domestic animals. 
Hornless sheep are present, supporting the evidence from Smilc̈ic of their domestication in the Adriatic Early Neolithic period. Hunting areas included the low mountains and foothilis inland some 10 - 15 kilometers, as evidenced by the presence of red and roe deer. It appears that the inhabitants also hunted wild horse. known.

The presence of wild horse extends the area and time for which it is

Little can be said about the other animals on account of the smnall sample size.

\subsection{CONCLUSIONS}

The results of the analysis of the mammalian faunas from Neolithic Smilcicic and Nin indicate a clear preference for domesticated animals and, within the farm animals, a strong selection of ovicaprines. Given the small sample of ovicaprine bones from each site, it is difficult to assess culling patterns by age and sex. The discovery of hornless sheep at Early Neolithic Nin demonstrates the domestic status of at least part of the ovicaprine population. In the light of rather different land use classes at the two sites, it is interesting that the faunal spectra are as similar as they are to the Early Neolithic fauna from Tinj. The availability of sizeable areas of arable at Tinj and Smilcić, compared with the saltmarsh pasture at Nin, offered high quality winter grazing. At Tinj and $\mathrm{Nin}$, the nearby bottomland provided summer grazing which is not so obviously available near Smilc̈ić. It is possible that the Smilciéc shepherds made use of the more distant upland summer grazing on the Velebit Mountains. 


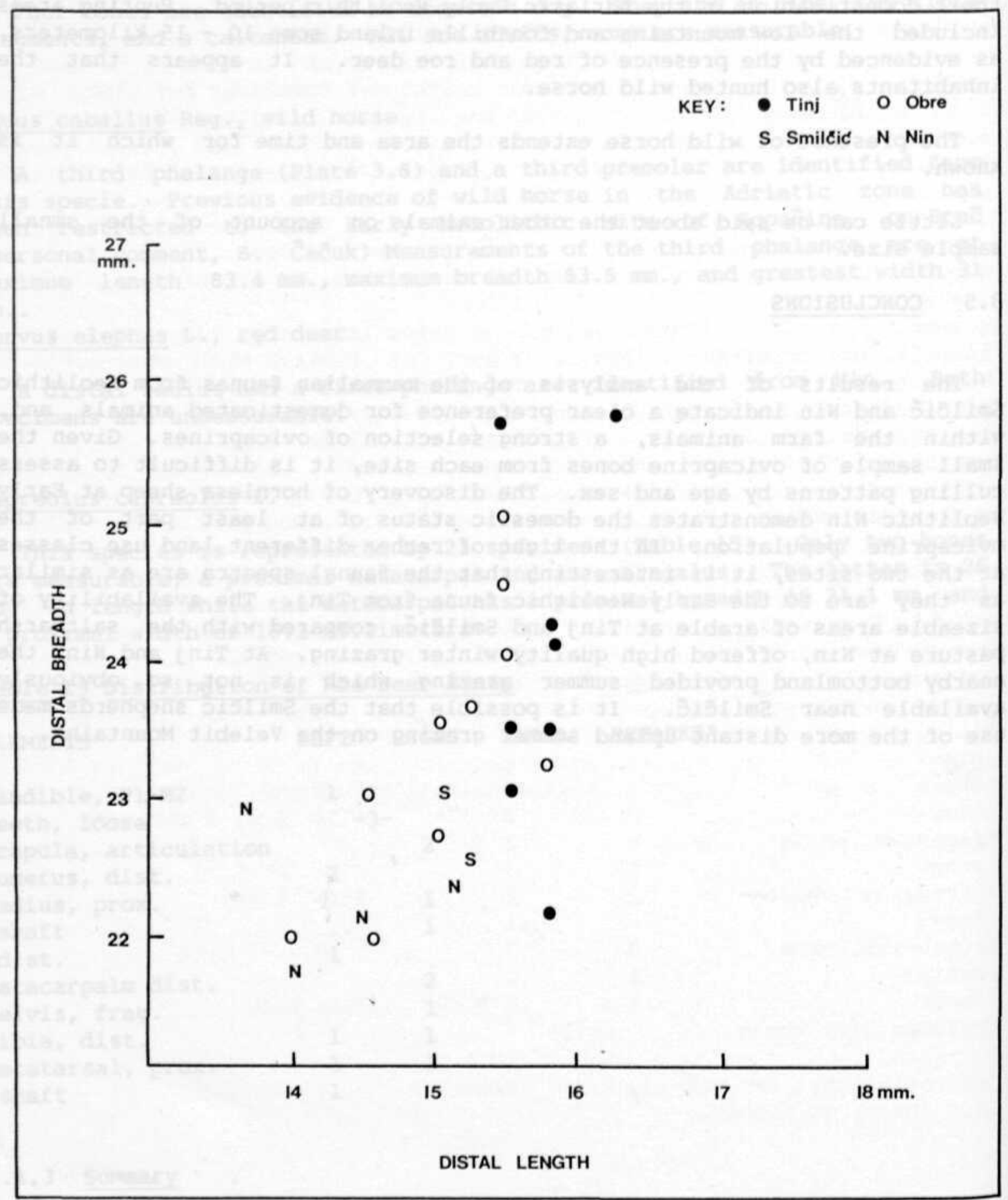

Figure 3.1 Variation in sheep metacarpals : Obre, Tinj, Nin and Smilčić. 


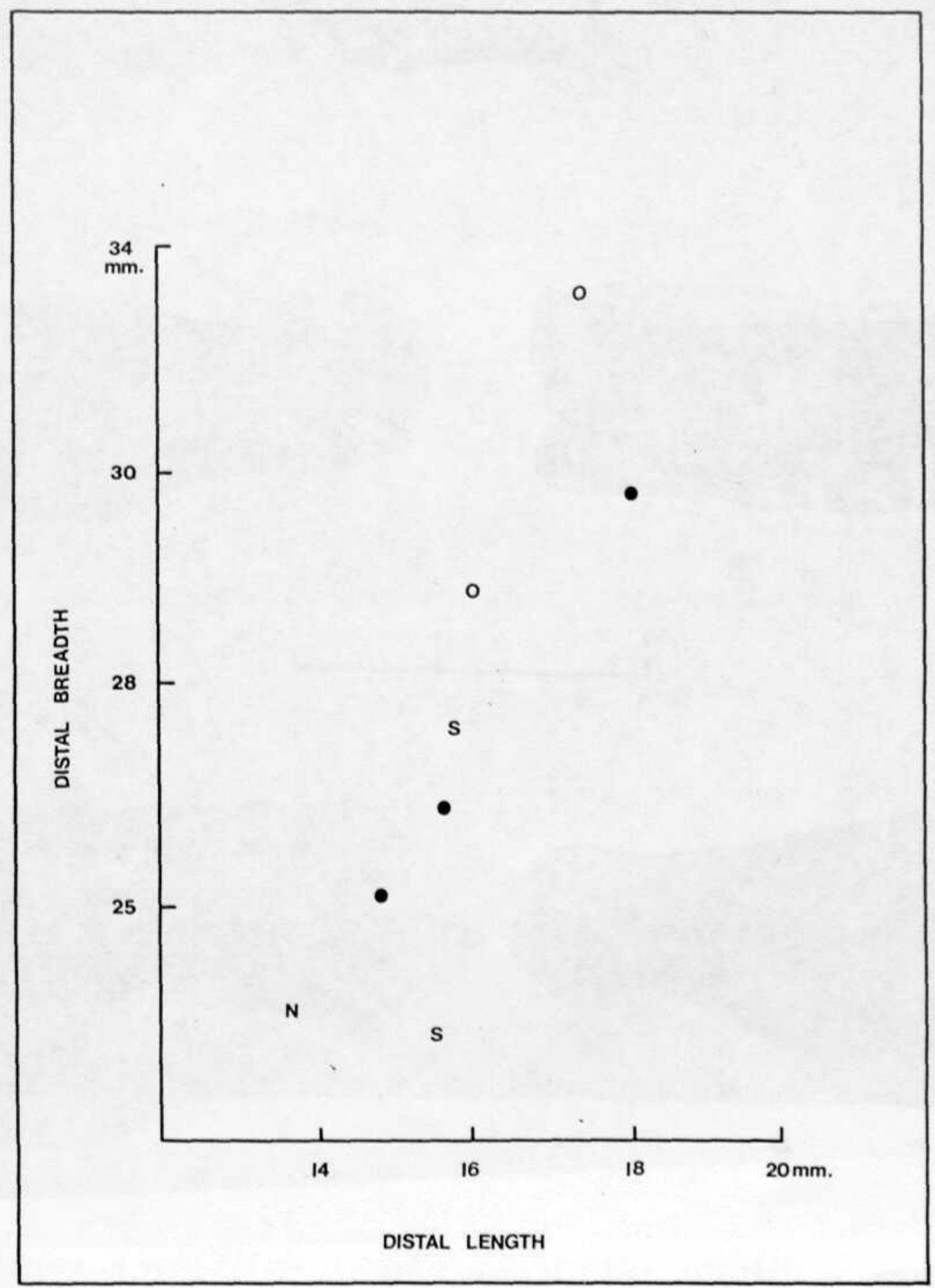

Figure 3.2 Variation in goat metacarpals : Obre, Tinj, Nin and Smilēić. 


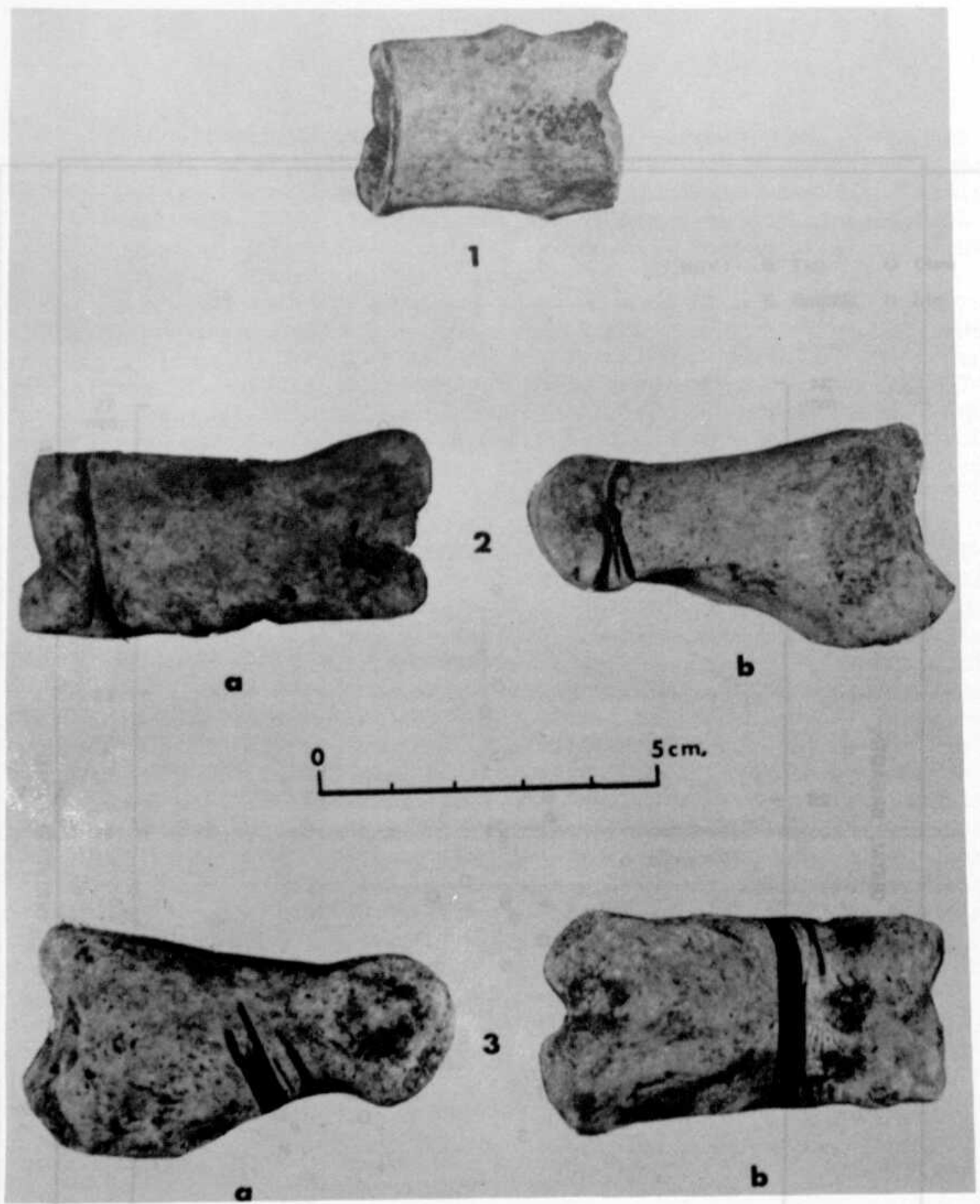

Plate 3.1 1. Cut marks. Cattle phalange III; Early Neolithic, Bag 44, 40-60 cm. 2. Cut marks. Cattle phalange III: a. dorsal view b. lateral view. Early Neo. Sonda $13,60-70 \mathrm{~cm} .3$. Cut marks. Cattle phalange III. a. medial view b. dorsal view. Early Neo. Sonda 15, 100-120 cm. 


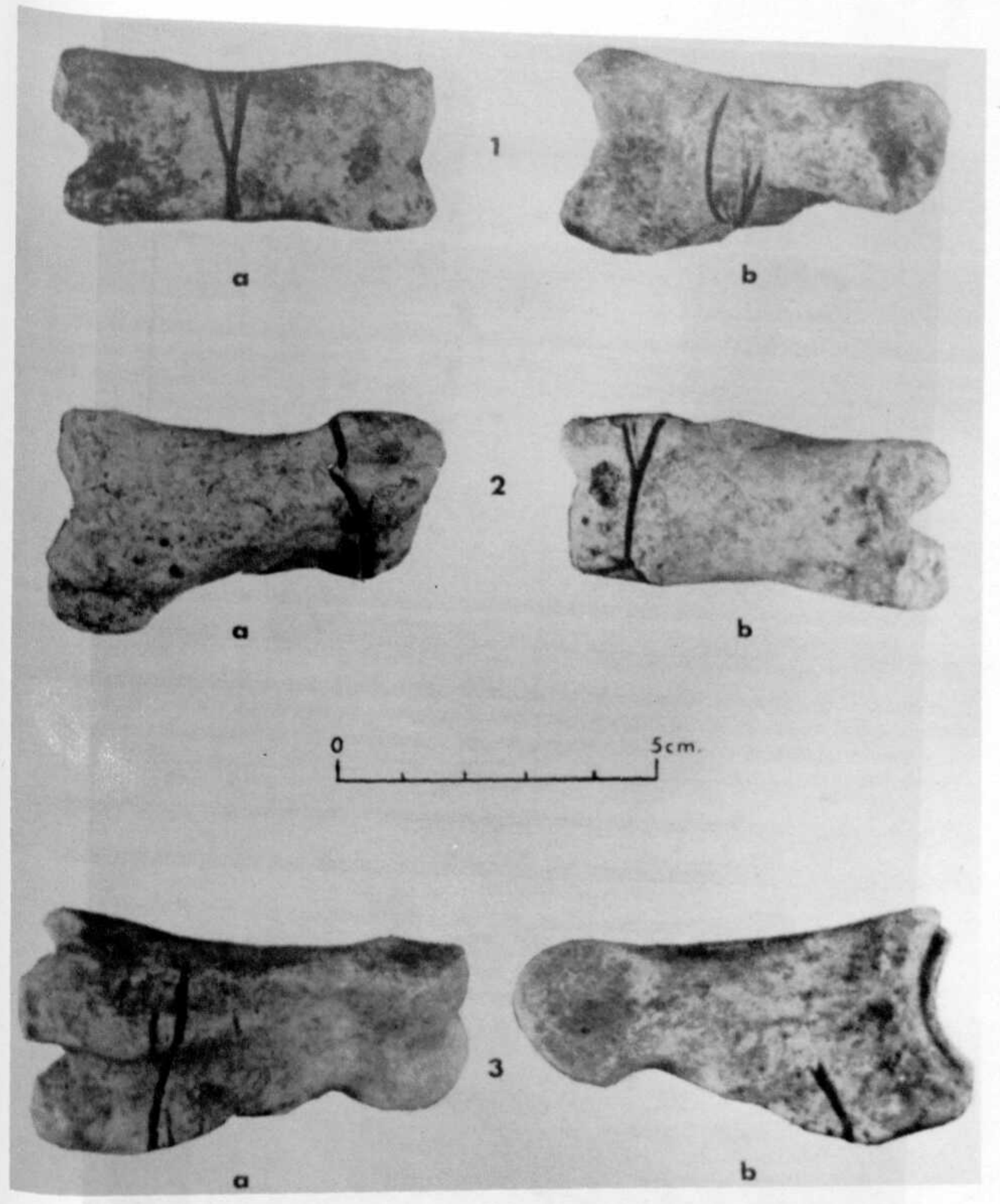

Plate 3.2 1. Cut marks. Cattle phalange III, dorsal view. Early

Neolithic Sonda 13, 60-70 cm, 2. Cut marks. Cattle phalange III,

view. Early Neolithictle phalange III, lateral Cut marks. Cattle phalange III, ventral-lateral view; Middle Neolithic. Sonda $12,30-40 \mathrm{~cm}$, 


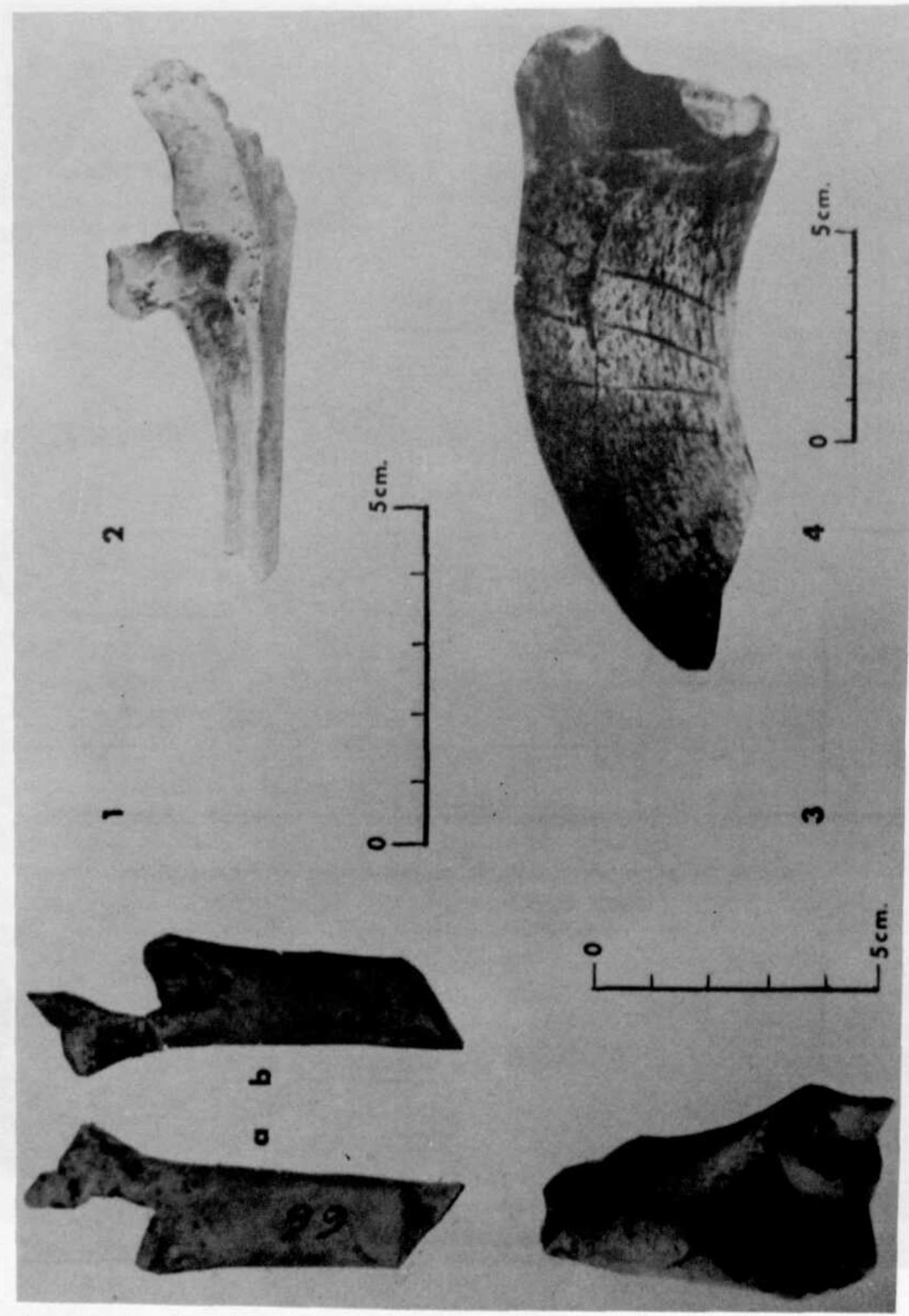

Plate 3.3 1. Gnawing. Domestic dog radius. a. dorsal view b. ventral view. Middle Neolithic Sonda 9, 160-180 cm. 2. Gnawing. Caprovine ulna, dorsal view. No location. 3. Gnawing. Goat distal humerus, ventral view. Middle Neolithic Sonda 1, 160-170 cm. 4. Cut marks. Sheep horncore; Middle Neolithic, Sonda 1, 80-130 cm. 
Plate 3.4 1. Premolar alignment (straight). Domestic dog mandible. a. lateral view b. dorsal view; Early Neolithic, Sonda 15, 150-160 cm. 2 . Hornless sheep skull fragment. Early Neolithic, Sonda 14, 100-120 cm. 3 . Premolar alignment (unaligned). Domestic dog mandible, medial view. Middle Neolithic, Sonda 9, 160-180 cm. 4. Modified. Caprovine acetabulum. Early Neolithic, Bag 44, 110-120 cm. 


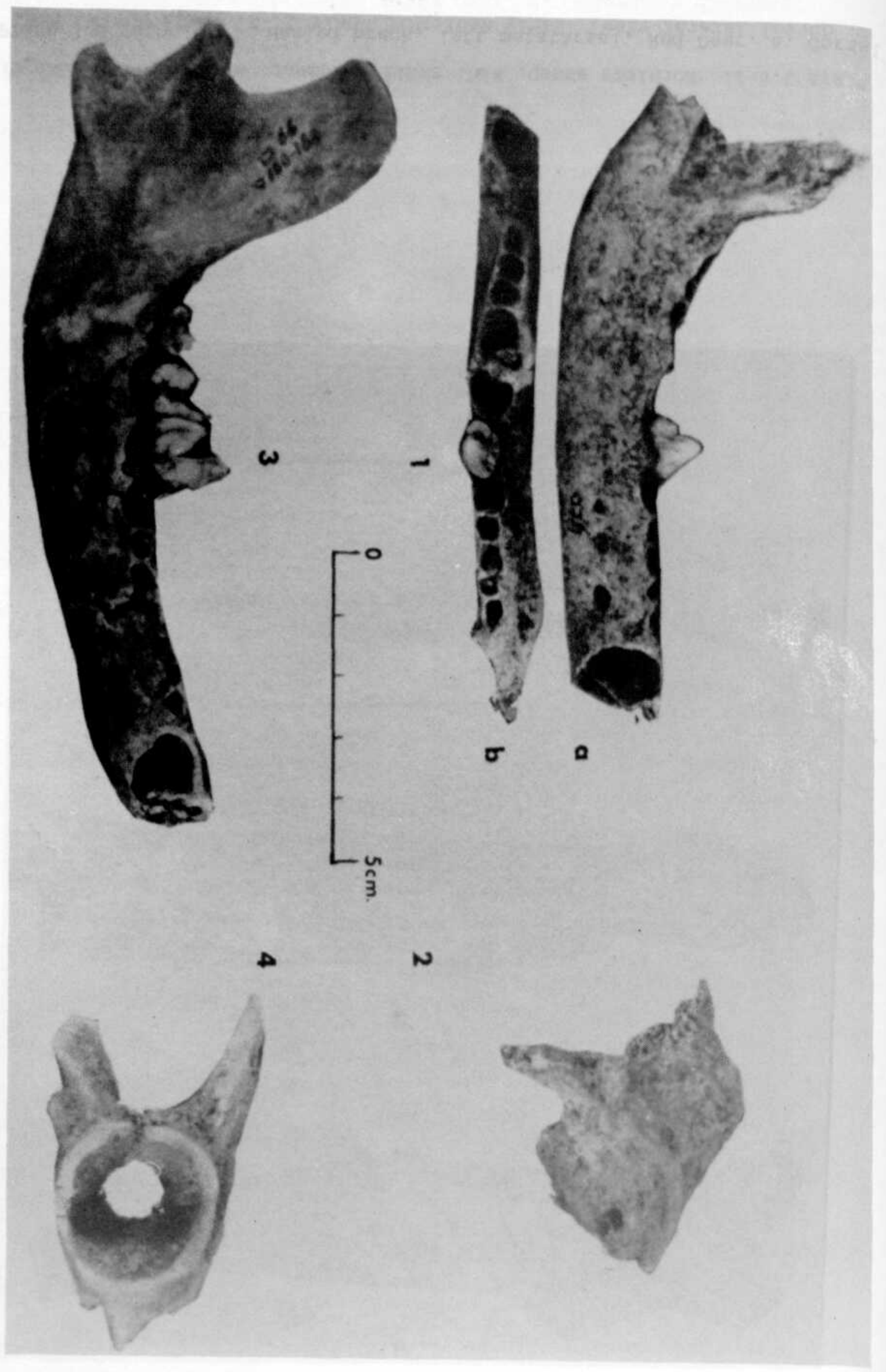




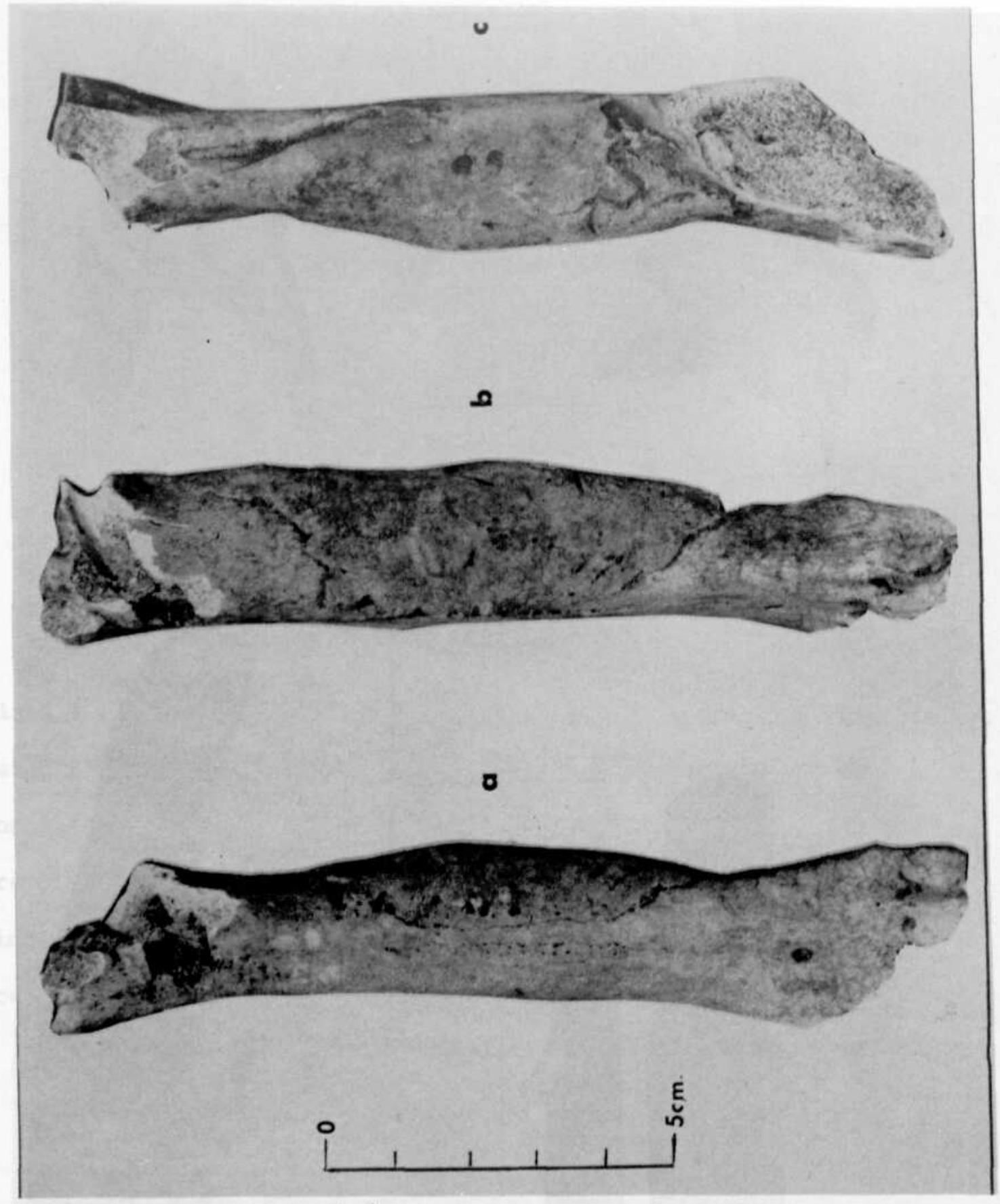

Plate 3.5 Pathology. Healed break, left metatarsal, Red Deer. a. dorsal view b. dorsal-lateral view c. ventral view. 


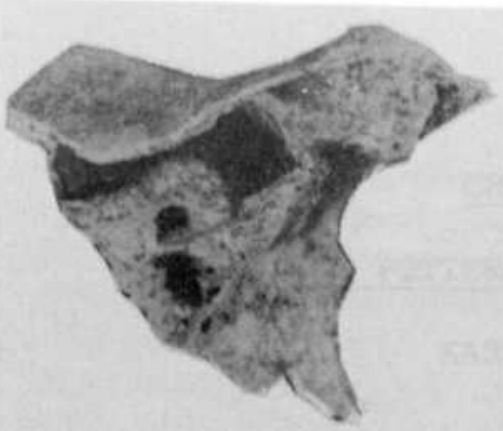

a

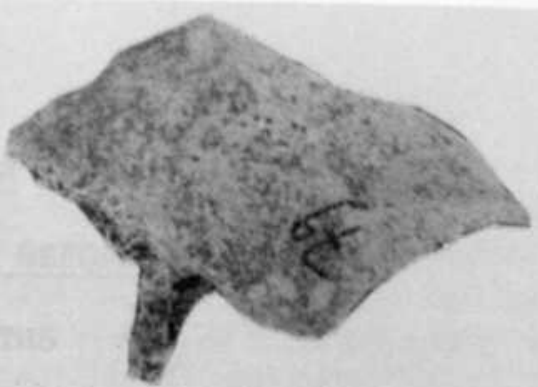

b

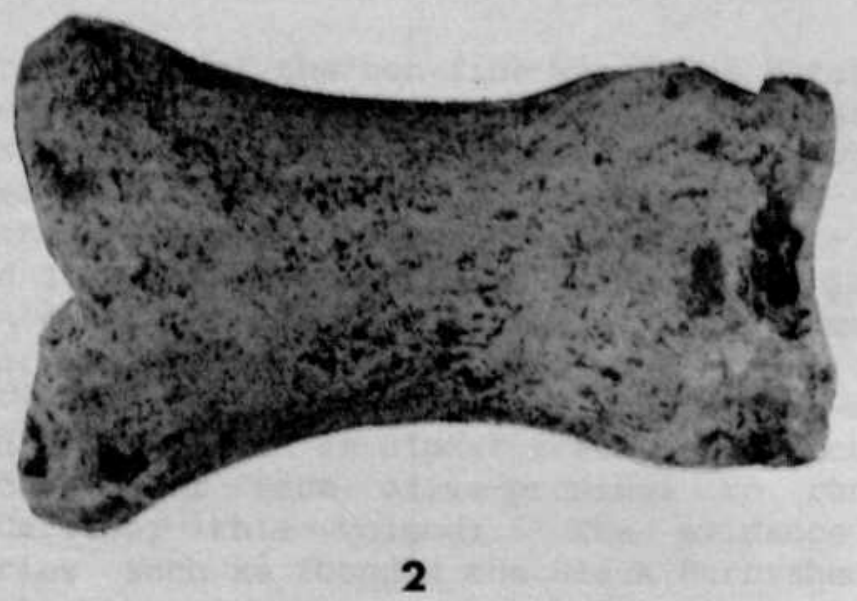

Plate 3.6 1. Hornless sheep, Nin: skull fragment. a. ventral medial view b. dorsal lateral view. Early Neolithic, Unit 2. 2. Wild horse, Nin. dorsal view. Early Neolithic, Unit 2. 


\title{
CHAPTER FOUR
}

\section{DALMATIAN POTTERY : SPOTS BEFORE THE EYES}

\author{
KAREN GRIFFITHS
}

My job in the summer of 1987 in Zadar was to attempt to produce a reliable dating sequence from the Roman coarse wares excavated by the Neothermal Dalmatia Project in 1986 at Nadin-Gradina (see Chapman, this volume). The idea was for John Hayes to establish the chronology from the well-known imported wares and for me to relate that chronology to the coarse wares associated with them.

The pottery came from six different sondas or trenches (Fig. 4.1). Sondas 1, 3 and 5 were dug by the Yugoslav team from Zadar University and the rest by the British. The condition of the pottery from the latter trenches was atrocious, heavily abraded and quite impossible to wash. This prevented my attempting any quantitative analysis of this pot. John Hayes merely identified what fine wares were recognizable. The pot from sondas 1 and 3 was in much better shape and efforts were concentrated on this material.

A numbered type series of the non-fine wares was established using the fabric analysis recommended in the Museum of London Department of Urban Archaeology Finds processing Manual (DUA 1984). Some twenty major fabric divisions were created in this manner. An unexpected feature of the assemblage was the huge percentage of imported wares - not only African red slip wares and Italian terra sigillata but also the large numbers of amphorae and even cooking wares which were not locally made. In fact, no contemporary pottery workshops have hitherto been found in the region. The reasons for this dearth are not clear. There are workable clay deposits to be had and, even in an almost treeless landscape, modern local potters find enough fuel from olive-prunings to run a viable firing programme (see Carlton, this volume). The evidence for indigenous pre-Roman industries such as founded the Black Burnished ware production in Dorset is also lacking. What we cannot tell as yet is whether Roman kilns or bonfire clamp firing sites still remain to be discovered in the area. The pottery from Nadin-Gradina provides a hint that such sites might in future be found at least towards the beginning of the Roman occupation and possibly the end as well.

Quite a noticeable feature of the upper levels from sondas 1 and 3 were the so-called Fabric 1 wares of the Nadin Type series. These were in fact rather reminiscent of BB wares, being apparently bonfire-fired, at least Some hand- rather than wheel-made, black or dark brown in colour and gritted with varying amounts of white calcite. The most common form was a jar with an everted rim (Fig. 4.2a). Wavy line combed decorations round the circumference were also characteristic (Fig. 4.2b). Such wares have previously been dated to the early medieval period in Yugoslavia and from their frequent presence in the upper layers this may well be correct. 
However it is apparent that they were also being manufactured in the fifth century A.D. and earlier. Their numbers peak, in Sonda 3 at least, at the same time as those of the African red slip wares on the site (Figs. $4.3 \&$ 4.4). Some of the Fabric 1 wares, namely Fabric 1D, are quite finely made and must have been wheel-thrown (Fig.4.2c). Their fabric is much less heavily gritted than the other Fabric is and in fact on examination bears some resemblance to that of the second and third century A.D. so-called 'Aegean' cooking wares (Fig. 4.2d). The 1D forms are also in some respects similar to the Aegean flat-rimmed, handled casseroles. The graph (Fig. 4.3) demonstrates the apparent replacement by the Fabric 1 vessels of the Aegean cooking wares, which had themselves prevously replaced the ubiquitous heavily calcite-gritted cooking wares of the Iron Age. No doubt many of the latter continued to be manufactured well into the Roman period. I should stress that these three wares were really the only obvious cooking wares found in Sondas 1 and 3 other than the occasional African casserole and baking lid.

There seems no doubt that the fine Aegean cooking wares were imported into Dalmatia. Many thousands of these vessels were discovered lying on the sea bed at the ancient port of Zaton (pers. comm., Z. Brusić). Thus we cannot look to them for a local pottery production. But what of the iron age/early Roman coarse wares and the much later Fabric 1 cooking pots? A closer look at the graph (Fig. 4.3) shows that though the heavy, cooking wares from the iron age levels never really die out (residuality can be discounted as both sondas had securely sealed median contexts consisting of floor levels), their numbers do clearly decline throughout the Roman period. It may be postulated that they are superseded to some extent from the second and third centuries A.D. by the imported Aegean cooking wares and when this supply fails towards the end of the third century a new source of cooking wares, the Fabric 1s, is found and this continues on into the fifth century and beyond. The heavy of ten burnished cooking wares of the iron age/Roman period seem strong candidates for a local production site or sites. Such primitive coarse wares are rarely transported far from their manufacturing site due to their low resale value.

One could perhaps construct a model of the town of Nadin-Gradina growing in economic stature during the Roman period as indicated by the appearance of fine terra sigillata from Italy and the eastern sigillatas A and B from Syria and Asia Minor (Fig. 4.4). By the second and third centuries A.D., there is a coincidecne in the availability of imported cooking wares and the ability of the Nadin population to purchase them. Imports of African red-slipped wares begin to rise at the same time. However, by the time imports of the latter peak in the fifth century, the importation of Aegean cooking wares has declined, very possibly to be replaced by the Fabric 1 wares. One can speculate that these too were locally made, perhaps even coming from the same sources as the never entirely defunct native burnished wares. Their uniformity and similarity of fabric to some of the Aegean wares might point to a source further afield though. Clearly more work is needed to resolve this problem. 
The analysis of the other imported wares by John Hayes held no surprises. The range of sources again indicates Nadin-Gradina's status during the whole of the Roman period (first century B.C.-sixth century A.D.) (Fig. 4.5). There were large amphora imports at all periods from the late first century A.D. onwards. The dominance of African sources in the fifth century A.D. is clear. Many of the amphora fabrics however remain to be identified and sourced, particularly those from the second century A.D., so no definite conclusions can be reached.

As for the fine wares there was the expected range of sources, including exotics like the Knidian pine cone Thymiaterion fragments, Corinthian lamps and Republican Black Gloss ware. Late Italian terra sigillata of poor 'provincial' quality is gradually replaced as the standard table ware during the first century A.D. by the African red slip wares, although there is quite an interesting fall-off in absolute percentages of 'red gloss' table wares somewhere in the second and third centuries A.D.. This is somewhat like the lacuna ('Trajanic gap') between the end of the Southern Gaulish terra sigillata industries and the rise of the Central Gaulish ones in the West. Changes in function on the site itself, however cannot be discounted as an explanation. As an aside, it may be noted that during the first half of the third century A.D., both sondas produce some heavily burnt sherds. Neither an historical nor an archaeological explanation has so far been advanced.

To conclude, it seems to me that the most valuable information to come from the Nadin-Gradina pottery is the overlapping of previously rigorously compartmentalised coarse ware potting traditions. The necessity of imposing an historical framework should not prevent the Roman archaeologist from recognising continuity within the Dalmatian ceramic assemblage as well as the changes imposed by alterations in economic patterns and local rises in socio-economic status. The short time I had in Zadar prevented me from seeing any but the broadest of chronological patterns. What is needed now is a major programme of inter-site ceramic analysis, a greater attempt to unravel the complexities of the amphora fabrics and a more detailed search for contemporary pottery production sites in the region.

Table 1 Nadin-Gradina 1986: Chronology based on imported wares

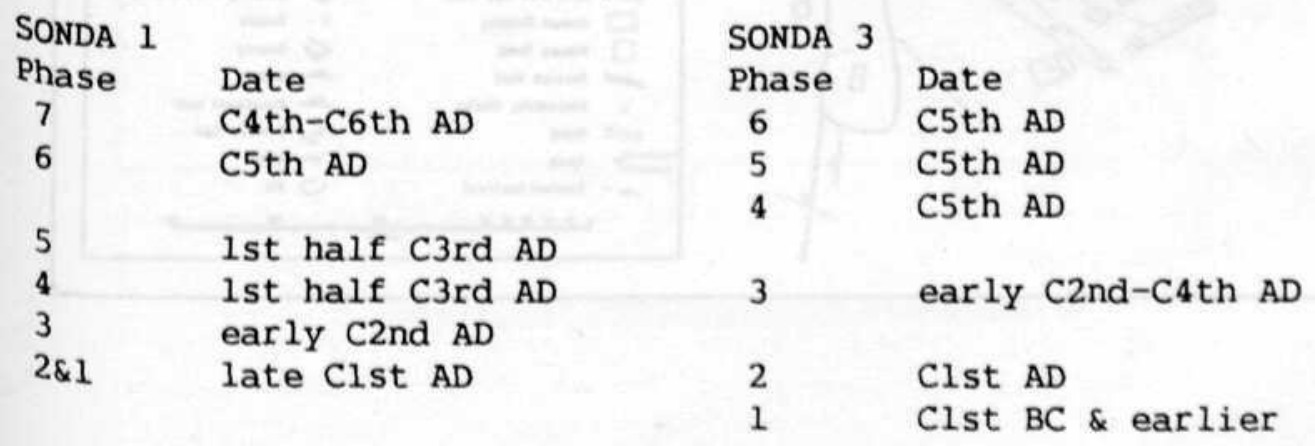




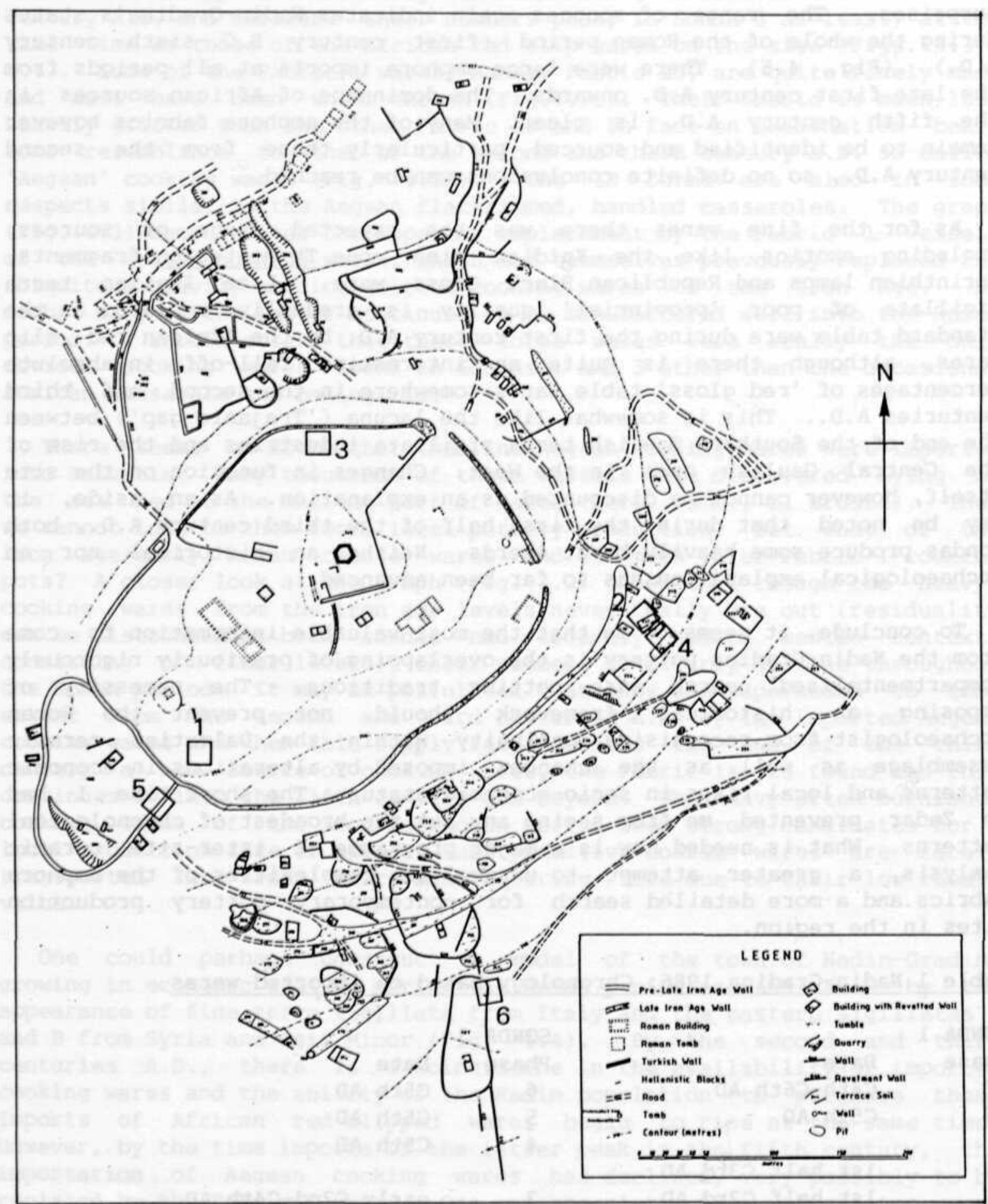

Figure 4.1 Plan of Nadin-Gradina, with location of 1986 sondas. 


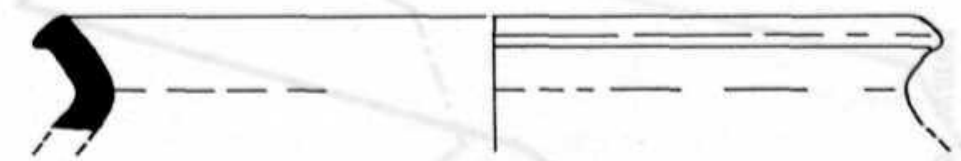

Type 1A Illust. no.I
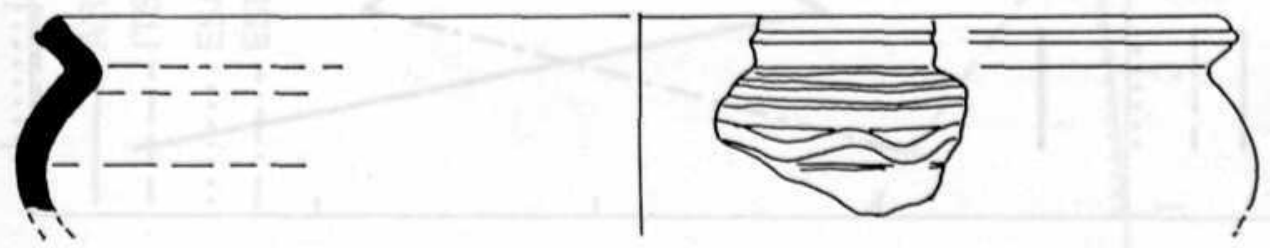

Type 1C Illust. no.V

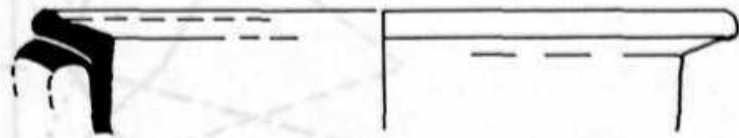

Type 1D Illust.XV
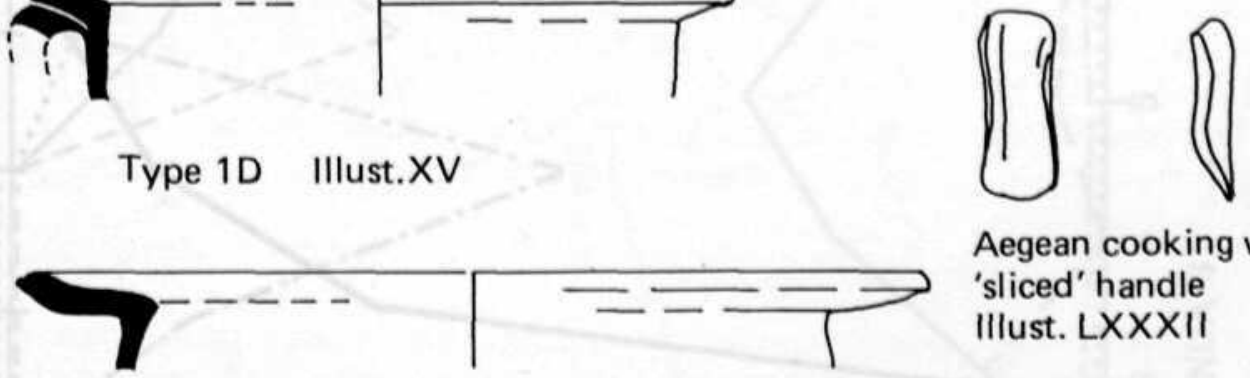

Aegean cooking ware

'sliced' handle

Illust. LXXXII

'Aegean cooking ware' Illust.LXXII

Figure 4.2 Cooking wares, Nadin-Gradina 1986 excavations. 


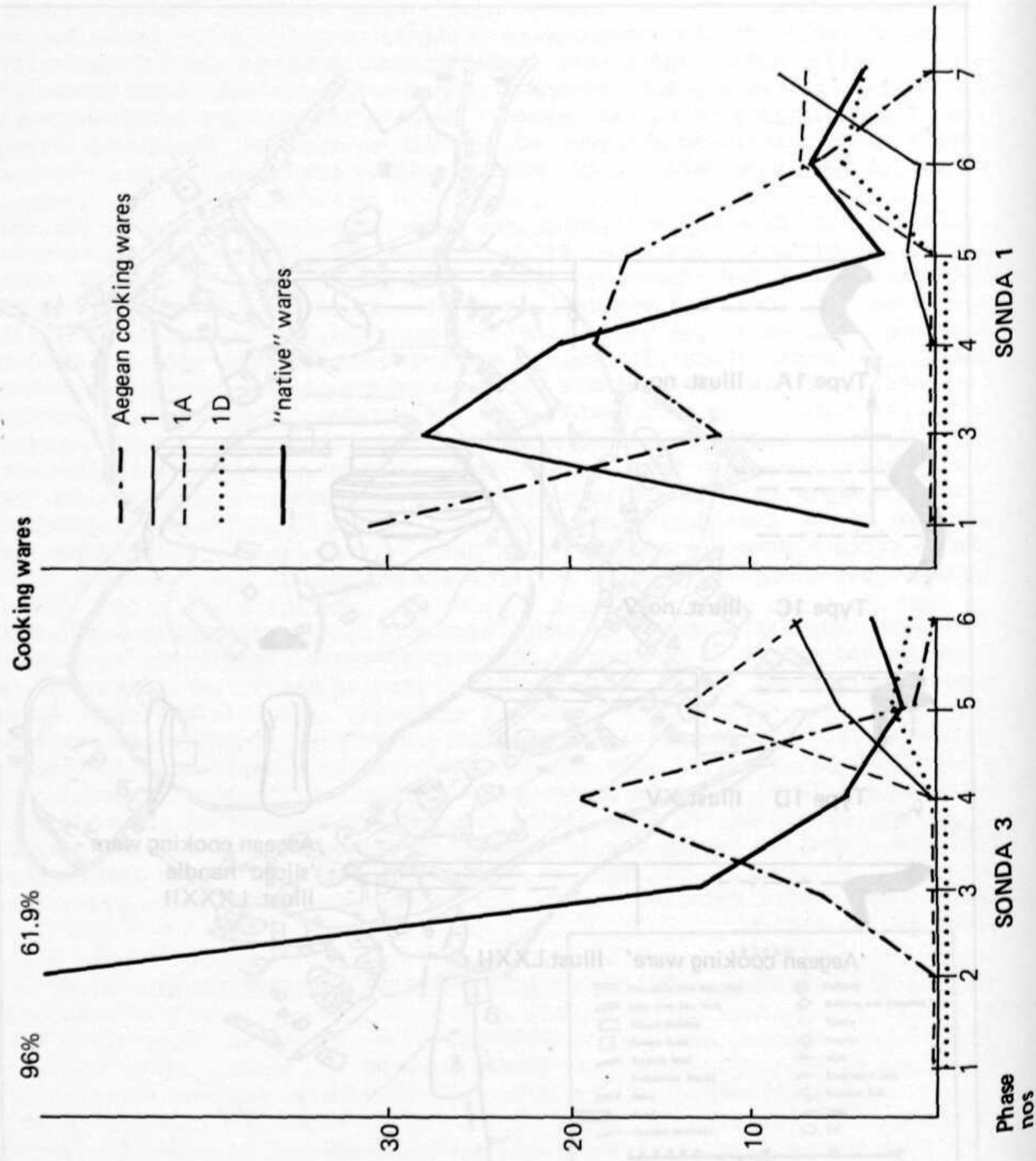

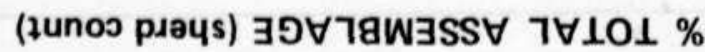

Figure 4.3 Distribution of cooking wares, Sondas 1 and 3, Nadin. 


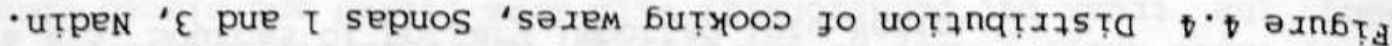

$\%$ TOTAL ASSEMBLAGE (s herd count)

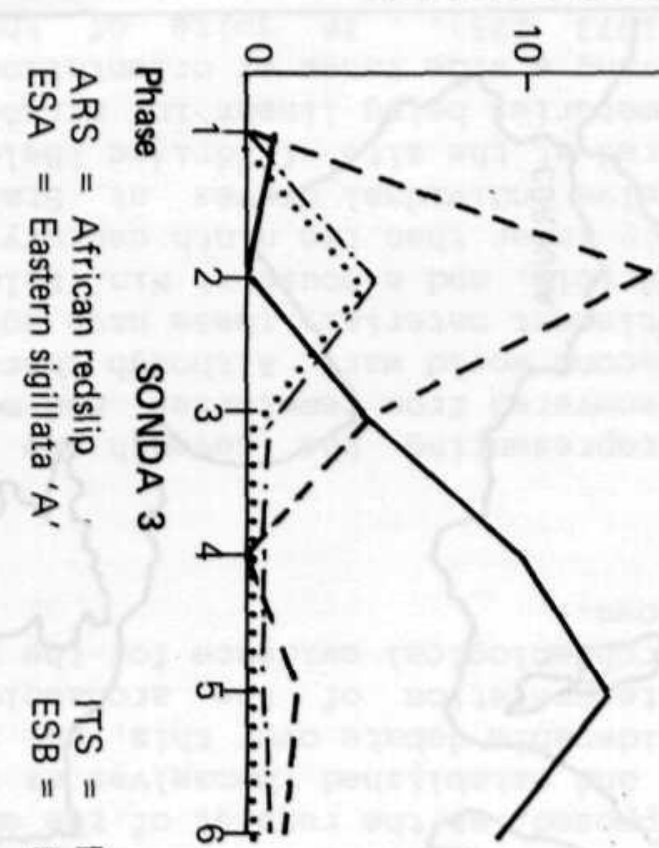

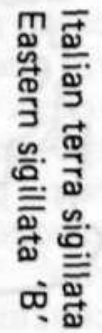

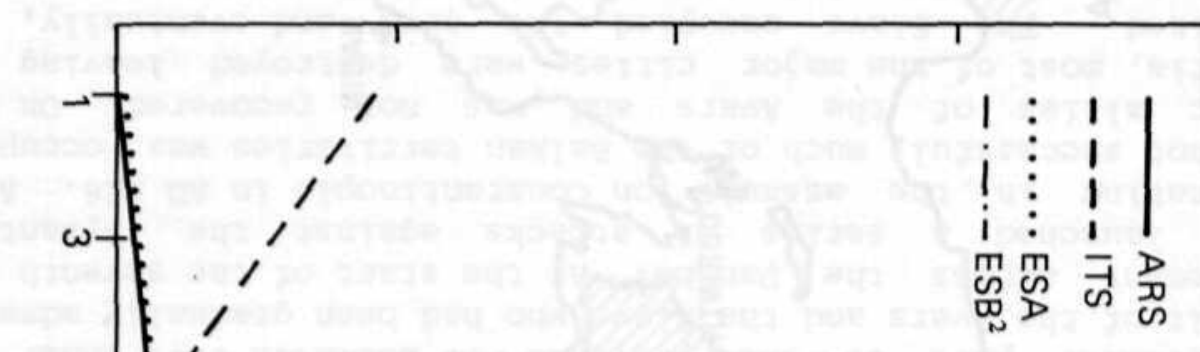




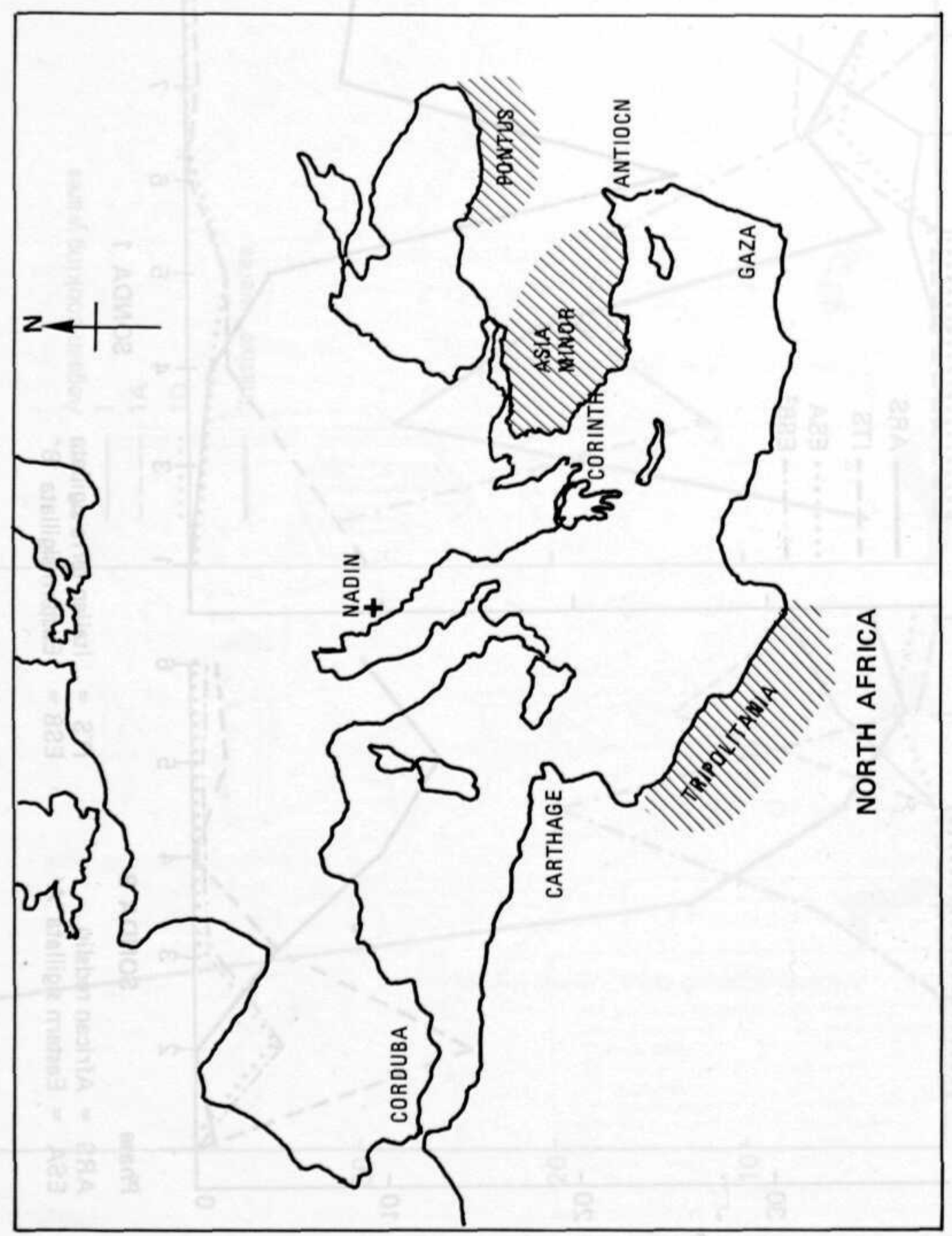

Figure 4.5 Sources of pottery imported into Nadin. 


\title{
CHAPTER FIVE
}

THE POTENTIAL FOR THE ANALYSIS OF EARLY MEDIEVAL POTTERY IN DALMATIA

\author{
HUW EVANS
}

The intention of this paper is to examine the present state of research in the field of early mediaeval pottery in Dalmatia, to assess the possibility of its contribution to broader studies of early mediaeval archaeology and to see if any advances can be made. The archaeology of the early mediaeval period in Dalmatia is primarily that of the barbarian settlers of the area who arrived in the early seventh century. Briefly, the greater part of the province of Dalmatia fell under the combined assault of the Avars and the Slavs who had been gradually advancing their settlement across the Danube. At the start of the seventh century, the Avars launched a series of attacks against the Byzantine empire culminating in the assault on Constantinople in $\mathrm{AD} 626$. Although they were not successful, much of the Balkan territories was occupied by the Slavic allies of the Avars and was not recovered. On the coast of Dalmatia, most of the major cities were destroyed leaving only Zadar inhabited. The slavs occupied the area and eventually, in the tenth century, the kingdom of Croatia came into being. One further complication exists; the Croats themselves are supposed, at the request of the emperor Heraclius, to have defeated the Avars and established themselves as rulers of the area. There is still considerable debate over this, but it has made little difference to the interpretation of the archaeological remains. A brief summary of the archaeological evidence for the period must be given, as it is not widely known.

\subsection{MATERIAL CULTURE}

The surviving material culture representing the seventh to ninth Centuries is for the most part recovered from cemeteries, and most of those have been excavated since the second world war. Although there are Sites in Dalmatia which must have settlement material, these have not been excavated apart from the hillfort of Bribir, and a house at Nin (Belos̄evic 1980, 81), both of which are probably later than the ninth century. The cemeteries vary in size, from only twelve individual graves at Stankovci (Belos̄ević 1985) to over three hundred at the site of Zdrijac (Belošević $1980,25)$ and in layout, with some cemeteries being linear in arrangement and others, such as Materiza, having a wide range of orientations and positions within a mound (Belos̄evic 1973 225). In spite of this, a considerable unity of burial rite exists. Bodies were placed extended upon their backs in graves that range in complexity between simple unlined pits and graves lined with several large stone slabs or dry stone walling up to three courses high (Belos̄ević 1980 72-76). In some cases iron nails are taken as indicating some kind of bier (such as in grave 130 at żdrijac (ibid, table $\mathrm{xxi}$ )). Most of the corpses were laid out with arms extended along the trunk but occasionally with arms flexed and placed upon either 
the waist or chest, or more rarely crossed on the chest. The corpses' legs were also in most cases fully extended and only in a small number of burials flexed or crossed. In some cases a fire was lit in the grave and the corpse partly burnt, whilst others had ashes scattered on the corpse. These rituals are seen as being related to an earlier phase when the normal rite was cremation, although there is only one presumed cremation cemetery - at Maklinovo Brdo (Belos̄evic 1974) - and only one cemetery has so far provided the remains of both cremation and inhumation that might be interpretable as transitional ( $\mathrm{Z}$ Gunjača, pers. comm). 'Ritual' behaviour is otherwise limited to the occasional placing of stones on the legs or body of the corpse, supposedly to prevent the spirit of the deceased 'walking', a few occurences of extra skulls placed in graves (Belos̄evic $198046)$ and the inclusion of material goods with the individual.

Although the range of goods which is found in the graves is wide and some two thirds of graves have at least one item, the more spectacular categories occur in only a few instances. The commonest finds in all the cemeteries are earrings or hairrings found in female graves. In male graves, pottery vessels and knives occur most frequently. More rarely are found Frankish glass vessels and swords, together with axes, bone combs, weights from spindle whorls, finger rings and other items of jewellery. Among the most unusual items are the deer antler salt holders, the nearest analogies to which were found in the cemetery of Sopronkohida in Hungary (ibid, 127). Whilst most objects were placed in close proximity to the corpse, probably having been part of costume, the pottery vessels were placed most frequently at the head or feet of the skeleton, and only occasionally alongside the trunk of the corpse (e.g. grave 3 at Stankovci (Belos̄ević 1985, 80)).

The vessels were made from clay that had been cleaned to varying standards (some clays are described as well cleaned, others as poorly cleaned (Belos̄evic 1980, 110)) and mixed with a temper of sand and ground calcite (ibid, 110), sometimes with the inclusion of crushed limestone. There is the possibility of organic temper in some pots as the surface of the vessels have numerous small holes. However it is conceivable that these represent the location of limestone that has now disintegrated as a result of firing or of burial. The size of the temper varies from very fine granules under $1 \mathrm{~mm}$ in length to much coarser pieces as large as $5 \mathrm{~mm}$ in some dimensions. It is generally accepted that the vessels were formed upon a slow hand wheel, usually upon the basis of the shape being more consistent than that held to be produced without a wheel, and that similar technology exists nearby and in much of Yugoslavia (Carlton, this volume). Firing was carried out in bonfires as indicated by the surface colour of the pottery, which ranges from orangish-red to dark grey or black. There seems to have been little control over the firing process and several pots must have been in direct contact with the fire itself. No traces of kilns have been found, but this is hardly conclusive. More important is the fact that an upper temperature limit of $650-800$ degrees $C$ exists for firing clay tempered with calcite or limestone (Rye 1976) and it is conceivable that a kiln would produce too high a temperature. 
Three forms of vessel survive in the grave assemblages, with one numerically dominant - the general purpose storage pot. The proportions of the height to the important vessel diameters vary but generally the widest body diameter (WBD) approaches the height and in a few cases exceeds it, whilst the base and neck diameters are roughly a half to two thirds of the height. After these basic ratios, the shape is constrained by the position of the WBD, determining whether the vessel is 'egg-shaped' or 'trumpet-shaped' (Belos̄evié 1962 passim). The bases are cut flat or are slightly concave, usually meeting the walls with a gentle curve, though occasionally a sharp, jutting junction occurs. On some bases small circular depressions occur, with diameter of between 1.4 and $3.5 \mathrm{~cm}$. WBD position determines the shape of the shoulder which can be either a gentle curve or a sharply formed neck. The throat of the vessel opens out and terminates in either a rounded or flatly cut rim. These vessels are between 10 and $15 \mathrm{~cm}$ tall. More rarely found are jugs with handles, which have the same shape as far up as the WBD; from there the body closes rapidly and terminates in a neck which accounts for about one third the height of the vessel. Finally, there are what are best described as mugs, vessels with rough handles and much straighter sides than the others.

Most of the vessels are undecorated, though their outer surfaces are occasionally burnished. When it does occur, decoration takes two forms:first, a small pattern made up of incised lines and, secondly, a series of horizontal lines incised around the vessel. The first form is usually found on the shoulder or WBD of the vessel and the symbols incised range from simple crosses to complicated designs of as many as nine strokes. The horizontal lines were incised either with a simple pointed tool or with something such as a comb and are either straight or wave-like, what could be described as a classic 'Slavic' form of decoration. These waves and straight lines may occur on their own on a vessel or in alternating bands, occupying one zone of the pot or all of it. Very rarely there occur firm zig-zag lines bounded by bands of horizontal lines at top and bottom. It does not seem that there is a coherent grammer governing the arrangement of this decoration.

\subsection{PRESENT APPROACHES}

Given this basic situation what has been the main direction of research hitherto ? The primary, and essential, task has been the dating of the vessels, by association with the other finds from the graves and also by comparison with the two main Central European pottery chronologies, those of Poulik (1950) and Eisner (1966). As has been made clear, the basic technology of manufacture has been determined but, beyond plotting a distribution of findspots (Fig. 5.1), it seems that very little else has been done. Yet there is potential to do more than this with the pottery and it is my intention in the rest of this paper to assess this potential and attempt some preliminary analyses.

Much recent research has been concentrated upon pottery, both in terms of the techniques of manufacture and the organisation of manufacture (Arnold 1985; Feinman et al. 1981) as well as the symbolic aspects of decoration (Richards 1987). Besides this, considerable work has been 
carried out upon the sourcing of the raw materials and the significance of distribution patterns. Some of the methods of analysis have more immediate prospects of employment in the conceivable future than others and for that reason methods such as thin sectioning will not be considered. Rather, methods that can either be applied now or have considerable potential for dealing with the specific problems of the period will be considered. The manufacture of pottery will be considered first.

This in turn can be broken down into analysis of the raw materials, the technology of production and the potters themselves. Then the use of the pottery, both in daily life and in burial contexts will be considered. From there the broader significance of the pottery can be assessed in the context of the debate over the relations between the various cultural groups in Dalmatia in the early mediaeval period and the possibilities for more accurate dating will be examined. Finally, the overall prospects for advance will be summarised.

\subsubsection{Manufacture}

The first and most obviously accessible category of information is that concerning the manufacture of vessels, as many aspects are reflected in the vessels themselves. Apart from understanding the various processes involved in manufacture, it should be possible to add the information gained to the general picture of the technological capabilities of the producer society.

Sources of raw materials for the pottery involve both the clay and the temper. The clay is not available across the whole landscape, but some parts have better prospects for producing workable deposits than others. Deposits have not been sourced for this period so there is no immediate idea of the method of exploitation. With regard to temper the requirements of sand (quite fine sand) and calcite are quite easily met; the former is widely available (several of the cemeteries were discovered as a result of recent sand extraction (Belos̄ević, 1980)) and the limestone geology of the area means no shortage of the latter. Organic temper, if it was in fact used, would presumably be available in all potting locations. Although none of these materials havsbeen sourced, given their general availability it is suggested there is little point in this undertaking at present. Some indication as to the exploitation of clay would be useful and there is one approach which might at least give that; the determination of preferred exploitation territories.

In his recent book 'Ceramic Theory and Cultural Process' (1985), Dean Arnold undertook an examination of ethnographic cases of present day pottery production based upon a loose systems theory approach. Whilst there is no need to accept the validity of cross cultural laws or perhaps even cultural process, Arnold does isolate a number of natural limits which affect pottery manufacture in many cases, and also some human limits which pragmatically seem to exist. One of the factors that Arnold isolated was the effect of distance to sources of clay and temper on their 
exploitation by potters. Potters tend to have limits beyond which they will not go for clay, or temper. Theoretically the exploitable thresholds of resources can be shown. The lines of gross returns and economic and social costs combine to produce the third line of net returns, the determinant of exploitation (Figure 5.2a). The distance from the base to $A$ is the preferred area of exploitation, here the returns rise more rapidly than the costs resulting in good net returns. From $A$ to $B$ the costs rise sharply to what is considered the normal maximum range of exploitation, threshold B. Finally, in times of economic crisis the poorly performing zone $B C$ may be used, but beyond $C$ there are no net gains as here costs have reached the same value as gross.

To demonstrate this for clay sources, Arnold plotted the distance from workshop to clay source for each of his ethnographic cases (Figure 5.2b). In $30 \%$ of the 111 cases, potters were obtaining their clay within $1 \mathrm{~km}$ of their workplace; beyond that some $60-70 \%$ of potters were getting their clay within $5 \mathrm{~km}$ of the workplace. For temper (apart from a group which travelled by canoe), all potters obtained it within $10 \mathrm{~km}$ of the workshop and again a considerable number within $5 \mathrm{~km}$ (Figure $5.2 \mathrm{~b}$ ). These results provide a significant indication of the economic limits of obtaining clay and temper. There is no intention to imply that these limits will automatically hold good for the potters of the early mediaeval period in Dalmatia, but the distances Arnold's results provide as the economically favoured zones may be useful in modelling the behaviour of the various potential potters.

The clearest limits which Arnold obtained, the $1 \mathrm{~km}$ and the $5 \mathrm{~km}$, were Superimposed on the main cemeteries in the area in order to see if any indication of sourcing patterns can be seen (Figure 5.1). The $1 \mathrm{~km}$ range for both Żdrijac and Materiza includes a number of sedimentary deposits, and the clay source at Privlaka, presently used by modern Iz potters, is within the $5 \mathrm{~km}$ range. The central group of cemeteries, Maklinovo Brdo, Glavẽurak, Razbojine and Biljane Donje all lie as close as $1 \mathrm{~km}$ to Seasonally flooded lowland areas which might conceivably have clay deposits, whilst the $5 \mathrm{~km}$ range for Biljane Donje just includes the Nadinsko Blato marshland near Nadin. There is a considerable overlap in potential exploitation zones for three of the cemeteries. Obviously, the fact that these are cemetery sites means that there is no logical necessity for there to be manufacturing sites nearby; there might be one Central settlement that made all the pottery for the area. The tentative results from this case do not attempt to deny that, but the eventual discovery of a shared source for the central cemeteries would not be Surprising. The southernmost cemetery of Stankovci also lies within easy reach of alluvial clay deposits. It may be that further investigation into the distribution of the pottery will enable more to be said about sources.

The technological component of the industry prior to the forming of the vessels, the cleaning of the clay, preparing temper by crushing calcite and mixing clay are procedures that might be detectable in a potter's work area were there any excavated. However, while no work area is available the techniques involved cannot be assessed and there seems little prospect 
of any further information at present. As has already been observed, the pottery is thought to have been made upon a slow wheel on the basis of the cylindricality of the vessels, far more regular than hand-made ones of a similar period elsewhere. Added to this are the smeared finger marks visible inside some vessels and also the small circular depressions found on the base of the pots (Belos̄evic 1962, 242). Again, without a work area or wheel, little advance can be made in this area, but it should be possible to measure the distance between the teeth of the tools employed. That might open up another means to attack the problem of indentifying manufacturing groups. Our knowledge of the firing process is again determined by examination of the vessels, with the varied colouring and the nature of the temper suggesting bonfire firing. The likelihood of identifying such a firing site is very low, on the basis of ethnographic comparison (Carlton, this volume), leaving the possibilities for advance in this area as slight.

If any further study of the techniques is at present impossible, is there any way of exploring the potters themselves? They are the next step in the of investigation of manufacturing. The question of whether we have many potters or just a few in one place is difficult to assess in the present state of knowledge and is related to the question of distribution. Are all the pots coming from one village, or from several, or even from all villages? No pattern analysis of the finds made so far can usefully be undertaken as there is no firmly known centre - only a distribution which concentrates upon the cemeteries. So the means of trade is as unidentifiable as the organisation of manufacture. Traditionally this has not concerned the archaeologists but if a deeper understanding of the society's economy is sought, then some attempt must be made to identify either local variants of vessels or assess the likelihood of all pots being manufactured in one place. The identification of individual potters will be examined later.

It was decided to compare the pottery from the cemeteries to see what level of variation existed between them and whether there could be seen to be significantly different groups. The required information for whole cemeteries was only available for Stankovci (Belos̄evié 1985) and Materiza (Belos̄evic 1962); these were suitable because they are the most widely separated of the seven. Rather than simply examine the vessels by eye, and in an attempt to get some measure of analytical rigour, the heights of the vessels from the cemeteries were plotted together against the WBD (Figure 5.3), the base diameter (Figure 5.4), and the neck diameter. The intention was that the comparison of these determining diameters would enable the assessment of similarity of cemetery pottery in the sample. From Figures 5.3 and 5.4 , it is clear that the distributions overlap and there is no clear difference between the vessels from the two cemeteries (the outlier on both figures is the same long necked jug). Whether this is the result of identical sources or the general pattern of the vessels of the period is difficult to determine. In order to assess this, a broader basic assessment of the pottery was required. The vessels illustrated by Belos̄ević (1980, tables LIII - LXIII) were taken as giving a basic spread of variation, as they came from cemeteries excavated recently and in the last century, as well as single finds. So that the 
figures of the shape rather than size could be assessed, the raw measurements of height and WBD were divided by the base diameters to give the values of Rheight and Rwaist. The results are shown in Figure 5.1. This demonstrates the basic unity of the shape of the vessels and the inevitable existence of irregular vessels (again some of the outliers may be jugs). It would seem from this that if a difference is to be sought between potting sources rather than between individual potters, a more complex analysis of the pottery is required.

One more possibility exists for the identification of potters - the analysis of the depressions on the bases of some of the vessels. These depressions are generally regarded as the impression made by a protrusion on the surface of the potter's wheel. It may be tentatively assumed that each depression (and hence protrusion) size represents a different wheel, probably used by a different potter. Is there any visible similarity among vessels with the same depression diameter? The vessels from Materiza, (the cemetery which has the highest proportion of depressions on the pottery) were plotted to produce Figure 5.6. If there is indeed a connection between vessels with, for example, the $1.5 \mathrm{~cm}$ diameter depression then the vessels produced include most of the range of variation observed and it would seem unlikely that pottery from different Centres could be identified. Croatia possibly has its own potter to match the Illington-Lackford potter (Hurst 1976:299) in the $1.5 \mathrm{~cm}$ depression potter.

\section{2 .2 Use}

Following manufacture and distribution pottery is of course used and here two spheres of employment can be identified. First, there is the domestic context, the preparation of food, storage and consumption of food and drink etc.. Secondly, there is the deposition of pottery in burials. As to the first, the inevitable situation is that, as there are no Settlement assemblages published, we have no real idea of the full range of vessel forms. There are the jugs, mugs and the ordinary vessels, but the present day industry of $I \bar{z}$ has produced a much larger selection of forms. Even from the later mediaeval contexts of Bribir, there have come larger vessels and thus a clearer indication of the variety of vessel forms (personal inspection of unpublished material). Yet the reverse side of this is that a deliberate selection must have been made from this presumably larger domestic range, for the evidence suggests that the time required to manufacture a pot is far longer. than the interval between death and burial.

The inclusion of pottery in the graves is a much broader topic and has Several facets to it. The first significant question concerns the reason for deposition of pottery in graves. The reason given by Belos̄ević is that the vessel was the container of travelling provisions for the after-life (Belos̄ević 1980, 135) deposited in the grave by the burial party. This notion is possible, but it involves a conception of the after-life that we cannot be sure that the Slavs held. Like the majority of groups which were converted to Christianity in the mediaeval period, their previous beliefs were not particularly carefully recorded. There 
are references to temples (Vana 1983:92), but the Slav world view has to be largely reconstructed from second-hand information. In the face of this, the commonsense view is cautiously reasonable, it is possible but not particularly satisfactory, for there is nothing in the explanation that can deal with the presence of vessels in some graves but not in others. It may be more reasonable to attempt to view the whole ritual of burial as a unitary phenomenon, with variation between graves being more structured than just the outcome of haphazard differences in preparation for an assumed after-life.

It might be suggested that there was a significant variation in deposition between gender groups in the cemeteries. Five cemeteries have sufficient graves to examine the distribution. The details are given in the following table.

Table 1 Distribution of bodies by sex

$\begin{array}{rrr} & \text { GRAVES WITH VESSELS } \\ \text { CEMETERY TOTAL } \% & \text { FEMALE } \%\end{array}$

MALE 웅

$\begin{array}{llll}\text { Maklinovo Brdo } & 33 & 41 & 32 \\ \text { Materiza } & 15 & 25 & 50 \\ \text { Stankovci } & 62 & 80 & 50 \\ \text { Żdrijac } & 43 & 42 & 39 \\ \text { Razbojine } & 35 & 56 & 39\end{array}$

There is clearly no exclusivity of deposition for one gender at the expense of another, but in four out of the five cases a greater proportion of female graves than male graves has a vessel deposited. The difference is not always startling and at present no reason can be put forward to account for it. Before leaving the possible differences between genders, an attempt was made to see if there was a difference in the form of pots deposited in male or female graves. This was first attempted with the pottery from Stankovci and it was observed that on the plot of height against WBD the line of the $1: 1$ ratio for these two divided the vessels from male graves from those from female graves. However this did not hold for the other cemeteries where the data was available and probably occurred at Stankovci because of the small sample size.

\subsection{WIDER IMPLICATIONS}

So far the focus has been upon the importance of understanding the pottery itself and not upon the broader significance beyond the narrow territory of Croatian culture. Larger questions that remain to be tackled include that of the nature of relations between the late Antique Romano-Illyrian population and the Slavs. According to the historical sources (in particular Constantine Porphyrogentinus in De Administrando Imperio) some of the antique population fled to the islands when the Slavs and Avars invaded whilst others were killed. However, it seems probable that some remained, so what happened to them? Some of the pottery forms (e.g. the long-necked jug) suggest late antique influence and the continued presence of some of the population. Yet is there any way of 
quantifing the survival, even in terms of crude proportions? It seems unlikely given the lack of information concerning the middle part of the Seventh century, the transition period when it might be possible to see a fusion of the basic Slavic shapes and the subtler forms of the antique world.

Related to this is the final aspect of the pottery which demands consideration; the dating. Given the lack of a secure chronology, it is not surprising that disagreement occurs here. It seems that the the main trouble relates to the situation previously outlined, the aboriginal (i.e. late antique or Byzantine) influence upon the pottery and the insistence of employing chronological series from Central Europe. The confusion is best demonstrated by considering the dating of the cemetery of Razbojine, which is disputed by Belos̄evic and Jelovina. Of all the material from the Cemetery, the most closely datable is the pottery and it is thus upon this that the debate turns. The points of agreement are considerable, both agree that Razbojine is contemporary with Materiza, that the Dalmatian pottery is special and that it also fits into phase II of the Central European chronologies of Poulik and Eisner (Belos̄ević 1980; Jelovina 1968). However, when it comes to assigning the precise range of the pottery, Belos̄ević opts for the eighth to ninth centuries and Jelovina for the seventh to eighth. Given the available accuracy the debate seems insoluble and there appears very little way in which this Central European chronology would be capable of bearing the refinement demanded of it when the influence of late antique pottery is so broadly claimed. What is required is a full pottery chronology that will cover the region and properly take into account the effect both of the continuing antique population but also the constant influence of the surviving city of Zadar and the consequent flow of Byzantine styles that can be seen in the jewellery. Such a chronology would also have to take into account the situation in Istria but would enable the pottery to be properly considered in its stylistic context.

From the overview of the present situation and the attempts at advance given in this paper, there is a temptation to pessimism. However, there do exist possibilities for advance and for the study of early mediaeval pottery in Dalmatia to be put into a somewhat broader context between the Roman and the high mediaeval. It should also be possible to see how this industry, which apparently closely resembles the recent rural production of pottery in Dalmatia, developed from the mediaeval era onward. Clearly much work still remains, some sites remain unpublished, settlements remain unexcavated, but the potential for further study certainly exists and should be taken up. 


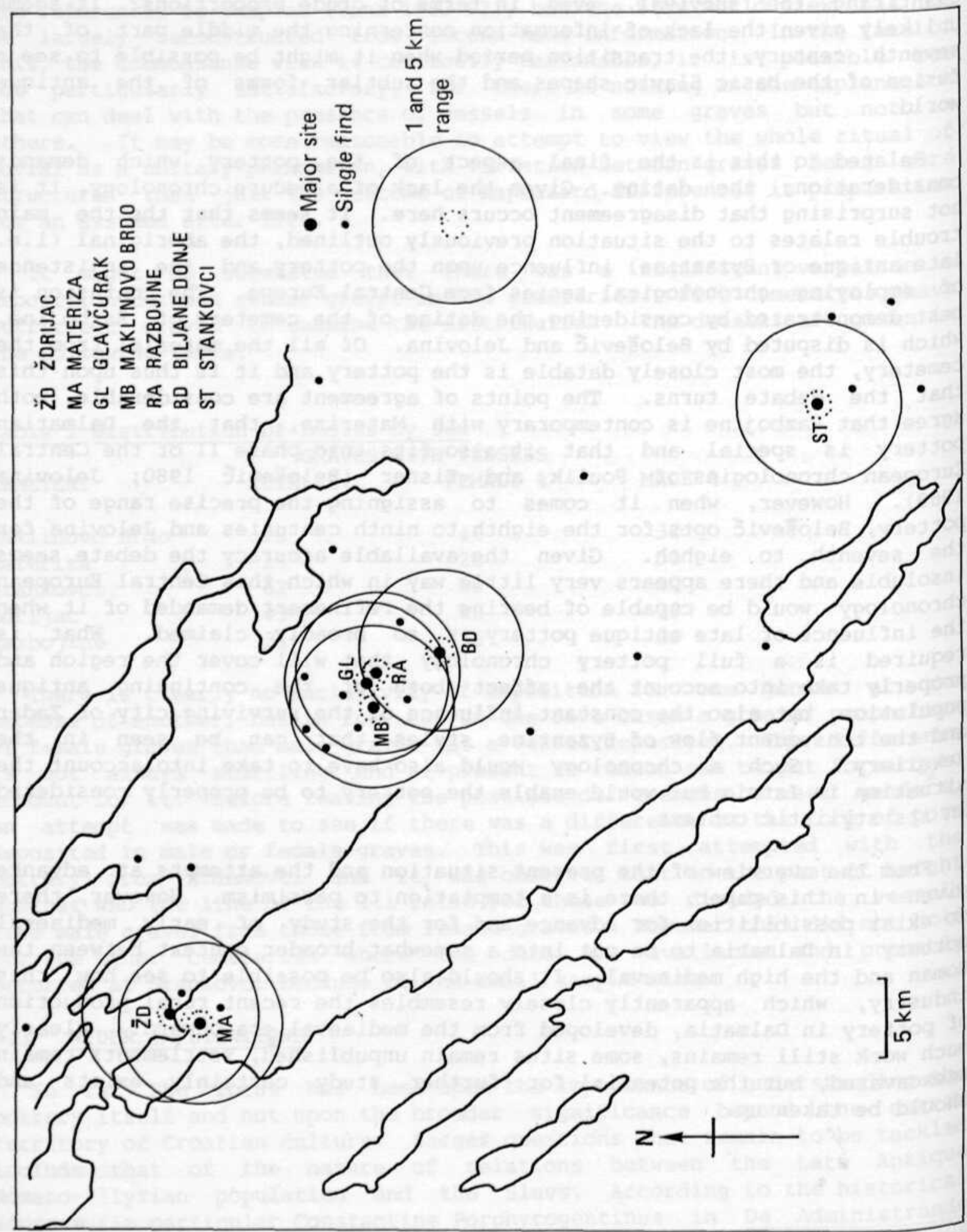

Figure 5.1 Distribution of findspots of Early Croatian pottery in north Dalmatia 


\section{EXPLOITABLE TERRITORY THRESHOLDS}
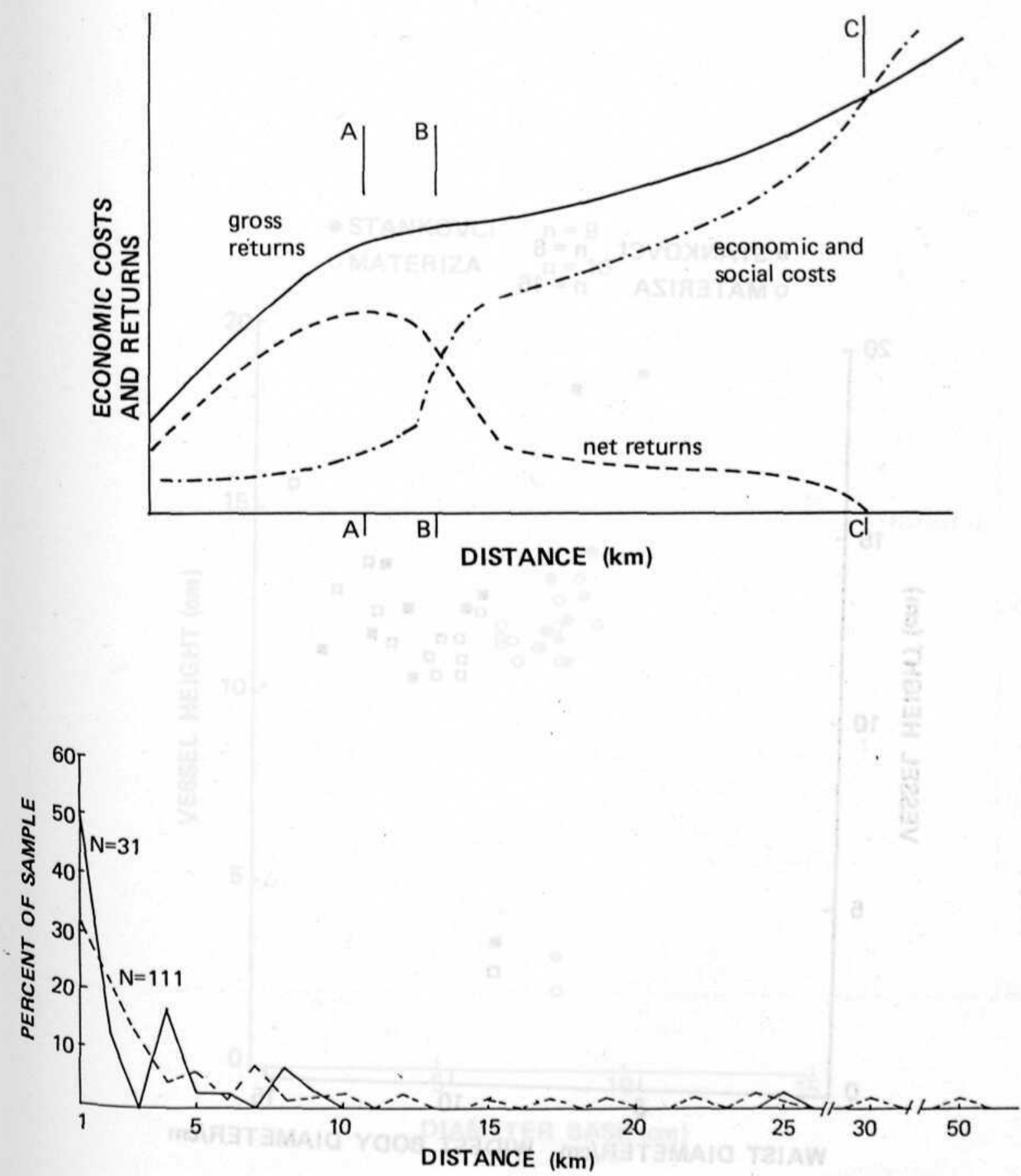

Figure 5.2 a. A model of economic costs and returns of pottery production. Source: Arnold 1986.

b. Travel distance for potting clay (solid line) and temper (dashed line). Source: Arnold 1986. 


$$
\begin{array}{ll}
\text { - STANKOVCI } & n=8 \\
\text { MATERIZA } & n=16
\end{array}
$$

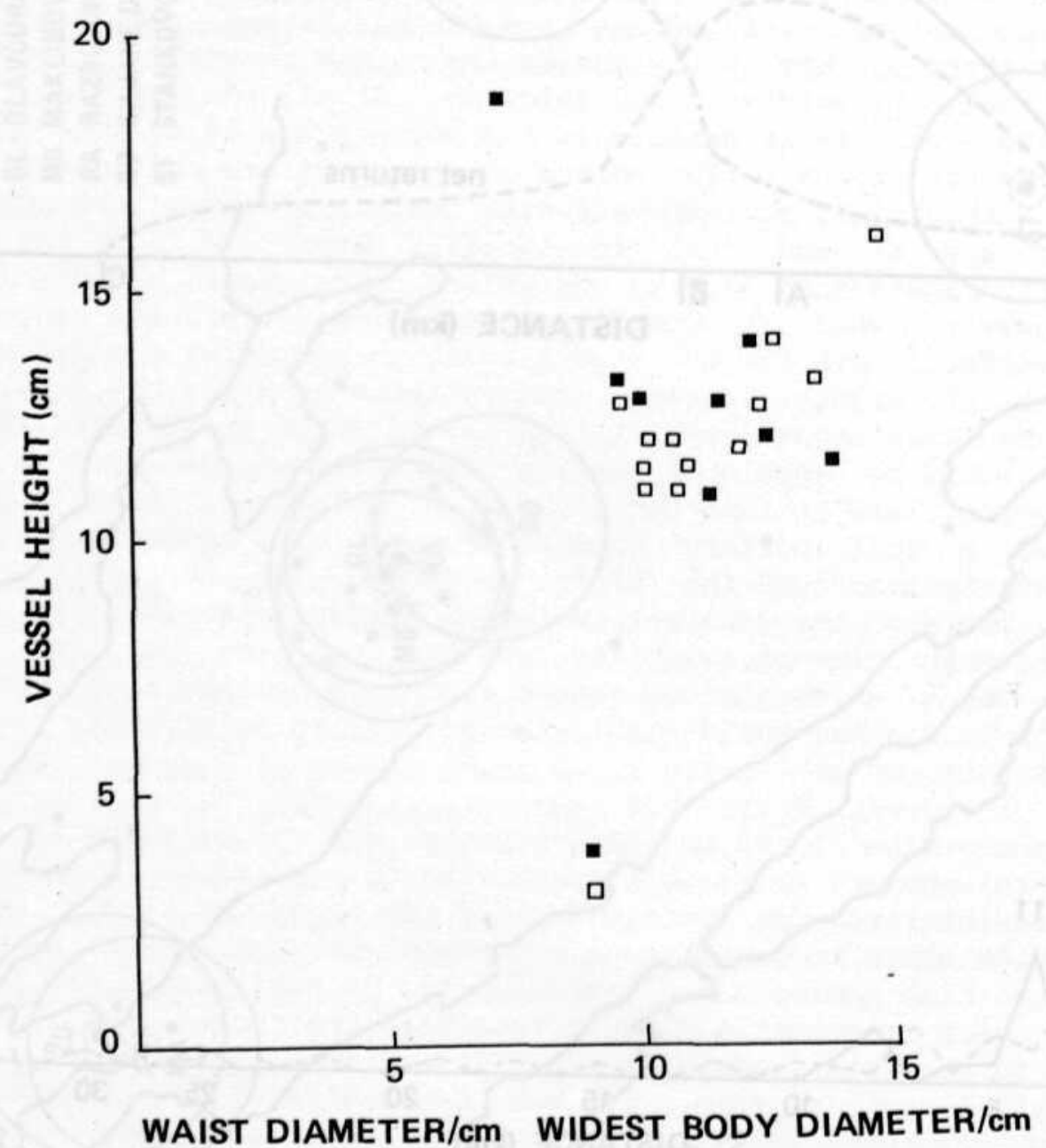

Figure 5.3 Vessel height vs. waist diameter/widest body diameter: Stankovci and Materiza. 

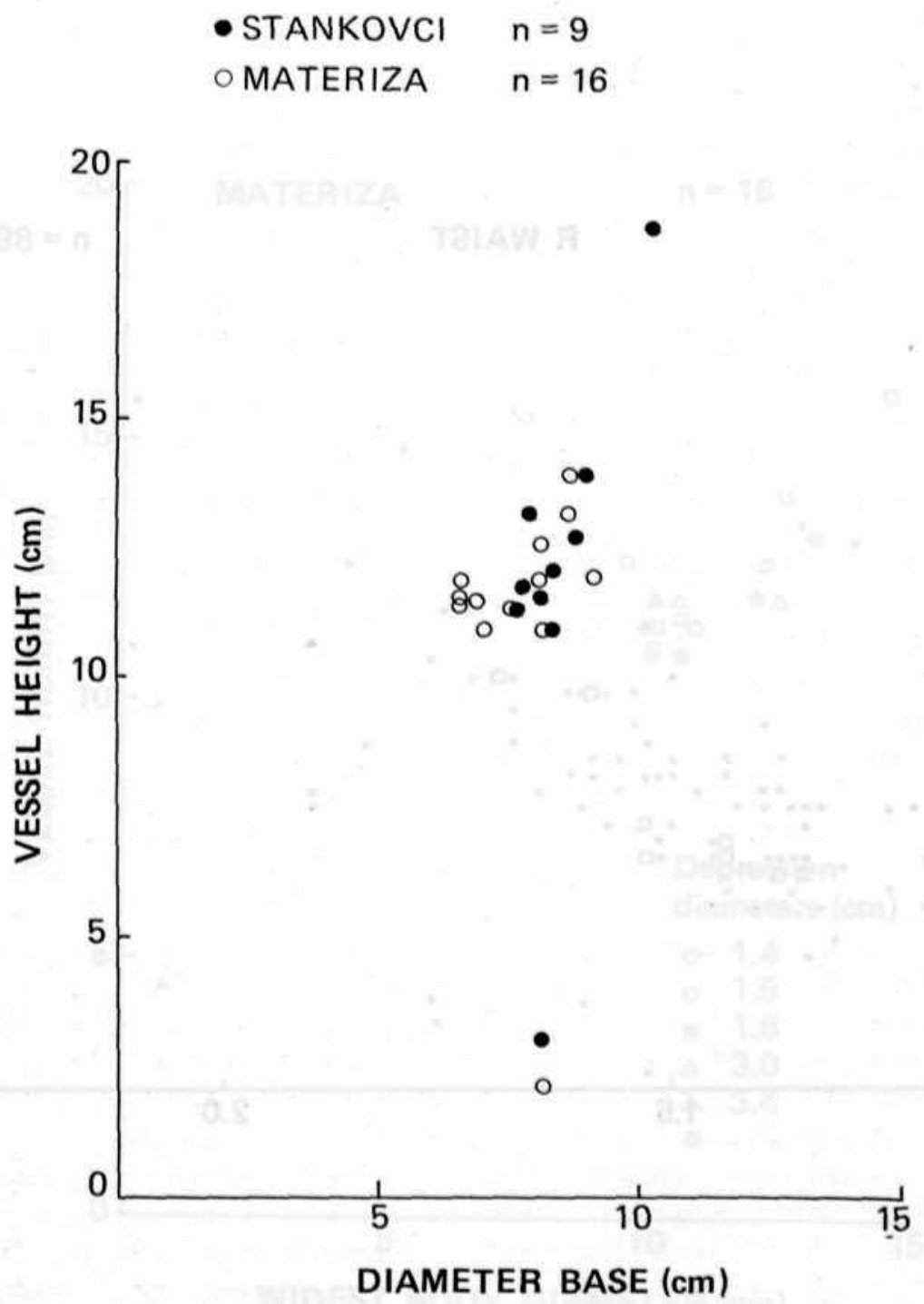

Figure 5.4 Vessel height vs. basal diameter: Stankovci and Materiza. 


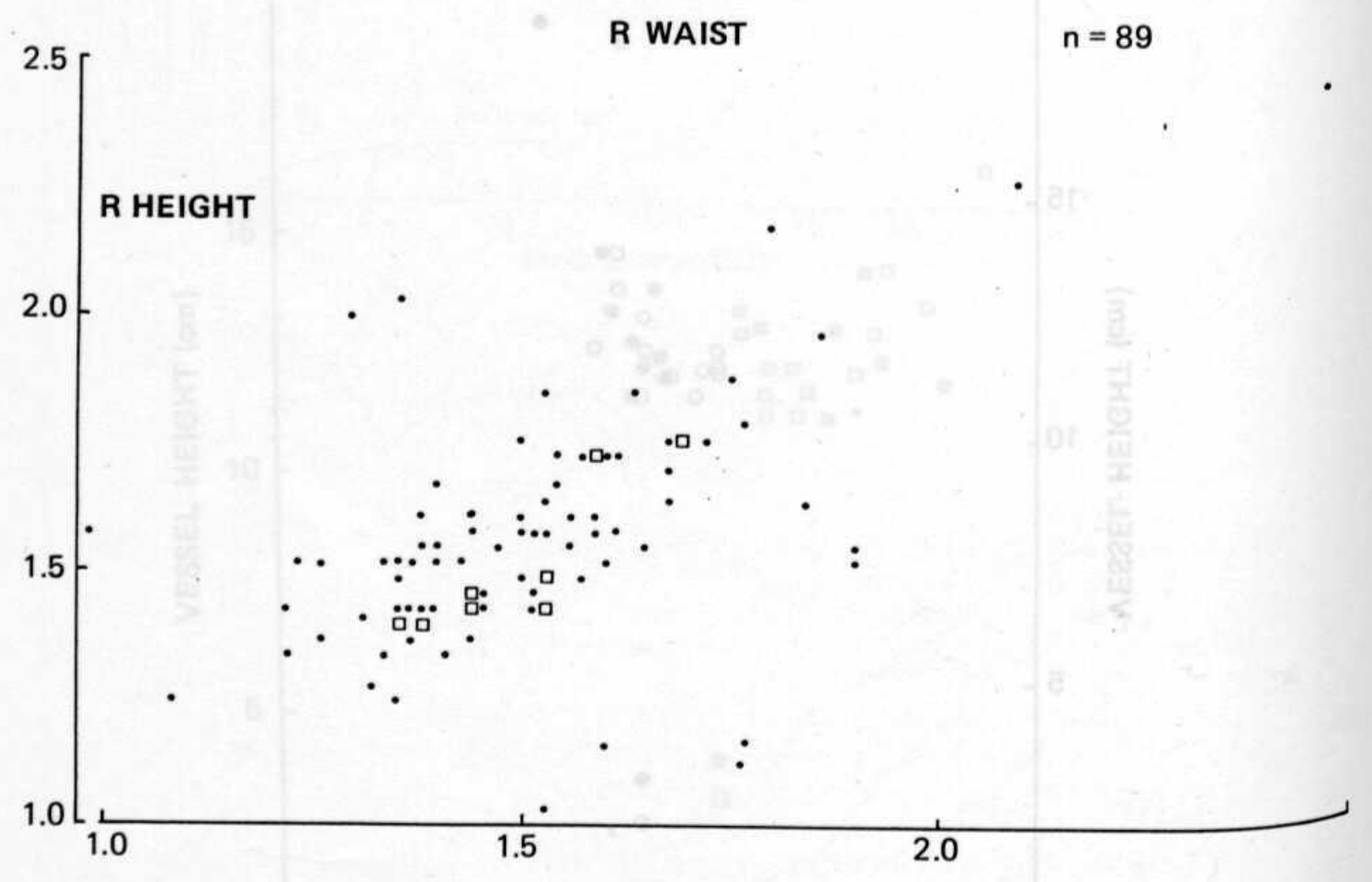

Figure 5.5 Rim height vs. rim waist, all vessels. 


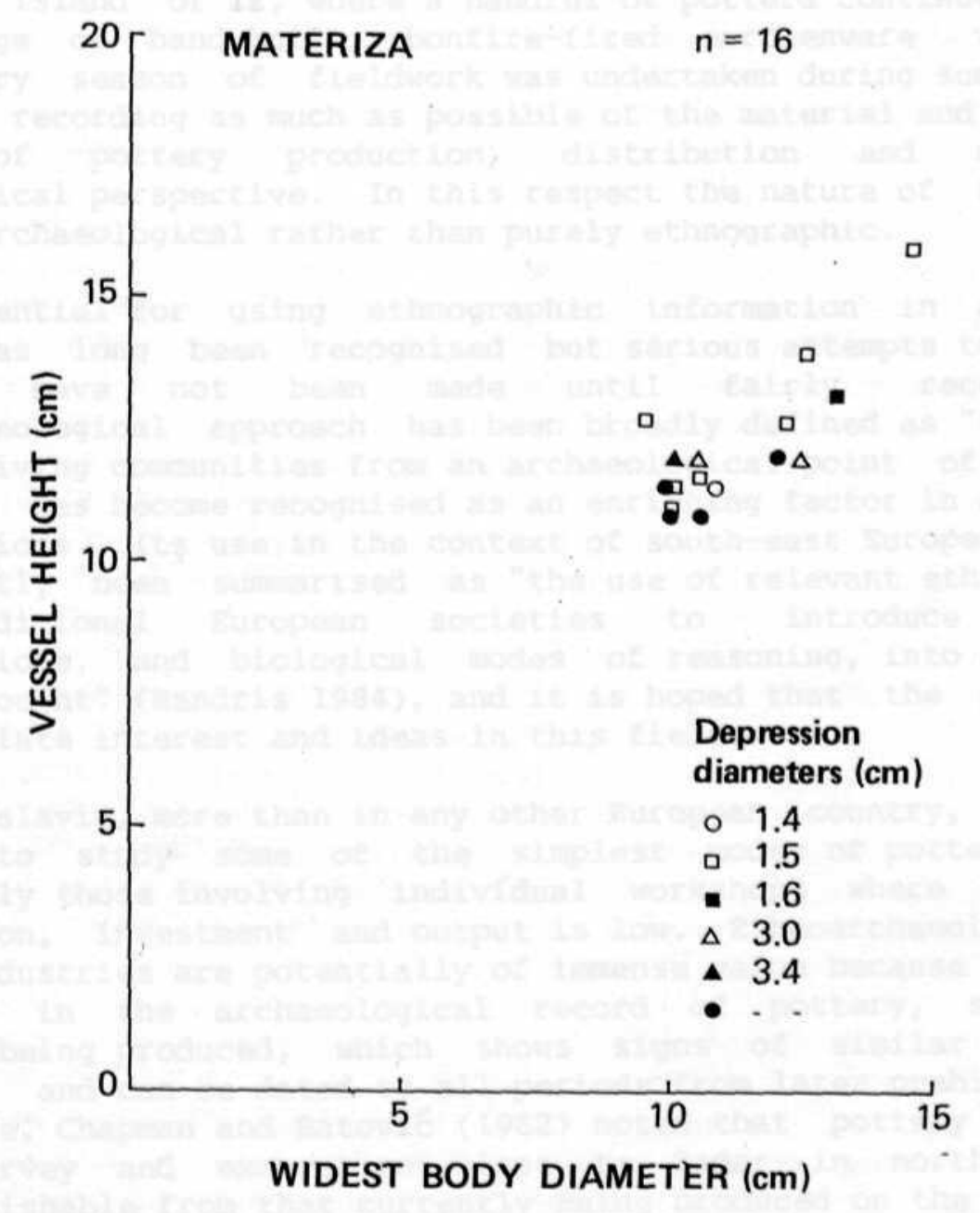

Figure 5.6 Vessel height vs. widest body diameter: Materiza. 


\section{CHAPTER SIX}

\section{AN ETHNOARCHAEOLOGICAL STUDY OF POTTERY PRODUCTION}

THE DALMATIAN ISLAND OF I $\bar{Z}-R$. CARLTON

\section{RICHARD CARLTON}

\subsection{INTRODUCTION}

This paper is concerned with the pottery-making industry on the north Dalmatian island of $I \bar{z}$, where a handful of potters continue to produce a Small range of hand-built, bonfire-fired earthenware vessels. An introductory season of fieldwork was undertaken during summer 1987 with the aim of recording as much as possible of the material and non-material aspects of pottery production, distribution and use, from an archaeological perspective. In this respect the nature of the fieldwork was ethnoarchaeological rather than purely ethnographic.

The potential for using ethnographic information in archaeological studies has long been recognised but serious attempts to realise this potential have not been made until fairly recently. The ethnoarchaeological approach has been broadly defined as "the first hand Study of living communities from an archaeological point of view" (Orme 1981) and has become recognised as an enriching factor in archaeological intepretations. Its use in the context of south-east European archaeology has recently been summarised as "the use of relevant ethnographic data from traditional European societies to introduce behavioural considerations, and biological modes of reasoning, into archaeological ways of thought" (Nandris 1984), and it is hoped that the present study will stimulate interest and ideas in this field.

In Yugoslavia, more than in any other European country, it is still possible to study some of the simplest modes of pottery production, Particularly those involving individual workshops where the level of organisation, investment and output is low. Ethnoarchaeological studies of such industries are potentially of immense value because of the common occurrence in the archaeological record of pottery, similar to that currently being produced, which shows signs of similar manufacturing processes, and can be dated to all periods from later prehistory onwards. For example, Chapman and Batovic (1982) noted that pottery found during field survey and excavation close to Zadar in north Dalmatia is indistinguishable from that currently being produced on the nearby island of $\mathrm{I} \overline{\mathbf{z}}$, and suggest a continuation of coarse-ware production in the area from the Iron age to the present.

Unfortunately, despite the potential benefits of such studies, and the awareness of this potential by earlier ethnographers such as popovic (1959), relatively little interest has been shown in Yugoslav potters or ethnographic records of them, the efforts of fieldwork being directed elsewhere. However, more interest has recently been shown in the subject, by Peacock ( 1981 and 1982) for example, and it is to be hoped that more work will be undertaken before the remaining centres of production cease 
to function.

\subsection{THE ISLAND}

I $\bar{z}$ is a small, rocky island of 19 sq. $\mathrm{km}$, situated $12 \mathrm{~km}$ to the south-west of Zadar in the north Adriatic sea (see Chapman \& Shiel, this volume, Fig. 1.1). Topographically, it consists of a series of hills which form a virtually continuous ridge along the length of the island, reaching a maximum height of 170 metres on the Peak of Korinjak, which overlooks the village of Veli I $\bar{z}$. Where secondary ridges run parallel to the main one, narrow strips of lowland are enclosed between the two. Elsewhere, most of the land slopes steeply down to the sea, though gentler slopes occur at various points on the coast and around the crest of the ridge. Outcrops of rock commonly occur on the hill-tops and steeper slopes, but only a small proportion of the land surface is totally denuded of soil. On the hillsides, stony terra-rossa soils are preserved in terraces, whilst those of the lowlands are stoneless and deep.

The climate is typically Mediterranean, with long dry summers and fairly mild winters. Natural vegetation is rich and varied, and most of the abandoned agricultural land has been colonised by mixed oak woodland, pine forest, or macchie (a dense mixture of thorn bushes). Areas of grassland are also to be found, particularly on the hill tops and in recently deserted olive groves. The range of species and overall density of vegetation on $I \bar{z}$ is much greater than on land with similar relief characteristics in the Zadar lowlands (see Chapman and Shiel, in press, for a description of the geography and natural vegetation of this region) where soil erosion has been more damaging (Shiel and Chapman, this volume).

The island is also rich in natural fauna. A large number of bird and reptile species are present, along with a smaller number of amphibian and mammal species. No species of predatory animal dangerous to man or domestic animals is present on $I \bar{z}$, though several species are to be found on the nearby mainland (Nandris, this volume). Pheasant, Partridge and Hare are the three species most commonly hunted, though their contribution to the subsistence requirements of the islanders has probably never been more than minimal.

\subsection{POPULATION}

The two villages on the island, Veli I $\overline{\mathbf{z}}$ and Mali I $\overline{\mathbf{z}}$, are located next to natural harbours on the north-east facing coast. Both villages are actually comprised of several geographically discrete settlements, each of which is associated with a pocket of good quality agricultural land. Each has its principal social, administrative and commercial centre close to the harbour, though secondary meeting places exist in each of the component settlements.

The population level has been falling sharply during recent decades from a peak of about 4000 just before World War 2, to a present figure of about 500. About three-quarters of the current population is resident in 
Veli Iz. During the summer months, many of the hundreds of people who left the island after World War 2 return with their families for holidays, thus swelling the population to four times its winter level. These returning natives tend not to participate in traditional economic activities but, by maintaining and constantly consolidating land ownership, they reduce the likelihood of incomers reviving farming and fishing activities on the island.

The two villages, Mali $I \bar{z}$ and Veli $I \bar{z}$, have established their own Separate identities, maintained by certain linguistic, musical, economic and other differences. For example, the men of Veli I $\mathbf{z}$ are traditionally builders and potters, whilst those of Mali $I \bar{z}$ are traditionally commercial fishermen. Such differences are becoming increasingly less obvious, but there remains a strong sense of rivalry between the two groups, and communication is surprisingly limited, even though the distance separating them is only about two kilometres.

\subsection{ECONOMY}

The traditional economic system was based upon farming and fishing at subsistence level, each household farming its own land producing olives, grapes, figs, potatoes and other vegetables for its own consumption. Each household also owned between two and five sheep and the same number of chickens. Almost all agricultural produce was intended for domestic consumption or local exchange (e.g. potatoes for pottery), but surplus olive oil or dairy products could be exchanged or sold at market in Zadar. Most of the fields are now abandoned, but a network of field clearance walls measuring up to eight metres wide, five metres high and hundreds of metres in length, remain as evidence of intensive agricultural practices of generations of farmers (see Bintliff and Gaffney, this volume, for a description of similar monuments on Hvar).

Fishing was usually practised from small boats by men working alone or in pairs. Several methods, including netting, spearing and trapping were employed, the choice of method being dependent upon a variety of factors, Such as climatic conditions and the species being hunted. Any surplus catch from these small-scale activities could be sold or exchanged at the harbour front. Commercial fishing, involving the collective effort of Several boats and many men over several days, was also practised, the catch being sold at the fish market in zadar. This activity mainly involved boats and men from Mali I $\bar{z}$.

A wide range of craft industries was also practised on $I \bar{z}$, mostly to provide for the basic material needs of those involved in the farming-fishing economy. However, at times when the traditional farming-fishing base was unable to support all the population, greater investment was made by some families in certain craft industries in order to develop an alternative economic base. Some of the main products of these industries included shoes, cloth, barrels, agricultural implements, fish-traps, boats and pottery. The industries responsible for these Operated on three basic levels:- 
1. Household production; for domestic consumption within the household of source.

2. Household industry; for both domestic consumption and sale.

3. Workshop industry; almost entirely commercially orientated.

Most industries were able to operate simultaneously at different levels in different households, according to the specific needs of the individual households concerned. For example, the traditional craft activity of shoe-making was practised as a workshop industry by one household until 1986, but was also practised on an occasional basis in many other households to satisfy immediate requirements.

In conclusion, the majority of households was primarily involved in farming and fishing, but for economic and social reasons, did not normally choose to specialise in either and did so only when circumstances prevented them from exploiting both land and sea resources. Traditional craft industries were exploited as alternative sources of income by households which were unable to support themselves fully by farming and/or fishing. Pottery-making became the most successful of the craft traditions adapted for economic purposes in this way, and remained a crucial source of income to a large number of households until recent times.

\subsection{THE POTTERY INDUSTRY}

Questions concerning the origins of industries such as this in Yugoslavia have been much discussed by Yugoslav ethnographers such as Popović (1959 and 1960) and Tomić (1983), who have discovered similarities between Yugoslavia, Poland, Czechoslovakia and the Soviet Union in the language used to describe the materials and processes of pottery production. However, there is very little or no evidence to suggest that pottery technology or pottery styles accompanied the linguistic elements in their move southwards. Interestingly, potters questioned on this subject in northern Bosnia stressed the Turkish origins of their tradition, although their terminology was entirely Slavic.

The industry on $I \overline{\mathbf{z}}$ appears to be a surviving remnant of a highly evolved, very widespread pottery-making tradition. Ethnographic records can be used to locate many industries of this type, as far as Istria to the north-west of $I \bar{z}$, and Hvar, in south Dalmatia, to the south-east. The distribution of these centres is mainly coastal, but some are located up to $50 \mathrm{~km}$ inland, as at Listica in Hercegovina, where a single potter was still working in 1987. Exactly when the present mode of production was introduced to $I \bar{z}$ is impossible to determine. Fragments of pottery indistinguishable from that currently being produced are visible on the island's two Iron age hill-forts, but several factors suggest that manufacture at this time was restricted to household production. If it is accepted that the commercially-orientated workshop industry only began when the economic need arose, then it is plausible to suggest that a 
population rise caused by the 17 th Century migrations to the islands of mainland peasants escaping ottoman harrassment (Bracewell, n. d.) may have been the primary catalyst for this development. Whatever its origins, it is known that an industry had become established by 1753, when the first known documentary reference to a specialist potter on I $\bar{z}$ was recorded. By the mid-1930s, up to 40 families were involved in the industry but since then that number has been falling continuously.

Pottery production on $I \bar{z}$ is practised by specialist potters for commercial gain, but differs in several respects from other specialist industries on the island. Particularly significant from an economic point of view is the fact that it is a seasonal occupation, practised between the months of May and September when climatic conditions are favourable. This period is also the season of least agricultural activity, which means that time is not invested in pottery production at the expense of other economic activities. It is also significant that the level of investment in equipment is very low - all the equipment necessary for the manufacture of pottery can be quickly and easily made out of freely available wood or Stone and all the larger pieces of equipment last for at least several decades after construction. Thus, pottery production involves almost no outlay of capital investment at any stage, and in this respect differs from other (actual or potential) commercially orientated craft industries. Until recently the industry was also outstanding in respect of the overall scale of its producton. It was the only specialist industry to produce a Vast surplus above the requirements of the villages on $I \bar{z}$ and neighbouring islands, and the only one to depend on an extensive market away from the immediate area of source. The industry also occupied many more men, working in many more workshops than any other industry. The reasons why pottery production became so much more important than any other craft industry in Veli I $\bar{z}$ will probably never be fully understood, but its development must have been helped by the fact that it could be practised without diverting material resources, money or time from existing economic ventures. The remaining potters in 1987 keenly maintained their farming and fishing interests throughout the potting season.

The I $\bar{z}$ industry has previously been described by Ostrić (1978) and Gavazzi (1965), but these accounts are limited to descriptions of materials and processes, with little apparent awareness of the social and economic implications of manufacture and use. These brief accounts also lack an appreciation of the archaeological perspective. This also applies to many other studies of similar industries in Yugoslavia, though a few attempts have been made to describe and explain pottery production in Social and economic terms (e.g. Tomić 1983) and others have recognised the potential for the use of such information in archaeological work (e.g. Popovié 1959).

\subsubsection{Preparation of raw materials}

The pottery-making process begins with the collection of 'raw' clay. Until recently, this came from the bay of Soline on the south-west facing coast of the island (approximately three kilometres from the village) where clay was mined by individuals from the bottom of pits up to three 
metres deep, and carried back to the village by working parties of between two and five men. Recently, the few remaining potters have begun to collect their clay from the mainland, where a more easily accessible source is available at Privlaka.

Back in the village, the 'raw' clay is broken into small lumps and left to dry in the sun for several days. A wooden mallet is used to break the dried clay into smaller pieces (smaller than $2 \mathrm{cu}$. cm), then impurities such as small stones and vegetable matter are removed. The refined, dried clay is mixed into a half-full barrel of water and left to soak for 24 hours or more.

The next stage is to temper the soaked clay with particles of calcite, blocks of which are collected from the limestone hills around the village. Two distinct methods of preparing the calcite can be observed. The first involves hitting large pieces of this material with a wooden or metal hammer until a small pile of fragmented material is produced. This is sieved in order to separate the usable particles (approx. $0.03 \mathrm{cu}$. cm). from the larger fragments, which must be beaten again. The second method follows the same course except that the sieve is much finer, being designed to collect only powder and very fine particles (which are used later to prevent pottery bases sticking to the wheel during manufacture). The remaining material is reduced to particle size in a simple, hand-driven quernstone mill (Fig. 6.1). Clay and temper are mixed by foot for up to two hours until an even mixture of correct, workable consistency is achieved (about five parts clay to two parts calcite). The refined, tempered clay is then wrapped in damp sacking ready for immediate use.

\subsubsection{Manaufacturing process}

The terminology used for describing turntables and wheels of various kinds is not very clear, though attempts have recently been made by Loebert (1984) and others to define types more satisfactorily using a number of variable characteristics. Such definitions are important because the type of technical appliance used to make pottery is connected with the level or organisation of the industry concerned, although fieldwork in Yugoslavia has shown that it is extremely difficult to assess the nature of such relationships in general terms.

The equipment used on İ̄ consists of a simple hand-wheel or turntable (KOTUR), which is a wooden disc $35-45 \mathrm{~cm}$ in diameter and about $5 \mathrm{~cm}$ thick, mounted on a cross-shaped substructure. This revolves upon a stationary axle (TULAC), set into a limestone block (TRUPICA). Technical appliances of this type have previously been referred to in several different ways, but the most precise definition is provided by Loebert (1984) who defines such appliances as high-mounted hand-wheels, a term which suggests the position of the bearing in the wheel and describes the mode of propulsion used. However, whereas on $I \bar{z}$ these function as turntables for making coil-built pots, at Ularice in Bosnia they are used to make thrown pots (Fig. 6.2). This suggests that it is less important to dwell on the precise nature of the equipment used in pottery production than to define the way in which pottery is formed using that equipment. 
The process by which pottery is formed on the hand-wheel by the potters of $\mathrm{Iz}$ is as follows:-

A ball of clay is beaten into the shape of a flat disc about $4 \mathrm{~cm}$ thick (Fig. 6.3). This is coated on one side with calcite powder (to prevent sticking), then placed on the wheel and roughly centred. Working from the centre, clay is pushed outwards with the thumb to form a low wall up to $8 \mathrm{~cm}$ high (Fig. 6.4), which acts as a base for the addition of coils at the next stage of manufacture. Great care is taken to ensure that the shape of the base is perfectly circular and that the low vessel wall rises vertically from the base before the series of coils or rings is built up.

A roll of clay is held between the index finger and thumb of the right hand and gradually squeezed onto the top of the vessel wall, which is supported, and at the same time rotated by, the flattened palm of the left hand (Fig. 6.5). Final shaping is done with a simple wooden tool (RAZGANACA), while the vessel is rotated in an anti-clockwise direction on the wheel (Fig. 6.6).

Handles may be added at this stage, but larger vessels are allowed to dry overnight before this is undertaken. Completed vessels are left to dry in the sun for an hour or two after manufacture, before being carefully removed from the wheel and stored inside to dry for at least two weeks prior to firing.

The time taken to complete the manufacture of a single pot varies considerably between potters. For example, two potters were observed to take an average of 60 minutes to complete the basic shape (minus handles) of a large bread-oven, but others were observed to take an average of 25 minutes. This has a significant bearing on the total number of pots produced by individual potters in a season, and since all pots of the same type cost approximately the same amount regardless of time taken to produce them, it is clear that the fastest workers benefit financially.

\subsubsection{Vessel forms}

About a dozen types of vessels are known to have been produced on $I \bar{z}$ within the last 40 years and examples of most can be seen in the island's ethnographic museum. All,are flat-bottomed (or flat-topped, in the case of large vessels used 'upside-down' as bread-ovens) and most are Orange-brown in colour, though a few older examples in the museum are almost black.

In 1987 only four types were made.

1. CRPNJA or CRIPNJA. This is a very large vessel, measuring between $45-58 \mathrm{~cm}$ in diameter across the rim, used for baking bread on open hearths (see Nandris, this volume, for a fuller description of its use). The remaining potters of $I \bar{z}$ all specialise in production of this type, and in $198771 \%$ of all pots which were seen to be fired were crpnje. 
Vessels of the same basic form used for the same purpose are still manufactured elsewhere in Yugoslavia, and probably also in Romania, Greece and Bulgaria. Further work is planned to determine the distribution of these in ethnographic and archaeological contexts throughout south-east Europe.

2. FOGUN. This is a moderately sized, proportionately deep pot which functions as a simple stove, a cooking pot being rested on the rim. Two or more holes cut into the side of the vessel allow stoking to take place and permit the passage of air. Only one potter made a few of these in 1987, but several different kinds of this basic type can be seen in the ethnographic museum.

Similar vessels are made for the same purpose by two potters working in separate villages close to the north Bosnian town of Doboj.

3. TEC A. Bowl-shaped cooking vessel with two handles attached just beneath the rim. Used on a tripod over an open fire for cooking fish and vegetable stews. Rim diameters vary between 19-37 cm, and each potter makes a variety of different sizes in each batch. Some potters decorate their Teçe whilst still on the wheel with incised lines, which may be continuous, broken or wavy. These are applied very quickly with the tip of a wooden shaping tool. $17 \%$ of all pots seen to be fired in 1987 were of this type, making Tece the second most common type of vessel produced on the island.

Elsewhere in Yugoslavia, vessels of this type were produced in 1987 at Sinj in Croatia and Listica in Hercegovina, and are known to have been produced within the last 40 years at many other points along the coasts of Istria and Dalmatia, as well as up to $50 \mathrm{~km}$ inland. Together with Crpnja and Lopiz (see below), the Tec̄a appears to have been one of the basic ceramic components of the hand-wheel pottery tradition which flourished until recently throughout much of Istria, southern Croatia (including Dalmatia) and Hercegovina.

4. LOPIZ. A similar type of cooking pot to the Teča, but proportionally deeper and with handles attached to the top of the rim (actually, upward extensions of the rim with holes pushed through). A single piece of wire passed through both handles allows vessels of this type to be hung over open fires during use. Only a few examples of this type were produced in 1987, so an accurate assessment of their size range is not possible, but on average they are probably slightly larger than $\mathrm{Tec}$ e.

Their distribution elsewhere in Yugoslavia also seems similar to that of Tec̄e (see above) and potters at Listica and Sinj produced vessels of this type in 1987. 


\subsubsection{The firing process}

Firing takes place in an open bonfire at a permanent site on common land after the pots have been allowed to dry slowly and thoroughly (Fig. 6.6). The firing process itself is characterised by a similar slow and thorough approach, all factors which are not under the potters' direct control, such as climatic conditions, being carefully considered before the decision to begin firing is taken.

Preparation for firing begins early in the day when pots are taken to the edge of the firing site and left to heat up in the sun (Fig. 6.7). A small fire of dried grass is burnt to warm the ground surface, then the Sun-warmed pots are stacked ready for firing in the warm ashes, so raising their temperature a little higher. The preferred combustible material used in the main fire is dried olive wood in the form of cuttings taken during winter pruning (the estimated 87,000 olive trees on $I \bar{z}$ would have provided ample resources even at the peak of potting activities). A small fire of this material, mixed with dried grass, is lit on top of the pots and allowed to burn itself out (Fig. 6.8). A larger fire consisting entirely of olive cuttings is then burnt, and again allowed to die. This is repeated several times, each fire raging intensely for about two minutes, until the pots become light orange in colour, showing that vitrification has taken place. Almost immediately, the pots are hooked out of the ashes with a long pole and left to cool a short distance away. The potters may fire another batch if they have prepared two batches for firing. If not, another potter may make use of the heated ground to fire his own pottery (thus saving fuel). This is an accepted practice but cannot really be said to be an act of cooperation since no prior arrangements are made between potters for this purpose.

Each workshop normally makes enough pots for three separate firings during a season, and normally makes enough pots for two batches to be fired each time - a batch consists of between $30-40$ pots, of which the majority are Crpnje. Single-batch firings are much less common, but sometimes occur at the very beginning of the season, or at times of particularly high demand. Until recent decades it was common practice for individual workshops to fire two batches up to seven times during a Season, adding up to a total of over 500 pots per workshop each season.

\section{5 .5 Sale of Pottery}

Until very recently, pottery was taken to neighbouring islands and the mainland by sea, to be sold from boats moored in the harbours of market towns. In a predominantly non-monetary society, it was exchanged for essentials such as corn and cloth, and became the property of peasants living many miles inland who travelled to markets at such coastal towns as Zadar, Biograd and Sibenik. This trade went on along the coast up to a distance of $200 \mathrm{~km}$ from $\mathrm{I} \overline{\mathbf{z}}$, at a time when potters there were competing not only between themselves but also against other potters in Istria, Dalmatia, inland Croatia, Bosnia and Hercegovina. Exactly how this trade perated and what the effects of competition were will be the subjects of further research. 
In recent years almost all of the potteries which were in competition with I $\bar{z}$ have ceased to produce, and since the output from I $\bar{z}$ has decreased at a much greater rate than demand, it is no longer necessary for potters to travel further than Zadar in order to sell (and most manage to sell all their pots without travelling anywhere). However, in spite of the apparent lack of economic need to do so, one potter recently began to trade in the lowland rural districts surrounding Zadar, travelling around various villages. with a car-load of pottery, breaking from the traditional practice of transporting and selling pottery by boat. The man in question is also the only potter who has seriously attempted to exploit the potential tourist market in Veli $I \bar{z}$ and Zadar; he also produces the greatest range of forms and maintains the highest output. Although at over 80 years old, he is the oldest of the present potters, his attitude contrasts sharply with the conservatism of the others, and illustrates how individual innovators can provide the mechanism for change and adaptation. In this case, he has adopted what has become the most logical mode of transport, in order to sell his pots where he can demand a higher price than on $I \bar{z}$ or in Zadar. This also highlights the point that the economic role of pottery production has changed from being an activity vital to the survival of the household, to one which is participated in through choice and provides a welcome supplement to an already adequate income. In the case of the innovative potter, not only does he work more than he needs to by making pots at all, but he also devotes more time to marketing than he needs to because he has no difficulty in selling his wares locally. Potters are no longer governed solely by economic considerations, being economically free to choose whether to continue working, and if so, when to work, and how to sell their produce.

Rice (1984) has concluded that pottery production responds only gradually to cultural change, and such subtle changes may not be demonstrable using the techniques of analysis normally employed by archaeologists. Great socio-cultural changes in Yugoslavia over the last 50 years or so have not led to changes in techniques of production or stylistic changes in the types of pottery produced on $I \bar{z}$, but have indirectly led to pottery-making becoming much more lucrative for those who continue to practice it. In turn, this has led to a change in marketing strategies employed by potters and a reduction in the number of forms produced. These are the two most visible responses made by the industry to recent socio-cultural upheavals.

Although the system of marketing has recently changed, and pottery is now sold for a fixed price, it still reaches an almost exclusively peasant market on the islands of the Zadar archipelago and in the Ravni Kotari region on the mainland.

\subsubsection{Level of organisation}

Recently there has been a growing acknowledgement of a need for models in ceramic studies to enable more meaningful assessments and comparisons to be made of pottery producers in different areas. Models may be constructed in different ways, deriving inspiration from such sources as economic theory or the ethnographic record (Peacock 1982). But all such 
models depend upon assumptions of general regularities in human decision making. Arnold (1985) has isolated a number of natural and human limits which illustrate such regularities. For example, potters seem to have limits beyond which they will not usually travel for raw materials. Van der Leeuw (1984) has argued that "our premise must be that at least it is possible (albeit difficult) to discover 'objectivity' in human behaviour", and in an attempt to do this has used the ethnographic record to define 'levels of organisation' of pottery producers in a hierarchical scheme, from the simplest to the most complex. Peacock (1982) has developed a similar scheme, using economic theory to define eight 'modes of production'.

However, as Peacock has pointed out, conceptual frameworks such as these are not perfectly reflective of a situation which may be infinitely variable in practice. For this reason it is difficult to define the industry on $I \bar{z}$ in terms of a particular 'level of organisation' or 'mode of production', especially since differences exist between workshops, all of which have been undergoing considerable, though non-simultaneous changes over recent decades. In most respects though, the industry complies with the criteria which van der Leeuw uses to define a 'village industry', comparable with Peacock's 'nucleated workshops' mode of production. This level of organisation is characterised by a high degree of standardisation in terms of raw materials, techniques of production and product, by the clustering of several discrete workshops, and by the commercial orientation of production. Naturally, pottery production on I $\bar{z}$ differs in several ways from the proposed models, particularly with regard to the lack of inter-workshop cooperation, but it is more important at this stage to stress that in most ways it fits remarkably well into both frameworks, although neither model was constructed with any reference to the industry on $I \bar{z}$ or to any others in the region. It is of foremost importance to establish new data sets such as this within established frameworks, because only then can the differences be recognised and meaningfully assessed. Up to now, ethnographic studies of pottery producers have provided a multitude of cautionary tales warning against over-simplification and cross-cultural generalisation in archaeological interpretations, but the advent of model building in this field has made it possible for these to be used in a more constructive way.

6.6

MATERIAL REMAINS OF POTTERY-MAKING ACTIVITIES

The approach used during fieldwork on I $\bar{z}$ was primarily ethnoarchaeological, aimed at recording information from an archaeological Perspective. Thus, material culture, the 'raw data' of archaeologists, remains at the centre of this study. A wide variety of visible remains of pottery-production were recorded on $I \bar{z}$, and a brief outline of the nature of this evidence is given below.

\subsubsection{The firing site}

The clearest material signs of activity left by the $I \bar{z}$ potters are at the firing site. This site has been used continuously - that is, each Year during the 5 month pottery-making season - for over 40 years. Before 
that another site had been in use for at least 150 years, but no visible traces of it remain. An assessment of the number of times the present site has been used during the last 40 years is difficult, but a conservative estimate of 2,000 times is reasonable.

Its principal features are: a surface covering of ash spread over a roughly circular area of about $40 \mathrm{sq} . \mathrm{m}$; a linear grouping of about 10 large stones (up to $35 \mathrm{~cm}$ long) lying towards one side of ash deposit, and a smaller number scattered elsewhere; about 20 large stones dotted around the perimeter of the site about five metres from the ash deposit; a general low-density scatter of pottery, with concentrations around the periphery of the ash deposit.

These features can be accounted for by observations made during the firing process:-

Ash accumulates where burning takes place, and since different batches of pottery are fired in slightly different positions, the ash is spread over a much greater area than that occupied by a single batch of pottery during firing. Post-depositional processes such as human and animal activity, and wind, also help to spread it out.

The group of large stones on the ash deposit was used in the stacking of pottery during firing. Those distributed around the periphery are used as weights to secure piles of olive cuttings which are left to dry around the firing site. Stones from these two groups are interchangeable; many show signs of burning, and most of the smaller stones littering the site are in fact fragments of larger stones which have become fractured by repeated heating and cooling over the course of time.

The paucity of broken pottery on the site and the small sherd size of most of that which is visible, is of particular interest. It is often assumed that bonfire firing results in many breakages, and that bonfire firing sites are therefore identifiable by large amounts of broken pottery strewn about them. This is certainly not the case on $I \bar{z}$. In fact, very little pottery is damaged during the firing and the discard rate is negligible (too few pots were fired in 1987 for this figure to be accurately assessed in percentage terms). This is the single most important factor in explaining why so few sherds lie on the firing site, but a secondary factor is the tendency of potters to discard pots which break away from the centre of the firing area. Most of the larger pieces were found close to the stacks of drying olive cuttings and at the place where pots are left to cool after being removed from the fire. The small amount of pottery which does become distributed over the site is quickly broken down by the activity of humans and animals, as well as by the effects of climate and other weathering agents. Having been broken down to a very small size ( $\max$. length $=2 \mathrm{~cm}$ ) it is re-deposited towards the periphery of the ash deposit when the site is swept after firing to remove unburnt organic debris.

The observations made of the firing process and its material remains indicate the difficulties which are involved in identifying such sites 
archaeologically. The insubstantial, unstable nature of the material remains and the location of the site away from occupation areas are particular relevant factors in this respect. However, it is worth bearing in mind that the industry on Iz is highly evolved and highly specialised, and all stages of pottery production, including the firing process, are closely controlled in order to ensure maximum returns. Wastage rates of pottery may well be higher where the craft of pottery making is not so specialised. More ethnoarchaeological work is needed in order to define the criteria by which different kinds of bonfire firing sites can be recognised archaeologically.

\subsubsection{Pottery and other material remains}

The pottery itself is found in a variety of contexts on the island and elsewhere. Complete vessels are found in unfired and fired form in workshops or drying/storage rooms (if different), and in the possession of many households around the village and elsewhere. Very few examples are found in modern houses where kitchens are not equipped with the open fireplaces and large hearths necessary for their use, and no examples were traced in Mali I $\bar{z}$ where brick bread-ovens attached to the side of houses have been favoured for at least two generations. Discarded fragments of broken pottery are unevenly distributed, the main concentrations being found in and around workshops, at the firing site (see above), on field walls (particularly those close to sheep huts and shepherds' shelters, and those closest to the village), in refuse tips and in the harbour, where almost complete specimens were sometimes deposited with other household refuse.

Ethnographic enquiry revealed that the primary mode of distribution from the village into the surrounding countryside was by farmers who used cooking pots when working away from the village, and discarded those which broke on the field walls. It is also probable that some were used as animal feed containers and were discarded on field walls when broken beyond use. Very little pottery is visible in the fields, partly because of a bias against deposition there and partly because of its tendency to degrade very quickly when in contact with the earth.

Most other material remains of pottery making activities result from the collection and storage of raw materials. They include the following features: clay extraction pits; clay storage dumps, located close to the workshops; stone wheel-bases, of ten found in secondary contexts having been reused; calcite storage dumps, located close to or inside workshops; broken and complete quernstones. All of these features are associated with individual workshops except the clay pits which are on common land, though it has not yet been established how the resources of the different pits were controlled. Quernstones are in many ways the most interesting of these remains, because their use on $I \bar{z}$ is solely restricted to grinding calcite for the pottery industry, a possibility which is often overlooked when they are discovered in archaeological contexts. Unfortunately, the study of quernstones is not yet well enough developed for determinations of use to be carried out on the basis of material and morphological characteristics, but the potential for developing techniques of functional 
analysis in this field is considerable (pers. comm., A. Welfare).

\subsection{SUMMARY}

During fieldwork on $I \bar{z}$ in 1987, various technical, social and economic aspects of pottery production were examined within their particular cultural context. In addition to looking at the present situation, attempts were made to introduce a time dimension by examining how the industry has changed over the past 50 years (as far back as the reliable limits of human memory). The five potters working in 1987 continued to make pottery using the standardised techniques and processes which they inherited in the early part of this century. Recent socio-cultural changes have not affected the way in which pottery is produced but have caused an overall decline in the size of the industry, a reduction in the range of pottery types produced and a change in marketing strategies. The social and economic status of those who continue to pot has risen quite dramatically in recent years and production is no longer motivated by economic necessity.

Further ethnoarchaeological fieldwork studies are planned to take place on $I \bar{z}$ in order to clarify and add to the information recorded in 1987 . It is anticipated that the industry will become extinct within 5 years and that the last of Yugoslavia's hand-wheel potters will cease production before the end of this century. In the meantime, it is hoped that further studies will contribute to our general understanding of pottery production, by making use of these hitherto largely overlooked potential sources of information and ideas. 


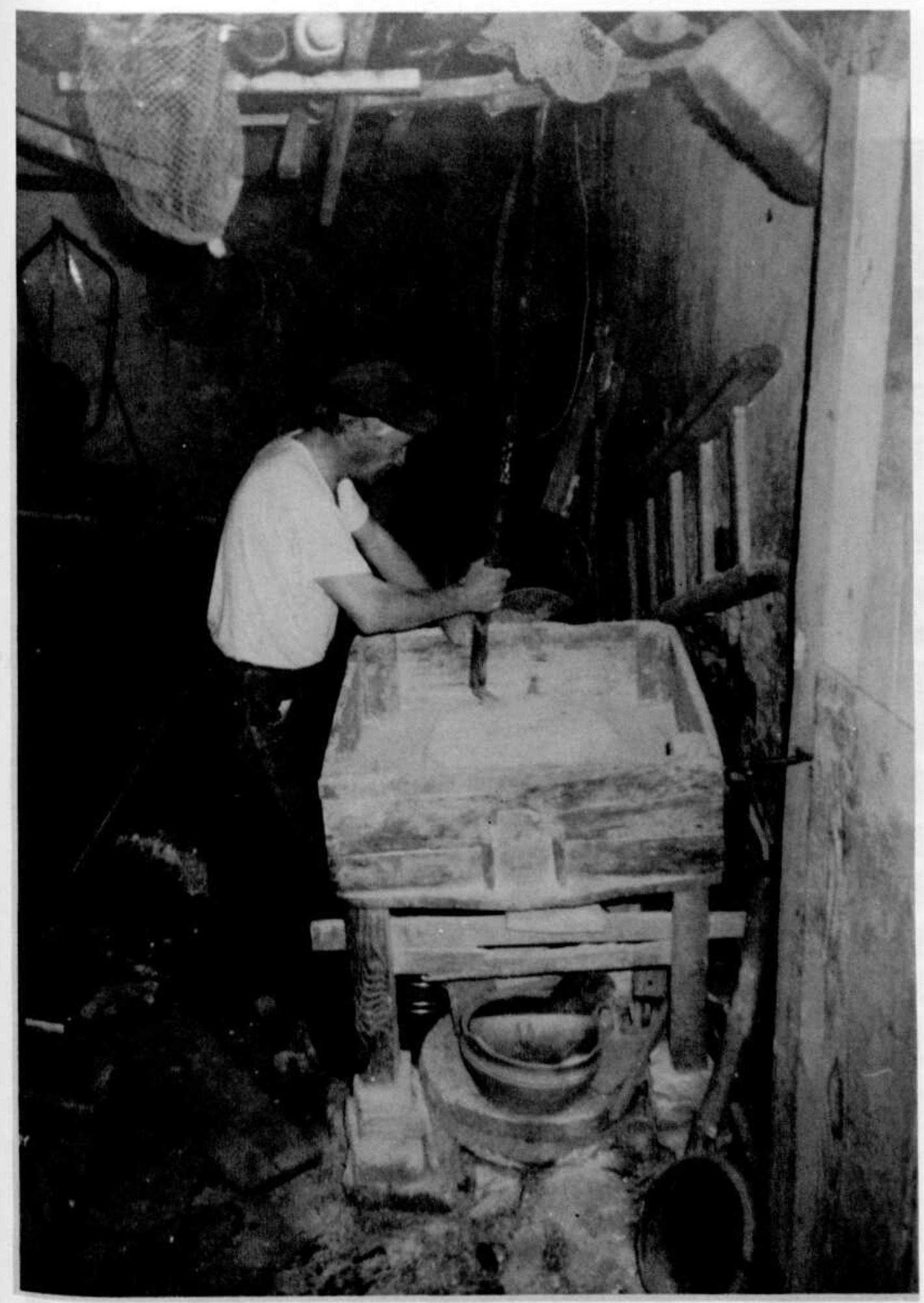

Plate 6.1 Romano VLAKHOV, Potter, using a quernstone mill to grind calcite for use as temper. Veli I $\bar{z}$, Dalmatia. 


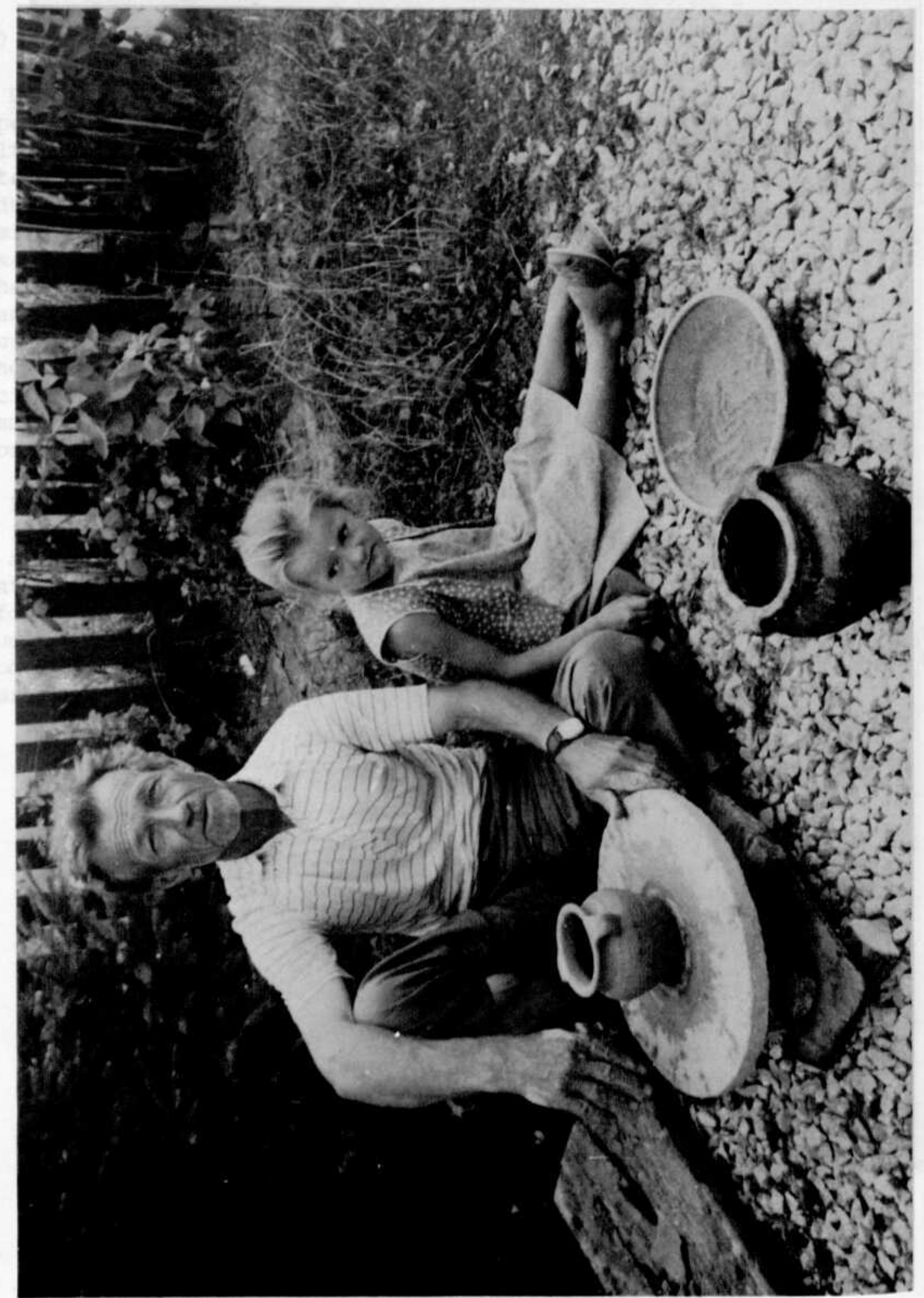

Plate 6.2 Mato GAVRAN, Potter, with his hand-wheel and a newly-thrown pot. Doboj, Bosnia. 
Plates $6.3-6.8$ Stages in the manufacture of a large bread-oven, or crpnja, by Marijan and Libero SuTLoví́.

Veli İ̃, Dalmatia. 


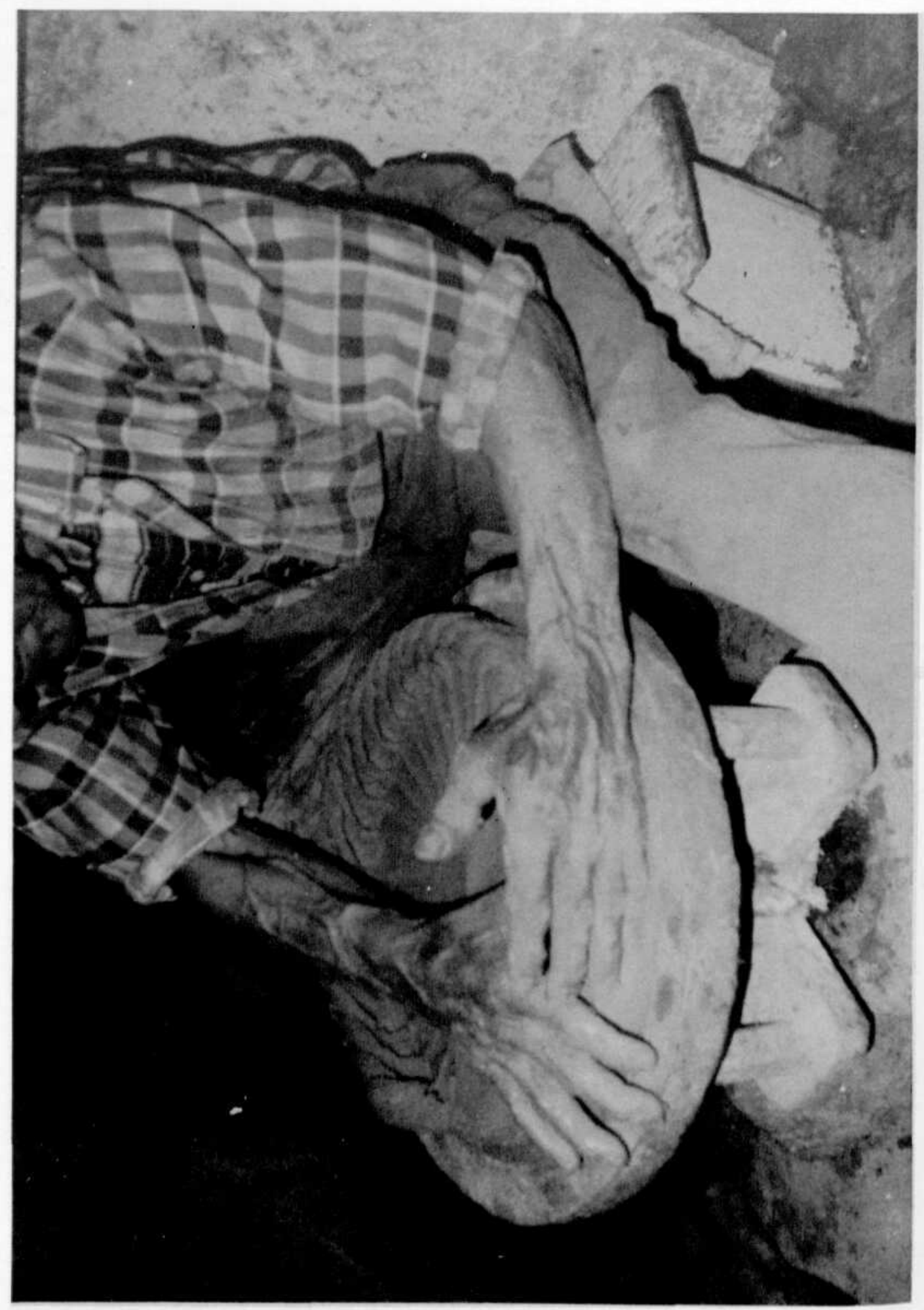

Plate 6.3 Forming a base for the vessel sides. 


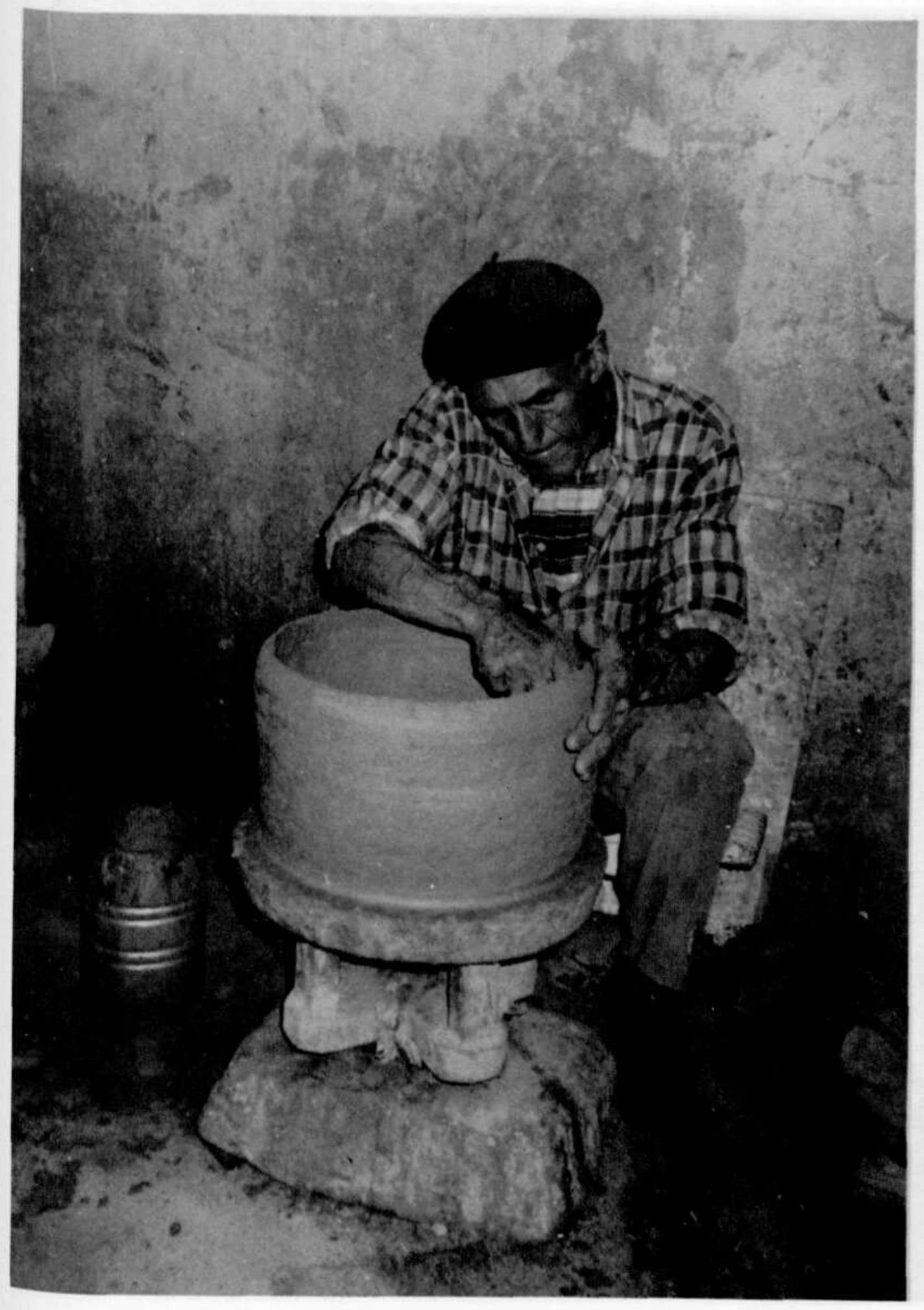

Plate 6.4 Adding the last coil prior to smoothing and shaping. 


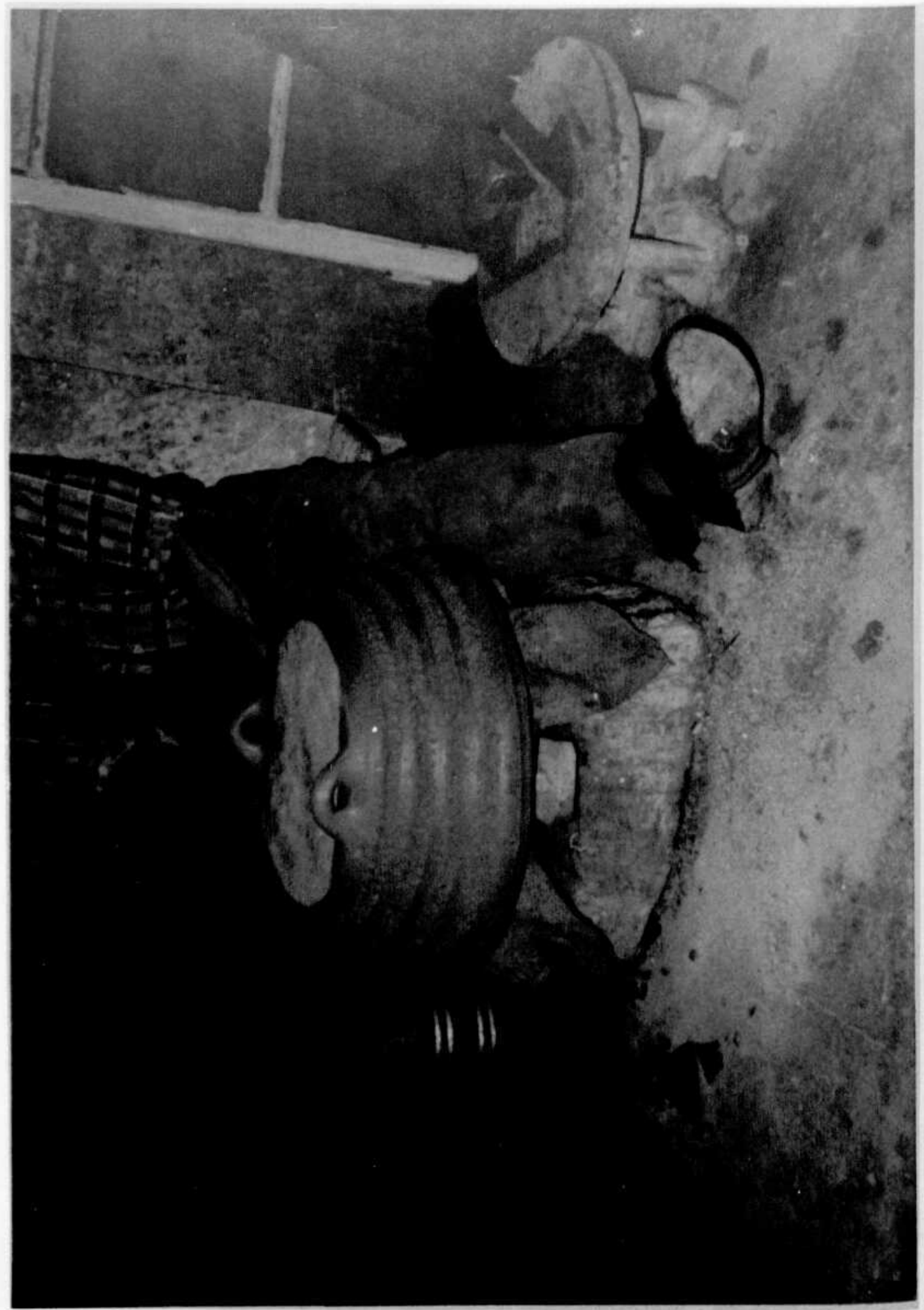

Plate 6.5 Adding the handles. Note the complete range of wooden tools to the right of the potter. The clay used by both potters in the workshop is behind the water container. 


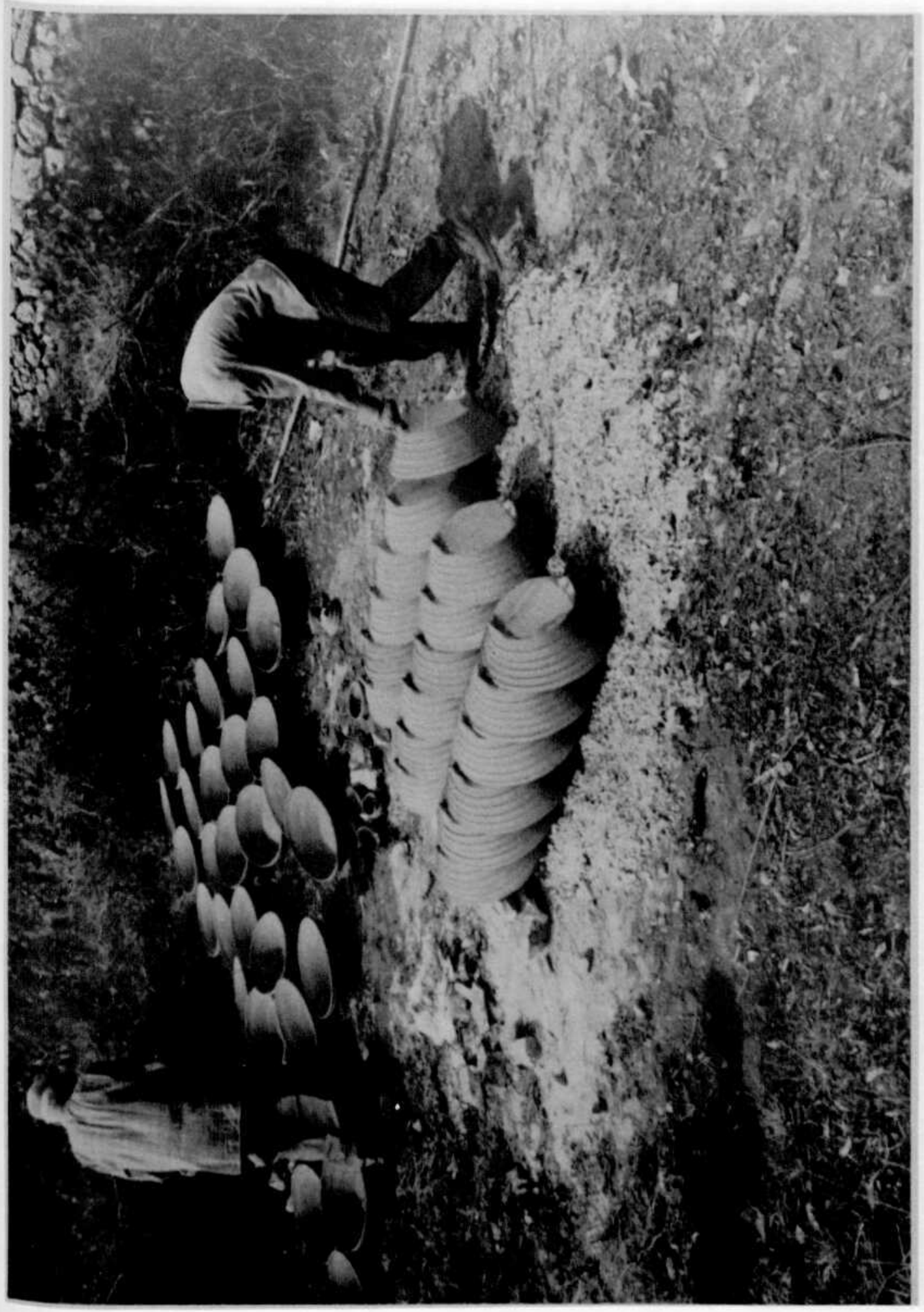

Plate 6.6 Pots being positioned ready for firing, after being pre-heated in the sun. 


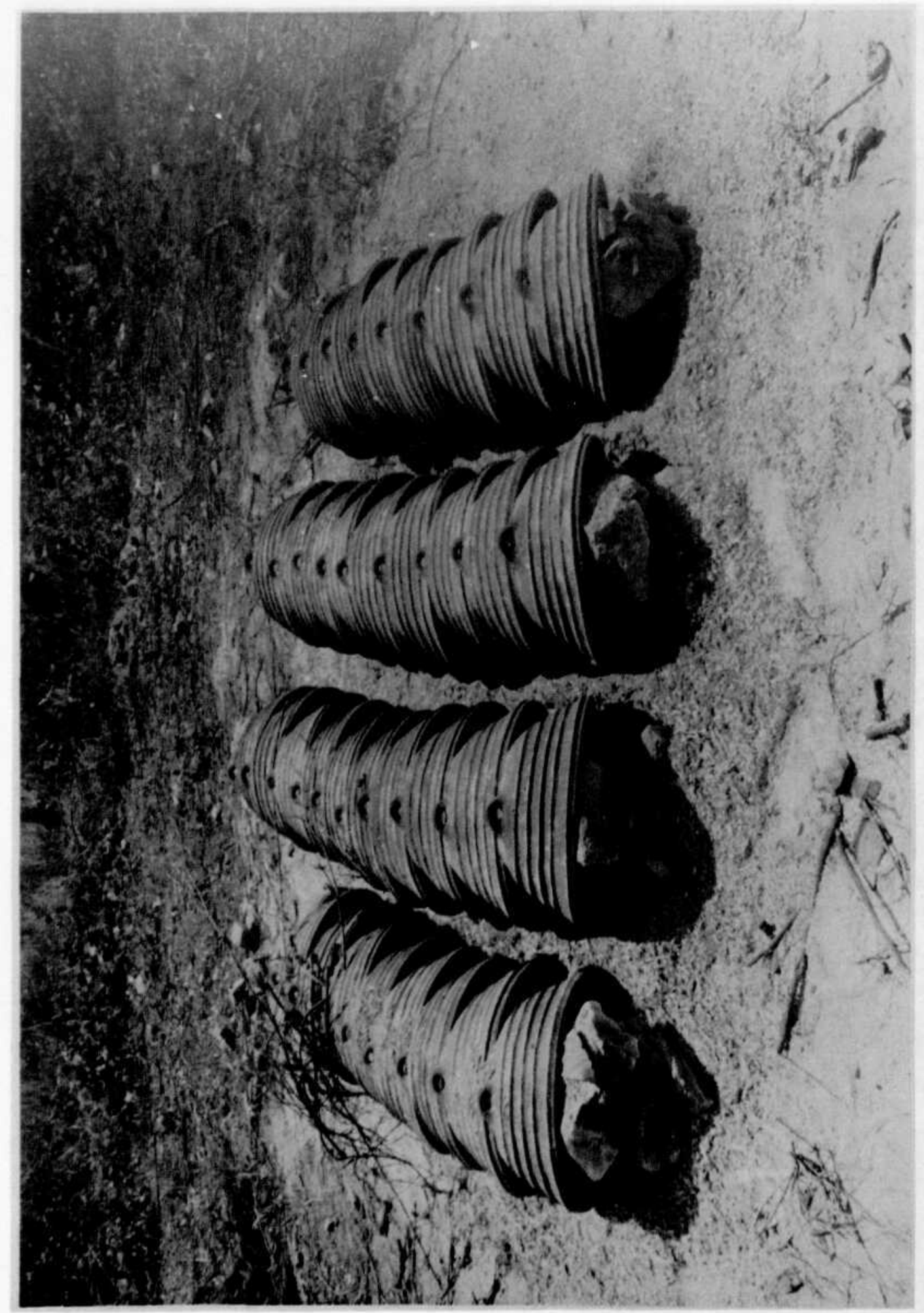

Plate 6.7 Crpnje in place ready for firing. Note the use of large stones and a broken sherd in stacking the pots. 


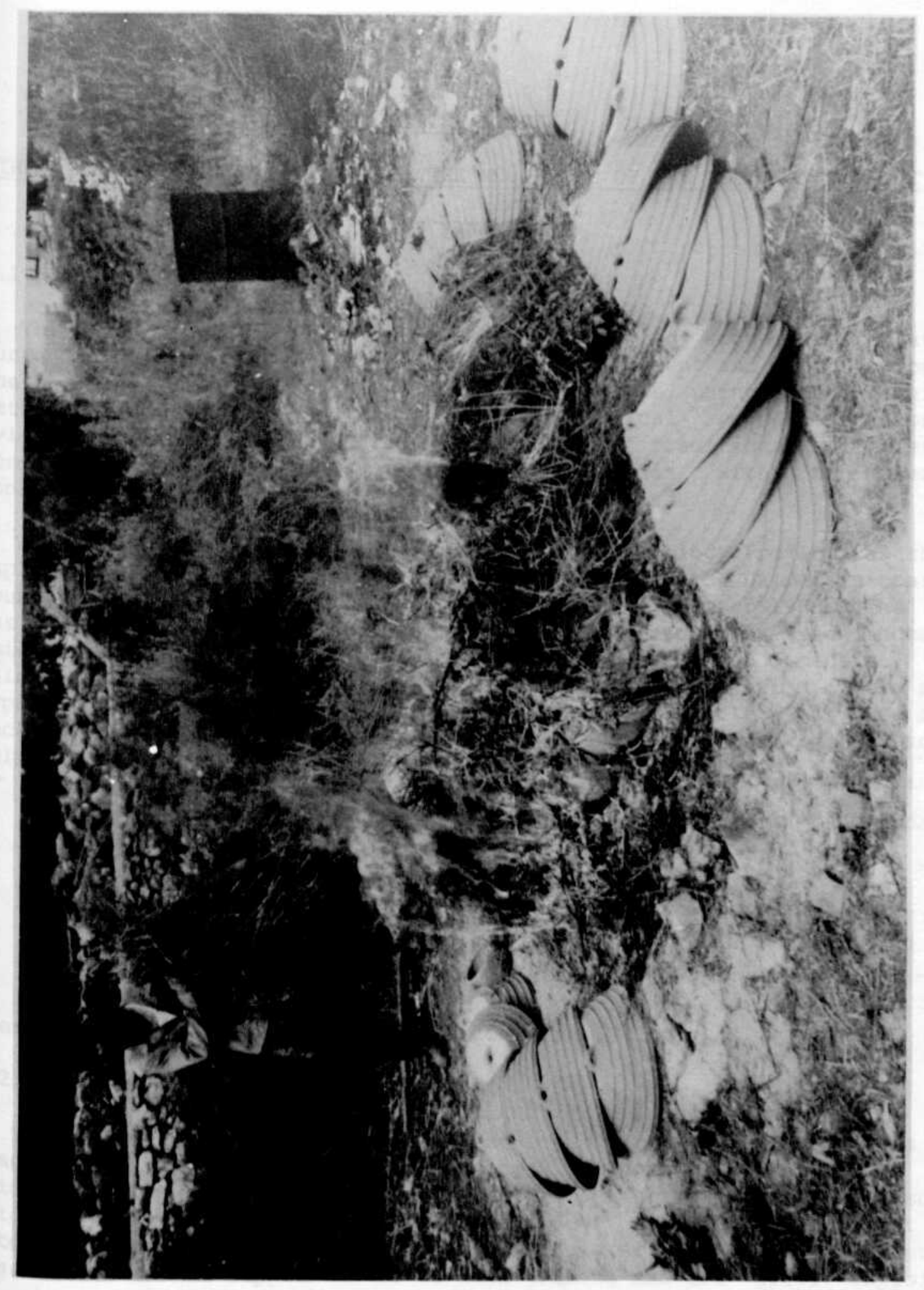

Plate 6.8 Burning dried grass and olive cuttings on top of the pots. Note the rubbish tip (top right), which slightly overlaps with the firing area. 


\subsection{INTRODUCTION}

The main aim of the Highland Zone Ethnoarchaeology Project is to extend our understanding of prehistoric and recent settlement and exploitation of the highland zone throughout south east Europe, using archgaeological methods (Nandris 1985). The ethnoarchaeological approach interprets evidence for the material outcome of behaviour of traditional societies in these regions but of its nature also deals with non-material considerations.

As an extension of the Highland Zone Ethnoarchaeology Project, a short exploratory season of fieldwork was carried out in the Dalmatian coastal mountains of the Velebit, inland from Zadar, during Summer 1985. The aim was to supplement the survey work in the Zadar lowlands (see Chapman \& Shiel, this volume) by a consideration of the higland zone dimension. The main objective was a preliminary study and classification of the main types of sites and environment in the southern velebit. It is also necessary to study the lowland villages to which the highland zones relate. These villages lie in three main areas:-

1. the regions known as the Bukovica and Ravni Kotar, inland from Zadar.

2. the inland valley of the Lika.

3. the coastal strip further north known as the Podgorje.

These geographical areas are shown below (Fig. 7.1).

\subsection{GEOGRAPHICAL FEATURES}

The Velebit range forms part of the coastal mountains of Dalmatia and reaches a height of 1758 metres in the peak of Vaganski Vrh. These are arid limestone mountains integrated into the waterless karstic landscape which stretches from Trieste in the north down the Dalmatian coast to Kotor. Although so poorly provided with water, these uplands offer an essential seasonal supplement to lowland grazing and are still exploited by the coastal lowland communities. There are flat-bottomed dolina sink holes, providing shelter and humus on their floors, as well as a number of caves in the limestone.

The Velebit rises abruptly from the Adriatic coast. Ferocious winds can result from the ensuing temperature and pressure gradients. The strong cold northerly wind is called bura (cf. the Latin 'Boreas'); the southerly wind. or juga ('south') is dry and warm. Winds are often an 
important element affecting both prehistoric and recent patterns of settlement throughout south east Europe. When persistent and regional, such as these two, they can affect man and animals adversely. When localized, they may affect the location of individual sites. Because their influence is micro-climatic and varies seasonally, they are usually ignored as a factor in site territorial analysis.

The inland valley of the Lika drains internally into the karst, so that, by a quirk of drainage, areas of the velebit lie almost within the catchment of the Danube, the nearest point of which is $300 \mathrm{~km}$ inland at Vukovar. For example, Liscani Bunar / $/ /$ is a copious spring which drains towards the Lika, yet it lies only $8 \mathrm{~km}$ inland from the Dalmatian coast.

Direct access from the coast into the Velebit is provided mainly by two precipitous gorges, the Velika and Mala Paklenica. The Borišov Dom hut lies up the Mala Paklenica at $550 \mathrm{~m}$. At Knez̄evir above Boris̄ov Dom to the east are structures which include solidly-built stone cliff-houses as well as what is claimed to be the oldest house in the area (c. 400 years old). The area of these structures was probably a refuge during historically troubled periods on the coast. Above and east of the Velika Paklenica gorge, opposite the Manita Peć cave, is the hamlet of Jurlina (a hamlet named after that family and now inhabited by one person of that family).

Between the coast and inland ridges of the summit, there are one or two basins or polja, notably those of Veliko and Malo Rujno /2/ and Libinje, which is even less accessible. Both in the basins and around the upland sites, there are numerous stone structures attesting to the importance of these polja for more or less recent seasonal settlement and exploitation.

One route across the Velebit runs via the precipitous limestone steps of the Buljma pass at c. $1,400 \mathrm{~m}$, to the S̄tirovac hut at $1350 \mathrm{~m}$. This hut lies above a flat-bottomed polje in the forest and was formerly a stop-over for the trans-Velebit trading caravans going from the Lika valley to the coast. The easier main route is the Austro-Hungarian stone road built via Kraljevina Vrata and Mali Halan /3/.

\subsection{PREHISTORIC MATERIAL}

Mesolithic and other as yet sporadic prehistoric material has been recently discovered in the Velebit at, e. g., Vaganac and Jatare. Vaganac lies south of Pod Rujnom and south of the area of Veliko Rujno. Caves high in the walls of the Velika Paklenica gorge contain traces of prehistoric material (Forenbaher \& Vranjićan 1982). Their inaccessibility compares with that of some other sites in Yugoslavia, such as Odmut and Crvena Stijena in Crna Gora. There are successive prehistoric occupations in the lowlands around Zadar, suich as those of the Neolithic at Smilcic, Nin and Tinj, which presumptively or demonstrably could have incorporated the Velebit in their annual territories. 
Ethnoarchaeologically, three main patterns of seasonal movement into the Velebit have been established. These are outlined by the pioneering work of Arnold Beuermann (1967) and the intensive fieldwork of Tomo Vinscak (1983), both based on first-hand field studies. The remains of these seasonal mechanisms can still be found in operation. Their antecedents in the region include such historical human groups as the Bunjevci (Pavelie 1973), the Uskoci (Bracewell n. d.) and the Latin-speaking Morlachs to which this paper draws special attention.

The three patterns of seasonal movement are :

1. All along the coast of Velebit, the coastal villages used to move seasonally to the top pastures, with intermediate stopping points. Whole families with their livestock were involved.

2. From the Bukovica, north of the Ravni Kotar between Zadar and Sibenik, the Bukovic̄ani went up into Velebit (cf. Beuermann 1967). This movement now consists largely of a group of three families.

3. The Likanci came up from the inland Lika valley which runs parallel to the coast and they would continue over the Velebit to the Adriatic.

Given that the Bukovica is not strictly coastal, the Podgorje lies on the Adriatic and the Lika is virtually Danubian, we have here an exploitation of the same mountain zone by villages of three different zones (inland, coastal and foothill). Another remarkable variant on seasonality discovered in this season was that identical areas of the velebit are exploited seasonally on a shift basis both by the Likanci and the Bukovicani; one group moves out to allow the other up later in the summer. It also emerges (Vinscak 1983) that the very same mountain pastures may be exploited, on a strictly timetabled basis, during the course of one summer by villagers originating from the widely separated Lika and Ravni Kotar regions. One set of shepherds will vacate their stan (see above) half way through the summer so that the other may use its pastures. This is not a mechanism usually envisaged for prehistory; but the model could, for example, be applied to the exploitation of resources such as the prehistoric axe-factories in the highlands of Britain.

\subsection{DATA COLLECTION}

Data on many aspects of the technology, behaviour and seasonality of the sites was collected in the short preliminary season of the 1985 survey. The information sought included such questions as the number of Sheep, dates of ascent and descent, village of origin, plant use or cultivation at the site, the altitude, nature and extent of the pastures, types of other animals present, milking practice and products, form and function of material objects present, shepherding practices such as the daily timetable, dates of lambing, butchery and veterinary practice and 
use of salt.

\subsection{MATERIAL CULTURE AT UPLAND SITES}

Studies of material culture with adequate (let alone complete) inventories of the items at an ethnoarchaeological site are a very lengthy process; the discrimination of anachronisms, the assessment of survival rates and the attribution of assemblages to behavioural patterns increase the complexity of these studies. Since the Velebit season was a preliminary investigation, only certain details of the material culture were recorded. Some details are given in the site descriptions.

\subsection{SCALE OF PASTORALISM}

Up to the Second World War, the village of Jasenica alone had at least 20,000 sheep. By contrast, now it has c. 100 goats for milk and meat and c. 100 sheep. There is a much reduced overall total of sheep on Velebit nowadays, amounting to c. 5,000 sheep from all the villages. The number of stine (folds) is also presumably much reduced, to judge by the veliko and Malo Rujno area with its remains of ruined structures. It could be expected that the stine which do remain in use will be in the most favoured locations.

\subsection{CLASSIFICATION OF SITES}

Although outwardly simple, the upland sites of the velebit are in practice quite complex. This is very characteristic of such sites throughout south east Europe. A working classification has been evolved in the course of the fieldwork of the Highland zone Project. While it applies especially to the Romanian sites, those in the Velebit can be seen to fit into it. There are not enough sites still in operation for strict distinctions to be drawn between them. The classification is, in reality, a series of divisions imposed upon a spectrum of sites and it is doubtful whether strict divisions in the spectrum of functionally flexible sites are realistic.

In the Velebit, four classes of sites are known. These are, from the highest altitude down :

$\begin{array}{ll}1 & \text { the stina } \\ 2 & \text { the salas } \\ 3 & \text { the katun } \\ 4 & \text { enclosures }\end{array}$

The category of 'enclosures' (4) is necessary to accomodate a variety of structures. In its simplest form, the Highland Zone project classification is threefold:

1. the stina comprises relatively high altitude sites (such as Dusice, 
Oglavinovac or Marasovac, in the Velebit) where sheep dominate. In the Velebit, these sites are known as stani, but one treats the terminology with care because all seasonal upland sites tend locally to be called 'stan'. Similarly, in Romania, many people will refer to going to a stina, when the site they are visiting is in fact a salas.

The stan of the Velebit can be compared morphologically and functionally to the stine of the Carpathians. The regularities in shepherding practice are in fact remarkable and the linguistic peculiarities to which attention is drawn in this article offer some clue as to the processes of transmission of behaviour. Sheep, dogs and men (not women) predominate and there is no cultivation. But, in the velebit, families are also present, visiting the site in a capacity which is both functional and recreational.

2. The salas is represented by sites at medium altitudes where, while the sheep are important, there is also small-scale horticulture and women and children are regularly present. At the site of Vrh Prag, walled gardens called vrtaca are created in small pockets of soil among the limestone rocks and on the polja. The main crops grown are root vegetables and some Secale (rye). This may involve coming up to the highlands at a time when the stani are not occupied, in order to plant root vegetables for the summer occupation.

3. The katun corresponds to the hamlets of permanently occupied houses, singly or in tiny groups, at the upper limits of perennial settlement (e. g., at Meki Bunar or Nekica Kuca). These sites are more like high altitude farms, but include such functions as housing the maintenance man for the road across the Velebit.

The range of sites in this threefold classification are defined primarily not so much by their morphology (ground plan and elevation) as by their social composition and relationships and by the behaviour that takes place at them. Important questions include : the degree to which the sites were perennial ; whether and for what purposes is there cultivation; the frequency and nature of contact with the village base; the presence or absence of women and children, and how far this is recreational; the presence of animals other than the primary ones (e. g., sheep) for which the site ostensibly exists. As with other stine and katun sites, there are varying degrees of relationship to the perennially Settled agricultural villages in the Zadar lowlands, which were studied in 1985 .

The indicators for all these behavioural differences have to be sought at small sites which are morphologically often not very dissimilar. The archaeologist tends to deal primarily with the morphology and, in any Case, overwhelmingly with the material culture of his sites. For example, for many years ground plans formed the basis of attempts to explain the megalithic tombs of the European Neolithic. Ground plan alone will of ten not differentiate between a site in use as a stina and one in use as a salas. This highlights the nature of the archaeological problem of 
interpreting this type of highland zone settlement.

\subsection{PREDATORS}

In the Velebit, there are few predators on sheep, compared with areas such as the Maramures of northern Romania. There are probably only some 80 bears left in the Velebit, along with some wolves, wild boar (whose diggings have an impact on the pasture) and the highly venemous and aggressive poskok snake.

\section{$7.10 \quad$ DOGS}

Sheep-dogs are almost universal in south east European pastoralism, because of the presence of predators such as bears, or to guard against human interference. A surprising feature in the technocomplex of modern pastoralism in the velebit highlands is the effective absence of guard dogs. It is certain that prehistoric pastoralism would have been unsuccessful without the aid of dogs, and they must therefore be sought as one of its correlates.

The same behaviour can be observed among bears in both Romania and Yugoslavia. Bears rely on their strength, and are not easily deterred by a pack of dogs. They will break through any fence and come mainly at night, preferably in dirty weather when they cannot be so readily sensed by the dogs. Having carried off a sheep, they first drink some blood, then conceal the body in a pit covered with branches, coming back to eat more after several days. As mentioned above, there are said to be some 80 bears in the Velebit, but relatively few have acquired the taste for sheep meat.

The young dogs present at Dus̄ice Stan were not effective in a guard role. This may be in part because the velebit shepherds do not carry firearms (carrying arms is not allowed in Romania, where there are many more bears), in part because bears in Yugoslavia are not such a problem. Certainly, the strongly developed territoriality of the Romanian sheep-dog pack is absent.

By contrast with bears, wolves rely on stealth and speed, and may come at any time of the night or day. They can outwit the dogs, who are of ten afraid of them, and aim to consume as much of the sheep as quickly as possible, literally 'wolfing' their food. The wolf is not a problem in the Velebit.

\subsection{MATERIAL CULTURE}

The baking dome

'Testa, gastra, peka or cripnja'

It is of interest to find the continuation in use in the velebit of a method of baking bread which is attested from prehistory. This is also found in Romania, where it is known as the testa ('tsesta') or gastra an 
it is well known amongst the Sarakatsani of Greece. In the Velebit, the Croatian term is peka (the bread is 'pec̄enje kruha') and on the Adriatic islands cripnja.

It consists of a thick heavy domed lid of fired clay or pise : this is heated up in the hot ashes of the fire, which are then smoothed over. The dough is placed on the hot surface below the fire, and the lid placed on top and covered with ash. The bread rises underneath into a lentoid shape, asnd should be turned once to achieve the thick even crust which is one of its best features. The operation takes only about thirty minutes. The clay dome can be substituted with a metal lid upon which hot ashes are heaped, but this should not be confused with the Bedouin metal lid, upon the top surface of which flat pitta breads are baked in the Near East.

The baking dome is potentially detectable archaeologically. Convincing examples of it have been excavated at Nin from the local 2nd. Liburnian Iron Age, datable to the 5 th - 3rd centuries BC. It is recorded in south east Europe in the first decades of this century in the photographic records of Tache Papahagi (1928 - 34).

The peka was seen in use during 1985 at S̄tirovac hut and at Oglavinova Stan, and otherwise has been recorded by the Highland Zone Project only in Romania and among the Sarakatsani of the Pindus in 1977. A complete account of the prehistoric and ethnoarchaeological distribution of the artifact over south east Europe would be informative but this needs further study.

\subsection{FUNERARY MONUMENTS}

A type of ancillary funerary monument called mirila is found in the region of the southern Velebit (Troselj 1981-2). When a corpse is carried down from the mountains to a cemetery or churchyard for burial, it is set down at the point on the outskirts of the settlement where the procession comes in sight of the burial place. The custom of placing lighted candles beside the resting corpse is widespread in Yugoslavia. This last resting place, or pocivala, is marked by clearing stones from an area in the karst. Limestone slabs are laid down to form a paved area the size of an extended body, with a vertical headstone perhaps $30 \mathrm{~cm}$ high and usually a foot stone. Sometimes these stones are decorated. There may be several mirile side by side.

\subsection{RELIGIOUS FESTIVALS AND THE PASTORAL CALENDAR}

On Veliko Rujno, at the chapel of Sv. Bogorodica, a service is still held on the 15th August which is well attended by people from the stine and their related villages. The celebration of this feast in these particular circumstances by Catholic Croats at a highland site is as much a component of the pastoralist technocomplex as are traits of material culture or the enumeration by them of sheep in Latin. The 15th August is the feast of the Virgin Mary and is also celebrated in the orthodox Calendar by both the Romanian shepherds (Sfința Maria Mare) and the Aromani. The feast of the virgin is the major marker of descent from the 
mountains in the autumn, just as the feast of St. George (23rd April) marks the ascent in the spring. Although the actual dates of ascent and descent will vary locally, these are still significant dates in the calendar of pastoralism throughout south east Europe.

\subsection{COSTUME AND TEXTILES}

By contrast with some other areas, such as Romania, the distinctive embroidered regional and traditional costume seems to have been abandoned in the Velebit some two generations ago. But it was still possible in 1985 to observe some features of textiles and costume outside the museum context which may have special significance. As is often the case, it is in the sphere of transmitted female culture that some of the ancient elements are most persistent.

There is a very striking and close technical relationship between the high quality woollen blankets (ㄹebe) which are still made in the velebit and the identical cerga of the Maramures in northern Romania and those of the Aromani (Vlahs) of Greece. One type of Aroman blanket has become well known because it is propagated as a Greek tourist and export item. This is the one with a long, hairy pile, known as flokati. However, there are other types without this pile which are usaed in the home. The technical requirements and resemblances seen in this item are too close for there not to have been a common source of transmitted cultural tradition between the three regions. In this case, tradition is combined with practical utility to ensure survival; the blankets are light and warm and also have social and economic value for the family.

Several stages of manufacture are necessary to achieve the end product. Processes using water power are as essential as those of the actual weaving for the production and finishing of such woven items. One of these is tumbling in an artifical whirlpool (in Romanian, vrtiste or viltoare). There is an example of one of these water-powered mills in the southernmost Velebit at Roskki Slap, which is used for finishing the blankets.

Anklets (bic̄ve nazubci and, in Croatian bjec̄ve) are an item still woven in the Ravni Kotari lowland. They consist of a heavily embroidered upper part attached to a knitted stocking. Similar anklets are worn by the Sarakatsani of Greece. There are indications from such sources as figurine material that items such as anklets and aprons were components of prehistoric dress in south east Europe.

The kaban, a heavy cloak and hood worn by shepherds, and comparable to the kappa of the Aromani, was also used in the Velebit. Such items were probably transmitted in the same context of pastoral technology as the Latin enumeration of sheep.

The use of chain stitch on felt is a feature of embroideries in the Velebit. This particular tradition has analogies in the embroidery of the Sarakatsani of Greece, or the Padureni of Cerbal in Romania, but is probably insufficiently exclusive to postulate a connection without 
further study.

The women in the velebit used to wear aprons, which were abandoned in the course of the last two generations. These used to have high-quality woven designs which belonged to an ancient geometric tradition, comparable to those of the Romanian Banat. Good quality shoulder bags, or torba, are still made in a similar but more widespread tradition.

\subsection{POTTERY AND WOOD}

There are pottery-making centres on the island of Veli I $\bar{z}$ (see Carlton, this volume) and at Kaludjerovac near Gospic, while black reduced pottery is made at Ervenik.

Wood is still worked, especially at Zelengrad, Z̄egar and Jasenica, into items such as mallets, spoons, flutes and bowls and as components of musical instruments such as the guzla and the bagpipes. The extensive use of maple among other species may seem surprising for this karstic region; but the tree is still found, and may have been more widespread, in the lowlands. It gives its name javor to the village of Javornik.

For a number of these crafts, there must formerly have been connections over wide areas of south east Europe, leading to some of the technical and stylistic relationships which can be detected.

\subsection{ETHNOHISTORICAL AND LINGUISTIC DATA ON LATINITY IN THE VELEBIT}

The ethnoarchaeological work in the velebit, as is so often the case, incorporates an ethnohistorical dimension. One of the most important results from the fieldwork is evidence for the former presence in the region of an ancient Latin-speaking population, probably to be identified with the Morlachs.

The Morlachs were a Medieval population, whose name has now vanished but is historically attested from Dalmatia. They were Latin speakers and we can probably equate them with the Aromani (vlahs, Cincari) of the Balkan peninsula south of the Danube. Geographically close to the Velebit, there is a related Latin-speaking population, the $\mathbf{C} i \overline{c i}$ ('Chichi') of the Istrian peninsula, in particular the mountain of Uc̈ka (1396 m) west of Rijeka.

The evidence for Latinity in the Velebit, where Croat is the only language in common use, comes most strongly from the evidence for counting Sheep in Latin, and not in Slavonic.

It was confirmed during the 1985 fieldwork that, although the shepherds of the Velebit are Croat speakers, they still employ a system of Latin numerals to enumerate sheep. These are identical to the Romanian or Aroman numerals and so is the way in which the counting is done. The Sheep are counted in even-numbered pairs : 'Doua, patru, shase, opt, zeci $\because{ }^{\prime}$. The counting system continues with 'deset-doua, deset-patru ... dvadeset-doua ...'; i. e., from ten upwards, it is admixed with slav 
numerals, using 'deset' instead of 'zeci' for 'ten' in compound numerals. At Maras̄ovac Stan, the unintelligible word 'zhobi' was used for 'eight', 'shasto' for 'shase' and 'pato' for 'patru'.

This legacy indicates that the population from whom the present shepherds learnt the techniques of pastoralism were certainly Latin-speakers, and the probability is that these were their predecessors in the Velebit, that is to say the Morlachs.

There is a map dating from before the Turkish conquest of the region in 1527 which clearly shows 'Morlacha' in the area of the Velebit under study. A copy of this map can be seen in the library of the Franciscan monastery of Karin, situated strategically where the land route crosses the southern end of the Velebitski Kanal. The monastery also preserves a collection of Roman stones and inscriptions. Numerous Roman inscriptions from the whole region of the Velebit, along with other remains, were published early this century by Patsch (1900).

The procedures and practices of the Velebit shepherds are very similar to those of the Latin shepherds elsewhere in the Balkan peninsula. One might have argued that this simply indicaters common functional requirements and an indirect transmission of knowledge, but the linguistic evidence makes it necessary to postulate closer contacts.

In the Medieval archives of Dubrovnik, documentimng the extensive trade between the Vlahs and the port, Morlach and Vlah are accepted as synonymous. The Presbyter Diokleas, writing in the mid-twelfth century, says :

\footnotetext{
"Inde (Vulgarii) debellando ceperunt totam Macedoniam. Post haec totam Provinciam Latinorum, qui illo tempore (sc. 980-990 AD) Romani vocabantur, modo vero Morovlachi, hoc est nigri Latini vocantur."
}

This clearly defines Morlachs as Latin speakers inhabiting Macedonia and called Romani, lacking only the characteristic a-prefix of the Aromani. At the same period as this, Thessaly too was inhabited by Latin speakers and was known as Megali vlahia. Wace and Thompson (1914:257) allude to two districts of Morlachs in Dalmatia, known as Greater and Lesser vlahia; but these terms were also used for areas of overwhelmingly Aroman settlement in Greece (e. g., Thessaly and Acharnania). Tozer (1869:Ch. XVI) gives the explanation for the term 'Mavrovlachi' (Black vlahs) as derived "probably from the colour of their tents", and says it is used for the "Wallachs" north of the Danube.

The possibilities for confusion can be clearly seen in the ways that these terms were applied in distinct historical periods, and by different authors, for varying motives. But this in itself only accentuates the closeness of definition between these Latin speakers. We do not really 
know what became of the Morlach population of the Dalmatian area, but they are perhaps not so much of a mystery as supposed. The Morlachs of the Velebit were surely Aromani like any others, coming and going at various times according to historical expediency, and in their search for pasture.

\subsection{TERMINOLOGY AND TECHNOLOGY}

Transhumant pastoralism around the northern shores of the Mediterranean is remarkably strongly correlated with Latinity and with the former areas of extension of the Roman Empire. The countries in which it is practised, for good ecological reasons, are Romance-speaking : Spain, southern France and Piedmont, the Italian peninsula and north of the Danube in the former Roman province of Dacia and beyond.

When we come south of the Danube to the Yugoslav and Macedonian areas of Slav speakers, and to Greece, we still find that the shepherd populations are very strongly dominated by Latin speakers; the $\bar{C}_{i} i \mathrm{i}$ and Cincari (Vlasi) of Yugoslavia, ranging from Istria down the Adriatic coast into Macedonia; and in Greece, the Latin-speaking Aromani, who have made outstanding and largely unrecognised contributions to Greek civilisation and commerce.

The Aromani are the most important of these groups and the one to which the others are more or less strongly related. In turn, they relate closely to those other great exponents of transhumance north of the Danube, the shepherds of Romania. These speak a Latin language, mutually intelligible with that of the Aromani, and both of them embodying the closest posterity of provincial vulgar Latin. The Romanians in turn carried the practice of transhumance far to the north into central Europe along the high pastures of the whole Carpathian chain and into the High Tatras of southern Poland.

Both the technology and the terminology of pastoralism used by the Romanian shepherds of the Carpathians and by their counterparts the Aromani in the highlands south of the Danube are so well-defined and highly evolved as to indicate that they are part of an adaptation of great antiquity. As in the velebit, this adaptation forms the practical basis for most other highland zone pastoralism throughout the "Balkans" and among the Carpathian chain, as far north-west as Czechoslovakia and Poland, whatever the ethnicity of the groups involved.

In Romanian, the linguistic terms which it is least possible to dissociate from the highly evolved technology of pastoralism - such as stina for the sites themselves, and strunga for the narrow milking gate, with others such as brinza ('cheese') for the products, are of ten held to be older than the Latin substratum and to derive from the Dacian or Thracian terms. The term stan, derived from stina, is used in the velebit for the sites themselves, just as in Greece, where it becomes stani. Other terms, along with the technological practices and the material culture, reflect the same background of Aroman and Romanian pastoralism which are the most highly evolved exemplars of the type. At the velebit site of Dusice Stan, the occupants used the word struga (from the term for 
milking gate, strunga) to mean the site itself, although the site is one of the best-defined stine of the area.

\subsection{EMPIRICAL AND IMPERIAL SEASONALITY}

Both the Romanian and Aroman shepherds are Latin speakers. The marked association around the northern Mediterranean between transhumant pastoralists and the Romance languages is an economic as well as a linguistic legacy of the Roman Empire. The forms taken by pastoralist seasonality do not exist in Arcadian isolation but are closely conditioned by surrounding economic structures.

The strategies involved can be defined as Empirical or Imperial. There are certainly differences between an empirically founded seasonality, such as was practised in prehistoric times, and the wider-scale organisation of transhumance which emerges under Empires such as the Roman or Ottoman occupations of south east Europe. Under such Empires, trade barriers are lessened, the effects of frontiers are mitigated and large-scale markets are made available. One question is whether these differences are of a kind or a degree: whether they are truly antithetical or comprise the poles of a spectrum of behaviour.

In the Imperial case, it is possible to refer to trade; in the case of empirical seasonality, the economic mechanisms are socially embedded and it is inappropriate to speak of trade. The term "trade" is too loosely used in the prehistoric context, for example in reference to trade in stone axes. This usage fails to discriminate between surrounding social circumstances, which form part of the base essential to define the economic superstructure.

Hicks (1969) and Skydsgaard (1974) have both discussed the role of transhumance as an economic stimulant in the early period of classical Italy. Hicks considers the rise of the market in customary and command economies. Skydsgaard (1974:30) discusses the creation of demand in the course of this mobility and remarks that, since the transhumant calles (or tratturi) led from inhabited regions to uninhabited pasture, the ensuing economic stimulus was sporadic.

There is an important contrast to be noted here. The Aromani travelled very widely outside their transhumant network to Trieste, Odessa and Vienna to initiate trading possibilities for themselves, and flourished as muleteers then as bankers and merchants. These pecalbari were very different from the more recent Gastarbeiter in the way they created situations of prosperity and independence for themselves. This was a social initiative and a cultural solution, not one determined by the fact that they inhabited mountains and were pastoralists.

The mobility of pastoralists, both in prehistory and later on, and whether empirical or imperial, was an important mechanism, leading to :-

1. the transmission of ideas 
2. the redistribution of rare raw materials

3. the distribution of finished products

4. the archaeological distributions of the resultant material traits

It really is necessary to distinguish between all these, and not to lump them indiscriminately under such terms as "trade" or "seasonality". Even "mobility" has to be carefully defined and may be quite closely circumscribed by customary usages and social and territorial constraints, as much as by optimising economic strategies.

It is also apparent from ethnoarchaeological study of the Aromani and of Near Eastern pastoralists that seasonal pastoralism is an important social mechanism and not merely an economic one. The very act of transhumance, in particular when it involves whole families, contributes strongly to the social solidarity of the group.

\subsection{CONCLUSION}

It remains to carry forward this preliminary study on a comparative intra- and inter-regional basis and to integrate it fully with the lowland zone surveys. It is possible to compare the present situation with previous accounts, such as that of Beuermann (1967), as well as with material collected by the Highland Zone Ethnoarchaeology Project from all over south east Europe.

The southern velebit mountains are a surprising ethnoarchaeological enclave in the relatively modernised Dalmatian scene and still contain locally the richest variety of mechanisms for the exploitation of the highland zone. The mobility and well-developed intra-regional connections of pastoralists in south east Europe make it fruitless to study individual regions without being able to put them into the wider context. The work of the Highland Zone Ethnoarchaeological Project to date makes it possible to attempt this.

\subsection{ACKNOWLEDGEMENTS}

The fieldwork of the Highland Zone Ethnoarchaeology Project in south east Europe is supported by the British Academy; the Wenner-Gren Foundation for Anthropological Research; the Institute of Archaeology (University College London); the Central Research Fund and the Hayter Fund of London University; and the Society of Antiquaries of London.

The work in Dalmatia took place in close collaboration with J. Lulic, Director of the Narodni Muzej (Etnografski Odjel) Zadar and with the Neothermal Dalmatia Project co-directed by $\mathrm{Dr}$. J. Chapman of the University of Newcastle upon Tyne and Professor S. Batović of Universitet Zadra. Other institutions involved in the collaboration included the Obrovac Ethnographic Museum, the Ancient Monuments Institute of the 
Yugoslav Academy in Rijeka (Tihana Stepinac-Fabijanie) and the Ethnological Institute of Zagreb University (Dr. Tomo Vinscak).

\subsection{FOOTNOTES}

\subsection{APPENDIX OF SITES AND VILLAGES VISITED}

\subsubsection{Sites}

1.

\section{MARASOVAC}

At c. $1450 \mathrm{~m}$, between S̄tirovac Hut and the Buljma Pass. 800 sheep. Family of Petar (Peko) Lezaja, who also manages the S̄tirovac mountain hut with Stana Lē̄aja. Base village Zelengrad, zaseljak Lez̄aja; but descend to Bokanjac in winter.

2. DUS̄ICE

At c. $1400 \mathrm{~m}$, south east of the Sveto Brdo summit of the Velebit chain, which rises to $1751 \mathrm{~m}$. The main functioning stine of the southern velebit. Water is available $600 \mathrm{~m}$ away at Liscani Bunar; the well dug $100 \mathrm{~m}$ from the site dried up this year (1985). Duscie has 700 ewes, 200 lambs. Horses are used for transport. The dogs present are too young or small for guard functions. The family is Jurjevicí. Base village Krus̄evo. There are no goats since there is plenty of goat pasture at Jasenica village one shepherd plus one other, but four in all with boys and a girl of the family helping. Although they call the site a "struga", this is a true stina and there is no cultivation. Firearms were in use to scare off bears; sheep ear markings were punched out with the spent cartridges.

\section{OGLAVINOVAC}

At c. $1200 \mathrm{~m}$ in the basin of Oglavinovac NW of Javornik. C. 1000 sheep. Family of Breuli, 5 persons including one woman who has a separate hut. Base village Krus̄evo. Poor or non-existent water supply; wooden troughs are used to hold melted snow fetched from a distance. The Gastra or Testa is in use for bread making. Walking sticks of hazel bent using heat being made at the site. Plant use "sirc̄anje" - the roots are steeped in water or alcohol for 24 hours since they are held to be good for the heart.

\section{JAVORNIK (POLJE, STINA AND RUINS)}

At c. $1300 \mathrm{~m}$; "javor: means "maple", which is surprisingly common in this part of Dalmatia and is used for woodwork. The polje is two $\mathrm{km}$ long and lies to the south east of Oglavinovac and west of S̄tirovac. It is covered with ruined structures, houses and walls, especially at the eastern end. It is not clear whether these are former stine because they lie on the valley floor, not on the forest margin slope. They may have been partially horticultural. Semi-wild horses are 
pastured here. The poskok snake is common.

5. LIBINJE (POLJE)

At c. 800 - $1000 \mathrm{~m}$; extensive basin south west of Debelo Brdo and Dusice Stan. Some stine in operation and walled fields, with vegetables. Traces of extensive previous use of this sort. Difficult of access.

6. VELIKO RUJNO (POLJE)

The two large polja of Veliko and Malo Rujno (the greater and smaller 'ruins' of dry-stone walled structures) lie at c. $900 \mathrm{~m}$ and together total some six $\mathrm{km}$ in length from south east to north west.

On Veliko Rujno, there are extensive walls, enclosures and ruined buildings attesting to former settlement and seasonal exploitation. These structures recall the structures on the pastures of the Aromani at Metsovon in the Pindus, at the site known as "Imperatores". There are salt stones, i. e., stones devoid of lichen, upon which salt has been given to the sheep.

An anthropomorphic cross on the cornerstone of one of the huts near Sv. Bogorodica (see above) is of a form which may indicate Bogomil influence. Another structure was claimed to be a stone altar on which animal sacrifices were made until quite recently. It is supposed locally that there was an Illyrian settlement on the site, but there are no traces of it, unless it be in the rock-cut cisterns and drainage channels still used to catch the rain water. These are often the only source of water in this karstic area. To the west of Veliko Rujno, there is a huge rock which itself has been an object of worship, with a chapel beside it. Some of these features do recall the tendency of the Thracians in south east Europe (e. g., in the Romanian Banat, the Rhodope and Thrace) to create rock sanctuaries in high places where there are striking rock features.

7. VRH PRAG 1

8. VRH PRAG 2

9. VRH PRAG 3

The stina complexes of Vrh Prag lie at c. $950-1000 \mathrm{~m}$, in a complex area of limestone relief among the doline below Tulove Grede. The "Tulove Grede", which rise to $1120 \mathrm{~m}$, are the dramatic bare limestone peaks of the south eastern Velebit which overlook the Austro-Hungarian trans-Velebit highway running through Mali Halan to the Lika valley in the north.

Vrh Prag 1 is a complex comprising two families (Zvonko S̈arlija and one other), with pens, huts and walled gardens at the bottom of the Vrhprag dolina, below the Austrian road and west by north of Tulove 
Grede. It is manned by the women of the families and comprises both horticulture in the dolina and a wide range of animals, which is typical enough of sites with women in occupation. As well as the sheep, there are cows, mules, hens, a dog, goats, hares being kept in a hut and bees being kept to feed on the rich assortment of herbs and flora in the hollows of the adjacent limestone. Caraway seeds and other herbs are being grown. The gastra is in use in two cooking huts adjacent to the living hut and the mandra.

Vrh Prag 2 is the small stan of Nikola Maruna. It is located immediately above Vrh Prag 1 and to the west of Tulove Grede. The site lies at c. $1000 \mathrm{~m}$. An interesting crop grown here was raz̄ = Secale, grown in the vrtace for the purpose of stuffing mule saddles (called samara here, the same word as in Aroman) as well as mule fodder; however, there is so little of it that fodder is not a primary aim. This is one of several examples found during the Highland Zone project of Secale (rye) being grown in south east Europe at an otherwise pastoral site for a special purpose (e. g., at the goat mandra of Petrota in Thrace, it was grown specifically for thatching the mandra). The owner was also making axe handles at the site, having paid for rights to obtain the wood from the forest some distance away. This activity therefore gave no indication about the environmental resources at the site.

A feature which was open to misinterpretation by the archaeologist was a cup and ring mark on a boulder by the hut door. It consisted of a ring with a hollow in the centre surmounted by a cross. The maximum diameter of the ring vertically was $14 \mathrm{~cm}$, and the total height with cross was $27 \mathrm{~cm}$. Although the whole engraving looks significant, it was actually made by the son at the age of six years (in 1985, he was 13) to amuse himself. The cup is now used to give milk to a kitten; it appears to have no other significance.

Vrh Prag 3 Below the large Kapljuv sink hole at the north west end of Tulove Grede lies the upper stan of Vrh Prag, with extensive enclosures.

\section{MALI HALAN 1}

\section{MALI HALAN 2}

\section{MALI HALAN 3}

\section{MALI HALAN 4}

Mali Halan is a substantially-built Han or caravanserai, lying on a grassy polje just north of the summit of the pass, on the Austro-Hungarian highway which crosses Velebit between the Lika and the Ravni Kotar. A large cistern with a domed stone-covered roof is still in use, supplying the stine of Mali Halan $1-4$ with water. This is carried in tins on hor seback for perhaps a kilometre. The area around here is known as "Dacija" and was the former frontier 
between Dalmatia and Lika, where tolls were extracted from passing trade.

Lying in order of distance away from the pass to the south east are the stine:-

\author{
Mali Halan 1 \\ Mali Halan 2 \\ Mali Halan 3 \\ Mali Halan 4 Pavel Nekić
}

South of these is Cestarska Kuca, a house in perennial occupation on the road. Lower down, another house, called Nekica kuć, overlooks Vrhprag. Both of these would be classified as katuni. There are numerous remains of vrtace below these, for instance at Kraljicina vrata. The area is also used today for mobile seasonal bee-keeping, using lorries adapted to carry banks of hives.

14. MEKI BUNAR

Meki Bunar is a sink hole some $10 \mathrm{~m}$ in diameter, containing non-drinking water which is used for watering goats. There are houses in the lower polja, lying at or below $500 \mathrm{~m}$. These settlements already contrast with the stine in being perennially occupied and practising agriculture rather than horticulture.

15. NEKICA KUĆA

This perennially occupied house belongs to the same family as Mali Halan 4 (Pavel Nekic).

16. KRALJIC̄INA VRATA

Thee are also numerous vrtace in the doline north of the Kraljicina Vrata pass.

17. ZULJINA

Zuljina lies in the south eastern Velebit and has c. 1000 sheep. Base village Golubić. Family of Prso vlaica.

18. BUNOVAC

The stan of Bunovac has c. 500 sheep. Base village Krus̄evo. Family of Ante Vrkić. 


\subsubsection{The villages}

The villages in the Ravni Kotari (Zadar Lowlands) which can be related to the sites in the Velebit are as follows :- Jasenica, Posedarje, Krus̄evo, Zaton, Z̄egar, Zelengrad, Medvidja, Golubić and Bokanjac.

\section{$\underline{\text { Jasenica }}$}

The annual movement of animals from Jasenica on 23rd April (St. George's Day) was onto the lower slopes of the Velebit. On their return in october, they went beyond the village down to the coast. The village is favoured with good pasture only $600-700 \mathrm{~m}$ distant, and fields in which potatoes, green vegetables, cabbage etc. are grown but not wheat.

At Jasenica, as at other villages in the Zadar lowlands, several kinds of structures associated with animal husbandry can be observed :-

TOR is the term used for sheepfold. Sheep dung is cleared out of the tor; the tor is not moved. As is the case elsewhere in south east Europe, it is usually situated on a slope for drainage.

SJENICA is a round dry-stone structure roofed with branches, which is used as a sheep shelter during the summer, near but a little distance away from the village. A tree may be used as a centre post and, here too, small brushes made of plants are used to clear out the dung.

JARA is a rectangular structure located within the village, close to or even part of the houses, which is used for sheltering sheep in winter. Shingles of beech wood up to $1.30 \mathrm{~m}$ long may be used to roof the jara, which has an enclosure behind it called the pritorak. A cross within a circle is made in sheep's blood on the door of the jara and sometimes on the houses themselves (this was observed by J. Lulic at Easter 1984 in Slivnica). Animals may be held in the jara over winter, or equally under the first floor living rooms. Horses and goats may be stalled together, but not horses and sheep.

\section{Bokanjac}

In winter, the stine of Maras̄ovac, Oglavinovac and Bunovac go down to katun sites at Bokanjac near the Adriatic, in the suburbs of Zadar. They descend c. 8th September and go back up in late June the following year. 


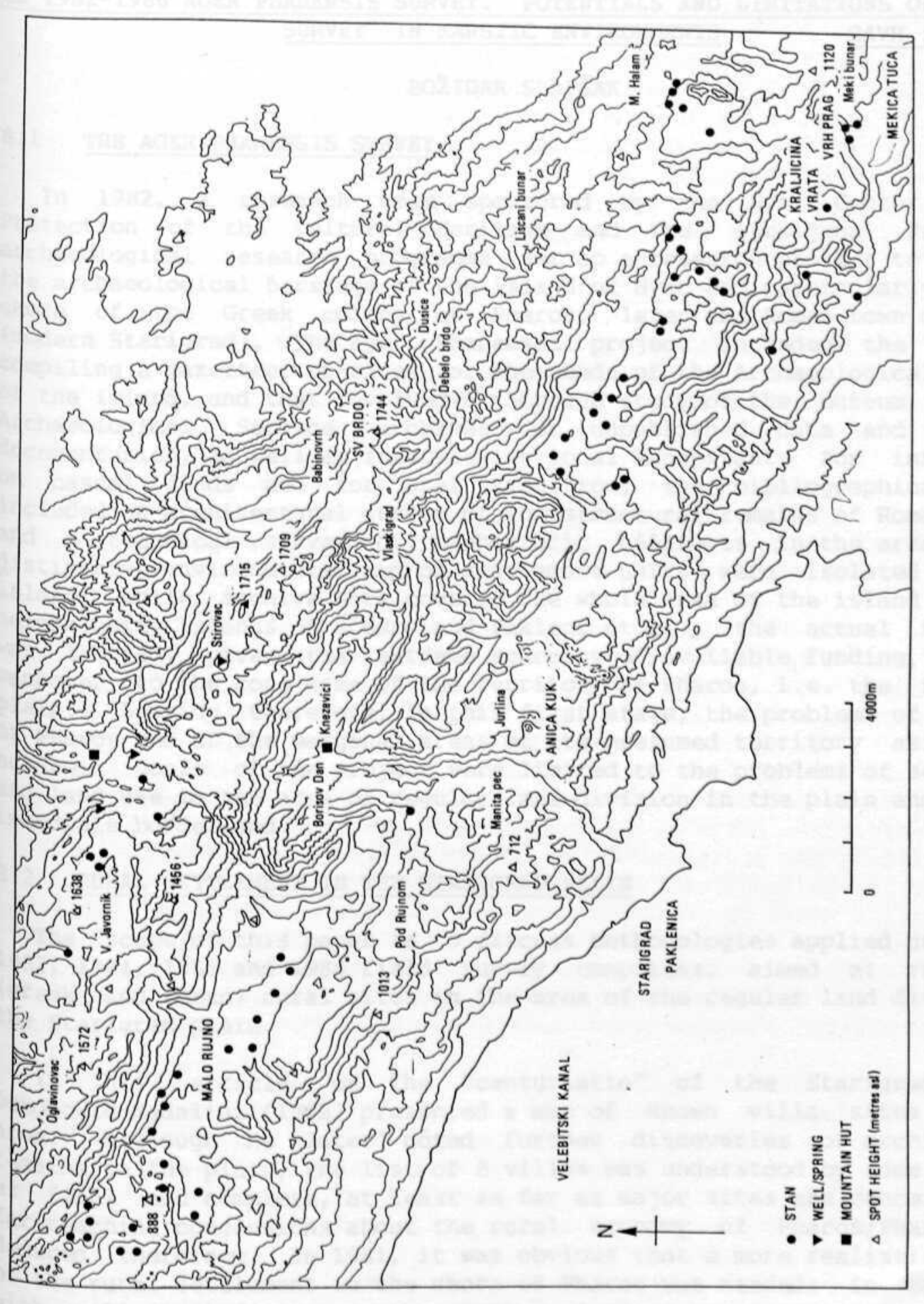

Figure 7.1 Map of southern Velebit Mountains, Yugoslavia. 
PART TWO : HVAR 


\section{CHAPTER EIGHT}

THE 1982-1986 AGER PHARENSIS SURVEY. POTENTIALS AND LIMITATIONS OF "WALL SURVEY" IN KARSTIC ENVIRONMENTS

\section{BOZ̄IDAR SLAPS̄AK}

\subsection{THE AGER PHARENSIS SURVEY}

In 1982, a research team sponsored by the Hvar Center for the Protection of the Cultural Heritage and the Ljubljana University archaeological research programme set up a research project to evaluate the archaeological heritage of the island of Hvar and particularly of the chora of the Greek colony of Pharos, later the Roman town of Pharia (modern Starigrad). The Ager Pharensis project included the task of compiling a gazetteer of sites for the needs of the Archaeological Service of the island, and that involved a thorough study of the museum and the Archaeological Service archives for unpublished data and original documentation, as well as interviewing local inhabitants for information on casual finds and for oral tradition; the bibliographical survey included an architectural survey of the structural remains of Roman villas and a technical survey of prehistoric hillforts in the area. Eight distinctive environmental and/or settlement units were isolated on the island; while archive work covered the whole area of the island (and the neighbouring islands of S̄cedro and Pakleni otoci), the actual fieldwork was limited, given the extreme scarcity of available funding, time and manpower, to the core area of the territory of Pharos, i.e. the Starigrad plain. Leaving therefore, in this first stage, the problems of the town of Pharos and of the marginal areas of its presumed territory aside, the academic goals of the project were limited to the problems of settlement and land use in the area of regular land division in the plain and in its immediate borderland.

\subsection{RURAL SETTLEMENT IN THE STARIGRAD PLAIN}

The scope of this paper is to discuss methodologies applied during our 1982, 1984, 1985 and 1986 field survey campaigns, aimed at recovering (greek and roman) rural sites in the area of the regular land division in the Starigrad plain.

In his article on the "centuriatio" of the Starigrad plain, Duboković-Nadalini (1962) presented a map of known villa sites in the area. Although he later noted further discoveries of architectural remains in the plain, the list of 8 villas was understood by some scholars as final and complete, at least as far as major sites are concerned, and far-reaching conclusions about the rural economy of Pharos/Pharia were deduced therefrom. In 1981, it was obvious that a more realistic picture of the rural settlement in the chora of pharos was needed: in comparison with well-studied areas, the number of sites was unconvincingly small, especially if we take into consideration the time-span and possible developments in land-ownership; furthermore, no reliable data on diachrony was available and the relationship between rural settlement and land 
division remained largely unexplored. It was felt that there was a vast potential for the study of greek and roman rural settlement and land use in the territory of Pharos.

We therefore proposed to explore the possibility of recovering, through the application of archaeological field procedures, a (near) complete network of rural sites, hoping to be able to collect thereby also enough functionally and chronologically diagnostic portable finds on single sites to enable us to consider the structure and development of the overall agricultural settlement there. An adequate survey methodology had to be decided upon to fulfill these aims.

\subsection{THE 1982 BIBLIOGRAPHIC SURVEY}

In an initial phase of the 1982 campaign, the known sites in the plain were revisited, to be located on the 1:5,000 maps, and standard descriptions were made thereof; local people, including the owners of the landplots in question, were interviewed and information about previous discoveries and finds was checked and controlled. The main purpose of this bibliographical survey, however, was to study the state of preservation, surface visibility of the structures, post-depositional changes through cultivation and agricultural terracing and the distribution and densities of pottery and ceramic building material.

The result was a series of observations which, although pre-methodical in a way, were not based on formal procedures to be applied to a sample of the area under regular land division:

- all landplots where roman building structures have been identified have been subject to major transformaition through subsequent intensive Mediterranean-type agricultural land use.

- far from being uniform over the whole area of the site, the preservation of the structural parts of the buildings is markedly differential: parts of the building are preserved astonishingly well, buried under clearance cairns or inside terraces; structural remains may be re-used and included in the terrace walls or retaining walls of other clearance features; cisterns may be re-used or adapted as reservoirs of water for agricultural purposes; on the other hand, on the surfaces under cultivation, original levels may be completely lost, walls (including foundations) destroyed, all archaeological residues being contained within the topsoil.

- in a typical situation, the vast majority of small finds will be found on the clearance features; in cases of low ground visibility, archaeological material may be traceable on clearance features only.

- small finds surface distributions seem to be rather anomalous; clearance features will incorporate larger pieces of ceramic building material and some categories of pottery (amphorae, pithoi) at some distance from their supposed original position.

- field surface visibility varies from one landplot to the other considerably as a consequence of differing actual land-use (vineyard, lavender, olive trees) as well as of a high percentage of abandoned land. 
In order to gain initial information on the density and variety of archaeological sites, we decided to apply an intensive survey procedure on a sample of four 1 x 5 stadia land division units in an area where no sites had previously been identified in the central part of the plain. The observation, during the survey of the known villa sites, that the vast majority of portable finds was to be found on the clearance walls and stone heaps prompted the decision that all such features should be checked in totality. The field surfaces however were walked at 5 -meter intervals so that a sample of $20 \%$ of the total surface was covered. The area was walked by field plots, inside the grid of the ancient field system (1 stadion units). The orientation of traverses was adapted to the field situation on each plot (vineyard rows, terraces). Finds were numbered and plotted on a copy of the cadastral map; if continuous, they were numbered and plotted by units of $20 \mathrm{~m}$ at most. Off-site and low density finds were totally collected, while in the obvious on-site situations the site area was plotted and only diagnostic finds collected.

A total of 59 scatters or single small finds was recovered, of which 46 were on clearance features (these comprise over $90 \%$ of the collected finds). Two villa sites with standing building structures were found and another 4 located with certainty through spatially well-defined high density scatters of building material (imbrices, tegulae, mortar) and pottery (amphorae, pithoi). A number of scatters however remained unexplained. No pre-roman material or discrete post-roman sites were identified.

The 1982 intensive survey raised a number of questions concerning possible interpretations of the partially quantifiable distributions. On the other hand, the apparent success of the survey in identifying "villa sites" tended to conceal methodological flaws in the procedure. Poor Performance of the survey team on surfaces other than clearance features meant that our attention concentrated more and more on these. In fact, a Simplified time-and-laboureffective-procedure was proposed, limiting the Survey to these features only. Its goals were limited, it was understood as a locational device for the category of sites as found in 1982. This procedure was applied in 1984 and 1985 to cover more extensive areas in the Starigrad plain.

8.5 THE 1984-1985 WALL SURVEY

During the 1984 survey, $20 \%$ of the overall surface of the Starigrad Plain was surveyed. A total of 32 "villa sites" was recovered. The same System of numbering and plotting was applied as in 1982, but using the new l:5,000 maps. Scatters which did not fit into the "villa" scheme were not studied further.

The rationale of the wall survey is very simple. It is assumed:

that the choice of archaeological material normally found on the clearance walls (building material, storage containers, amphorae) is 
indicative of the presence of a villa site.

- that it is unlikely that such material, given its considerable size, was indicative of any other activity (manuring).

- that its original position in the archaeological context is unlikely to be more that $30 \mathrm{~m}$ away from its actual findspot.

- that the wall and other clearance surface display close to 100\% surface visibility.

- that the wall surfaces have a constant input of new archaeological material from cultivated land, together with cleared stone.

- that in the majority of cases, the villa-specific material will be found prevalently (or exclusively) on the wall surfaces.

- that in the case of low field surface visibility (meadow, olive trees, abandoned arable land) walls and stone-heaps may be the only places where any surface archaeological material can be expected at all.

Typical wall assemblages (ceramic building material, pithoi, amphora) would therefore, even at relatively low densities, be understood as indicative of villa sites. This evidence can be used directly at an initial level of the study of villa settlement and rural settlement and landholding. Intensive procedures, including total collection on the field surfaces and on the high density wall scatter surfaces, and the sub-surface survey (Bintliff and Gaffney, this volume), will be essential to control these initial indications and provide reliable information on the sites, together with standard descriptions of them.

\subsection{THE 1986 SYSTEMATIC WALL SURVEY}

In 1986 , for the first time, the project was able to employ a properly manned survey team. We decided to stick to the slightly modified 1982 procedure of a $20 \%$ unstratified random sample of the area under regular land division. The survey units were the 1 × 1 stadion greek cadastral units ( 72 of the total of 390 units). In 1986, we were able also to use, for the first time, the aerial photographs of the area. The finds were plotted on $1: 2,000$ photograph enlargement transparent overlays. A total of 23 "villa sites" was identified (see Bintliff and Gaffney, figure 9.2), of which several had been known before (1982, 1984 and 1985 surveys). The total number of scatters (or single finds) registered is 207, of which 185 are on clearance features.

\subsection{CONCLUSIONS}

We would maintain that, as a site-oriented locational strategy, the wall survey proved its validity in karstic environments under intensive agricultural land use. In such environments, which normally abound in clearance features of all kinds, it is a time-and-labour-effective method of recovering at least one specific category of site, namely the rural architectural complexes, farmhouses and villas in the greco/roman context of the territory of Pharos. Additional interest in wall and other clearance features in the Mediterranean comes from the fact that they of ten represent very old land division features, of greek origin to a certain degree in the case of Pharos, and are to be studied as archaeological structures as well. 
On the other hand, the limitations are considerable. Besides those deriving from the very definition of the wall survey as suggested above, there are specific problems like quantification which, although not unsurmountable, have not been satisfactorily resolved.

Field surface survey, as carried out parallel to the wall survey in 1982 and 1986, however, is much more problematic and is not up to the standard of modern systematic surveys. Poor performance of our team in recovering background material, although partly due to unfavourable surface visibility conditions during the field season, is to a large degree due to the team's confidence in wall information (over $90 \%$ of total small finds in 1982), in the framework of a site-oriented strategy, and therefore reflects a lesser input of methodological effort in the complementary surface survey. Landscape and off-site survey did not enter the horizon of our interests during the 1982-86 work and no direct information for land use other than settlement was expected from survey data. Also, our survey was basically period-oriented and although data on other periods were hoped for and collected, it was primarily designed for the recovery of one specific type of archaeological information.

A combined strategy, using the potentials of both extensive survey procedures on the field surfaces (Bintliff and Gaffney, this volume) and of the wall survey, especially its advantages in the low- and zero-visibility area of non-intensive land-use and on agricultural land plots, would seem to be a promising compromise and a welcome improvement to the performance of the Hvar survey in critical areas. We would suggest, however, that it may also prove to be a more generally useable procedure in the karstic environments of the Mediterranean. 
CHAPTER NINE

THE AGER PHARENSIS/HVAR PROJECT 1987

JOHN BINTLIFF \& VINCE GAFFNEY

\subsection{THE AGER PHARENSIS SURVEY - JOHN BINTLIFF}

In the summer of 1987 a team from Bradford University collaborated with a team from Ljubljana University in the first season of an intensive survey on the Dalmatian island of Hvar. The field survey was jointly directed by John Bintliff (Bradford), Vince Gaffney (Bradford/Ljubljana) and Boz̄idar Slaps̄ak (Ljubljana).

For the British participants, it soon became clear that, even from three weeks' experience on Hvar, the island's history and prehistory are remarkably rich, offering ideal opportunities for archaeological research (Figure 9.1). Even the known monuments are sufficiently well-preserved and understood to be a resource of which the inhabitants of the island are proud, and the educated tourist soon made aware. These include the later prehistoric burial tumuli (gomile) and hillforts, the caves with Neolithic occupation, the remains of the ancient Greek colonial city of Pharos under medieval and modern Starigrad (such as the city wall). Recent excavations at pharos suggest that the local Illyrian population were already receiving Greek imports well before the arrival of Greek settlers in the 4 th century BC. Most impressive but less well-known are the truly remarkable (on a European scale) land divisions preserved since the days of the Greek colony, in the plain forming the hinterland of Pharos/Starigrad - a giant regular grid of stone walls marking the way the land was divided up amongst the greek colonists when they first cultivated the plain.

This system has already been the object of careful study by our Yugoslav colleagues (Slapșak, this volume), who have discovered traces of a whole series of Roman villas scattered across it (Figure 9.2). After an absence, hitherto, of monuments recording the early centuries of settlement by the Slavs, all the island's towns and villages reflect in a most impressive fashion the island's participation in the Croatian Renaissance (magnificent churches and private houses). More recently, chiefly after incorporation in the early 19 th century into the Austro-Hungarian Empire, a great boom in the export of the island's wine led to a new phase in the land use history of Hvar, when a phenomenal amount of new terrace building covered the island, even in the remotest and steepest limestone country.

This rich history and cultural heritage is an excellent basis for archaeologists and historians to try to uncover the how and why of these great achievements of the island's population. The initial approach adopted by the Bradford/Ljubljana team during 1987 was to begin an intensive field survey of the fertile hinterland plain lying behind ancient Pharos - hence the 'Ager Pharensis Survey'. Whereas in excavation 
archaeologists concentrate on a particular place where they have reason to believe there was an ancient farm or village, and proceed to dig it up, in field survey we are really trying to map out the whole pattern of settlement for particular periods of the past, from the earliest times up to today. From such a map, and the information about each settlement discovered, we can try to reconstruct the changing picture of population and agriculture, and the effects of social and political changes over hundreds and even thousands of years.

The specific form of field survey we adopted for the Hvar Survey is intended to be very thorough and exhaustive (both in cover and in physical effort!). Basically teams of student and staff fieldwalkers walk across all the fields in a particular sector of the landscape, spaced $10 \mathrm{~m}$ from each other and proceeding in straight lines from north to south and back. All the time, these teams are looking carefully at the ground to monitor all surface finds of ancient, medieval and early modern pottery fragments as well as occasional artefacts of other material, such as glass and metal. Every piece thus observed is counted on a manual device or 'clicker' and kept for further study back in the pottery laboratory.

Such work is relatively slow, and indeed in a three week season we only managed to fieldwalk completely some $1.5 \mathrm{sq} . \mathrm{km}$ in the central part of the great Pharos/Starigrad plain (Figure 9.3). However, the data thus collected sheds light on more than one important aspect of earlier settlement of the island.

First, dense concentrations of pottery on the surface, especially on particular stretches of field walls where farmers have thrown them, show us the main settlements of the past such as the numerous Roman villas. Secondly, outside and between these sites we find a continuous scatter across all the landscape of pre-modern pottery, which should reflect the activity of past farmers in their fields, chiefly via their practice of manuring using household rubbish with a high content of discarded potsherds (Figure 9.4). So we can find both the places where people lived in the past and the areas where they concentrated their agricultural activities at different periods of the past.

An obvious contrast revealed by our studies and previous work by our Yugoslav colleagues on this landscape is that, whereas since the Middle Ages, the inhabitants of this part of the island have lived in villages around the plain (cf. Figure 9.2), in Greek and Roman times, apart from the town of Pharos, most of the remaining population lived in farms and villas in the countryside. These often very impressive establishments were frequently located on the Pharos/Starigrad plain, as well as beside natural harbours such as that now dominated by the medieval/modern village of Vrboska.

In general, ancient sites found by field survey are not excavated, the main aim being to document the overall history of settlement over large areas. One can actually get most of the information one needs for this study from the careful and scientific study of the remains visible today on the surface. 
In the case of the Hvar Survey, once a pre-modern site was recognised in fieldwalking, a grid or network was laid progressively across the suspected settlement zone, using 2 -metre ranging poles in sequence. In each unit of the grid, or 10 by 10 metre 'cell', we collected all the pottery from the surface and counted it. Only with large tile fragments were samples selected from the total count observed, owing to the logistical problem of transport of such heavy items. When the numbers of pot dropped off into background levels in all directions, we could suspect that this indicated the edges of the settled area. Subsequent analysis of the pottery back at base will enable us to state in which periods such sites were inhabited and, if more than one period is involved, which parts of the site were in use at particular times.

I shall now present preliminary results from three of the four ancient sites studied in the 1987 season. The diagrams will display :- (1) the raw counts of pottery taken in fieldwalking that helped to indicate the site's presence in the first place, and (2) the counts obtained from grid sampling across the suspected site. An important approach to introduce here is the concept of a visibility filter. Since vegetational cover and degree of agricultural disturbance vary greatly from field to field, even within a single site, the amounts of ancient material visible on the surface can be expected to vary correspondingly. For this reason both in ordinary fieldwalking and in site sampling we estimate surface visibility for each transect or cell, respectively, from which the raw pottery can be recalculated to make allowance for visibility distortions. As our visibility range runs from 0 to 10 , we currently use a simple multiplier of raw counts to compensate. An additional technique which was widely operated on the 1987 Hvar season was the use of a large petrol-driven drill; the regular drillholes across our sites allowed direct testing of the pottery content of the topsoil and subsoil, to set against the varying amounts visible on the surface. Results from this technique for PHAROS SITE 3 will be discussed by Vince Gaffney (see below).

Of the four sites studied in detail during the 1987 survey, all are rural farm sites but of widely differing proportions and importance. The first site discovered, PHAROS SITE 1, was a small farm tentatively dated to the Greek Hellenistic era and conceivably the kind of family farm the average colonist from Greece was given in the initial land allotment (Pigures $9.5 \mathrm{a}, \mathrm{b}, \mathrm{c}$ ). Our study suggests it is only about 20 by 30 metres, in fact a fraction of a hectare, in area.

Our second site, PHAROS SITE 2, is totally different, and may prove to encapsulate in its contrast to Site 1 a great social and economic change that could have taken place between early Greek and Roman Imperial times. It is a giant Roman villa, doubtless the centre of a large estate that may have utilised many slaves or labourers. It covers some 1.25 hectares, which is about half the size of the estimated area of the Greek colony of Pharos (from traces of its walls still preserved) (Figures 9.6a,b,c).

PHAROS SITE 3 is another very sizeable Roman villa, and since particular attention was paid to this site, including rescue excavation both during our field season and subsequently, I shall leave discussion of 
it to Vince Gaffney (see below). PHAROS 4 is a small farm, whose exact chronology awaits detailed examination of its pottery, although it also belongs to Greco-Roman times. Within its some 0.25 hectare extent, surface finds included a loomweight, the kind of evidence of importance in suggesting that people actually lived through the year on their farms, rather than using such small establishments merely as storehouses in the vicinity of their fields (Figures $9.7 a, b$ ).

Looking ahead to what we hope will be a long-term survey project on Hvar, from the 1988 season onwards we would like both to continue the detailed, field by field survey of the pharos plain with its remarkable stone land divisions (Stančic \& Slaps̄ak, this volume), and at the same time extend our investigations into the origin and development of the Slavic villages that surround that plain - the earliest known settlements of the post-Roman period. Our aim here is to trace the way that population and society developed from the arrival of the slavs in Dalmatia, during the 7 th century $A D$, when they mixed with the local Illyrian and Greco-Roman inhabitants as a newly-dominant culture, up to the great flourishing of the medieval communes of Hvar island 600 years later, from the 13th century $\mathrm{AD}$ onwards - Hvar's 'Golden Age'.

\subsection{INVESTIGATIONS AT THE JEZ̄E VILLA (PHAROS 3)}

\section{Vince Gaffney}

The third site surveyed by the project team was that of the suspected Roman villa of Jez̄e. The area surveyed is situated at the head of a small inlet about 100 metres to the west of the modern village of Vrboska (Figure 9.8). Although the area of this particular site was not actually included within the survey area, the decision of the local authorities to permit the construction of a road through the known site prompted a survey of the area to record the extent of the site prior to destruction. The results from Jez̄e are worth considering in slightly more detail than other sites surveyed by the project team as work on the finds is at a more advanced stage.

The site was surveyed extensively, intensively and using the sub-surface strategy described above. The relative positions of the grids used for each technique are shown in figure 9.9. A total of 5.67 hectares was surveyed using the extensive survey technique. This survey produced 1531 artefacts, the majority of which were ceramic. Figure 9.10 gives the results of this work. This illustration shows the concentration of archaeological artefacts towards the centre of the surveyed area.

The information provided through extensive survey was then used as the basis for the positioning of the intensive surface survey which covered the core of the site; a total of 0.68 hectares was walked, and 4541 artefacts were recorded. The majority of the finds were ceramic: mainly tile, pithos or amphora. However, a small amount of painted wall plaster and mosaic pavement was also recovered. 
Figure 9.11 displays the distribution of artefacts collected through intensive collection. It is apparent that it tends to confirm the pattern displayed by the extensive collection. The core of the site appears to extend to south and west. The northern area of the grid shows a marked decline in artefact density with a very slight scatter in the central northern area.

However, the results from the sub-surface drill survey over the central and northern intensively surveyed area contrasted significantly with those produced through intensive survey. During this survey a total of 75 test boreholes were drilled using a "Tomos" petrol powered posthole drill. This machine, which is fitted with a bit of $20 \mathrm{cms}$ diameter was used to drill small test pits up to 70 centimetres deep at set intervals on the grid used for surface collection. The test holes were manually emptied and the residue sorted, all archaeological artefacts being retained. The depth of the test pit is measured allowing a volumetric assessment of the pit's artefact content. This procedure is useful as it allows direct comparison of the data from each pit by standard volume.

A total of 2445 archaeological artefacts were recovered from these boreholes. When corrected volumetrically, figures of over 10,000 artefacts per cubic metre were recorded. Again, the majority of material was ceramic, although tesserae, glass, iron slag and mortar were also recovered. The volumetrically corrected distribution is given in Figure 9.12. Comparison of these corrected results with those from intensive survey shows a number of discrepancies. The northern edge of the site, far from being almost devoid of archaeolgical activity, is shown to be a principal focus or at the very least a continuation of the concentration recorded further south by intensive survey. Distributions of mortar and tesserae (Figure 9.13) also indicate that the area at the north seems to be the position of what may have been a substantial building. The presence of a structural wall within a stone heap adjacent to the sub-surface artefact scatter would appear to be confirmatory evidence for the putative building.

Given that all the survey techniques used at Jeze produced useful general information on site location, how should we interpret the apparently contradictory spatial evidence produced by intensive and sub-surface survey? One approach to this problem is by a more detailed consideration of the source and nature of the surface artefacts. At a very early point within the 1987 season survey, the team realised that a very large quantity of material was being recovered from the stone heaps and terrace walls. Consequently a decision was taken to record the quantity of material collected from these features by individual recording unit. Retrospective analysis of the Jez̄e surface data reveals that no less than $48 \%$ and $58 \%$ of all artefacts were collected from stone clearance features during intensive and extensive collections respectively. This is a disturbing figure when it is considered that these walls and heaps, which are the product of field clearance, cover a maximum of only $10 \%$ of the survey area. All the indications are that the intensive agricultural practices used on the island have resulted in an extreme dislocation of at least $50 \%$ of the surface data. It is no surprise that the majority of the 
material found on stone heaps is tile, pithos or amphora. All of these are bulky artefacts which would tend to be cleared along with stone. Finer materials, glass, fine pottery etc. presumably attract less attention from workers involved in field clearance.

It is quite clear that the surface assemblage at Jez̄e is not simply the result of fossilized ancient occupation activity and that the apparent spatial patterning also reflects, to some degree, the pattern of cultivation. Partly as a response to this problem, a trial excavation on the route of the proposed road at Jez̄e has been undertaken with the deliberate intention of providing quantitative evidence on topsoil artefact content and its relationship to survey and stone heap ceramic assemblages (Bintliff et al. in prep). The trench at Jez̄e has already provided clear evidence for the impact of terrace formation and vine cultivation upon past and surviving archaeological stratigraphy and, as quantitative information upon the nature of the ceramic assemblage becomes available, further insights into the nature of assemblage bias will be provided. 

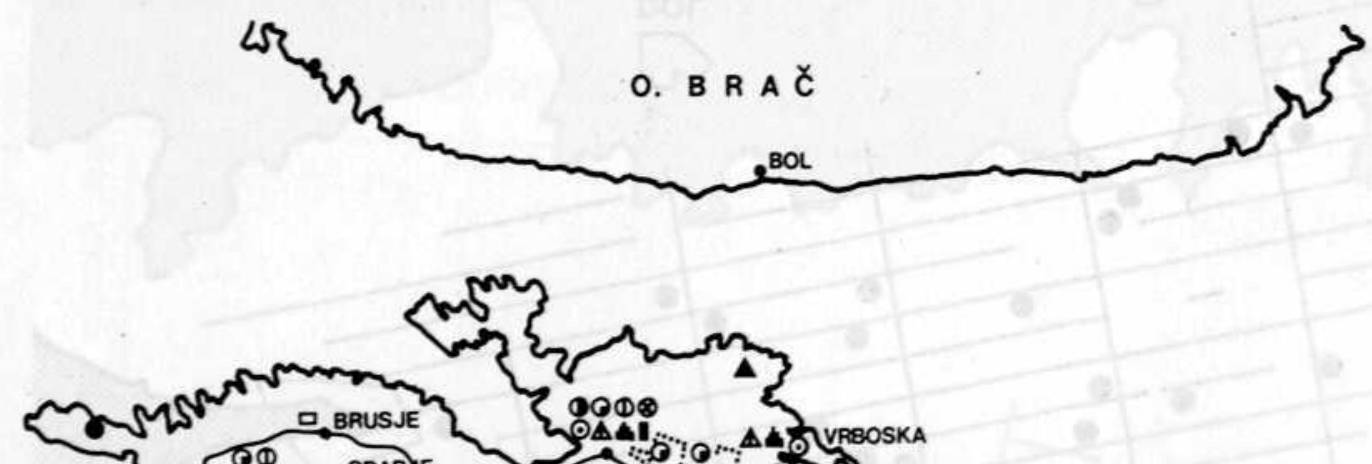

- Prehistoric monuments

- Illyrian monuments

- Greek monuments

:-: Greco-Roman land division

G Roman monuments

(1) Early Croatian/Slav monuments

8) Romanesque monuments

$\odot$ Monuments of Gothic, Renaissance and Baroque

14th century fortifications

ath century fortications

$\triangle 16$ th century harbours

- 17ther residences 16 th - 19 th centuries

- Principal artistic monums.

Houses fortified against pirates

$\Delta$ 19th century harbours

19th century fortifications

Outstanding ethnographic monuments

HVAR

Information supplied by the Tourist Bureau, Hvar
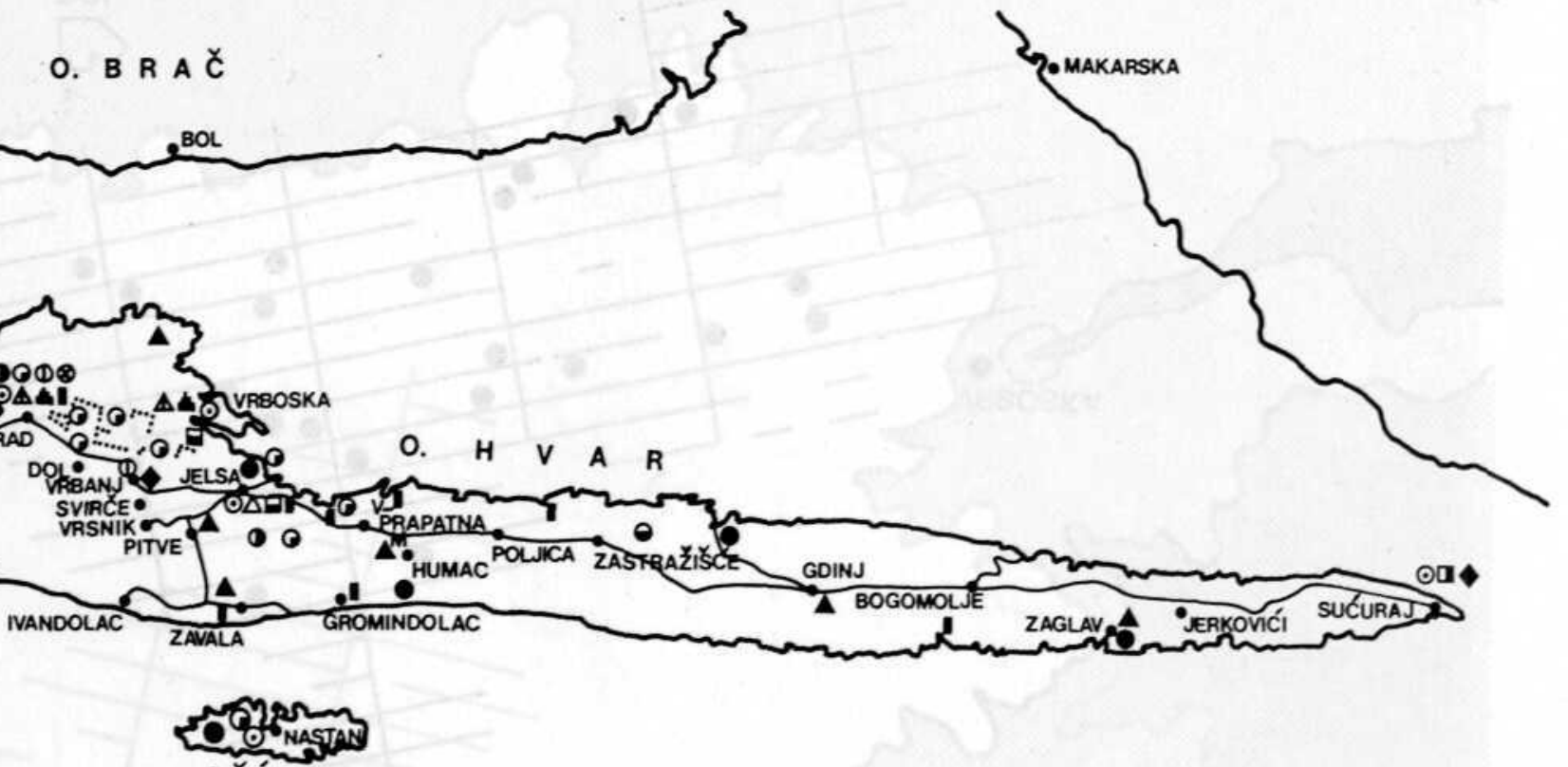

O. ŚCEDRO

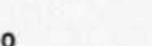




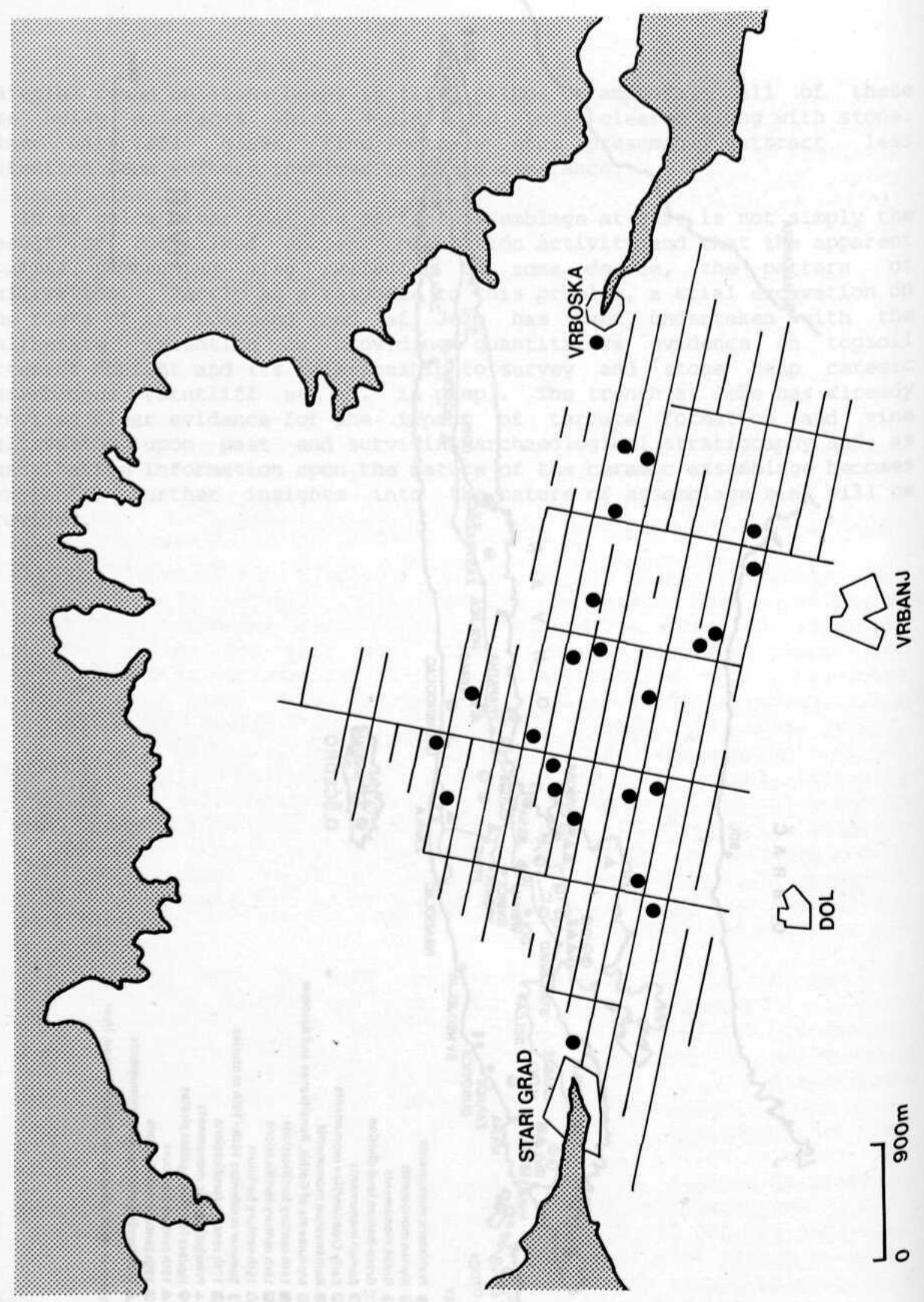

Figure 9.2 The Ager Pharensis land division system with known Roman sites. 


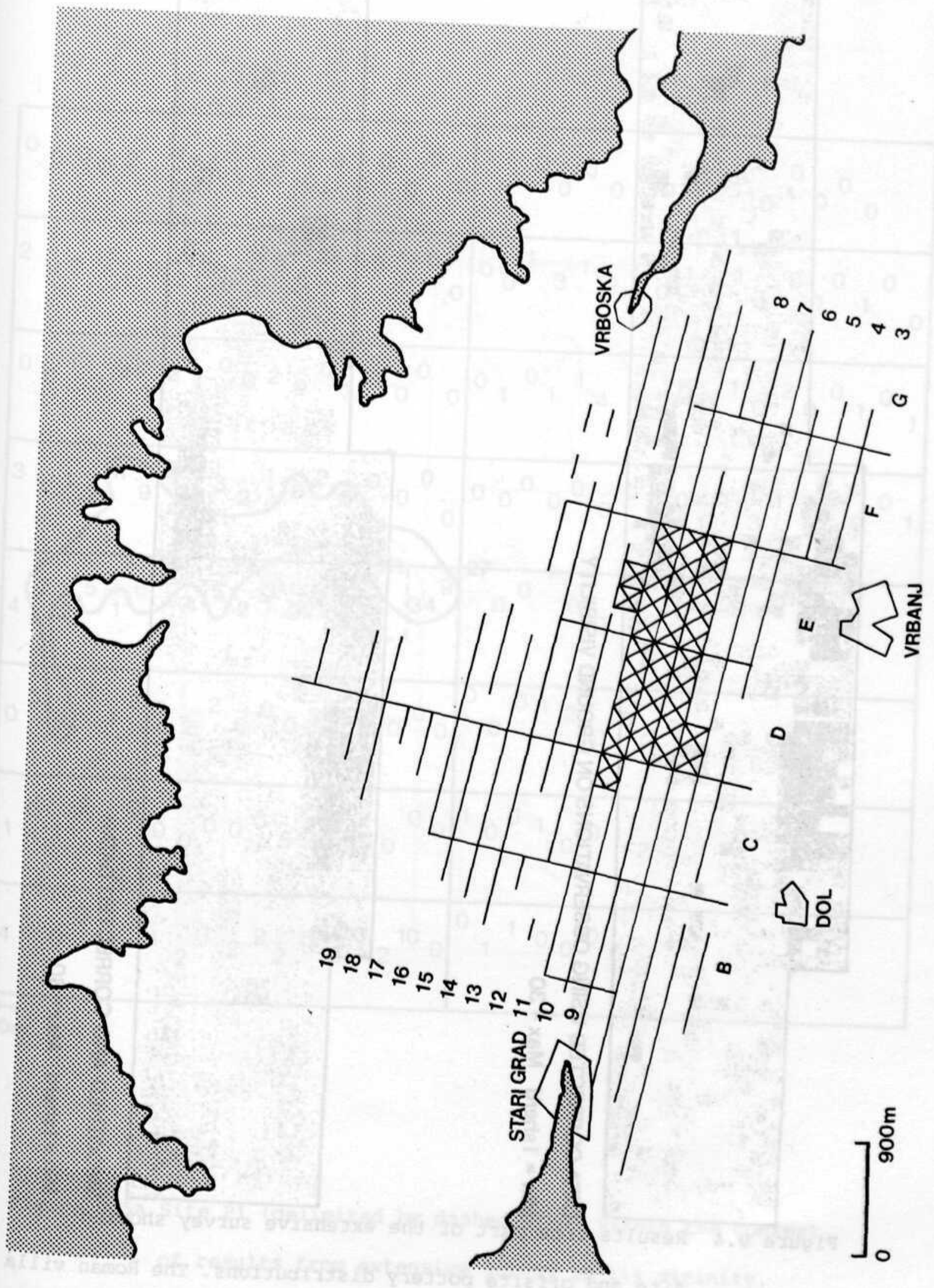

Figure 9.3 Area of field system surveyed in the 1987 season. 

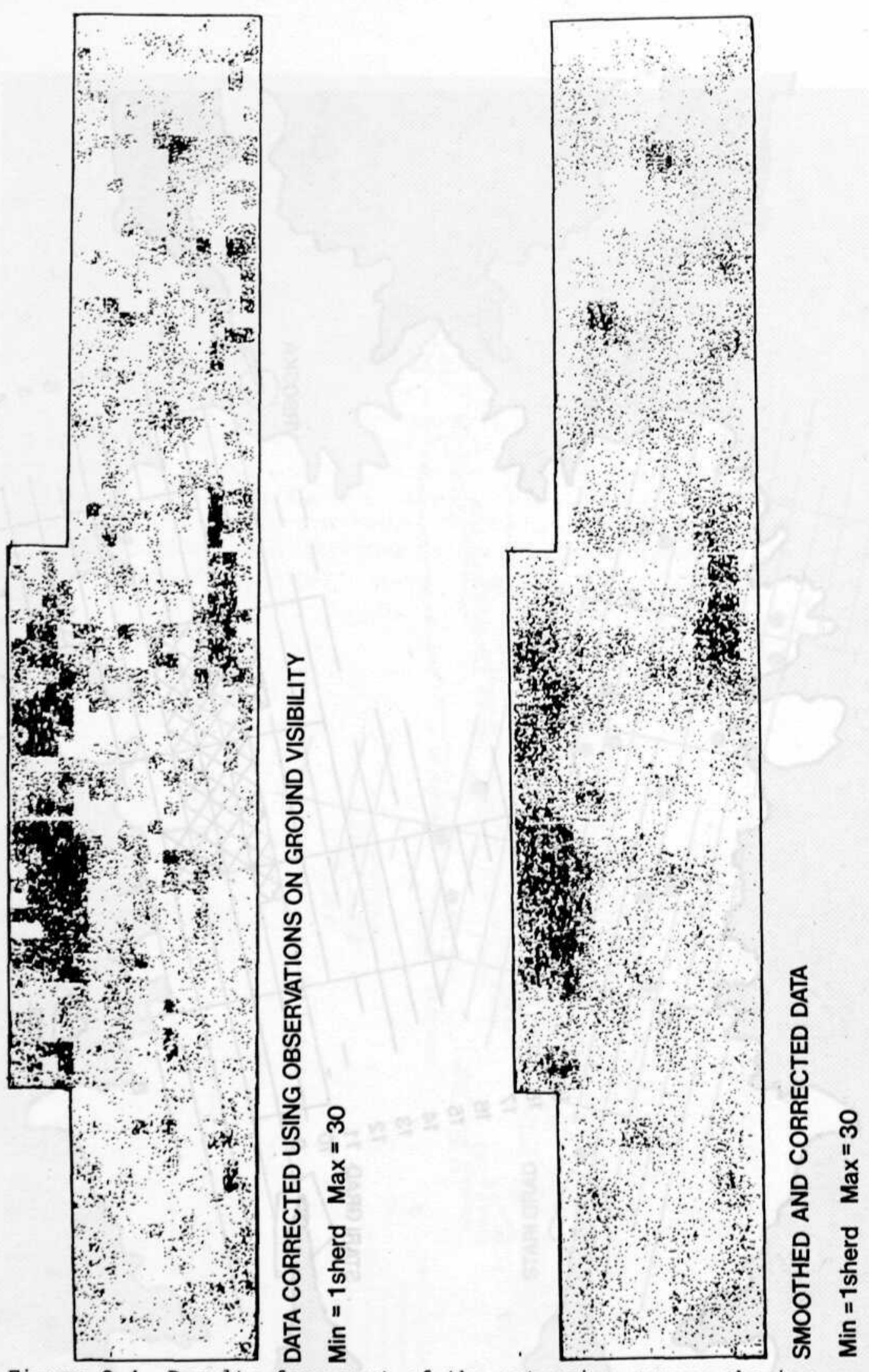

Figure 9.4 Results from part of the extensive survey showing

site and offsite pottery distributions. The Roman villa site of Cerevac is represented by the dense pottery concentrations at the top of the area shown. 


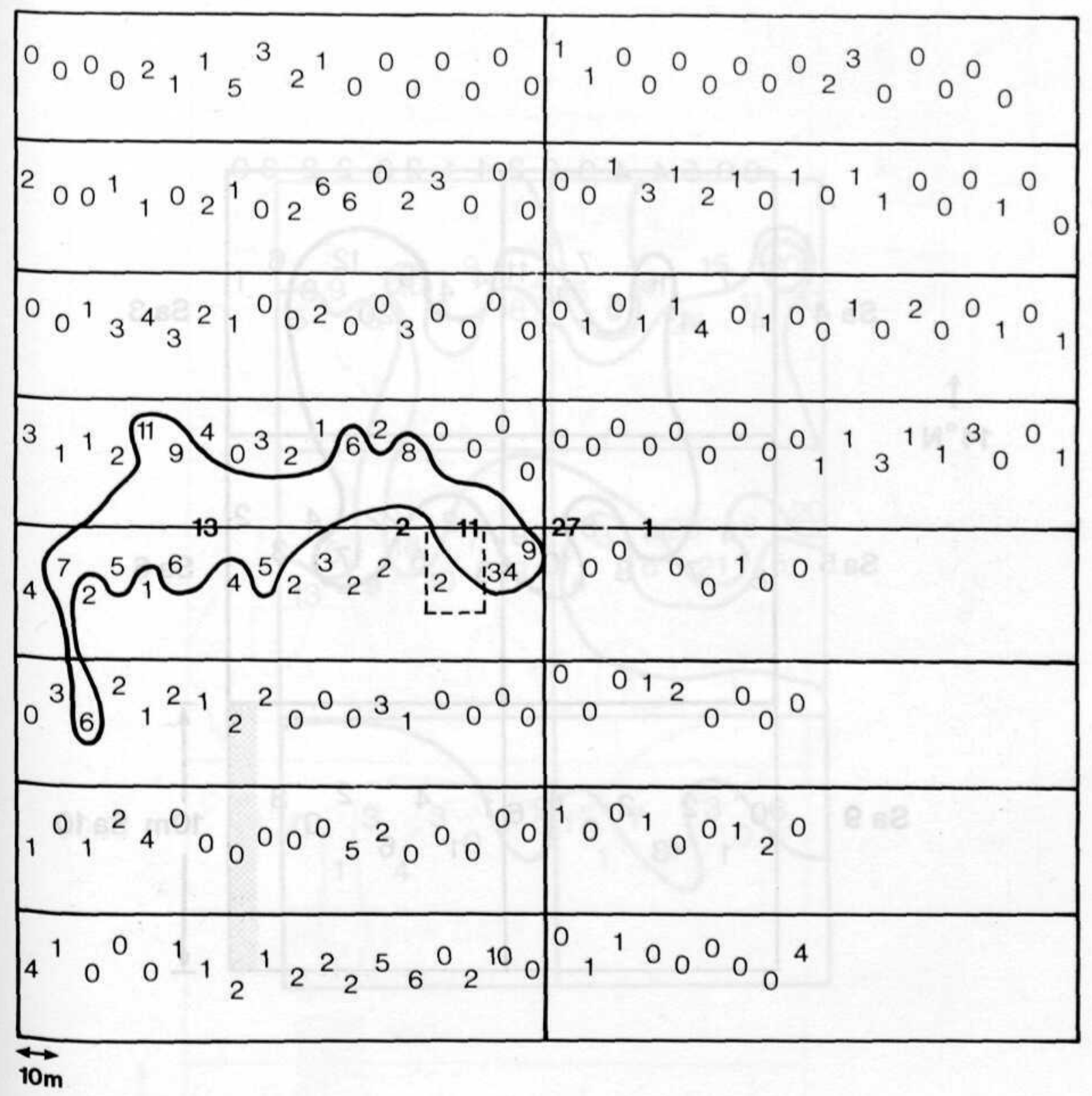

Figure 9.5a Site Pl (delimited by dashed area) within the context of results from extensive survey in its vicinity. Darker numbers denote finds on field walls; continuous line delimits area of artefact densities over 5. 


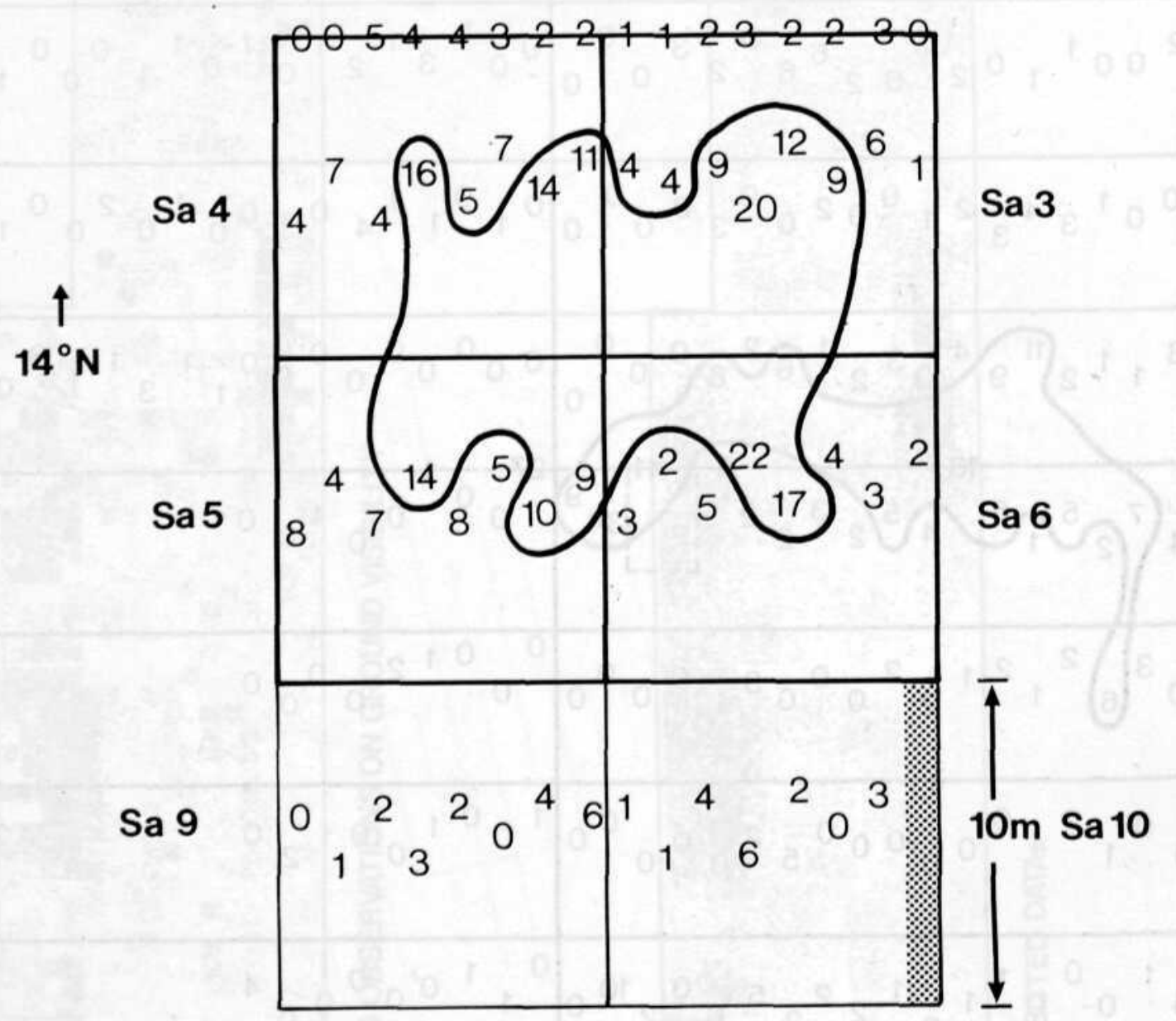

Figure $9.5 \mathrm{~b}$ Site P1, intensive survey results, contour at 9 sherds; shaded strip inaccessible. 


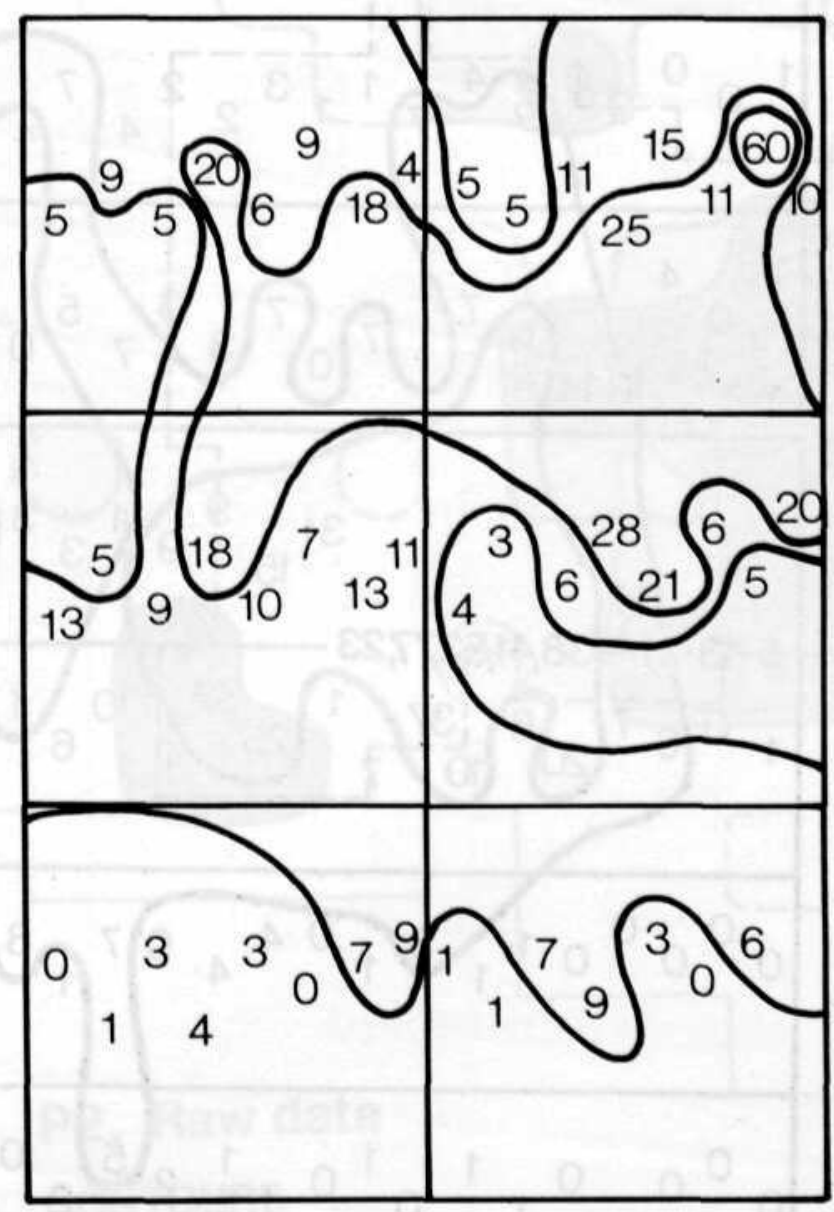

Figure $9.5 \mathrm{c}$ Site $\mathrm{Pl}$, extensive survey results after correction for visibility 


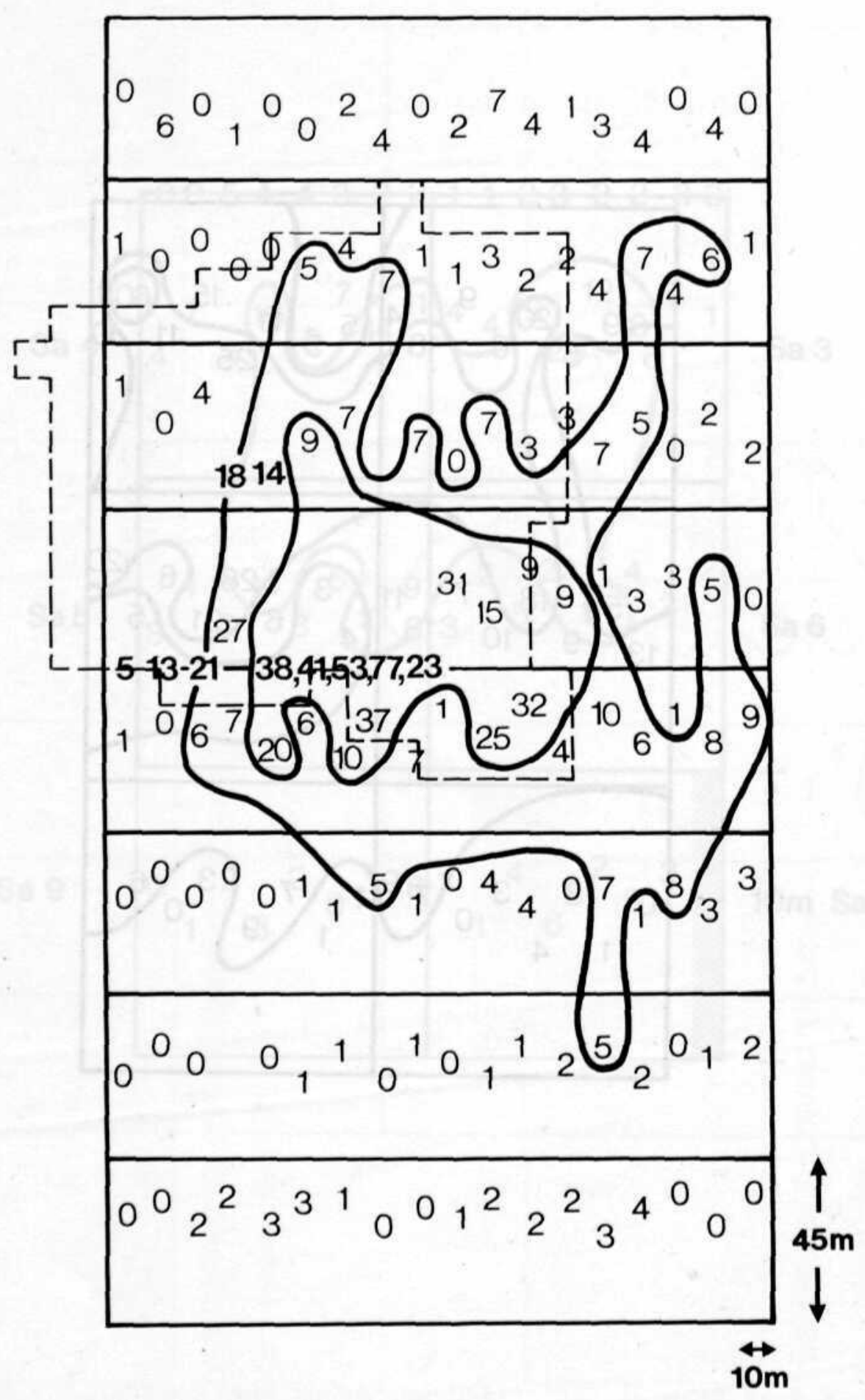

Figure 9.6a Site P2 (delimited by dashed area) within the context of the extensive survey results. For key, see figure $5 a$. 


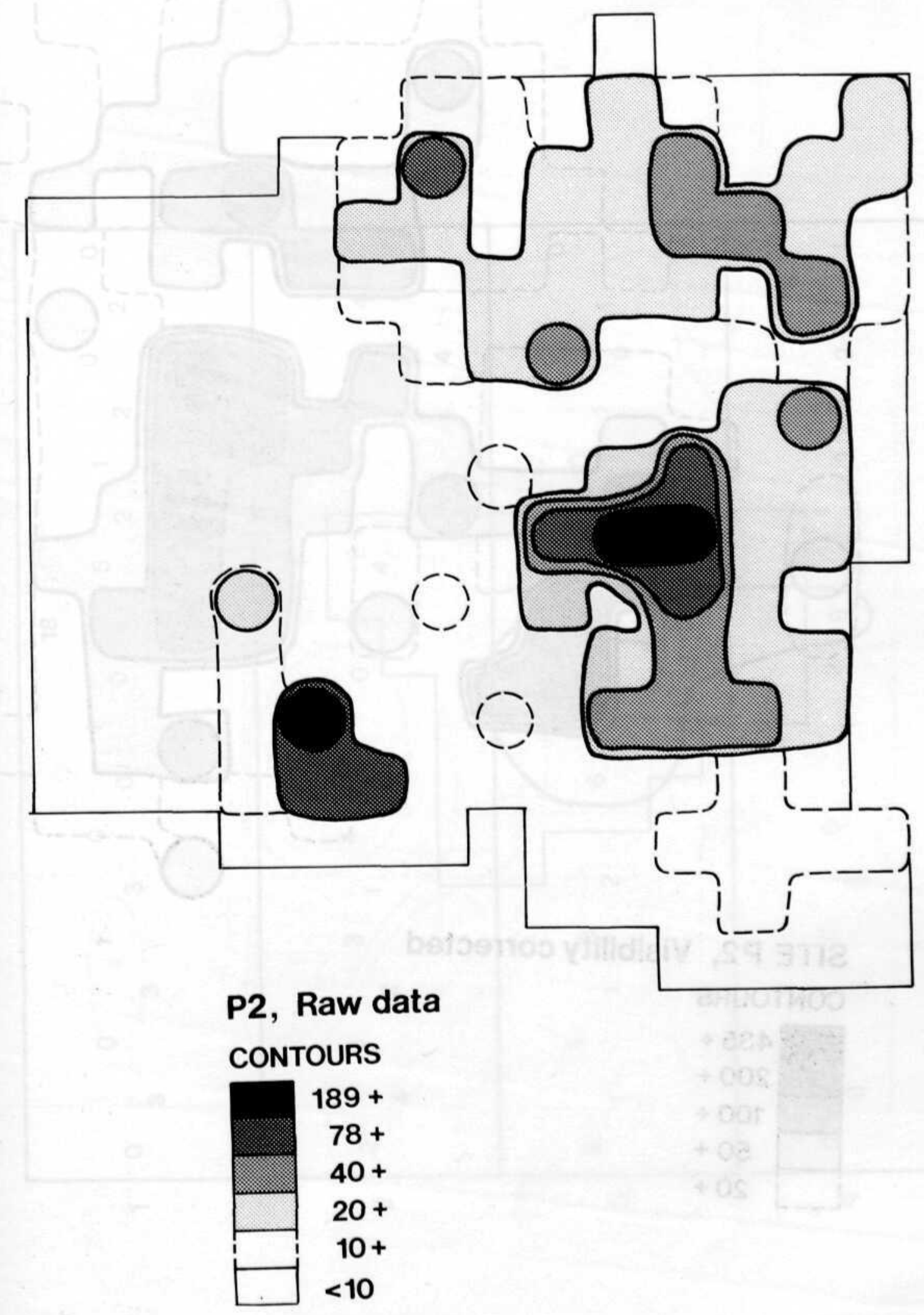

Figure 9.6b Site P2, intensive survey results, raw data. 


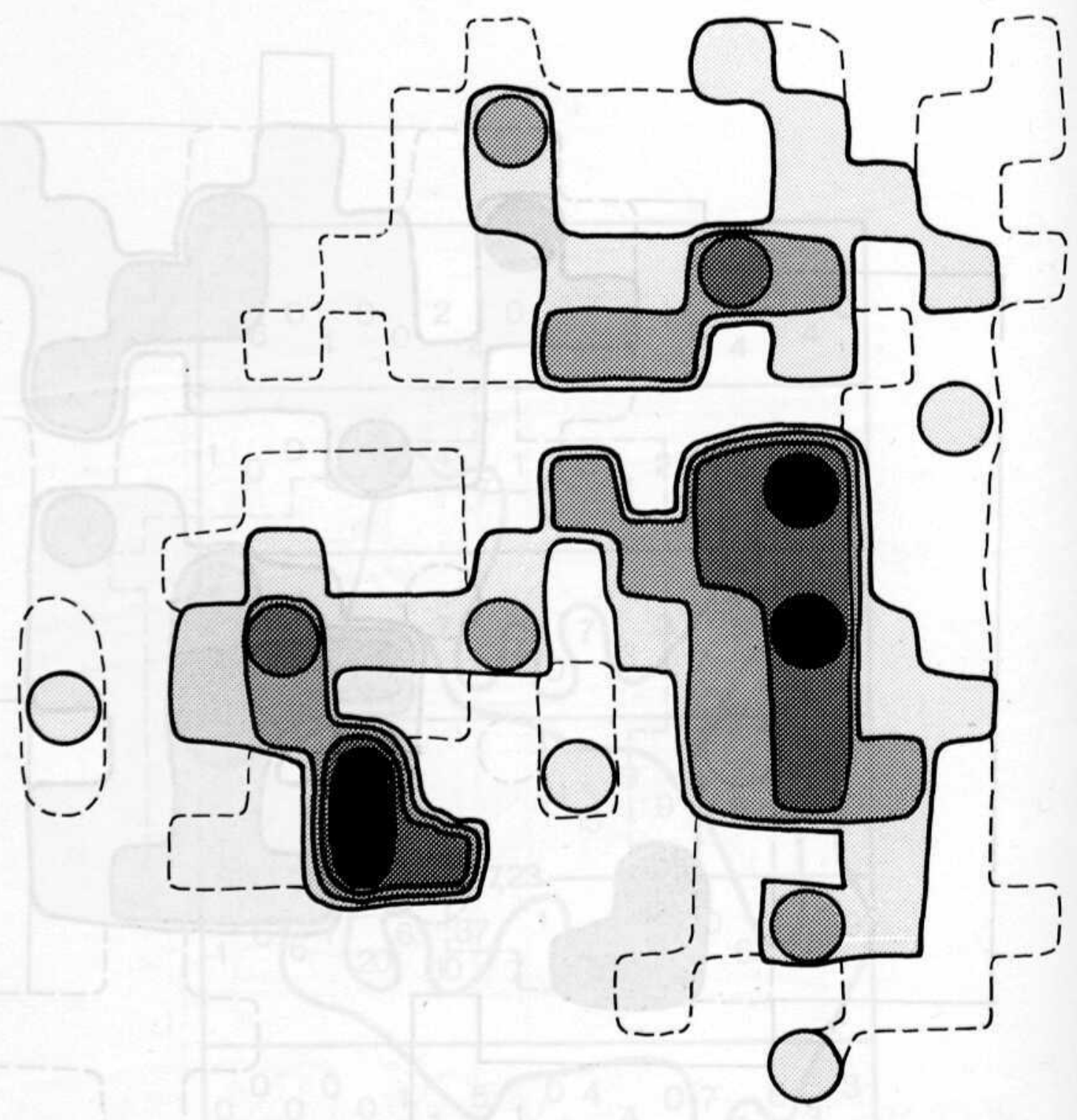

SITE P2, Visibility corrected CONTOURS

\begin{tabular}{rr}
$435+$ \\
$200+$ \\
$100+$ \\
$50+$ \\
\hline \\
\hline \\
\hline
\end{tabular}

Figure $9.6 \mathrm{c}$ Site $\mathrm{P} 2$, intensive survey results after correction for visibility. 


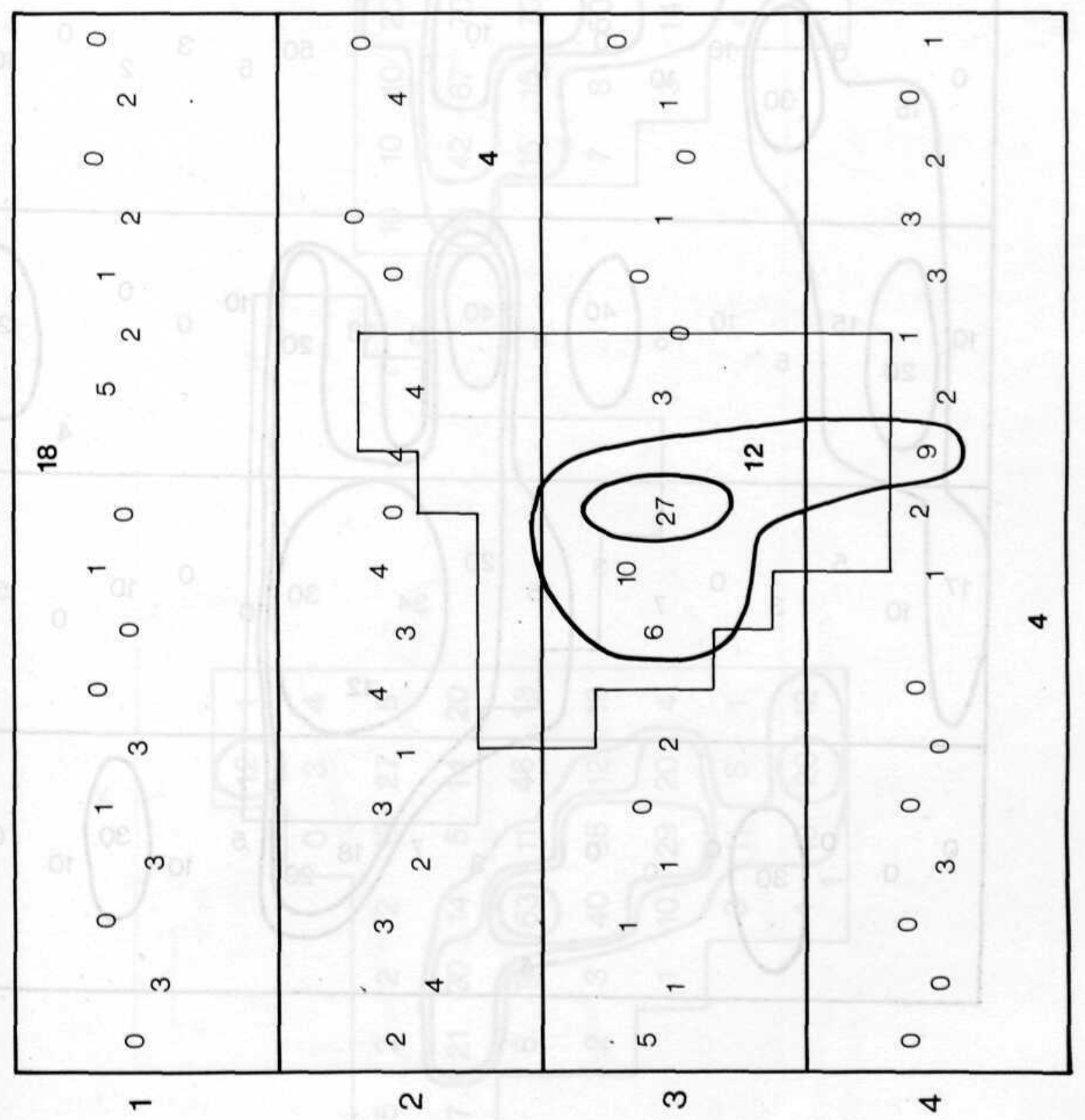

Figure 9.7a Site P4 within the context of the extensive survey results. For key, see figure $5 a$. 


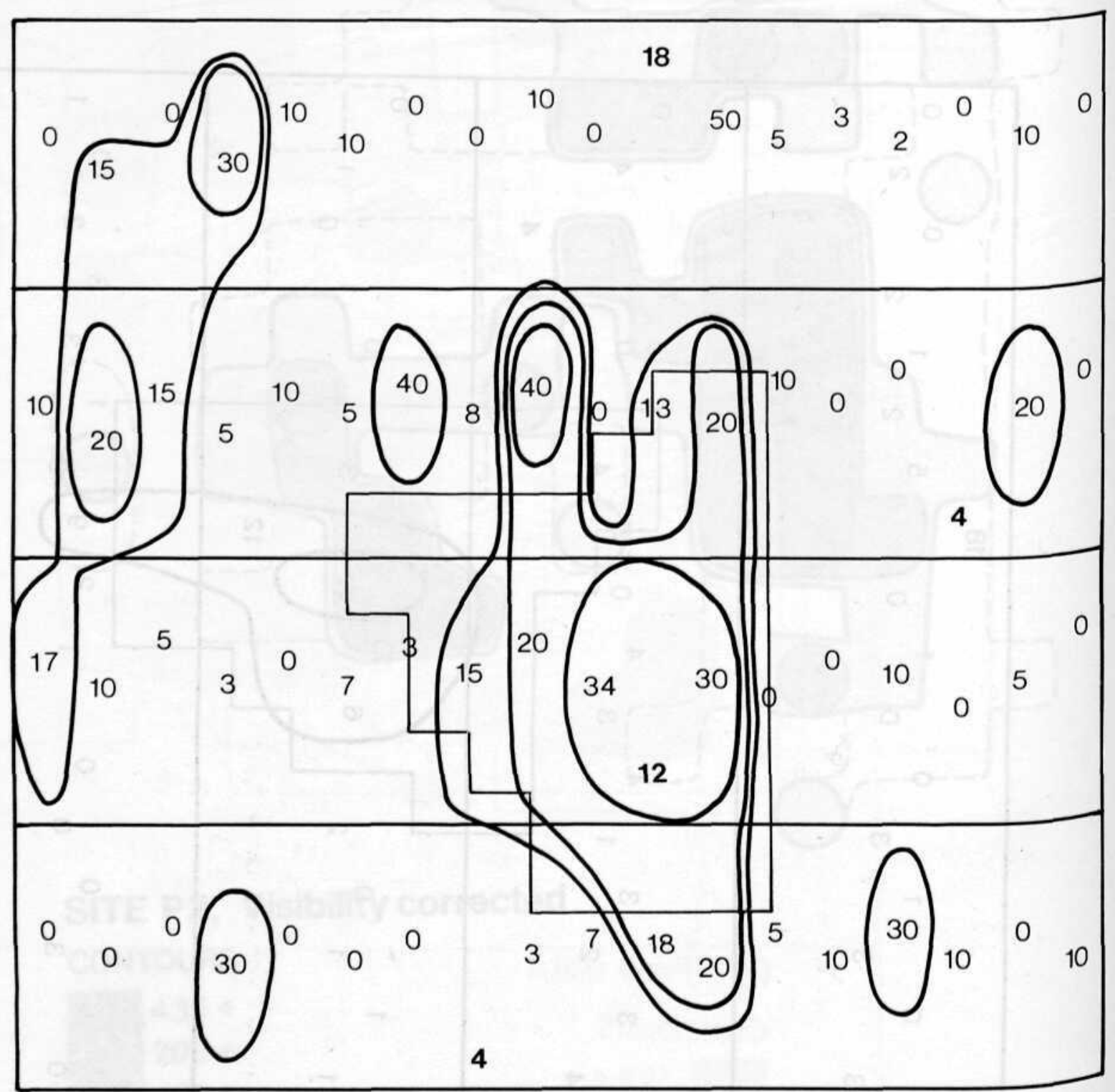

Figure 9.7b Site P4, corrected extensive survey results. For key, see Figure 9.5a. 

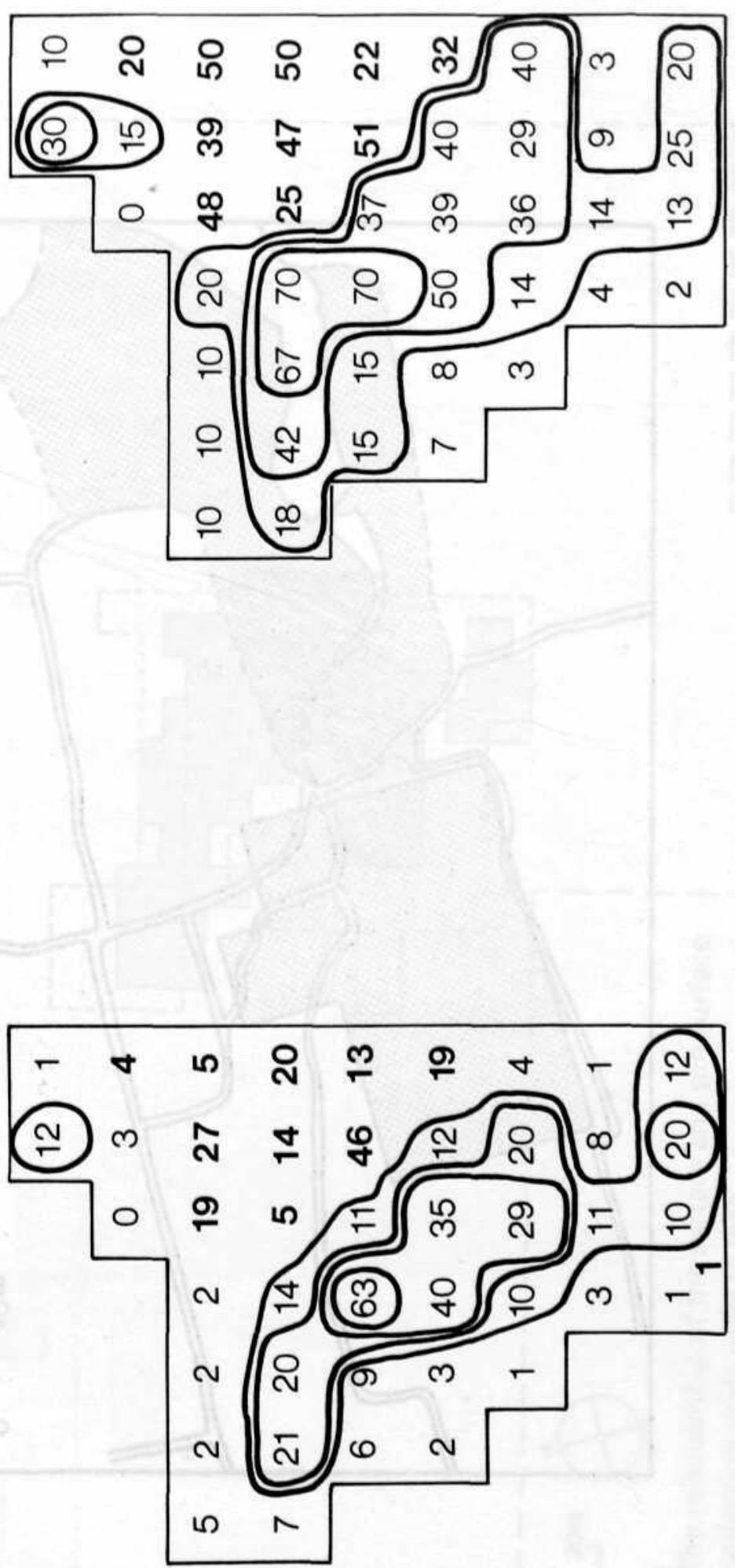

Figure 9.7c Site P4, intensive survey results. For key, see Figure 9.5a. 


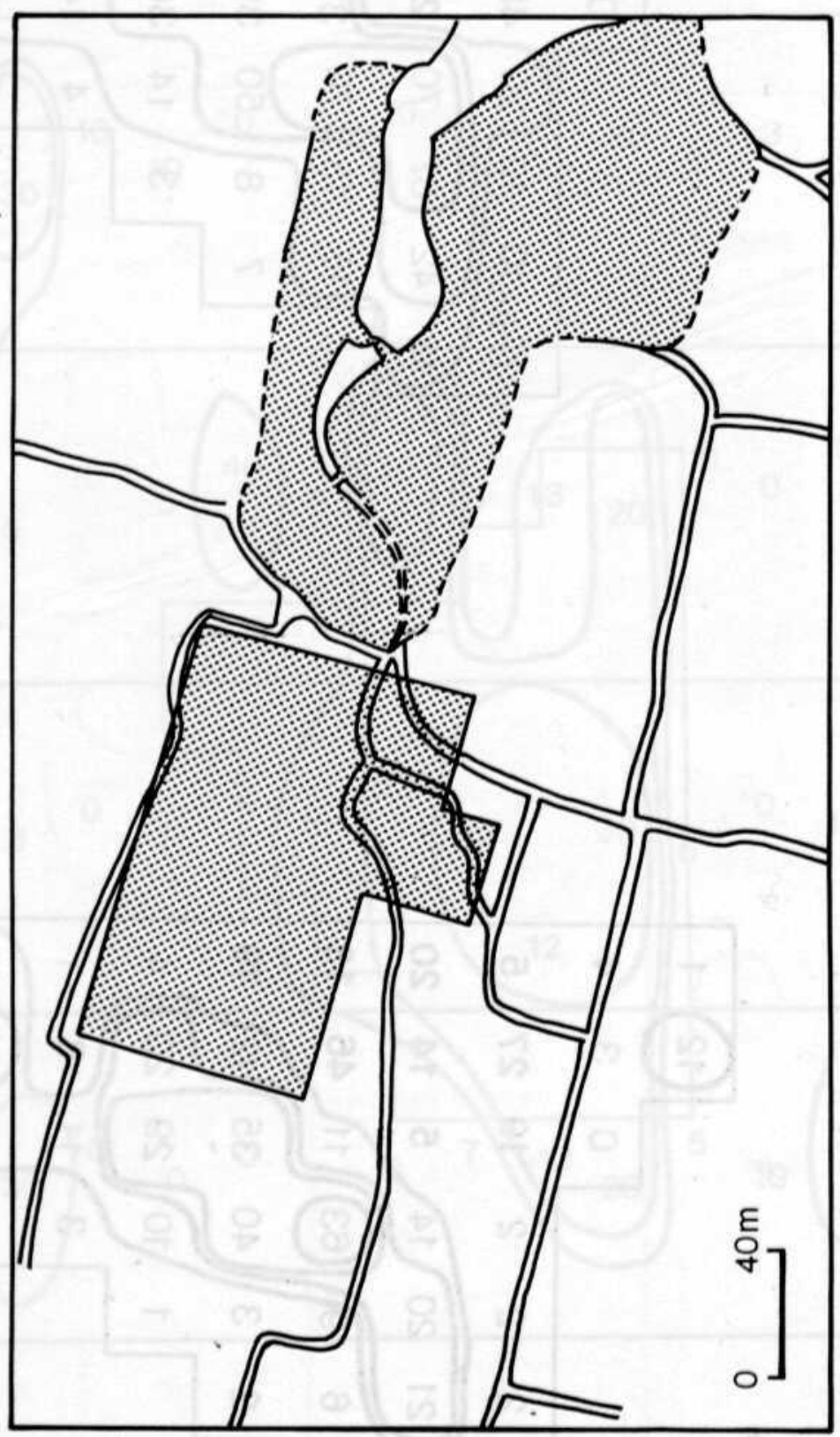

Figure 9.8 The situation of the Villa Jez̄e (left) and modern Vrboska (right). 


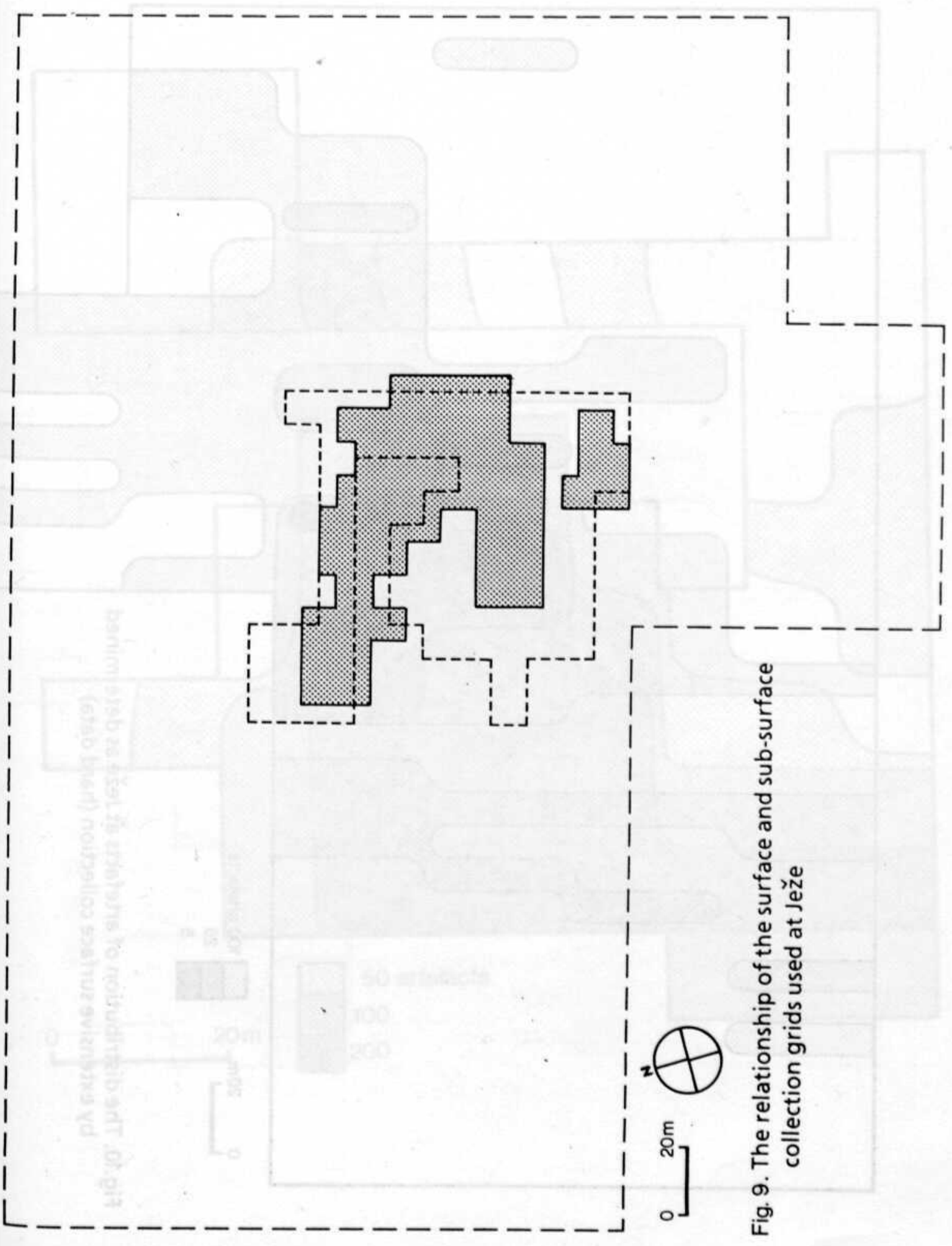

Figure 9.9 The relationship of the surface and sub-surface collection grids used at Jez̄e. 


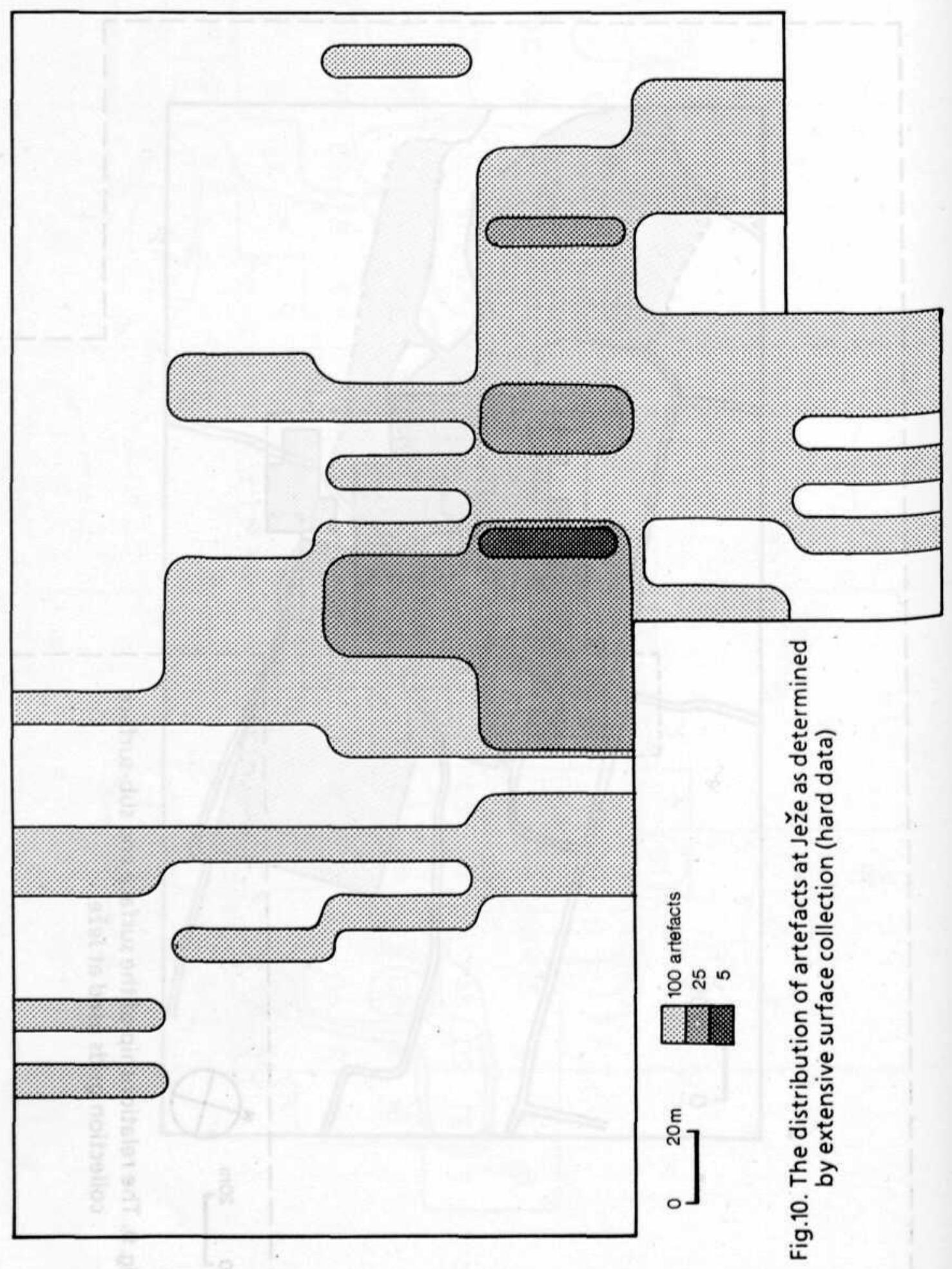

Figure 9.10 The distribution of artefacts at Ježe as determined by extensive surface collection (hard data). 


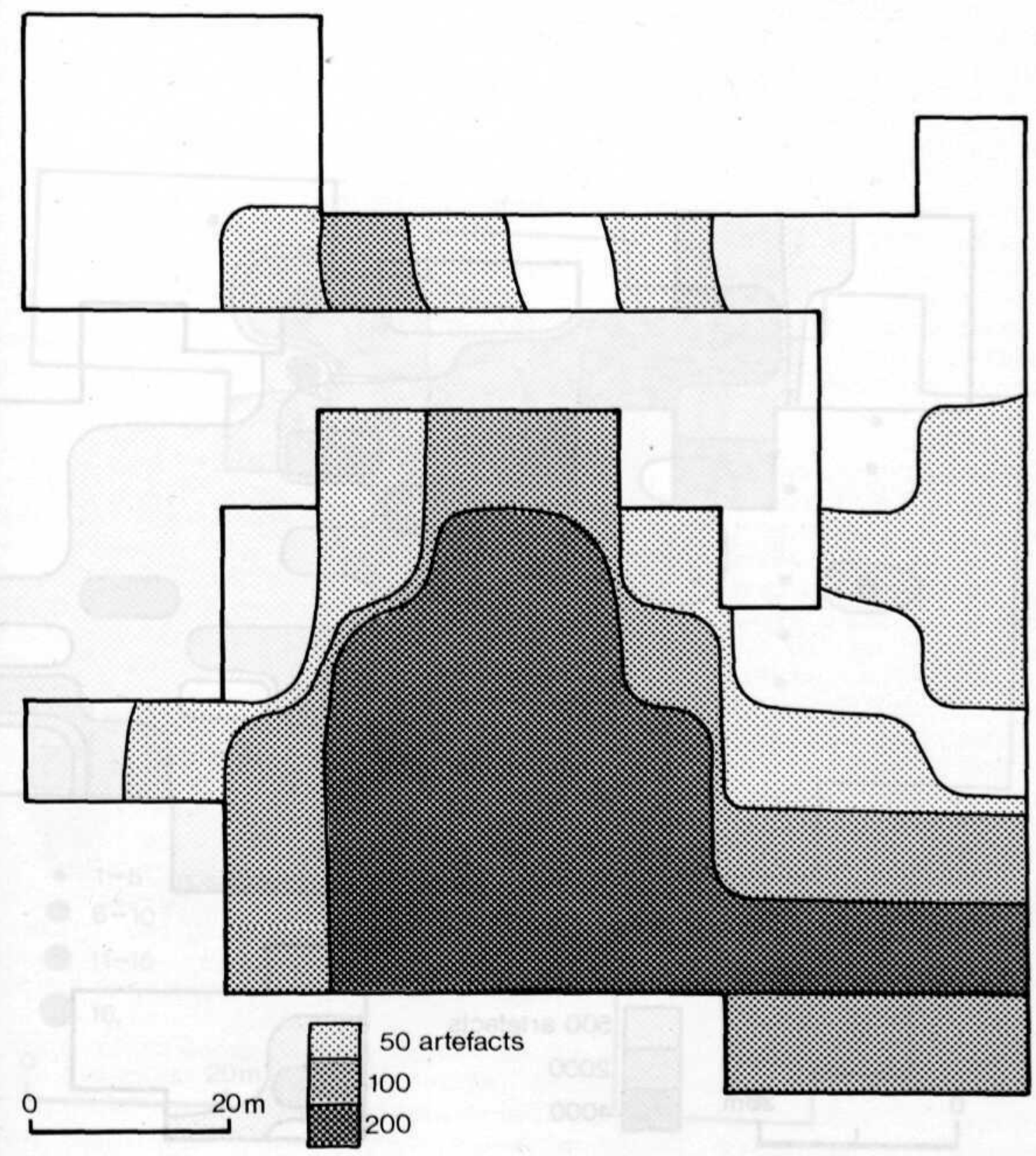

Figure 9.11 The distribution of artefacts at Ježe as determined by intensive surface collection. 


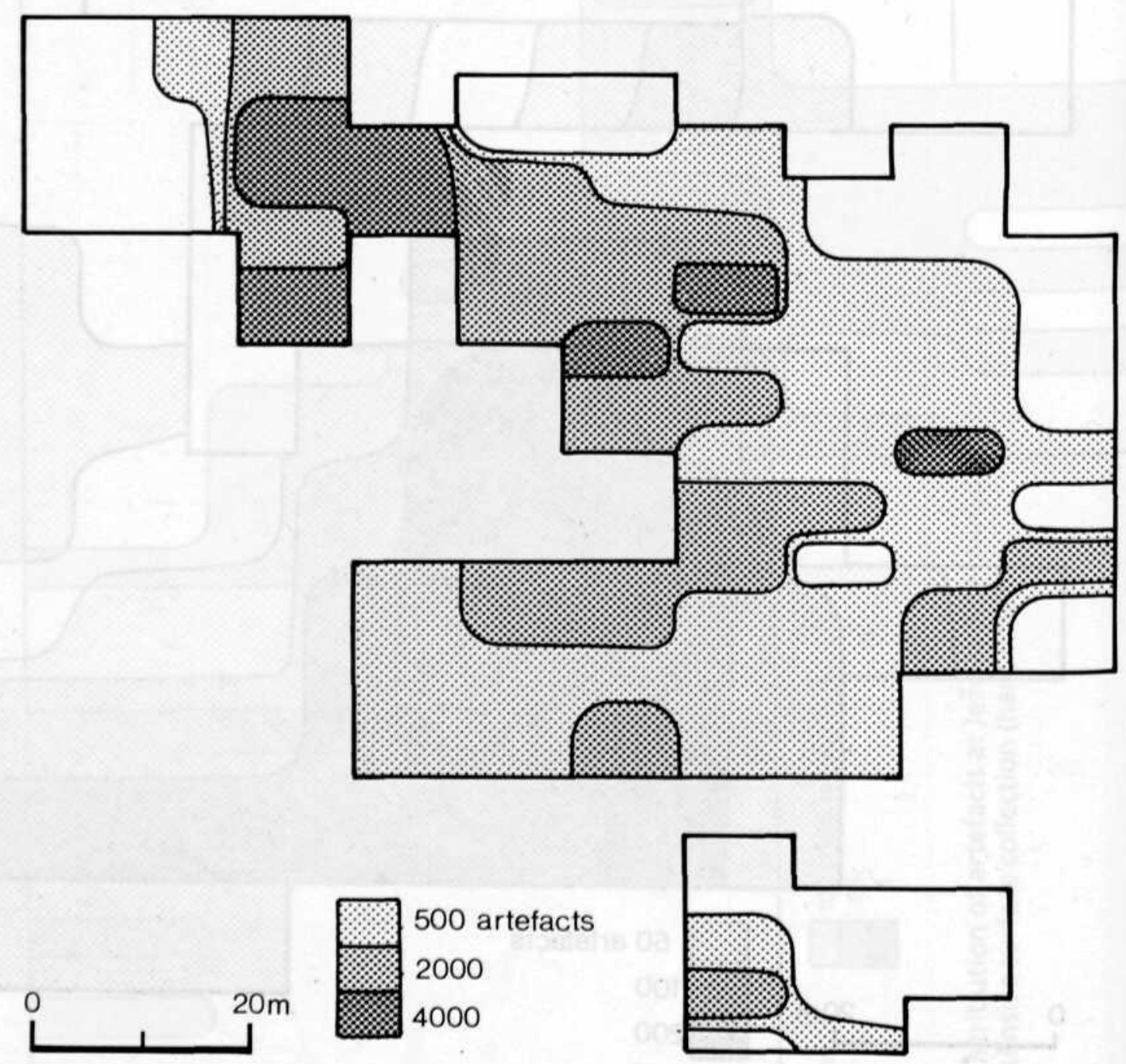

Figure 9.12 A volumetrically corrected sub-surface distribution of all artefacts at Jeẑe. 


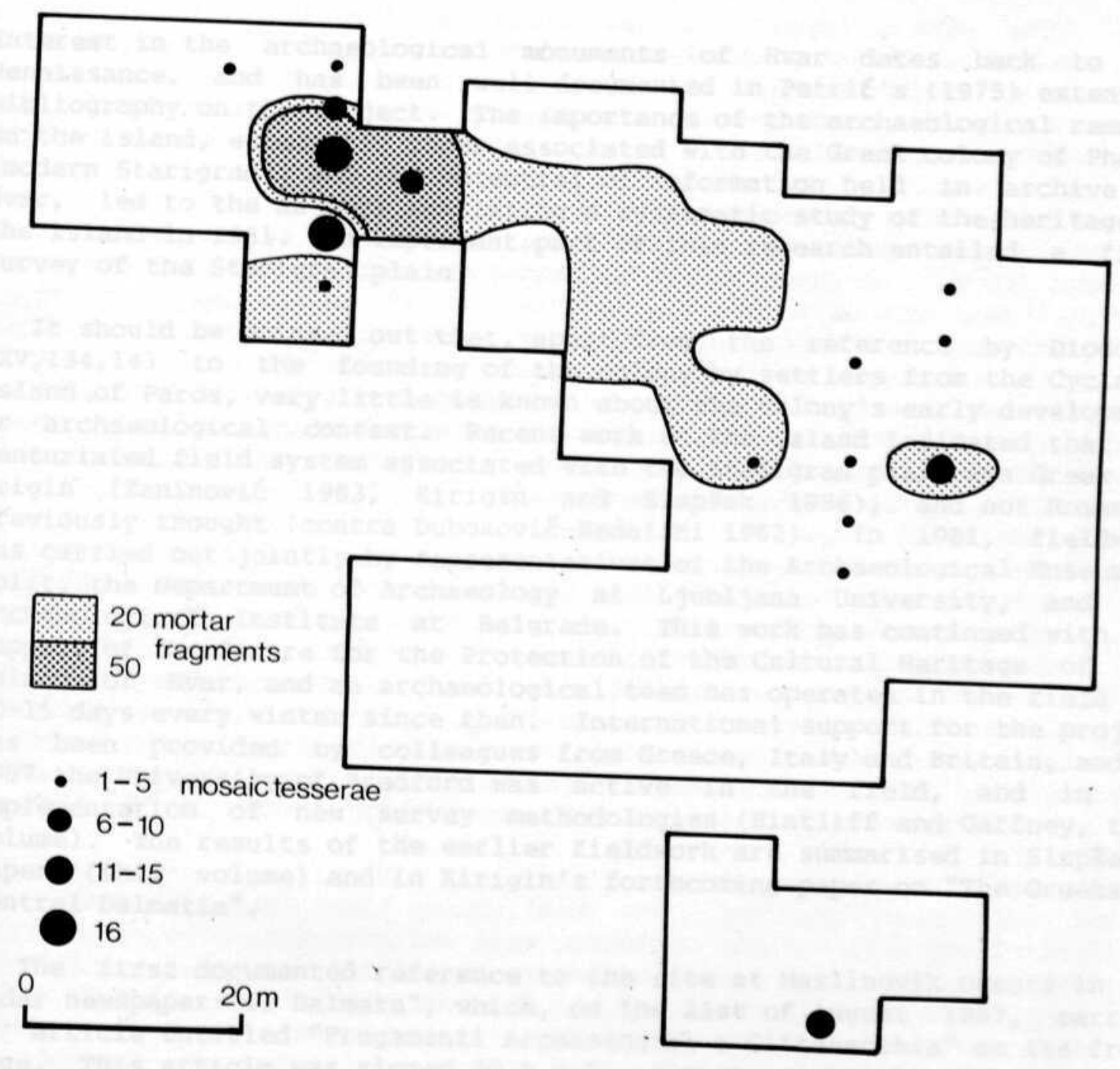

Figure 9.13 The distribution of sub-surface tesserae/mortar at Jez̄e. 


\title{
CHAPTER TEN
}

\section{MASLINOVIK: A GREEK WATCHTOWER IN THE CHORA OF PHAROS. A PRELIMINARY REPORT}

\author{
BRANKO KIRIGIN \& PETAR POPOVIĆ
}

Interest in the archaeological monuments of Hvar dates back to the Renaissance, and has been well documented in Petrit's (1975) extensive bibliography on the subject. The importance of the archaeological remains on the island, especially those associated with the Greek colony of Pharos (modern Starigrad), and the potential of information held in archive on Hvar, led to the authors initiating a systematic study of the heritage of the island in 1981. An important part of this research entailed a field survey of the Starigrad plain.

It should be pointed out that, apart from the reference by Diodorus $(\mathrm{XV}, 134,14)$ to the founding of the colony by settlers from the Cycladic island of Paros, very little is known about the colony's early development or archaeological context. Recent work on the island indicated that the centuriated field system associated with the Starigrad plain was Greek in origin (Zaninoviéc 1983, Kirigin and Slaps̄ak 1986), and not Roman as previously thought (contra Duboković-Nadalini 1962). In 1981, fieldwork was carried out jointly by representatives of the Archaeological Museum at Split, the Department of Archaeology at Ljubljana University, and the Archaeological Institute at Belgrade. This work has continued with the support of the Centre for the Protection of the Cultural Heritage of the Island of Hvar, and an archaeological team has operated in the field for 10-15 days every winter since then. International support for the project has been provided by colleagues from Greece, Italy and Britain, and in 1987 the University of Bradford was active in the field, and in the implementation of new survey methodologies (Bintliff and Gaffney, this volume). The results of the earlier fieldwork are summarised in Slaps̄ak's paper (this volume) and in Kirigin's forthcoming paper on "The Greeks in Central Dalmatia".

The first documented reference to the site at Maslinovik occurs in the Zadar newspaper "Il Dalmata", which, on the 21st of August 1897, carried an article entitled "Frugamenti Archeologici a Cittavecchia" on its front page. This article was signed "G.A.B.", almost certainly Gian Antonio Botteri, a lawyer from Starigrad, who was also known as an antiquarian. In describing the archaeological finds from the vicinity of St. Nicholas' church in Starigrad (a building which he felt was situated in the very centre of ancient Pharos), he gives a description of a tumulus and a square tower at purkin Kuk. He writes "...in ogni caso, a compagne sua altre torri in medesimo stile, sagoma, dimensioni e destino, uno in vetta all oliveto (Maslinovik) e l'altra sopra Gelsa nel Tor..."

The towers at Purkin Kuk and Tor are mentioned by Zaninovic (1982, 1983) but no further evidence existed within the archaeological literature 
for the third tower at Maslinovik, other than the statement in Botteri's article. Given that Botteri's writing indicated that he was familiar with, and understood the implications of, distinctive building styles, it was felt that some confirmatory work should be undertaken at Maslinovik. This work was carried out during the field survey season of 1987, during which convincing evidence for the tower's existence was discovered.

The site of Maslinovik lies on the top of a hill at 67.53 metres above sea level. It is situated on the northern edge of the Starigrad plain and has a commanding view of the whole plain on the south, the hilly land to east and west, and over the Hvar channel to the island of $B r a \bar{c}$, and the mainland to the north. At the time of discovery, the only evidence for the existence of the tower was the presence or several very large blocks of stone which had been built into a number of later structures, including the drystone walls of a hut, and a lime kiln some 15 metres to the west of the site. A number of these stones, probably those from the corners of the tower, displayed the distinctive chisel marks (anathyrosis), often found on such Greek sites. Removal of vegetation initially revealed the north west corner of the building and eventually the whole western wall. This wall was oriented in a north-south direction with a deviation of 12 degrees to the north east. It is interesting to note that this corresponds very closely to the orientation of the original Greek cadastral grid in the Starigrad plain.

Later in the year, between $30 / \mathrm{X} / 87$ and $10 / \mathrm{XI} / 87$, an excavation was undertaken with the aim of defining the nature and extent of the site (Plates 10.1-3). After the removal of the vegetation, the humic layer (c. 7-10 cm. thick), and the wall tumble, the eastern part of the site was uncovered, exposing a building, c. 7.5 metres square. For the purposes of excavating the interior of the building, a 1-metre grid was laid over the whole site, and a section line was established across the centre of the building in a north-south direction. The site was recorded photogrammetrically using a 12 metre high aluminium "A" frame (Plate 10.4 ).

The discovery of the Maslinovik tower was an event of some significance, given its assumed role within the colony's territorial defense system, the rarity of modern excavation on such sites and the high probability of well-preserved stratigraphy within the tower's interior. Although the present level of analysis on material at Maslinovik demands that this report can only be preliminary and descriptive, the site itself is of such importance that it merits inclusion within this volume.

The tower walls were 1 to 1.1 metres wide, and were composed of unmortared stone blocks of varying dimensions (Figure 10.1). These blocks were partly worked on the exterior faces and sometimes on the upper and lower surfaces. Only 3 or 4 courses of building blocks survived up to the height of 1 to 1.5 metres. The corner stones, the easiest to rob, were preserved in the lowest course only, but all surviving examples displayed the characteristic Greek working (anathyrosis). 
The tower was built upon bedrock which had been levelled for construction purposes. Two trenches excavated around the north western and south eastern corners indicated that the levelled bedrock was worked to accept the foundation blocks which were 15 to $20 \mathrm{~cm}$. wider than the exterior face of the upper courses. The interior of the tower, which measured $5.45 \times 5.5 \mathrm{~m}$., was levelled using a deposit of crushed stones. This deposit was up to 70 to $80 \mathrm{~cm}$ deep in the northern half of the tower. A very finely worked square block of stone lay in the very centre of the tower (dimensions, $50 \times 50 \mathrm{~cm}$ in width and $60 \mathrm{~cm}$ deep). This block was set into the levelling deposit and was packed with a number of stones. On the western, eastern and southern side of the central block lay three partly worked broken blocks (Plate 10.5). The stone overlying the south east edge of the central block had a gutter $10 \mathrm{~cm}$ wide and $20 \mathrm{~cm} 10 \mathrm{og}$ cut into it.

The northern part of the interior of the tower had been damaged by a later trench which had been backfilled with stones, loose soil and a large quantity of Greek tiles. This feature could be dated to the 18 th or 19 th centuries A.D., from the pottery contained within its lowest deposits.

A number of interesting features lay within the excavated area to the south of this later trench. From the south western and south eastern corners of the tower up until the central stone block, and directly over the levelling deposits, lay a deposit of ash and charcoal. This was directly overlain by a distinct concentration of lumps of burnt clay mixed with fragments of tile and large pieces of burnt wood. The whole of this area was covered by a great quantity of fragments of roof tiles of different dimensions and shapes. The tile distribution concentrates in the area south of the central block and is evidently continued on the exterior of the south wall of the tower. A cultural deposit of dark brown soil with traces of charcoal and burnt clay, between 8 and $10 \mathrm{~cm}$ thick was also discovered. Unfortunately, this layer was only well preserved in the northern part of the building, around the area containing the modern trench.

Datable finds associated with the tower deposits mainly comprised fragments of Greek fine wares, most of which were found in the south western area of the tower, near the walls and within the layer of ash mentioned above. Several sherds deserve comment and illustration at this moment. These include several rims of skyphoi (Figure 10.2/2,3,6), two skyphos bases (Figure 10.2/4,5), a sherd of a thin-walled vessel of grey clay, carrying a black glaze and painted white (Figure 10.2/7), and the base of a larger vessel (Figure 10.2/1). All of this material dates to the 4 th or 3 rd centuries B.C. .

As the analysis of the excavated material is not yet complete, it is hard to draw any precise conclusions. However, it is probable that the central stone block supported an internal platform and, given the abundant amount of burnt clay found during the excavation, it is also possible that the upper floor carried a clay structure (a fireplace?). The quantity of tiles found during excavation obviously points to a roof although we cannot be sure what form such a feature might have taken. On analogy with 
other similar structures, we can assume that the tower was c. 10 metres high (Orber 1987). Despite the preliminary nature of this report, we can state with some confidence that the tower's construction can be dated by the associated pottery to the 4 th or 3 rd centuries B.C..

A tower of similar size and architectural form is also situated on the high (250 metres above sea level), and barely accessible hill of TOR, above Jelsa (Plate 10.6). This tower overlooks the fertile plain of Jelsa and Starigrad, the Hvar Channel and the mainland coastline. The tower is intervisible with that at Maslinovik, some $7.5 \mathrm{~km}$. distant. It would seem logical to assume that both towers belong to the defensive system that protected the territory of the Greek colony of Pharos. These buildings, which are well known elsewhere in the Greek world (Adams 1982:71) functioned as watchtowers or phryktoria, and would have communicated with each other using beacons or smoke signals. In such a situation, the tower at Maslinovik would have functioned as a communication link between TOR and Pharos which lay another $3.5 \mathrm{~km}$. distant (Figure 10.3). Given the constant danger from pirates and the hostile native Illyrian population, such towers would have occupied a position of great importance in the defensive system guarding the chora of the Pharos colony.

\subsection{NOTES}

1 It is important to note that, while a similar tower is purported to have existed at Purkin Kuk, another hill some $2 \mathrm{~km}$. to the south east of Starigrad, recent excavation of the site did not reveal anything about the function of the structure which was discovered (Zaninovic 1984).

\subsection{ACKNOWLEDGEMENTS}

\section{In memoriam Foxy}

The excavation at Maslinovik was financed by the Centre for the Protection of the Cultural Heritage of the Island of Hvar. The following people asssisted the authors during excavation: $\mathrm{Dr}$. Vinko Sribar (Ljubljana University), Zoran Stančic (Department of Archaeology' Ljubljana University), Dunja Gerić (Architect, Zagreb) and Irena Radic (University of Zagreb). 

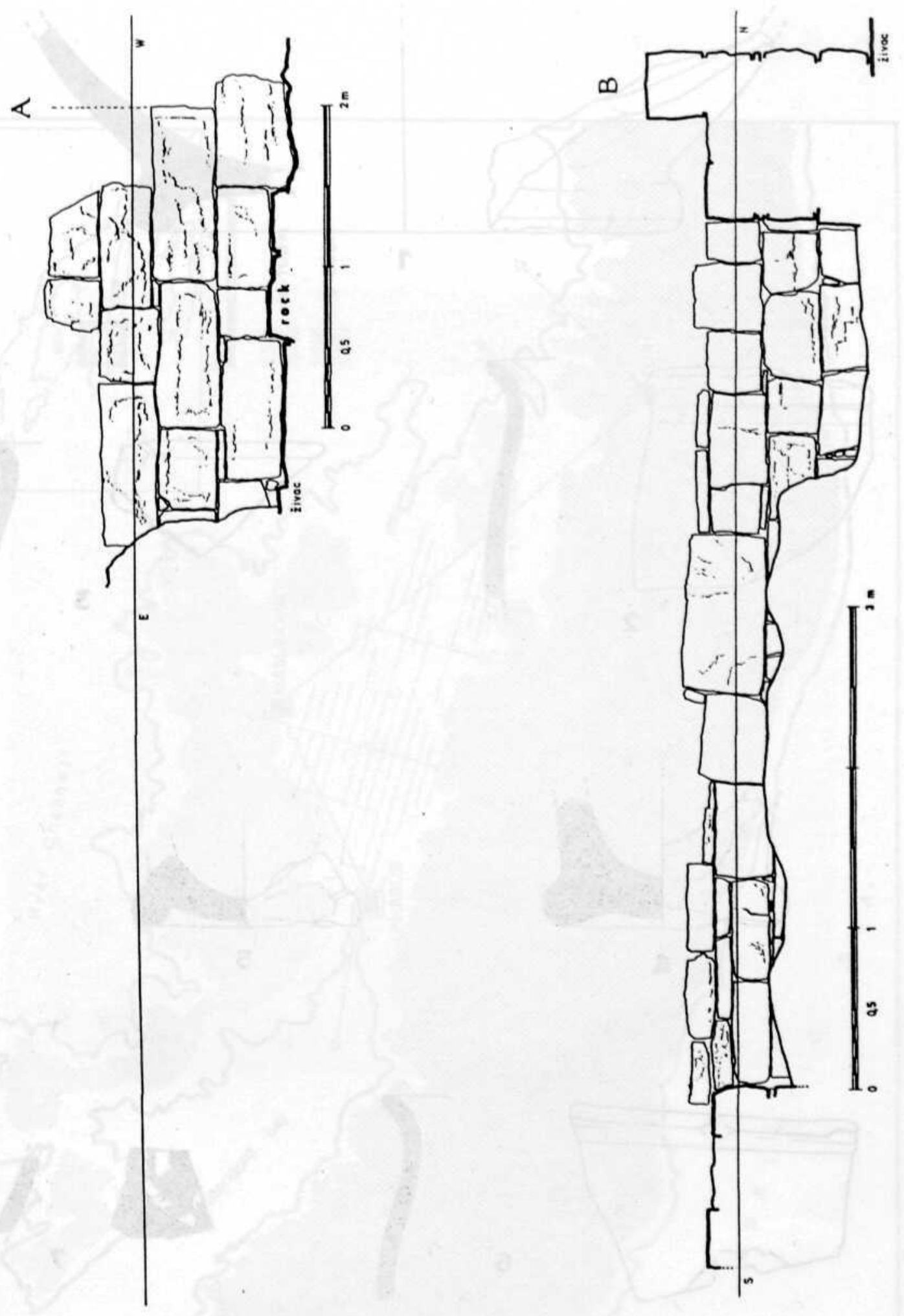

Figure 10.1 Elevation of tower, Maslinovik 

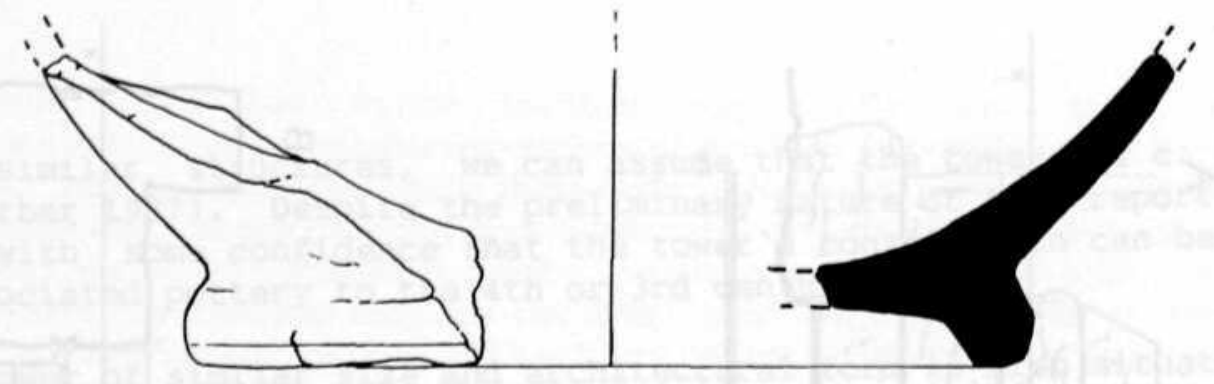

1
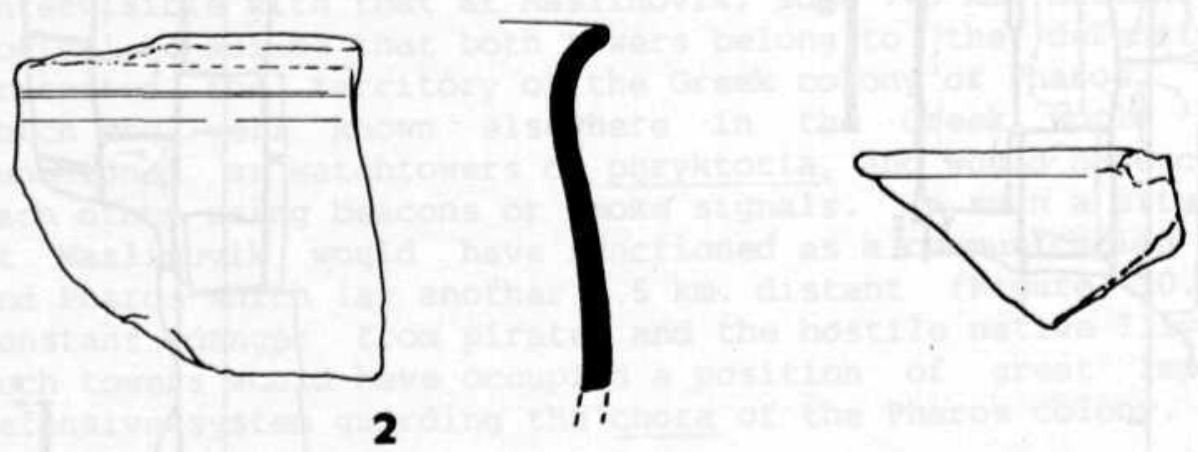

3
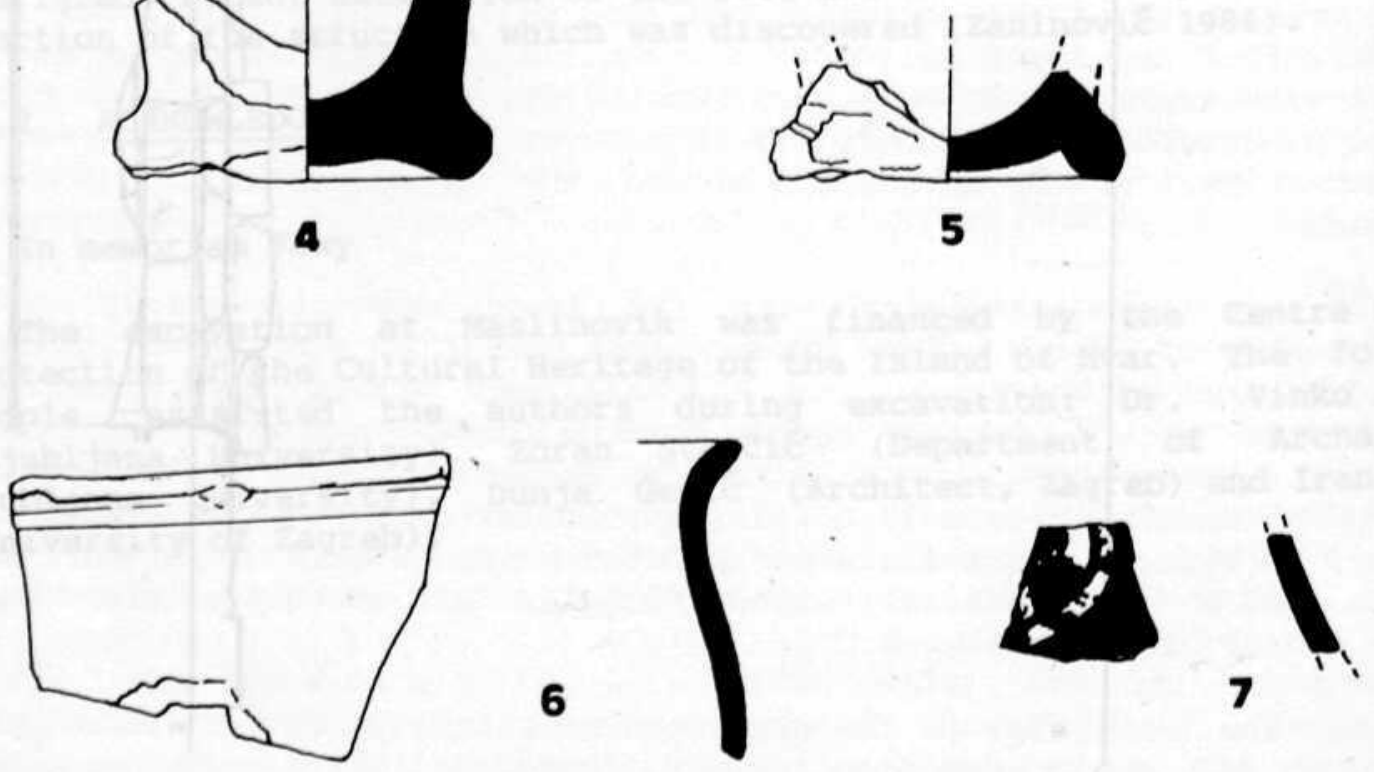

29. III 1988.

crtao: S.ŻITNIK

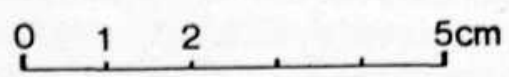

Figure 10.2 Pottery from Maslinovik. 


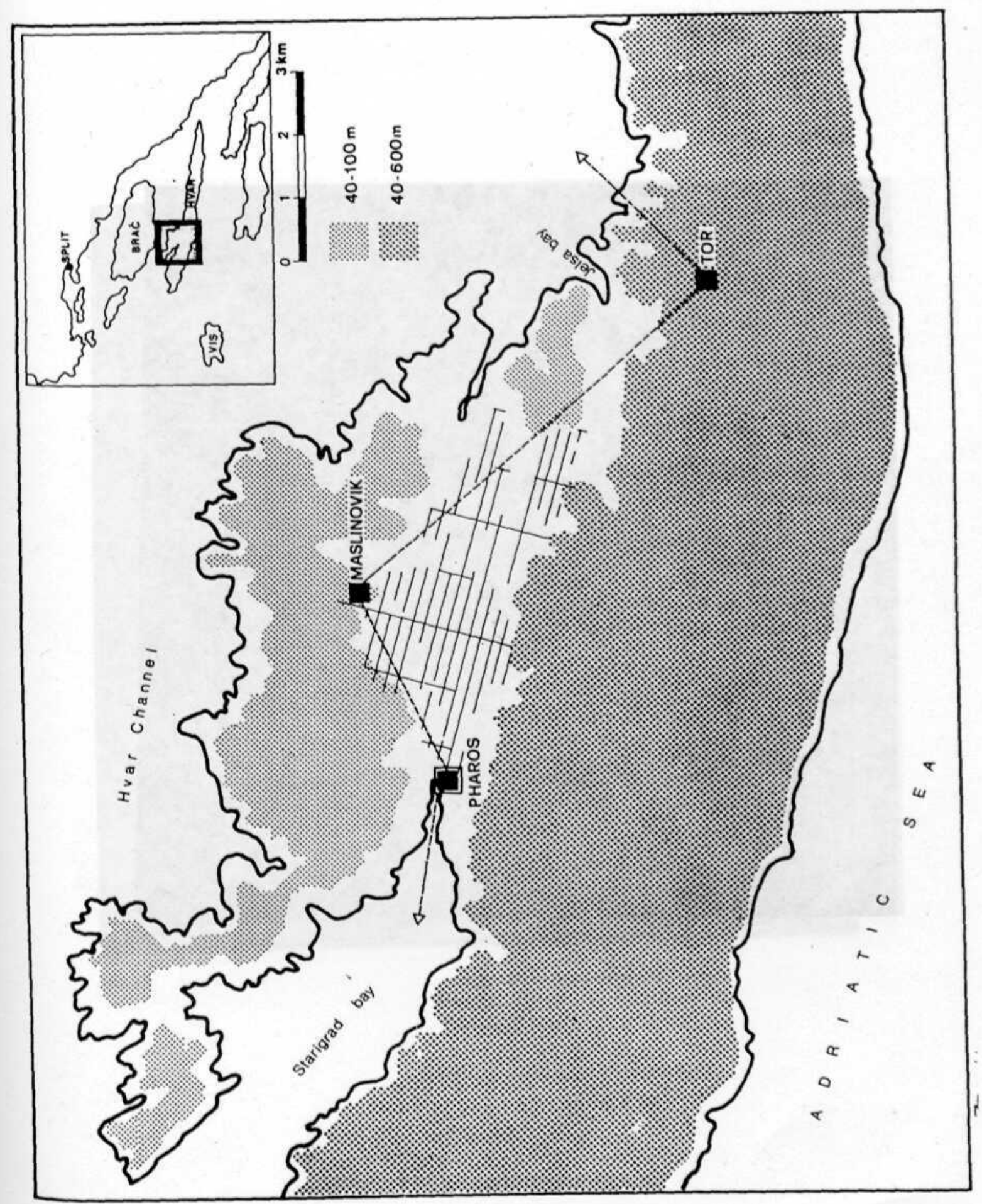

Figure 10.3 Map of the Starigrad plain, showing location of Maslinovik, Tor and Pharos, and lines of sight. 


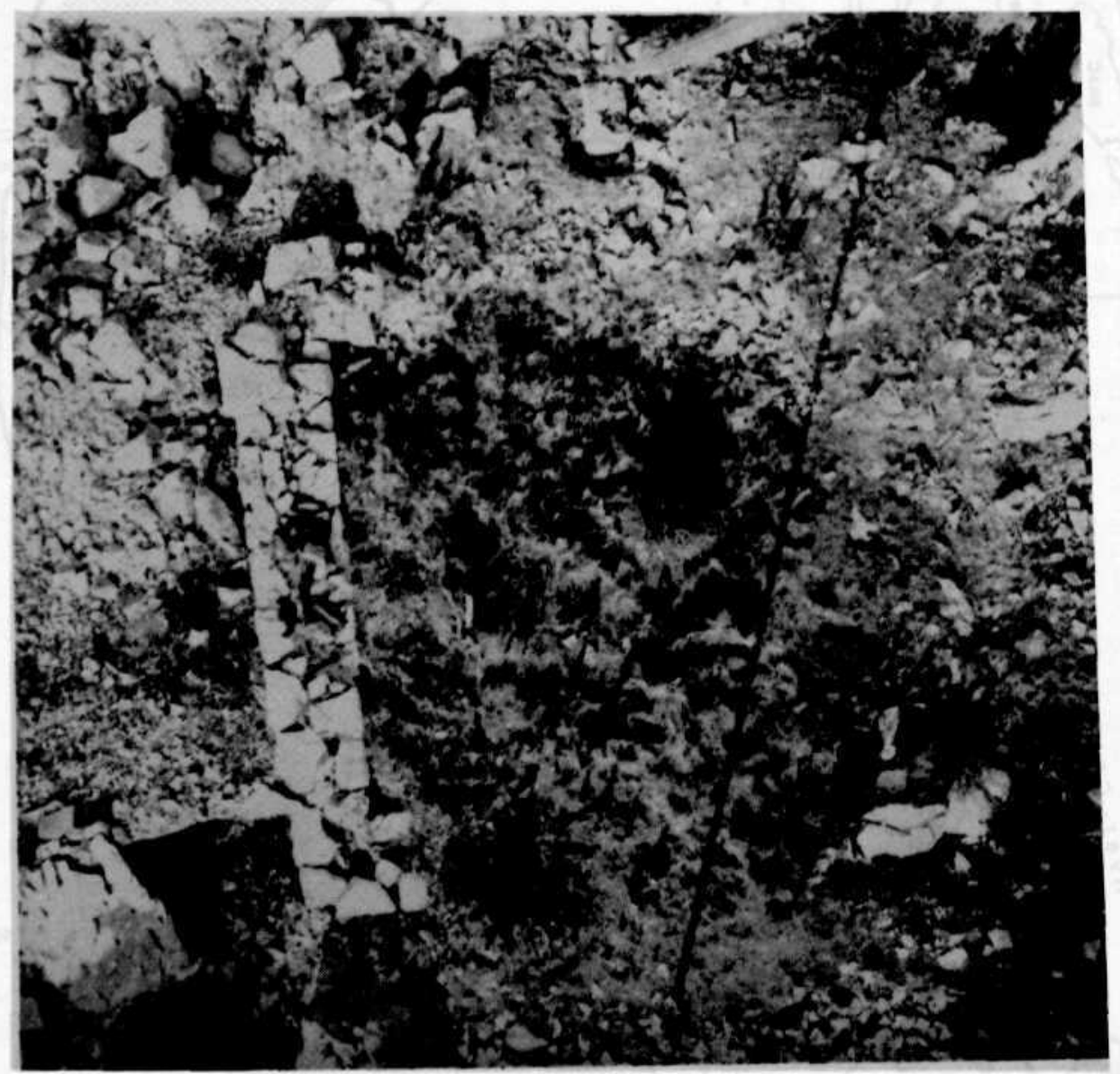

Plate 10.1 Excavations in progress at Maslinovik. North to top. 


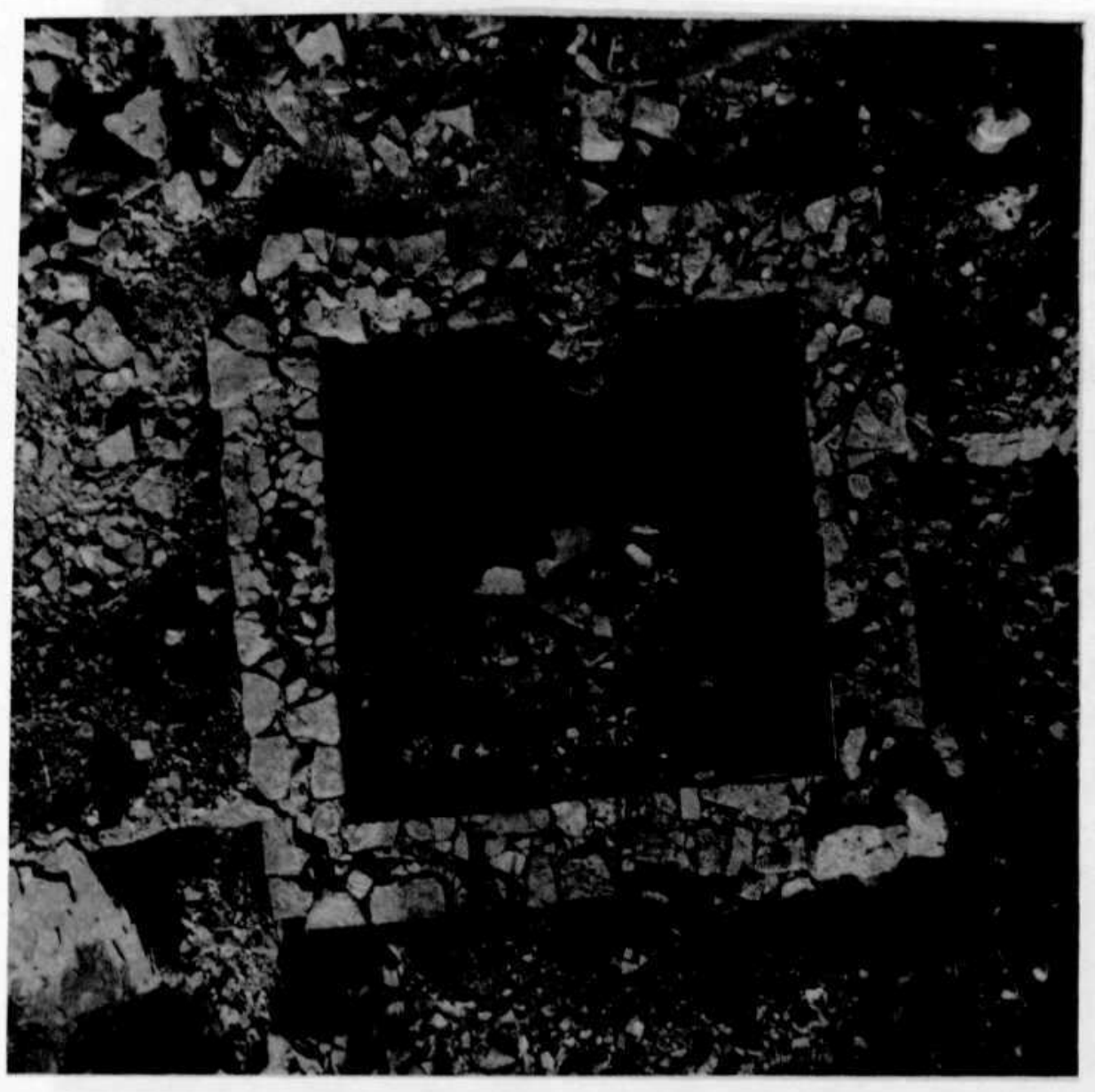

Plate 10.2 Excavations in progress at Maslinovik. North to top. 


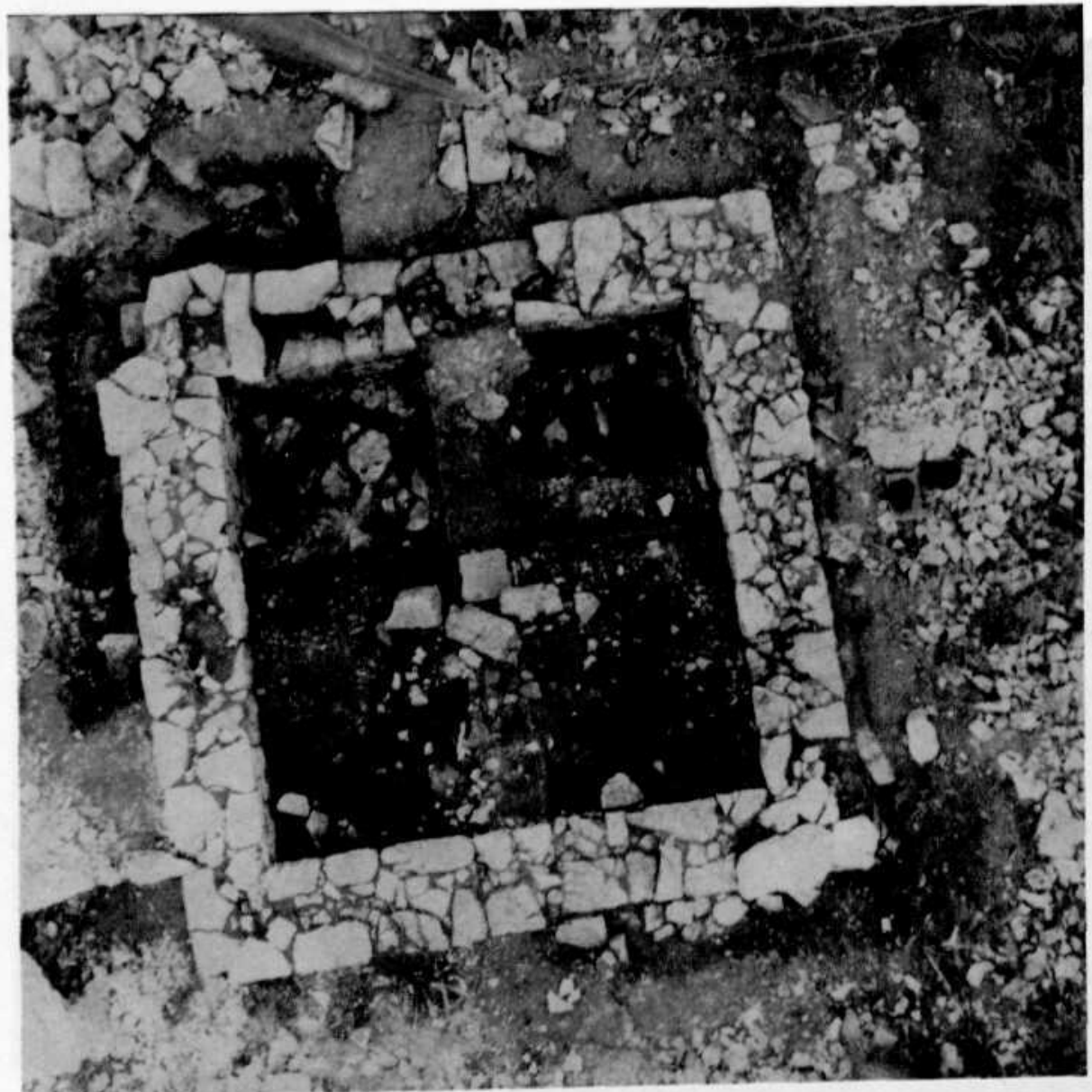

Plate 10.3 Excavations in progress at Maslinovik. North to top. 


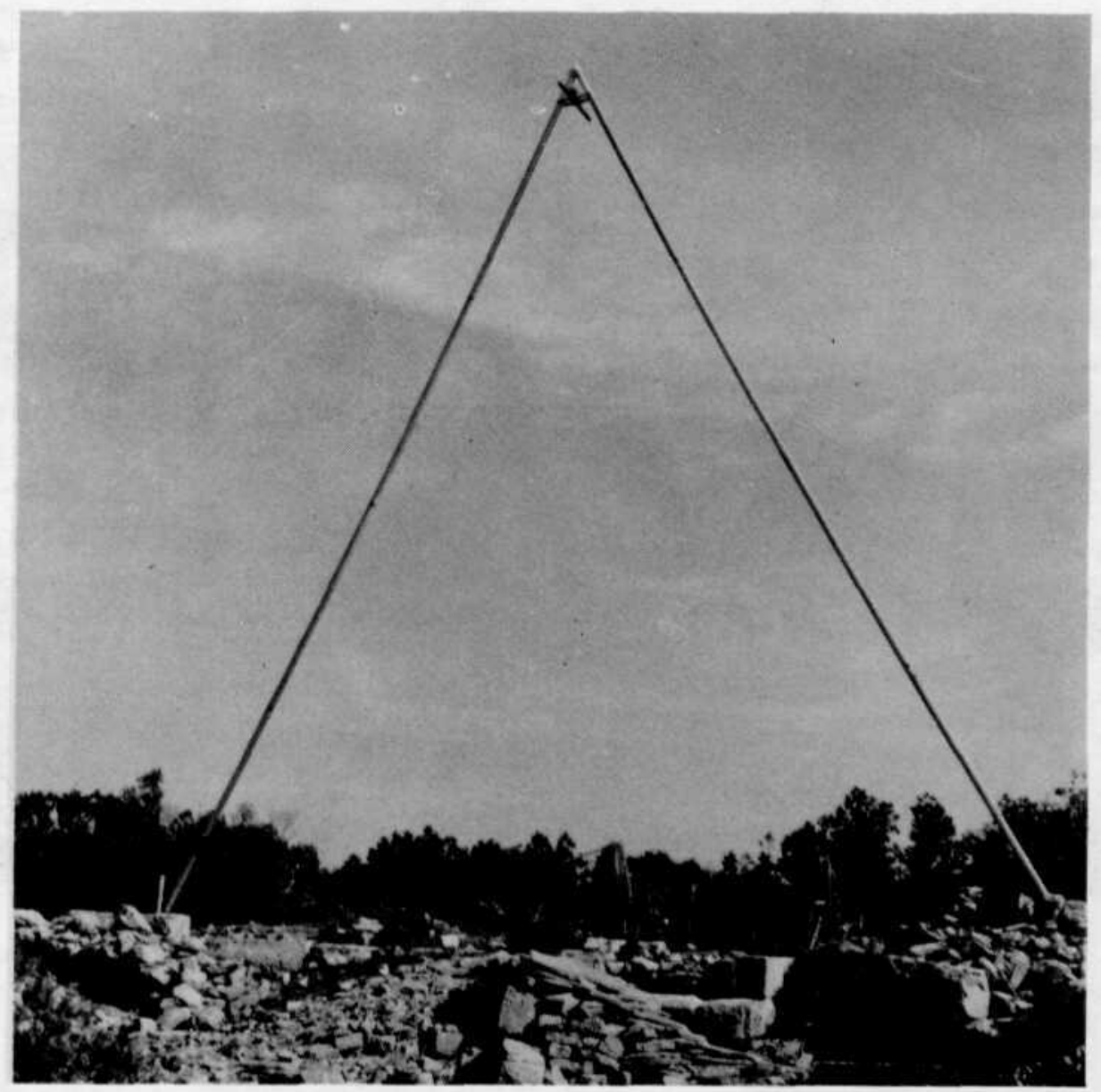

Plate 10.4 View of tower from South west. 


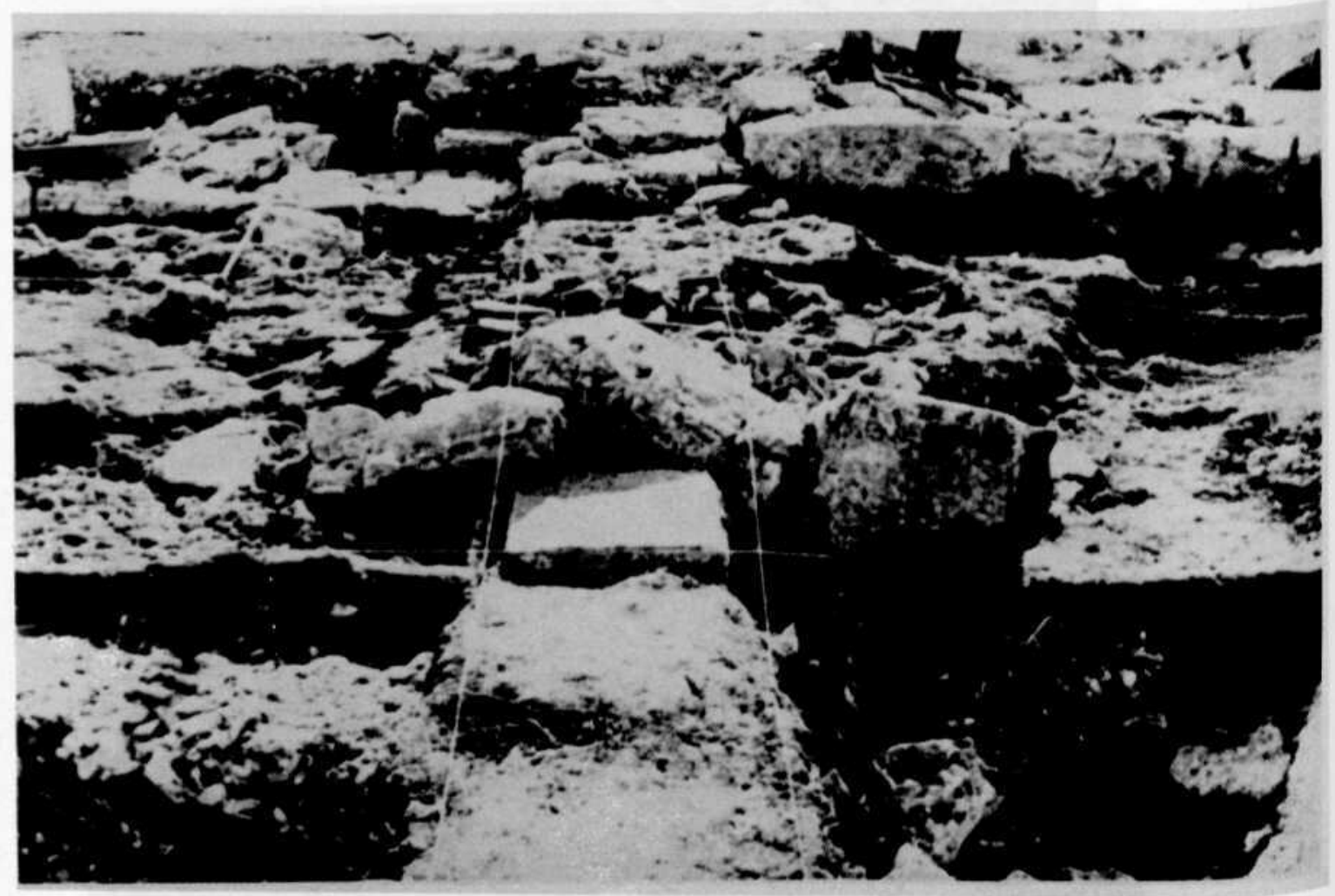

Plate 10.5 Interior of the tower from North. 


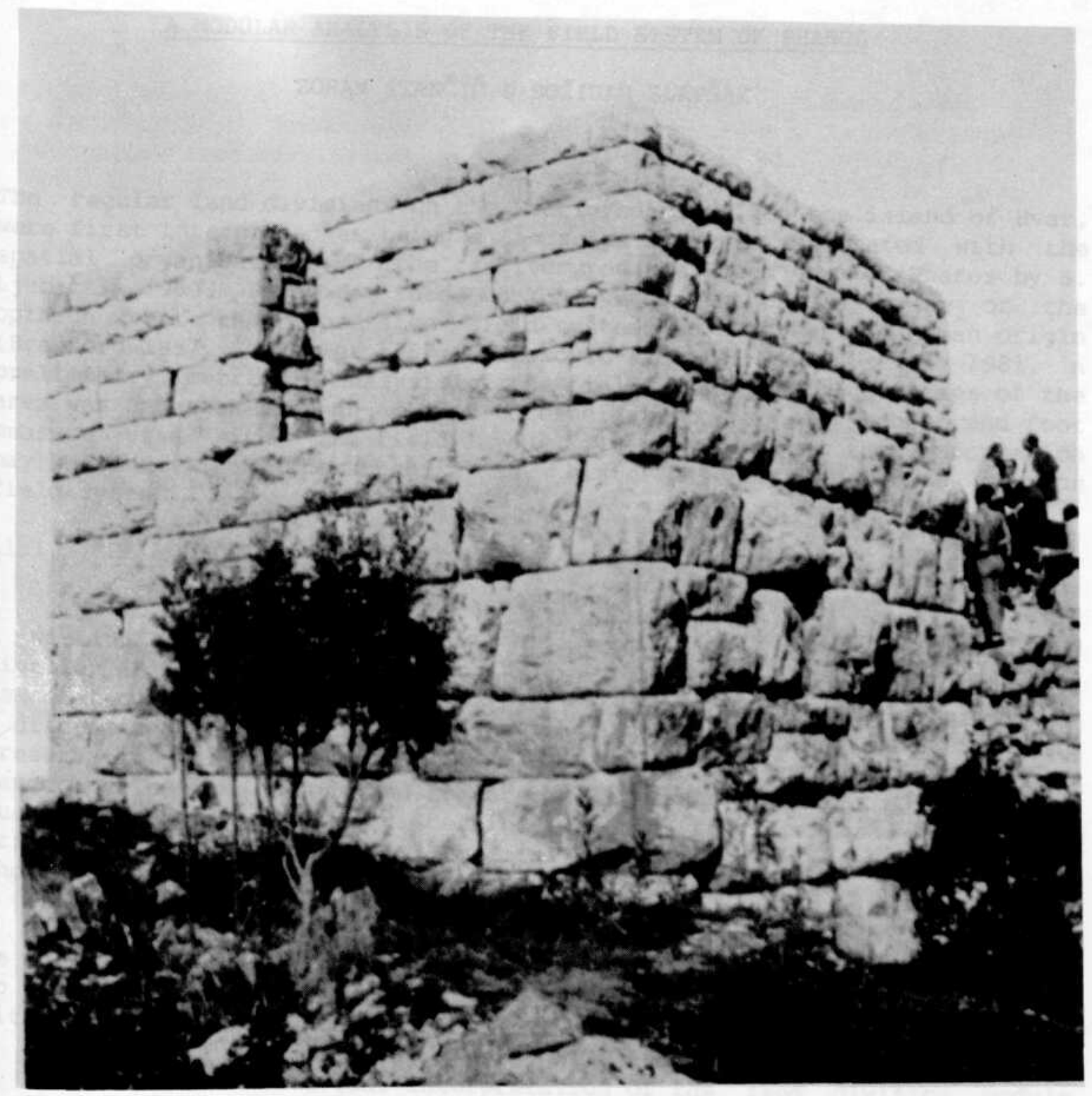

Plate 10.6 Tor : view of the South East corner. Upper part reconstructed. 


\title{
CHAPTER ELEVEN
}

\author{
A MODULAR ANALYSIS OF THE FIELD SYSTEM OF PHAROS
}

ZORAN STANC̄Í́ \& BOZ̄IDAR SLAPS̄AK

The regular land divisions on the Starigrad plain, on the island of Hvar, were first interpreted as being a landscape feature associated with the spatial organisation of the territory of the Greek town of Pharos by $S$. Ljubić in 1960. Prior to this work several authorities were of the opinion that the impressive field systems on Hvar were of Roman origin (Bradford 1957, Chevalier 1957, Duboković-Nadalini 1962). In 1981, a preliminary metrical analysis of the fields from the 1:5,000 maps of the area was undertaken in an attempt to elucidate the modular scheme and foot measure used within the field layout. It was felt that such information may be of critical importance in any historical interpretation of the field system.

\subsection{THE MODULE}

Within the analysis of the Hvar field system, the modular unit of land division is defined as that which appears to be delimited regularly by associated roads or paths, thus forming a continuous rectangular grid (for a discussion of the concept of 'limites', see Dilke 1974). The excellent preservation of the Pharian field systems within a number of substantial landscape features (stone and terrace walls, roads ets, ) has ensured that such units are readily discernible within the Starigrad plain. The principal lines of the system are easily identifiable from both aerial photographs (Bradford 1957), and cadastral maps of the area.

Using this information, land plots on the central part of the plain can be shown to be roughly $180 \mathrm{~m}$ wide and $900 \mathrm{~m}$ in length, and follow the east to west axis of the plain. These units can be interpreted as following either the 1 × 5 Greek stadia module or the Roman 5 × 25 actus module.

The metric and historical interpretation of the land division module used on the Starigrad plain must depend upon the definition of the foot measure used within the layout of the fields.

\subsection{THE FOOT MEASURE}

The work commenced on the basis that the sides of the land plots were in fact undivided multiplicators of an elementary unit. This seemed to be a reasonable assumption since initial analysis indicated that the land division module approximated the known stadion or actus values of $180 \mathrm{~m}$ or $5 \times 36 \mathrm{~m}$. The 50 plethra square units with a diagonal of a 1000 feet suggested from epigraphic evidence for Larissa, and the $210 \mathrm{~m}$ square with a 1000 foot diagonal, suggested for Hersonnesus (Salviat and Vatin 1974) 
cannot be accepted as the basis for analysis of the Hvar field layout. Such a scheme would produce an unnacceptably small foot measure of only $255 \mathrm{~mm}$.

Unfortunately, the 1981 analysis proved inconclusive. Whilst the results appeared emphatically to exclude the Roman and Attic foot measure of 297.6 as the basic unit used at Pharos, the mean value eventually produced by the analysis - $308.2 \mathrm{~mm}$, could not be fitted into any known foot measure. The result also indicated that there appeared to be inconsistencies within the measurements taken for analysis, the source of which demanded a far more systematic analysis. During 1986, one of the authors (z. Stancić) undertook a further re-analysis of the field system with the intention of isolating the basic unit of measure used on Hvar.

The plan designed to produce the desired result was essentially very simple. This involved three stages of analysis:

1. The measurement of a statistically adequate number of distances between fixed points on surviving ancient field boundaries.

2. The original foot measure should then be produced by dividing the length of each measured boundary by 600 , and its length in stadia.

3. The data from this sample would then be used to calculate the arithmetic mean of all measures. The final result of this work should be a figure which would correspond to a known Greek foot measure.

Naturally, there was a number of difficulties in applying such a scheme. Perhaps the most significant problem is that of the dynamism of the human landscape. On Hvar, the field system represents over 2,000 years of continuous development and modification. The original assumption made by the authors, that the boundary of abutting field units would originally have ran down the middle of the dividing roads, was obviously complicated by the fact that the width, and even the position of roads may have changed over time. Such changes may be the result of natural processes, erosion, or further human activity, including terracing, later land division or aggregation of land parcels. Whilst major deviations from the original layout are relatively easy to detect, and errors avoided, small scale errors are more difficlult to isolate. The cumulative impact of such small variations in the field layout must be expected to affect the results of any analysis of the field system.

\subsection{THE DATA BASE}

At the beginning of the study, it was decided to utilise a statistical sample of 100 measurements chosen randomly from those unit boundaries which did not appear to display major deviation from the original modular layout. Information gathered during the analysis included: the position of the boundary within the cadastral system, the length of the boundary in millimetres, its orientation (east-west or north-south), and its length in 
stadia, All measurements used in the analysis were taken from $1: 5,000$ scale maps. The mean error of measurement was $+1-0.2 \mathrm{~mm}$, or $+1-1 \mathrm{~m}$. upon the ground. This was regarded as sufficiently accurate for the purposes of the analysis.

\subsection{THE STATISTICAL ANALYSIS}

All statistical analysis was carried out on an Atari computer. The procedure for analysis involved the correction of all map data for distortion. The corrected data were then divided by (1) 600 , and (2) their length in stadia. The arithmetic mean of all 100 measurements was $306.01 \mathrm{~mm}$. The frequency distribution of all data is shown below (Figure 11.1). This result was problematic. Once again, the result did not appear to fit any known Greek or Roman unit of mensuration. In order to confirm that this figure was not the result of the use of a combination of different units of measurement, a refined analytical methodology was employed. The re-analysis of the measured data involved the re-definition of the sample into groups based upon the position of the measurement within the cadastral unit, and the measurement's orientation. This analysis revealed a significant difference between measurements oriented north-south and those aligned east-west. Application of a $t$-test indicated that this difference was not accidental, but was significant at the 0.99 level. This information is displayed below (Figure 11.2), showing two clear peaks within the frequency distribution broken down by orientation.

This new information prompted the idea that the measurements of the land units contained not only the original land units, but also some other quantity which affected north-south and east-west measurements differentially. The greater frequency with which roads crossed the field system in an east-west direction, as a consequence of the rectangularity of the land plots, rather than a north-south direction suggested that the inclusion of the roads within the analytical scheme might be the source of the error.

Consequently, it was hypothesized that, in order to isolate the original land units used in land division, it would be necessary to subtract the width of the road from the measurements used within the analysis. The immediate problem in posing such a solution lay in the fact that we did not know the original widths of the roads contemporary with the field system. In order to overcome this problem, the average width of all roads within the database was calculated using a simultaneous equation, producing a figure of $2983.5 \mathrm{~mm}$.

It was hypothesised that this value would represent an undivided multiplicator of an elementary unit. To isolate this hypothetical unit, an analysis was carried out using a series of values representing road width, and varying between 6 and 15 units/feet. The standard deviation of these units was measured, and it was shown that the standard deviation was at a minimum when a value of 10 units is used (Figure 11.3). By using this information, the graph of frequency distributions can be adjusted and 
shows a similar peak in both north-south and east-west directions (Figure 11.4). These data allow the modular unit utilized at Hvar to be fixed between $301.68 \mathrm{~mm}$ and $302.63 \mathrm{~mm}$ at the $95 \%$ confidence level. The arithmetic mean of the whole sample suggested a foot measure of $302.16 \mathrm{~mm}$.

\subsection{CONCLUSIONS}

The results of the analysis of the Pharian field system are interesting for a number of reasons.

1. These results put to an end the long and vexed discussion of the origin of the Pharian cadastral system. The final figure of $302 \mathrm{~mm}$ produced by the above analysis cannot be of Roman origin. The measure does, however, have suitable parallels in other areas of the Greek world, most notably the later stadia in Isthmia and Epidauros, which also date roughly to the period of foundation of the Greek apoikia on Hvar.

2. The study demonstrates that, in the case of Pharos, the assignation of land distributed to citizens was based upon undivided linear measures, and was exclusive of the roads which delimit the 1 × 5 stadia land divisions. It would seem reasonable to hypothesise that such a situation arose from the differing legal status of the plots: the basic communication network of the Chora was public property, whilst the cultivated land, including the access roads and tracks, was private.

3. The study also presents a simple procedure which can be used to verify the foot measure used within any rectangular field division. Its future application on other key sites (e.g. Hermessos) would be particularly interesting.

4. Finally, the work carried out on Hvar demonstrates that the Salviat-Vatin interpretation of the Greek land division system, based upon the 50 plethra square units, is by no means universal in application. It would follow, therefore, that specific analyses based on Salviat-Vatin's results, including Boyd and Jameson's (1981) discussion of the Halieis town plan module, should be re-evaluated in the light of the results from Hvar.

\section{5 .1 Footnotes}

1.

The land divisions on the western side of the plain, near Faros/Pharia, and the eastern area around the bay of vrboska, whilst following the orientation of the grid, and preserving the 1 stadion $/ 5$ actus north-south division, appear to be less rigorous in their application of the 5 stadia/25 actus east-west limites. Such areas would have to be treated separately. 


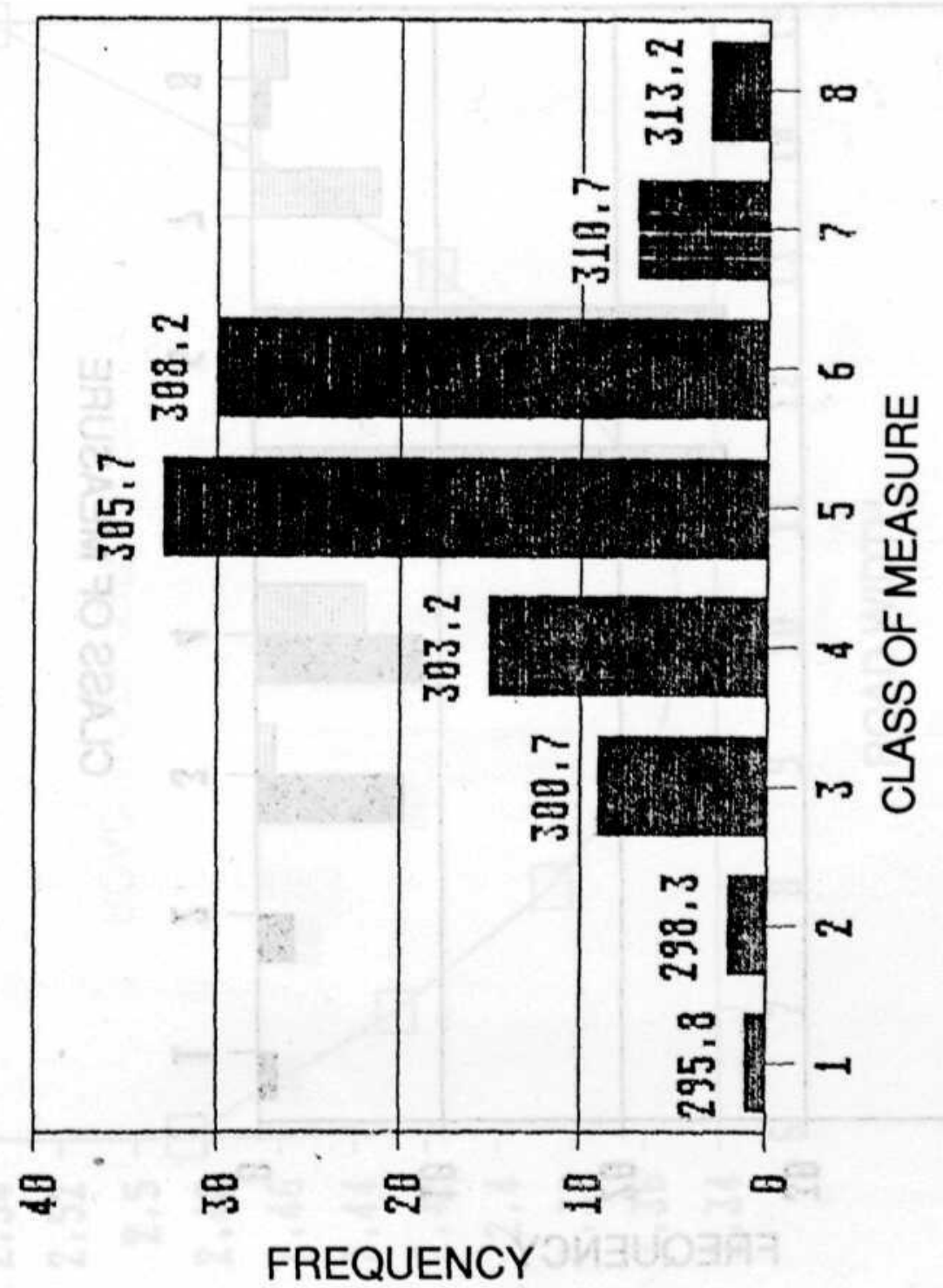

Figure 11.1 Frequency distribution of all measurements, pharos centuriation system. 


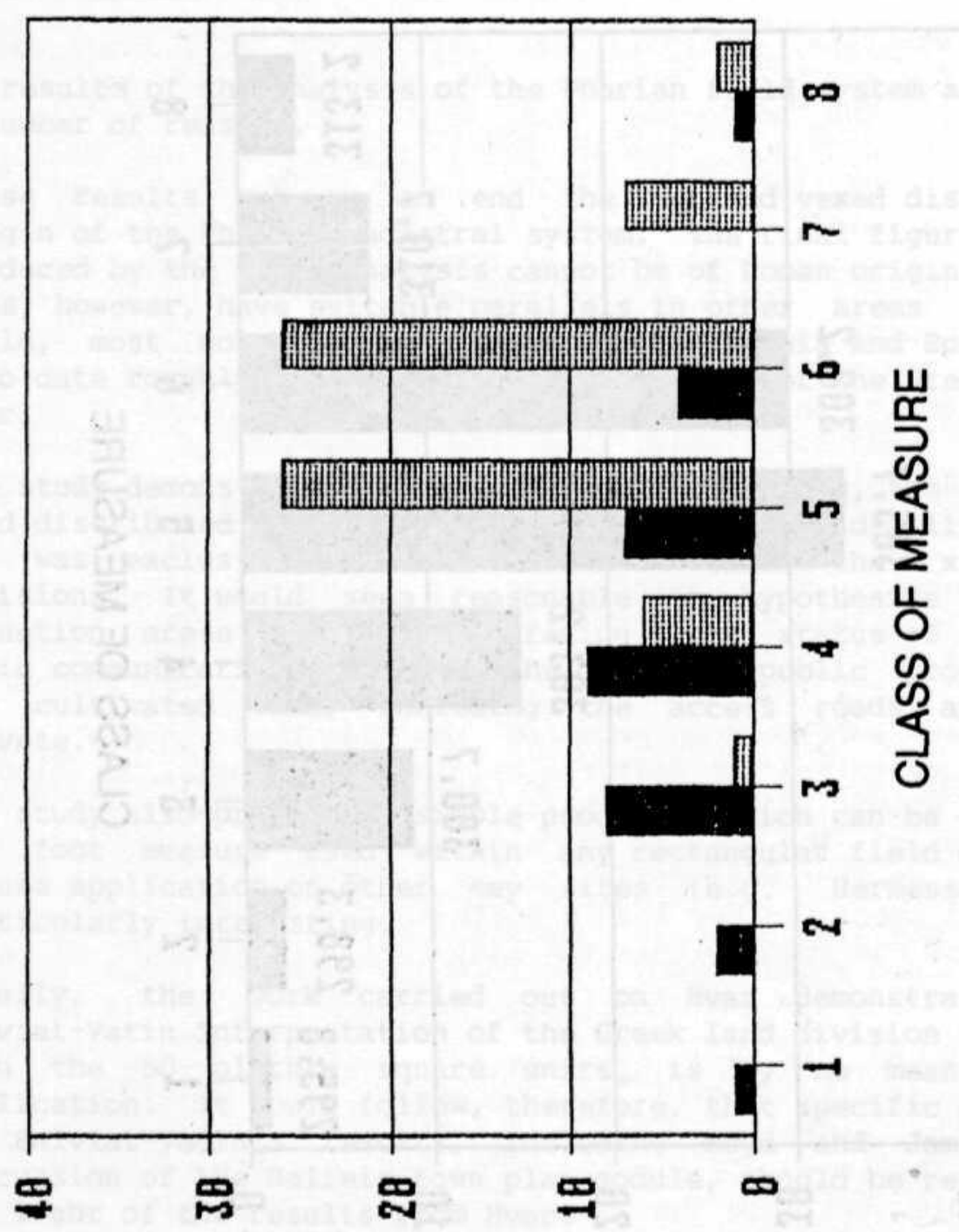

FREQUENCY

Figure 11.2 Distribution of measurements by direction ( solid bars $=\mathrm{E}-\mathrm{W}$; stippled bars $=\mathrm{N}-\mathrm{S}$ ). 


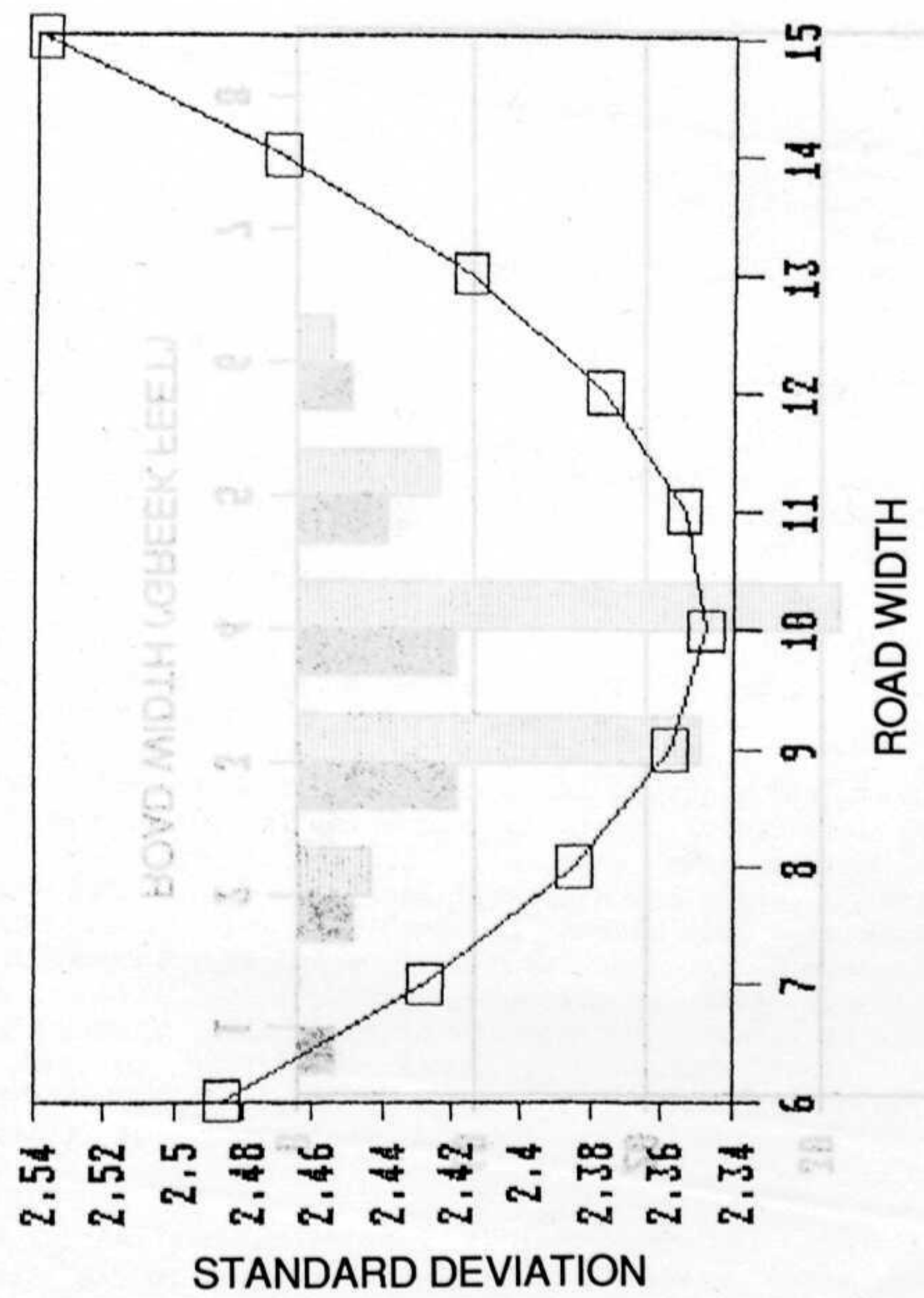

Figure 11.3 Standard deviation of road widths 


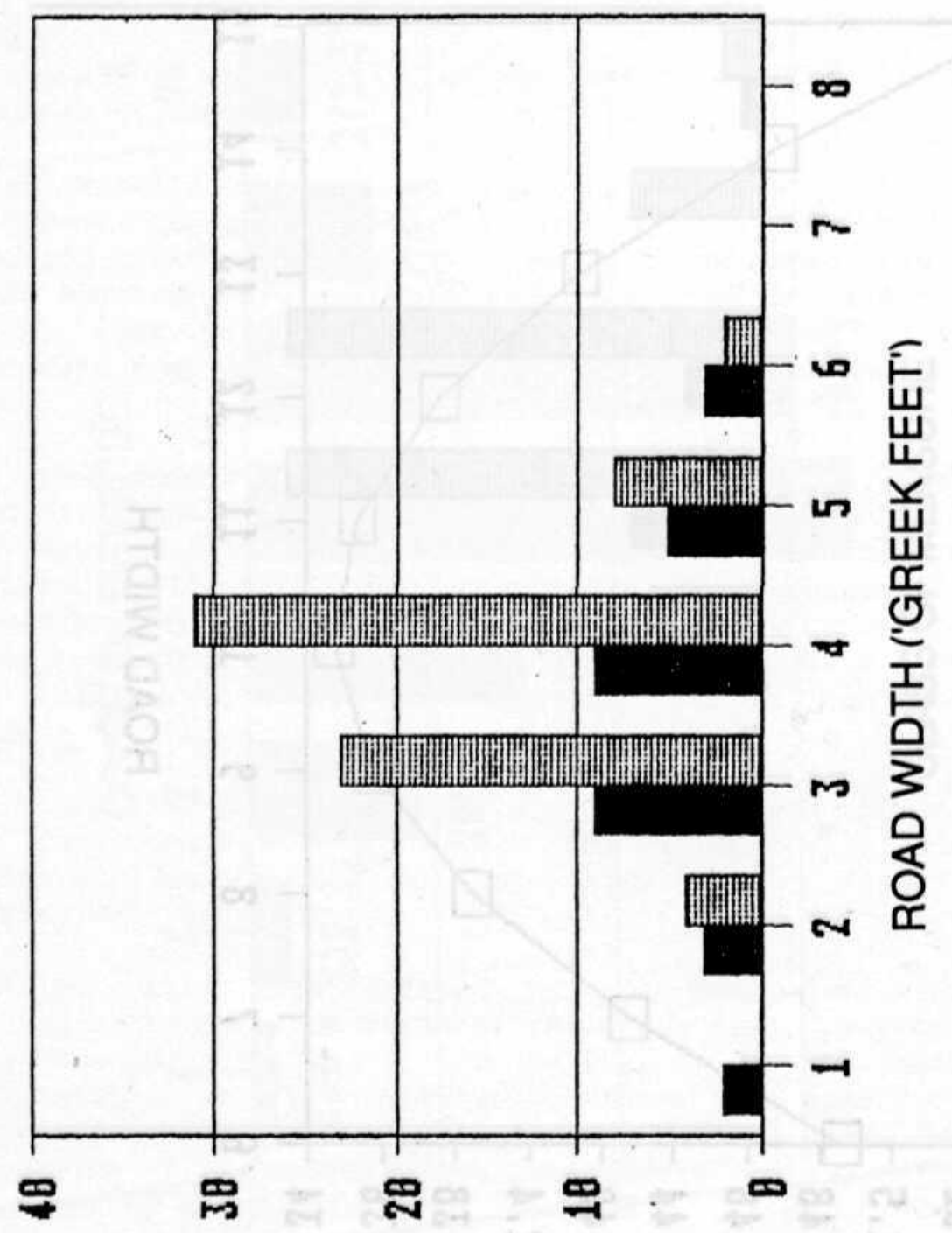

Figure 11.4 Adjusted frequency distributions of standard deviations of road width (key as in Fig. 11.2). 
PART THREE : SLOVENIA 
200 


\section{CHAPTER TWELVE}

MINERALOGICAL RESEARCH ON THE NEOLITHIC CERAMIC ASSEMBLAGE

FROM MOVERNA VAS

IGOR KLOPC̄IĆ

\subsection{THE DEVELOPMENT OF THE PETROLOGICAL RESEARCH STRATEGY WITHIN THE MOVERNA VAS PROJECT}

The petrological analysis of ceramics has become an increasingly important analytical tool over the past 20 years. Standard texts on the subject have been available for some time (Peacock 1970). Although similar work has been carried out within Yugoslavia (Osterc 1986), there can be little doubt that the subject is not so developed here as in many other parts of Europe.

The work described below is based upon the ceramic assemblage excavated at the Moverna Vas Neolithic site. Although Miha Budja's work at this site has been continuing for some time, petrological analysis of the excavated ceramics has only been in progress for less than a year. Undoubtedly it will be some time before an authorititativestatement can be issued regarding the final results; however, some statement of the aims, structure and preliminary results would be useful.

From the very beginning of the project a series of leading principles were formulated to guide the development of the research programme. These leading principles included the following points:-

1. Although much important mineralogical analysis has been carried out upon archaeological assemblages within Yugoslavia, the project team felt that too little of this work was carried out within a specifically archaeological framework and that, consequently, too few of the previous projects produced results that were directly relevant to contemporary archaeological questions. It is also true to say that very few past analyses within Yugoslavia were carried out upon a statistically valid sample of ceramics. It was an inevitable result of such an uncritical sampling procedure that, whatever such mineralogical analyses concluded, they could rarely be used either as a basis for comparison between sites or even as evidence for intra-site patterning.

A further problem related to mineralogical studies lay in the nature of archaeological ceramic analyses. The almost complete absence of quantitative fabric studies within Yugoslavia and a continuing emphasis upon vessel form typologies has not provided a suitable base for petrological analysis.

The petrological status quo appeared to be a situation in which neither archaeologists nor petrologists were aware of the needs, aspirations or potential of either discipline. 
2. It was felt that the full-time association of a geologist with the archaeological project team might well result in a fruitful academic partnership. Benefits from such professional co-operation were seen in the provision of an inter-disciplinary theoretical framework in which mineralogical analyses might be validly integrated within an archaeological context, and conversely for archaeological work to be planned with the aims of providing valid data for petrological research.

3. Given the nature of excavation at Moverna Vas, and the very small excavated area (a trench $8 \mathrm{~m}$ by $4 \mathrm{~m}$ : personal communication, Miha Budja), no possibility existed for intra-site analysis. It was therefore decided to concentrate on analysis of technological change over time. It was also hoped that such an analysis would provide a useful statistical data base of use for comparative purposes with similar studies on other sites. The provision of a regional mineralogical data base would also allow future archaeological research into the nature of technological and economic development over time and space.

4. The research questions at Moverna Vas and the quantity of sherds to be contained within the analysis made it essential that a fast and effective processing method was developed. The final procedure, which is described below, ensured not only rapid processing and classification of artefacts, but also allowed a continuous re-assessment procedure, such that several questions posed at the beginning of the analysis were discounted as a later stage.

5. At this point in time, the research project is still working on the refinement of analytical techniques relevant to the problems under discussion. Present work has allowed the classification of fabric types through the petrological analysis of inclusions and the study of their surface features. Future work will include the validation and extension of these results through the use of electron scanning microscopy and critical statistical analysis.

\subsection{THE DEFINITION OF RESEARCH GOALS WITHIN THE MOVERNA VAS MINERALOGICAL RESEARCH PROJECT}

It was felt essential that the research parameters of the work carried out at Moverna Vas were defined as a consequence of archaeological needs related to the site. The initial step in this direction lay in the creation of a pottery series using mineralogical and traditional fabric analysis as criteria for separation. During this phase of study, a number of questions was posed. Alongside the original aim of isolating technical change over time was the problem of the relationship of mineralogically defined fabric types to functional or morphological vessel groups; did petrological change over time reflect simple technical innovation or other factors including trade, differential social access to materials or functional intra-site patterning? What in fact does a fabric represent? Could such a category be regarded as a useful variable, and how should such a variable be used within archaeological analysis and interpretation? 
However, as the following description of the research procedure will show, many of these questions eventually became irrelevant to the ceramic sample at Moverna Vas and a completely new set of more relevant problems based upon the nature of the available archaeological sample and the results of the mineralogical analysis were adopted. Of the original "archaeological" questions only the most general have survived critical reappraisal.

\subsection{ANALYTICAL WORK CARRIED OUT ON THE MOVERNA VAS POTTERY ASSEMBLAGE}

\subsubsection{Sampling the ceramic population}

As noted above, it is essential that the ceramic sample used within mineralogical analysis has a valid statistical base. In order to achieve such a situation, analytical work was carried out upon all pottery contained within a single vertical column through the stratified deposits. This micro-quadrant, which is 1 metre square, will eventually carry the full burden of qualitative mineralogical analysis. The choice of this column rested upon the fact that it contained within its pottery assemblage examples of all defined fabric types. However, the representativeness of the analysed assemblage is being checked through the random selection of further micro-quadrants for fabric analysis. However it must be stressed that randomly selected quadrants will not be subject to destructive mineralogical analysis as it is essential that these control columns remain intact for future statistical analysis.

\subsubsection{Analytical research techniques}

The results from a number of the novel analytical procedures carried out within the research project let to a redefinition of research goals, and in some cases have given the expectation of a deeper insight into the analysed material. Traditionally many pottery analyses start with a simple visual classification based upon the comparison of the surface of freshly broken pottery fragments. However, this practice was not found to be of value for our analysis. In the case of thick-walled vessels the broken surfaces tended to be too small for our purposes. The exposed surfaces of the sherds were difficult to compare as a consequence of the varying degrees of coarseness of the pottery fabric. Experimentation showed that classifications based on this technique rarely survived objective re-appraisal. Much time was lost through attempts to standardise the pottery classification using traditional techniques. It was decided that a method had to be found to provide an increased and uniform surface for analysis. Eventually it was decided that such an aim could be achieved by the use of an electric dry grinder. The surface obtained by this method was very suitable for the purpose of providing statistically useful measurements of inclusions, and determining their size, shapes, densities and orientation (Pettijohn 1975). When the exposed surface was polished a number of other features also became visible. These included pores, cracks, traces of organic matter, clay mixing patterns and indications of primary and secondary mineralisation. 
Grinding took approximately 3 seconds per piece and polishing a further 5 seconds. The surface could then be compared visually and observed quartz densities formed the initial basis for fabric identification. At a later stage quartz densities were quantified using a grid. This is a time-consuming exercise and there are some problems in its application (see below); however, the results will be still be of use for statistical classification and validation of the fabric series. Sherds are usually treated upon their corners and are ground on both margins and transversally to the break.

One of the by-products of grinding was the raising of the temperature of the pottery surface. Inevitably some materials in the clay began to melt and in some cases produced a patchy surface film. These films were composed of bruised quartz grains fixed together with, probably, manganese oxides. However, the surface temperature and film formation can be controlled through the speed of the grindstone. These results are interesting in that these films can be used as another classificatory element, whilst their formation can be controlled and they need not develop into features obstructing further work.

The next stage in the analysis was designed to identify the range of inclusions present in the pottery and to decide which inclusions were naturally present in the raw material and which were added. This in turn led to structural analysis. The composition of the sherds was determined through inspection, under a polarizing microscope, of small quantities of materials scraped from inclusions and set within immersion oils. This again proved to be a very fast and efficient technique. However, it should be stated that questions related to some opaque crypto-crystallic materials can only be fully answered through the use of a scanning electron microscope or the use of chemical probes. Relevant chemical analyses can be divided into several groups: those which etch the surface of the inclusion and those which use a number of dissolving and heating probes. In the latter group the use of a borax pearl could prove a fast and efficient form of analysis (Nikitin n. d.). 
The techniques described above could provide information on the structure of inclusions which have previously been studied only through the use of a stereo-microscope. Another alternative method of structural analysis is the microscopic study of highly polished surfaces where the internal structure of opaque materials can be studied in a reflected polarized light. The natural structures examined using these techniques will be more accessible if inclusions are treated with vibro tools, chisels or needles which expose the core of the inclusion.

The next part of the analysis was directed at the most abundant of inclusions, quartz grains. Obviously these inclusions gain importance not simply as a result of their numerical densities but also because they form the qualitative basis for fabric differentiation. Initially, work proceded with the counting of quartz grains and the measurement of grains visible on the polished surfaces of ground sherds. However, although statistics of this type may provide some useful guidelines, they cannot yet provide reliable estimates of the true populations of quartz grains, some of which are macroscopically invisible. Improved polishing techniques might help to provide a more accurate estimate of such populations.

In order to attempt to provide a more accurate picture of the quartz population, thin sections of the ceramic were made (Streeten 1980). The preparation of thin section samples was simplified by excluding water as a grinding medium. Thin sections were achieved by dry grinding. The samples were air-cooled. This technique is desirable as unlike traditional thin section preparation no impregnation or drying is needed . The method proved more efficient than grinding in gasoline, although this is still used in the finishing stages. The advantage of using thin Sections rather than some of the methods discussed earlier lies in the technique's ability to display the internal structure of grains and their arrangement .

However, a disadvantage of the technique is the fact that some variables, for instance grain shape, cannot reliably be determined, whilst a certain number including the smallest of quartz grains may be hidden within a strongly limonitised matrix. A large number of thin sections should be analysed in order to compensate for these problems.

An alternative to the use of thin sectioning for these specific problems was developed. This involved the disintegration of the clay matrix of sherd samples through the use of a $10 \%$ solution of hydrochloric acid. As no carbonates have ever been identified within the Moverna Vas Ceramic assemblage, there should be no bias due to the loss of inclusions through the use of this solvent. Materials in suspension were separated from the heavier particles by decanting. Filtration could have also been used, but at this stage it was felt unnecessary to separate the residue further. The remaining muddy sediment was composed of clay minerals, Sericite, zircon, rutile, feldspar and quartz micro- and crypto-crystals. All of these were fluvial deposits sedimented from suspension (Pettijohn 1975). 
The residue of larger particles contained quartz, muscovite, haematite and other grains. Where necessary, opaque materials can be separated from dissolved ceramics through the use of bromoform and studied separately. This group also contained a certain amount of undissolved clay material which must of course retain other particles. We must therefore remain aware of this problem in carrying out further work. The use of a more concentrated acid would probably reduce this problem.

What then was the chemical effect of this process? Further work indicated that no gas was being produced during the reaction and that a yellow film which developed on the glass containers used indicated that irregularly shaped crypto-crystallic limonite minerals had formed a kind of sub-structure of microscopic veins within the sherd. This network collapsed after immersion for about an hour within the acid solution. The utility of this method was that the freed grains were directly available for analysis of shape, size and surface features; by contrast, these variables could be estimated using only other techniques. The quantity of grains released through this method is also far larger than the sample provided by thin sectioning and consequently the results may validily be used within a number of of statistical analyses. The speed of the technique also offers advantages over the more tedious and time-consuming methods of thin sectioning. Although this technique is totally destructive of the source sherd, proportionately less material is destroyed than the equivalent sample needed for thin sectioming. However, it must be stressed that thin sectioning will remain part of the analytical process as many features within the sherd matrix cam only be studied through this technique.

At this stage several other analytical techniques which could be of value in the clarification and validation of the fabric series might be mentioned. $\mathrm{X}$-ray diffraction could give information on the composittion of the sherd matrix and surface treatments. This technique would also offer an insight into those cases-where several different types of clays have been mixed within one sherd. Infra red spectroscopy could also answer some questions associated with the study of amorphous opaque material contained within ceramic samples.

\subsection{PRELIMINARY RESULTS}

The mineralogical work on the Moverna vas pottery assemblage is in most senses in a state of semi-completion. Although many valuable results have been obtained, few have been subject to statistical validation including uni-variate and bi-variate analysis or cross checking using alternative analytical techniques (Petz 1985). However, we can at this point describe the preliminary results.

Two basic mineralogical groups have been isolated although it is expected that further work (e. g., $\mathrm{X}$-ray diffraction) may well produce further divisions. The first of these groups was distinguished through a lack of mica. The second group was defined through a relative-abundance of this material. Within both of these groups are a series of 
sub-divisions based on the varying densities of quartz; several individual sherds stand out as a consequent of an anomalous population of quartz inclusions. It is possible that such anomalies may indicate the presence of an as yet unrecognized third mineralogical group. Another anomalous group of sherds contained within the Moverna Vas ceramic sample are those which contain voids whose shape indicates the former presence of organic matter. It is of interest that this organic matter was probably contained within the original raw material and not added. Further work will resolve the status of these anomalies.

As work has progressed, it has become apparent that the most significant inclusion for statistical analysis is quartz. Virtually all other inclusions seem to produce geo-chemical results which, whilst interesting, are not necessarily relevant to the archaeological problems being studied by the research team. Consequently the principal thrust of analytical work has centred upon the study of the ceramic quartz population.

The shape of the quartz grains has proved very informative (Pettijohn 1975). They show that, in some cases, the grains were crushed whilst others retained a sub-angular profile. Well-rounded examples are extremely rare. Broken grains tend to display shell-like breaks. Idiomorphic quartz mono-crystals often show signs of being broken although unbroken transparent crystal planes are well preserved and show no signs of mechanical erosion or pseudo-morphosis that could be attributed to the effects of firing. This indicates a firing temperature of below 600 degrees C. It seems likely, therefore, that other grains present should be well preserved and that their surfaces will be of use in determining erosional surface features (Marshall 1987). Such information would allow us to isolate, in some cases the source of the quartz grains. We could, for instance, attribute some grains to water- or wind-deposited sediments (Marshall 1987).

Diameters of the chemically freed grains are now being studied statistically (Love 1977). After study under a stereo-microscope, these grains have been measured to a 2 figure accuracy. Graphs compiled from these results show a normal distribution within single sherds. This was not expected as observations made during the grinding process had initially indicated preferential sorting, a situation one might expect if we were dealing with a deliberately added inclusion. It is an interesting point that grain counting may in some circumstances give a completely unrepresentative result because a certain significant proportion of grains may remain invisible on the surface of the sherds as a consequence of inadequate sample preparation. Perhaps the most significant consequence of the creation of a valid statistical base relevant to quartz grains will be the ability to isolate preferential quartz addition to archaeological Ceramics or to indicate whether such inclusions were simply part of the raw material. Given the fact that archaeologists ascribe significance to such inclusions, it is essential that any conclusions drawn from the analysis of such variables have a statistically valid base. 
In cases where preferential addition is suspected, it would be necessary to examine the surface of quartz grains for evidence of other processing activities, for example, crushing associated with the addition of temper (Marshall 1987). During the present work several grains have in fact been isolated which show evidence for breakage. At the present time it is unclear whether this is the result of thermal shock or some other processing activity (Marshall 1987). Future work involving an electron microscope would probably discriminate between these two possibilities.

The observations made above refer on the whole to grains which were not part of a suspension load. The smaller grains characteristic of suspension represent a separate and in some cases significant population. It is essential that these grain types are treated separately. of specific interest in this case are zircon monocrystals whose surface features are particularly useful in the analysis of erosion rates. Analysis of these crystals can discriminate between related clay sources which, whilst being mineralogically indistinguishable, have suffered a different erosional history.

Until recently, colour was not held to be a significant mineralogical variable. It was generally believed that differences that did occur were the result of firing technology. However, a solitary piece revealed a clear pattern indicative of the mixing of two clay types. Future work will have to anticipate the possibility of a mineralogical distinction occurring between sherds of different colours.

\subsection{CONCLUSIONS}

The preliminary nature of this paper vitiates the need for the presentation of a complete set of results. However, several points can, and should, be made. The initial contribution of the work at Moverna vas has been directed to the continuing development of petrological techniques. The use of a fast and efficient grinding technique is of particular note. The importance of this technique lies in its ability to process large numbers of sherds quickly. It is also significant that such a technique has a field application. There is little in the method which would not allow the processing of samples, including thin sections, on site. The simplicity of the preparatory stages of the above techniques means that the early steps of analysis could be carried out by archaeologists themselves, thus cutting down the amount of expensive specialist time required. In the past, the rather slow, laborious and expensive techniques used in petrological analysis have limited the application of such studies. The time-saving nature of the above study will reduce the cost of future analysis, thereby widening the number of potential applications. The potential for bulk processing also increases our ability to achieve a valid analytical data base. If such schemes are successful, in the future there will be no excuse for inadequate or unrepresentative sampling.

The results from Moverna Vas also emphasise that archaeologists should be concerned with all aspects of the nature of ceramics. In order to draw valid conclusions regarding the significance of such material in a 
technical or indeed social context, there must be an adequate knowledge of the material being studied. Whilst some of the results presented here may seem overtly petrological to some archaeologists, such studies are essential if we are able to isolate those variables which are significant to archaeological interpretation. We should be able to say whether inclusions within a ceramic object were deliberately added or naturally present. The techniques outlined above are part of an attempt to answer at least some of these questions and all were designed to aid and validate the ceramic classifications required by archaeologists. It is only through the results of such slow and accurate work that archaeologists will eventually be able to achieve their more ambitious aims related to ceramic studies. At the level of the site ceramic assemblage, such data will form the basis of the interpretation of technical variability and social hierarchy. Beyond the confines of the site, ceramic analysis will be an integral part of any comparative work. Petrological analysis has a part to play within this scheme and it is hoped that the work now being carried out at Moverna Vas will provide a useful contribution.

\subsection{ACKNOWLEDGEMENTS}

I would like to thank the following individuals for their help and assistance in the development of this project. For continuing financial assistance, the Tanja Klopēić "foundation". Laboratory space was kindly provided by Doctor Vasja Mikuz. Doctor Boz̄idar Slaps̄ak has provided much needed encouragement and advice. Vince Gaffney for textual help and much archaeological discussion. For assistance with petrological problems, I would like to thank Dragica Stermole. Milena Horvat and Miha Budja of the Department of Archaeology, Ljubljana for needed discussion and archaeological data. Professor Valerija Osterc at the Department of Geology for help. The manuscript was typed by Stefanija and Alenka Jamnik.

All the above individuals saved me from many pitfalls of my own creation; however the views expressed within the final publication are mine solely. 


$$
210
$$




\section{CHAPTER THIRTEEN}

THE SOCIAL CONTEXT OF THE INTRODUCTION OF IRON IN THE EARLY IRON AGE OF SLOVENIA

PHIL MASON

It is the intention of this paper to discuss the social context of the introduction of iron, and the change from bronze-using to iron-using, in the early first millennium bc societies in Slovenia, with specific reference to the sphere of prestige exchange and the development of hierarchical organisation. The discussion will be confined, of necessity, to prestige systems and archaeologically recognizable prestige materials, because the lack of data concerning the organization of agricultural production, precludes speculation about the nature of elite control over the apparently non-elite economy, and the role that this played, first, in the rise of the hierarchical societies, or, secondly, in the maintenance of the prestige exchange networks. The chronological parameters of the period under consideration extend from 1000 bc to $600 \mathrm{bc}$, encompassing the later bronze age and the initial phases of the early iron age in the region, the Hallstatt $\mathrm{Bl}-\mathrm{B} 3$ and Hallstatt $\mathrm{Cl}-\mathrm{C} 2$ in Central Europe (see Figure 13.1) (Dular 1973, 544-591; 1979, 65-100; Gabrovec 1973, 355, $368-373$ ).

The modern geographical region of Slovenia, a constituent republic of Jugoslavia, is located to the north of the head of the Adriatic sea, and is the main focus of the overland routes between northern Italy, to the west, and the northwestern Balkans and the Pannonian Plain, to the east and north-east, especially through the Sava and Danube river valleys in northern Yugoslavia, southern Hungary and southwestern Rumania. The physical relief of Slovenia is dominated by the Southeastern Alps in the northwest, and the Dinaric Alps or Karst in the south and southeast, whilst the eastern part of the region is dominated by the highly dissected limestone plateau of Dolejensko. Two major rivers drain from northwest to southeast, the rivers Drava and Sava, which together with the river Krka, a tributary of the Sava, provide the major areas of potential arable lowland, and the major arteries of communication and exchange utilised in the early first millennium bc, as can be seen in the concentration of late bronze are and early iron age mortuary and settlement sites in these river valleys (see Figures 13.2 and 13.3) (Pounds 1969, 624-627, 637-638; S̈as̄el $1977,157-160)$.

Archaeologically the late bronze age period, which dates from $1000 \mathrm{bc}$ to 750 bc, was characterised by the Rus̄e group, centred on the Drava river valley, and the Ljubljana group, which occupied the Sava and Krka river valleys (Gabrovec 1973, 368-371; Müller-Karpe 1959, 115-130). These two groups were the part of the widespread Central European Urnfield tradition. This name arises from the mortuary pracice, associated with this complex, of cremating individuals, and burying the inurned ashes in flat cemeteries. Ljubljana and Rus̄e group material is fairly typical of 
the so-called Pannonian Urnfield regional group, found in eastern Austria, western Hungary, northern Croatia and northwestern Serbia. The mortuary sites of these two groups consist of small, flat cremation cemeteries of no more than 400 graves, e.g. Ljubljana (Pus̄ 1971; 1982; Staré 1954), Novo mesto-Mestne njive (Knez 1966, 51-101; 1982, 119-132) and Ruse (Müller-Karpe 1959, 115-126), and of ten cemeteries with much smaller numbers of graves, e.g. Novo mesto-Brsljin (Knez 1967, 155-161), Molnik (Pü 1984, 134-162) and Brinjeva gora (ANS 1975, 296). This contrasts with other regions within the Urnfield complex, most notably Poland and East Germany, where cemeteries associated with the Lausitz group can contain up to 3000 graves (Coles and Harding 1979, 359-370). It should be noted that relatively few known settlement sites have associated later bronze material. The known sites are either on undefended hilltop locations (e. g., Brinjeva gora (Pahic 1981, 71-143)) or on the first river terrace (e. g., Ormo $\overline{\mathbf{z}}$ (ANS, 1975, 320). Other sites may lie beneath later buildings (e. g., Kranj-Parish Church (Horvat 1983, 140-218) and L jubljana-Castle Hill (ANS 1975, 187)). The archaeological data used here is drawn largely from mortuary sites, which show little evidence of differential deposition of grave goods, which is often taken as an indicator of social stratification. The emphasis is more on the deposition of relatively simple ceramic sets with only occasional pieces of bronze. This will be discussed in more detail below. Settlement sites have been neglected archaeologically, with the exception of those sites noted above.

The early iron age period extends from $750 \mathrm{bc}$ to $300 \mathrm{bc}$, but only the earlier part, dating from $750 \mathrm{bc}$ to $600 \mathrm{bc}$, is of consequence in this study (Dular 1973, 544-591; Gabrovec 1966, 1-48; 1973, 371-373). There is not only a major technological change in this period with the introduction of iron, but also major change in mortuary pracive and settlement location, although continuity in material culture is apparent from the later bronze age. The Dolenjsko group superceded the Ljubljana group in the eastern part of its territory, the Krka and Sava river valleys in east-central Slovenia, whilst the Ruse group was superceded in the Drava river valley by the Wies-Martijanec group, which also included southern Styria and northwestern Croatia (Dular, 1979, 85-85; S.Pahic 1973, 538-539). The most notable features of both these groups are that burials, which now included inhumations as well as cremations, were placed in barrows, which were frequently clustered in large groups around the new defended hilltop settlements. Examples of this can be seen in the c.70 barrows at Libna (Gus̃tin 1976, 20), the c.30 barrows at Magdalenska gora (ANS 1975, 200), the c.79 barrows at Podzemelj (ANS 1975, 242-243) and the c.130 barrows around Stic̄na (ANS 1975, 197), all of which lie in the Dolenjsko group area. A similar pattern is exhibited by sites associated with the Wies-Martijanec group (e. , the c.700 barrows surrounding the Burgstallkogel hillfort at Klein-Klein (Dobiat 1980) and the 78 barrows in the cemetery at Legen near Slovenj Gradec (Strmēnik-Gulić 1979, 101-150)). Isolated barrows are also known, (e. g., at Bostanj (Gus̄tin 1974, 99)) as are flat cemeteries (e. g., Vac̄e (Staré 1955)). Such mortuary/settlement complexes are usually situated on high ground dominating the major river valleys or lowland basins, such as the Grosuplje polje. These locations were thus important for maintaining access to potential arable land and 
maintaining control over major inter-regional communications (Figure 13.3).

The change in archaeological groups, described above, has previously been explained in terms of outside intervention, either through invasion or immigration. The continuity between the later bronze age and early iron age groups, which is stressed above and emphasized below, make these theories untenable. However, it is insufficient to hypothesize that the Ljubljana and Rus̄e groups had a more egalitarian social organisation than the later groups, or that the latter were the results of processes of increased hierarchisation. The mortuary record can often mask social differentiation, as well as express it. If this is the case with this data set, why is the social complexity in the later bronze age of eastern Slovenia hidden in this way? In his study of 19 th and 20th century burial practice in Britain, Parker-Pearson (1982) suggests that suggests that mortuary practice is a way of focussing the attention of the living on the status of the dead, but that this will not normally take place when there is a good reason for making such a public statement. Thus overt status will usually be shown in the mortuary recort during times of stress or change, either in an attempt to reinforce the existing system or to legitimate new structures. The later bronze age period in slovenia may then represent a period of social stability but with a society just as complex as in the early iron age. The new burial patterns show change in part of the Ljubljana and Rus̄e groups and a commensurate need to legitimate the new or re-aligned socio-political situation. This increase in overt status differentiation is a widespread phemonenon throughout much of Central Europe, appearing at the same time as the introduction of iron. The processes behind the changing pattern were not, however, uniform.

This can be better explained by an examination of the prestige economy of the Ljubljana group. The position of this group, in the Sava/Krka valleys, meant that it dominated the main routes between northern Italy and the northwestern Balkan region, along which which the major late bronze age exchange networks operated. The chief article of exchange which can be detected archaeologically was bronze. This was a prestige material, possession and exchange of which contributed to social status. In many ways bronze is the ultimate prestige substance, in that the most mundane of artefacts can be recast into prestige forms, so that the metal itself, like gold, was intrinsically valuable. The Ljubljana group was adjacent to the copper-producing regions of the Eastern and Central Alps (Pittioni 1980a, 33-37; 1980b, 77-92), and was thus ideally placed to manipulate the supply of one element essential in the production of bronze. The other, tin, was available in the Bohemian Erzgebirge, and in the Colline Metallifere in central Italy, although there is no direct evidence for the exploitation of these ore sources in prehistory (Gregory-Warden 1984, 349-364; Muhly 1973, 256; 1976, 99-100).

The burial data from Ljubljana group cemeteries seems to indicate that the social organisation was not as egalitarian as a simplistic interpretation would suggest. The first phase of the cemetery at 
L jubljana, the Ljubljana I phase ( $1000 \mathrm{bc}-800 \mathrm{bc}$ ), is represented by only 48 graves (Pus 1982, 196). There is no way of knowing the duration of use of the cemetery in this phase, but the finds can be dated to two chronological groups, Ljubljana $\mathrm{Ia}$ and Ljubljana $\mathrm{Ib}$, equivalent to Hallstatt B1 and B2 respectively. There are nine dated graves, four in the first phase and five in the second; the remainder can be dated only to the Ljubljana I phase in general (Gabrovec 1973). In this study, the burial population is treated as being evenly spaced over the 200-year period. On the assumption of a 25-year generation, this gives us a potential living population of 6 individuals/generation - hardly a viable social unit. However, the presence of bronze in some of this small number of graves may be significant; fitness for burial may have been an indicator of high social status. Lower status individuals may have been placed in other as yet undiscovered cemeteries, or disposed of in some other manner, perhaps by excarnation or river burial. Thus elites based at Ljubljana, Novo mesto and Mokronog in Dolenjska and at Bled in Gorenjska can be detected in this phase (Gabrovec 1973). All of these sites lie on key routeways, which would enable them to control the flow of prestige material. The pre-eminence of the site of Ljubljana is emphasized by the large quantities of fine bronzework deposited in the river Ljubljanica at Ljubljana.

This begs the following questions: how then was this stable system transformed into the apparently more complex early iron age social system, and why was iron adopted, when bronze served so well as a prestige good? The crucial period, in which the mechanisms behind these changes can be detected archaeologically, is the eighth century bc, the Ljubljana IIa and Ljubljana IIb phases in Slovenia (see Figure 13.1). A major source of archaeological material in this period are hoards - riverine deposits and single finds of bronze or scrap - which were deliberately deposited. Recent research in north-western Europe has suggested that the hoarding phenomenon is more complex than a simple collection of scrap metal for recasting, the deliberate concealment of valuables in times of trouble or the result of chance or accidental loss. The processes of hoard deposition may be linked to the destruction of wealth in the context of a system of prestige competition, examples of which can be seen in the recent ethnographic studies of pre-literate societies (Bradley 1982, 108-122; Levy 1982). The best known example of this is the potlatch of the Northwest Coast Indians of the United States and Canada, in which the deliberate destruction or giving-away of prestige material in a ceremonial context served to increase the social standing of the holder of the potlatch vis-à-vis his rivals for socio-political power (Drucker 1939, 55-65; 1955; Gould 1966, 67-89). A similar system may have existed in many parts of late bronze age Europe (Bradley 1984, 100-106, 114-124). However, the fact remains that hoarding intensified in the 8 th century bc. In northwestern Europe, this has been interpreted in the light of the large quantities of poor quality bronze in the hoards of this period. The advent of the early iron age in Central Europe resulted in the re-alignment of the exchange networks which supplied bronze to northwest Europe, particularly southern Britain and northern France. The result was that the metal in circulation became increasingly adulterated through successive recasting due to the scarcity of fresh supplies. Deliberate 
deposition or destruction served the purpose of maintaining the prestige value of the metal that remained in circulation by maintaining its scarcity (Rowlands 1980, 15-55).

However, such a scarcity and subsequent debasement of the bronze in circulation should not have been a problem in areas like Slovenia, which had access to good supplies of copper from the Eastern Alps. Tin supplies may have been another matter, if the increasing Greek contact with Etruria at this time was directed at the tin of the Colline Metallifere. However, the opposite seems to have been the case; the amount of bronze in the system seems to have increased. The deliberate deposition of bronze then had a two-fold function. First, it served to maintain the value of bronze by removing it from circulation in a system in which the metal was relatively plentiful, thus denying the non-elite population access to the main prestige material. Secondly, it was used in social competition and symbolizes the existence of an elite who are invisible in the mortuary record. The operation of a similar mechanism can be seen in the change in the potlatch system among the Northwest Coast Indians after European contact. Prestige goods became more widely available to the non-elite population and so the potlatch became more overtly concerned with the destruction of wealth as a means of re-affirming the status of the traditional elite at a time of stress. Naturally, this cannot be treated as a direct parallel to the late bronze age situation in Slovenia, because it concerns the impact of western political and economic forces on a traditional society.

The later bronze age hoards in the Eastern Alps and Styria, immediately north of Slovenia, may have had the effect described above. They also contain valuable evidence of a prestige economy in the Rus̄e group. Weapons and bronze vessels, common elite paraphernalia in the early iron age, were present in the hoards from Seeboden in Carinthia and Schonberg bei Oberwolz (Pittioni 1954, 518-521). The riverine deposits from the Ljubljanica also comprise significant numbers of bronze swords, spearheads, axes and occasional bronze vessels (Terz̄an, personal communication). This material may be indicative of the activities of a more clearly defined elite than that visible in the contemporary mortuary data. Indeed, they may represent a form of surrogate elite burial.

Hoards were numerous, in the Eastern and Southeastern Alps in the Hallstatt A period (c.1100-1000bc) but few settlement or cemetery sites are known (V.Pahic 1983, 106-128). This could be explained partly by the lack of extensive fieldwork in the area, but it does contrast strongly with the later Hallstatt B evidence. The Hallstatt A represents the first appearance of the Urnfield style in Slovenia and the material shows very close parallels with the Hallstatt A hoards and cemeteries from northwest Croatia. This complex seems to be connected to the expansion of long-distance exchange networks in metals. So the hoarding horizon represents a period of status definition, which led to the formation of a stable socio-political system in the Hallstatt B period, indicated by the lack of overt status differentiation in the mortuary data and the decline of hoarding. The riverine deposits of the Ljubljanica and, to a lesser extent, those of the rivers Krka and Sava constitute exceptions to this 
later pattern.

However, this strategy was not followed by the Ljubljana group in the 8th. century bc. Initially, in the Ljubljana IIa phase, bronze increased in quantity in the graves at Ljubljana and Novo Mesto-Mestne $\mathrm{N} j$ ive. However, in the second half of the eighth century bc, the Ljubljana IIb phas, a different picture emerges. For the first time, iron appears in some quantity, in fact replacing bronze in many cases. It is used in the same way as bronze, in the form of neckrings, bracelets, anklets and fibulae, not for weapons; it even found its way into riverine deposits (Gabrovec 1973, 369, 371-372). The introduction of iron in this way into a recognisably late bronze age group, like the Ljubljana group, may with good reason be described as an Ornament Horizon. Although the Adoption of iron as a prestige material may have resulted from a breakdown in at least one part of the metal supply (e. g., tin), it seems more likely that the impetus for change was to a large extent internal. New cemeteries appeared in Dolenjska and Bela Krajina, the eastern part of the Ljubljana group area, which seems to suggest that competition was increasing within the Ljubljana group. The apparently dominant elite at Ljubljana responded initially by making more overt use of bronze in mortuary rites and then by seeking a new scarce material which could be injected into the prestige goods system. The constant quest for new prestige materiasls and the progressive redundancy of old prestige materials is a common factor in many prestige goods economies, where possession of new and exotic artifacts conveys status and implies access to scarce esoteric knowledge, while more common and familiar forms may become mundane and enter the non-elite repertoire (Helms 1979).

Iron technology began to come into use in the lower Danube valley and the central and southern Balkans after $1000 \mathrm{bc}$. Indeed, iron artifacts have been found in contexts in Rumania in contexts which pre-date $1000 \mathrm{bc}$. This iron technology was ultimately derived from Anatolia and the Levant (Collis 1984,30-36). However iron was also adopted in central and southern Italy in the eighth century bc, through increasing contact with Greece and the Levant, an essentially maritime exchange process (Collis 1984, 58-61). The strong links shown between the site of Ljubljana and northern Italy suggest that the source of this new scarce material, at Ljubljana, lay in the Italian peninsula. However, the Ljubljana group elites in Dolenjska and Bela Krajina were better placed to exploit new exchange opportunities to the east, as will be shown below.

The Ornament Horizon was largely a phenomenon of the Ljubljana IIb phase (750-700bc), during which time the early iron age Dolenjska group developed out of the Ljubljana group. New settlement and burial patterns appeared, with greater evidence of hierarchy in the mortuary material. Iron did not retain the same functions that bronze possessed in the prestige system after $700 \mathrm{bc}$, as it did not have the same intrinsic properties, because it could not be recycled as bronze could be.

The widespread adoption of iron and the advent of the early iron age in northern Italy and the Balkans, gave an added impetus to the development of an elite in the Dolenjska group for a number of reasons. Firstly 
sources of iron were abundant, not only along the eastern Alpine rim, but also in Dolenjska and Bela Krajina, the heartlands of the Dolenjska group, to the east and southeast of Ljubljana, in the Krka and Kolpa river valleys (Knez 1972, 104). This meant that the local elites could manipulate the exchange of iron into northern Italy, controlling local supplies, as well as those in transit from the Eastern Alps. Links with the Bosut-Bassarabi group in the Yugoslav Danubian region and southwestern Rumania, and the Glasinac group of the central Balkans were numerous, and suggest that these areas were the main source of the new iron technology. These links first appear in the Ljubljana IIb phase with the introduction of the iron and bronze two-looped bow fibulae, and certain elements of ceramic decorative motifs, namely the Maltese Cross, the double spiral and the recumbant running $\mathrm{S}$. These motifs are found on vessels in Ljubljana IIb graves at Ljubljana and at Metlika-Borstek in Bela Krajina (Dular 1973, 544-591). The fibulae occur in Dolenjska in this phase, and derive from the Bosut-Bassarabi and Glasinac areas (Gabrovec 1970, 5-65). The new mortuary practices of the Dolenjska group, inhumation in barrows, also have parallels in the Glasinac group, and in the early iron age cemetery at Vergina, in Macedonia (Gabrovec 1966, 47-48). In Dolenjska the first barrow cemeteries, at sites such as Podzemelj in Bela Krajina, were contemporary with the Ljubljana IIb phase flat cemeteries at Ljubljana, Novo mesto-Mestne njive and Metlika-Borstek (Dular 1979, 65-100). However, there do not seem to be any earlier flat graves at Podzemelj, or at similar sites such as Stic̄na, Libna or Crnomelj (Dular 1979, 85). It would seem that the elites of the Dolenjska group were able to supplant the elite based on the old centre of Ljubljana, due to their possession of actual sources of iron, giving them control over a major exchange commodity, as we well as in the geographical situation of the elite mortuary/settlement complexes, which dominated the important eastern exchange networks, the source of the new additions to the prestige repertoire.

However it is clear that the Dolenjska group developed out of the preceding Ljubljana group for the simple reason that the contemporary flat graves and barrow graves of the Ljubljana IIb/Podzemelj I phase are identical in rite, cremation, and contain very similar grave good types, both in iron ornaments and ceramics. The innovations in the barrow graves at sites like Podzemelj are twofold, firstly the construction of a barrow mound over the graves, and secondly the first clear indications of a sexual dichotomy in the grave goods. These take the form of the deposition of weapons in some of the graves, normally iron spearheads, but in some of the graves, normally iron spearheads, but in one case a bronze sword (Dular 1973, 547). These weapon graves are the earliest manifestation of the later, typologically male, elite graves.

The typologicallly male elite graves contained many indicators of the nature of the early are elite system. Competition on an intrasite level, as well as on an inter-site level, can be observed in the differential distribution of important prestige artefacts, such as weapons and horse-riding equipment, whithin cemeteries. Another important part of the prestige set, which is often found in association with the above artefacts, is the the bronze vessel set. These are of ten elaborate, and 
were probably used in the ceremonial consumption of an alcoholic beverage. Indeed figural friezes in the Situla Art style, found on bronze vessels dating to between $525 \mathrm{bc}$ and $375 \mathrm{bc}$ (see Figure I), depict the use of bronze vessel sets in feasting, along with athletic competition, chariot racing and warfare (Eibner 1980, 261-296). Warfare also lies within this competitive system, the evidence for which can be seen in the construction of hillforts, and in the presence of weapons in mortuary contexts. Although display was partly involved in these phenomena, actual conflict over the control of scarce material resource and access to exchange networks can be seen as a legitimate part of the competitive system (Price 1984, 209-240). The location of the mortuary/settlement complexes is important in this respect, for they were of ten built to dominate not only scarce arable land, but also to control the exchange networks. Thus Libna in eastern Dolenjska dominated the $\mathrm{Kr}$ ško polje and the confluence of the Sava and Krka rivers, which formed the main routes into the northwestern Balkans, whilst Magdalenska gora in western Dolenjska controlled the Grosuplje polje and the main routes into northern Italy, which were formerly controlled by the site of Ljubljana.

Ljubljana itself went into decline after the Ljubljana IIb phase, the burial population becoming progressively smaller over time until burial ceased altogether at some point between $525 \mathrm{bc}$ and $450 \mathrm{bc}$ ( Pus 1973,396 ). This does not necessarily mean that settlement was also discontinued, but that the local elite population was unable to compete with the new elite centres in Dolenjska and so declined and became dependent on these new elites. It is noticeable that the classic traits of the Dolenjska group, barrow burial and evidence of hierarchy in the mortuary data, did not appear here at all.

The Dolenjska group reached its first floruit in the Sticna I phase, between $650 \mathrm{bc}$ and $600 \mathrm{bc}$ (see Figure 13.1). The elite burial population was composed of typologically male graves, which contained iron weapons, horse-riding equipment, bronze disc helmets or sheet bronze helmets, and a variety of bronze vessel types (Gabrovec 1960, 27-80; 1968, 157-188). Typologically female graves were usually less wealthy, containing bronze or iron bracelets, anklets, neckrings and fibulae of various types, although on occasion these could occur in some quantity, and in conjunction with sheet gold trefoil headdresses or diadems (Dular 1973, 572, 583 590). This wealthy "Princely Horizon" as it is often called, was based on the expansion of inter-regional exchange in prestige and mundane materials, particularly between the eastern and southeastern Alps on the one hand, and the Este group in northeastern Italy on the other. The exchange of iron grew in importance, and was supplemented by other materials, such as amber. The exchange networks concerned with copper and bronze continued to exist, but with some modification. Amber was exchanged along a route from the Baltic coast, via the eastern Alpine rim, to Dolenjska. The Dolenjska group then performed a middleman function in further exchanging the amber into northern Italy and Dalmatia (Malinowski 1982, 113-123). It is apparent that the range of prestige materials within the early iron age prestige economy was much greater than that of the late bronze age, which seems to have depended solely on bronze. This range of prestige goods in the early iron age perhaps served to reduce the 
risk of a crisis in the system, like that brought about in the late bronze age by a dependance on a single prestige material,

In conclusion, it is possible to see that the introduction of iron in the eighth century bc in Slovenia was a result of increased internal competition within the Ljubljana group, brought on partially by new exchange opportunities and by a possible temporary shortage of tin. Initially, iron was not adopted for its utilitarian properties but as a prestige material to replace bronze. It appears with a number of other prestige elements, which derived ultimately from the Yugoslav Danubian region and the central Balkans (Gabrovec 1981, 155-178). It was only later that it took on a more mundane role in society. The use and control over iron sources, along with that of amber, copper and salt, led to the aggrandisement of the local elites in Dolenjska at the expense of the traditional elite based at the site of Ljubljana. The need to legitimate the new socio-political circumstances led to the adoption of overt status differentiation in the mortuary record and the formation of the Dolenjska group. The continued existence of the Dolenjska group was dependent to a large extent on its role as a middleman in the long-distance exchange of scarce materials in early iron age east-central and southern Europe and on the large-scale production of iron. 


\begin{tabular}{|c|c|c|c|c|c|c|c|}
\hline & $\begin{array}{l}\text { Central } \\
\text { Europe }\end{array}$ & Ljubljana & Dolenjsko & Ruše & $\begin{array}{l}\text { Klein- } \\
\text { Klein }\end{array}$ & $\begin{array}{l}\text { Sv. } \\
\text { Lucija }\end{array}$ & Este \\
\hline & $\mathrm{Ha} \mathrm{B1}$ & Ia & & $\mathrm{Ha} \mathrm{B1}$ & & & \\
\hline \multicolumn{8}{|l|}{$\begin{array}{r}900 \\
B C\end{array}$} \\
\hline & $\mathrm{Ha} \mathrm{B2}$ & $\mathrm{Ib}$ & Lj Ib & $\mathrm{Ha} \mathrm{B2}$ & & & I \\
\hline \multicolumn{8}{|l|}{800} \\
\hline \multirow{3}{*}{$\begin{array}{r}700 \\
B C\end{array}$} & \multirow{2}{*}{$\mathrm{Ha} 83$} & IIa & Lj IIa & \multirow{2}{*}{$\mathrm{Ha} 83$} & & Tolmin & \\
\hline & & IIb & $\begin{array}{c}\text { Lj IIb } \\
\text { Podzemelj } \\
1\end{array}$ & & \multirow{2}{*}{1} & Ia & 11a \\
\hline & $\mathrm{HaCl}$ & IIIa & $\underset{2}{\text { Podzemelj }}$ & & & $\mathrm{Ib}$ & IIb \\
\hline \multirow{4}{*}{$\begin{array}{r}600 \\
B C\end{array}$} & $\mathrm{HaC2}$ & IIIb & Stična 1 & & 2 & \multirow{2}{*}{ Ic } & IIc \\
\hline & \multirow{2}{*}{ Ha D1 } & & Stična 2 & & 3 & & II/III \\
\hline & & & Sernent- & & & $\mathrm{IT}_{3}$ & IIT \\
\hline & \multirow[b]{2}{*}{$\begin{array}{c}\mathrm{Ha} \mathrm{D2}- \\
\text { D3 }\end{array}$} & & iform & & & Ha & \\
\hline $\begin{array}{r}500 \\
B C\end{array}$ & & & Certosa & & & & $\mathrm{IIb}$ \\
\hline \multirow{2}{*}{$\begin{array}{r}400 \\
B C\end{array}$} & $\begin{array}{c}\text { La Tene } \\
\text { A }\end{array}$ & & $\begin{array}{l}\text { Early } \\
\text { Negau }\end{array}$ & & & & \\
\hline & $\begin{array}{c}\text { La Tene } \\
\text { B }\end{array}$ & & $\begin{array}{l}\text { Late } \\
\text { Negau }\end{array}$ & & & $60=$ & IIIC \\
\hline
\end{tabular}

Figure 13.1 Comparative chronology in the South East Alpine region in the early first millennium $B C$ (after Dobiat 1980 and Dular 1982). 


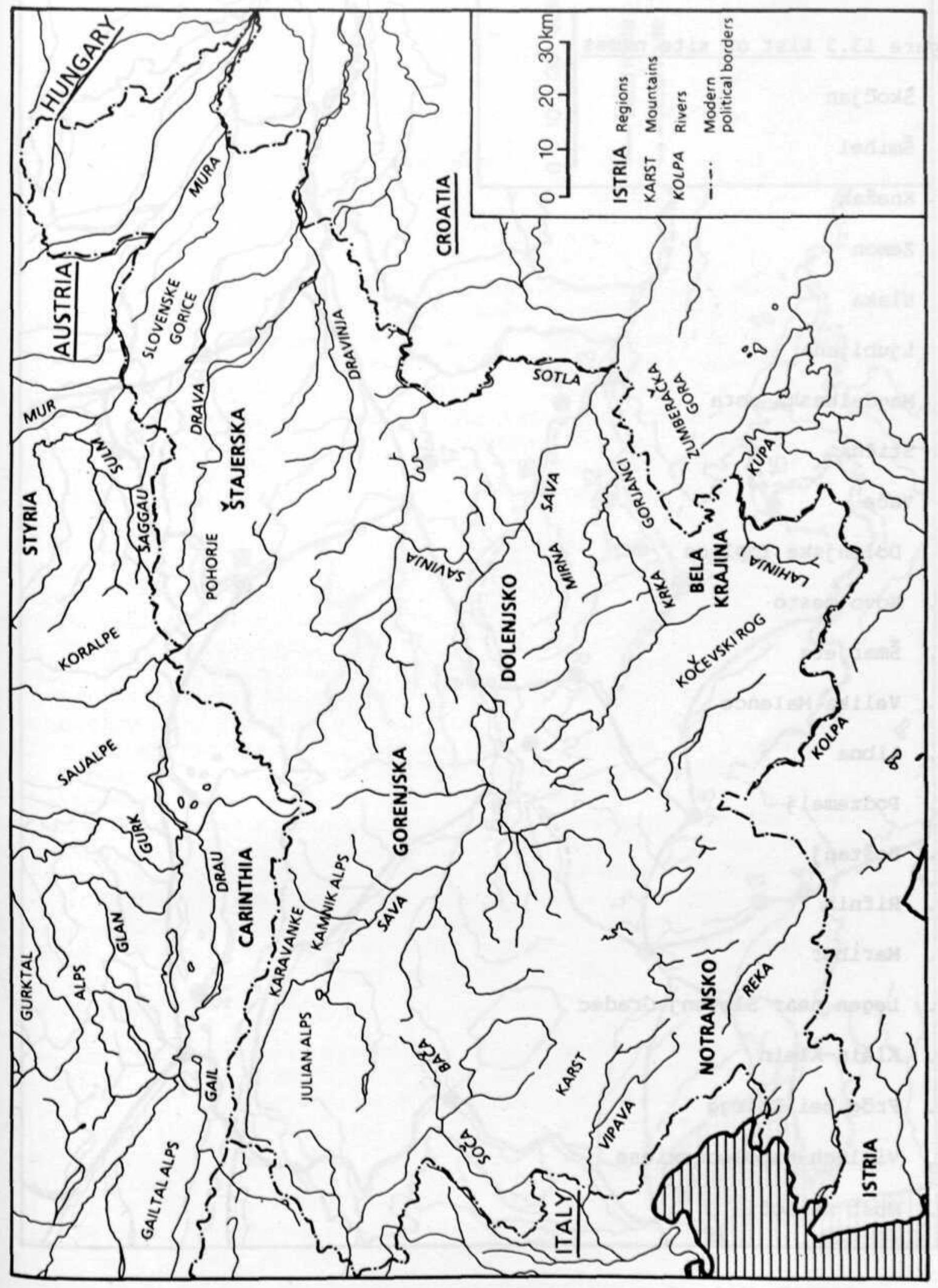

Figure 13.2 Geographical background of Slovenia. 


\section{Figure 13.3 List of site names}

1. Skō̄jan

2. S̈mihel

3. Knez̄ak

4. Zemon

5. Ulaka

6. L jubljana

7. Magdalenska gora

8. Stična

9. Vac̄e

10. Dolenjske Toplice

11. Novo mesto

12. S̄marjeta

13. Velika Malence

14. Libna

15. Podzemelj

16. Bos̄tanj

17. Rifnik

18. Maribor

19. Legen near Slovenj Gradec

20. Klein-Klein

21. Frög bei Rosegg

22. Villach-Napoleonswiese

23. Most na Soči 


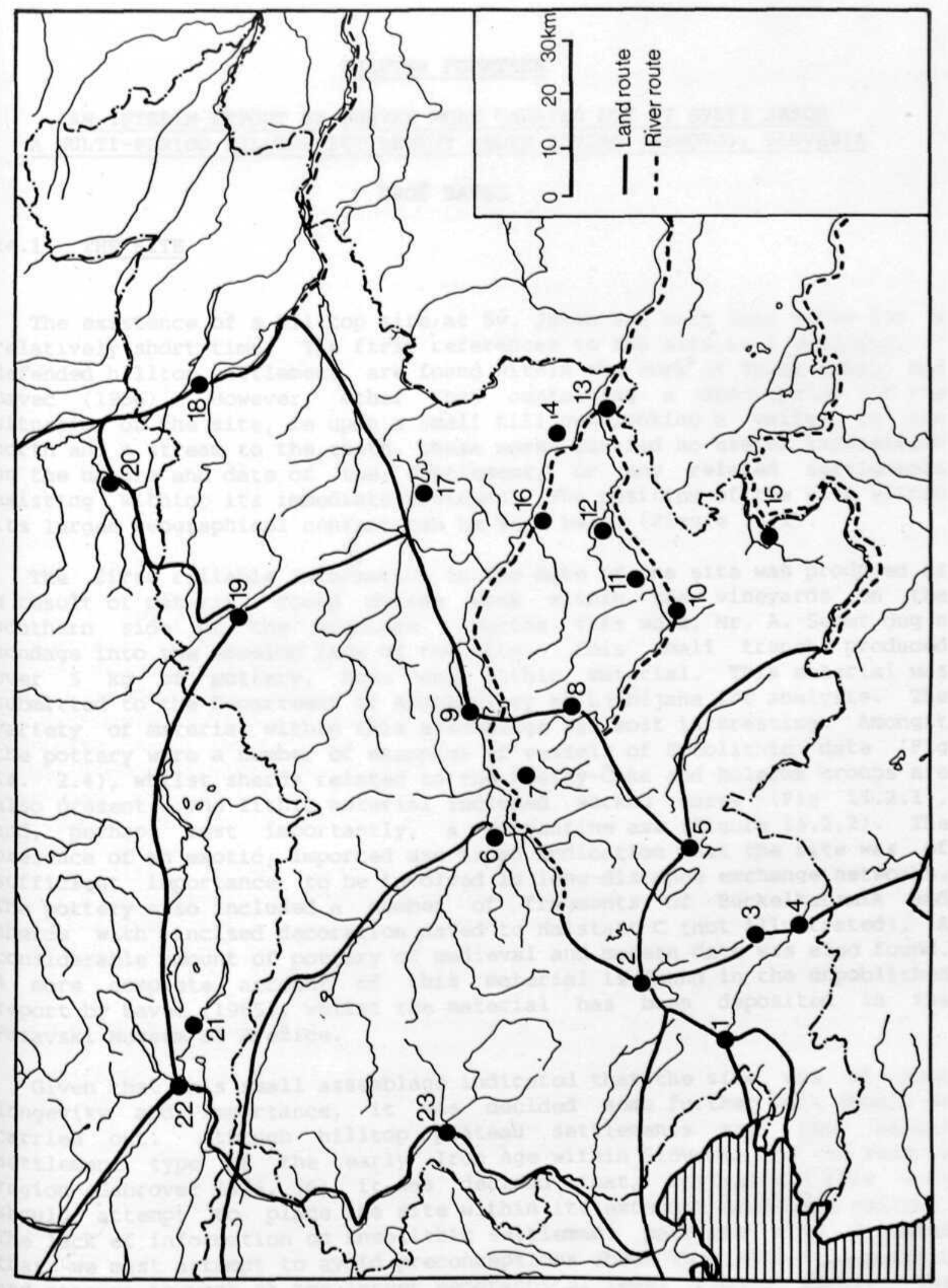

Figure 13.3 Prehistoric communications showing major Late Bronze Age and Early Iron Age sites (see facing page). 
224 


\title{
CHAPTER FOURTEEN
}

AN INTERIM REPORT OF SURVEY WORK CARRIED OUT AT SVETI JAKOB A MULTI-PERIOD HILLTOP SETTLEMENT ABOVE DOVSKO (SENOVO), SLOVENIA

\author{
UROS̄ BAVEC
}

\subsection{THE SITE}

The existence of a hilltop site at Sv. Jakob has only been known for a relatively short time. The first references to the site as a gradisce, or defended hilltop settlement, are found within the work of Trenz (1985) and Bavec (1986). However, other than containing a description of the situation of the site, ie upon a small hill overlooking a valley to the north and a stream to the south, these works carried no useful information on the nature and date of the settlement, or any related settlements existing within its immediate environs. The position of the site within its larger geographical context can be seen below (Figure 14.1).

The first reliable information on the date of the site was produced as a result of material found during work within the vineyards on the southern side of the gradisce. During this work, Mr. A. Seher dug a sondage into the erosion face of the site. This small trench produced over $5 \mathrm{~kg}$ of pottery, bone and lithic material. This material was submitted to the Department of Archaeology at Ljubljana for analysis. The variety of material within this assemblage was most interesting. Amongst the pottery were a number of examples of vessels of Eneolithic date (Fig 14. 2.4), whilst sherds related to the Kosihy-C̄aka and Boleráz groups are also present. The lithic material included worked cores (Fig 14.2.1), and, perhaps most importantly, a serpentine axe (Figure 14.2.2). The presence of an exotic, imported axe is an indication that the site was of sufficient importance to be involved in long-distance exchange networks. The pottery also included a number of fragments of Buckelkeramik and sherds with incised decoration dated to Halstatt C (not illustrated). A considerable amount of pottery of medieval and modern date was also found. A more complete account of this material is found in the unpublished report by Bavec (1985), whilst the material has been deposited in the Posavski Museum at Brez̄ice.

Given that this small assemblage indicated that the site was of some longevity and importance, it was decided some further work should be carried out. Athough hilltop plateau settlements are the normal settlement type of the early Iron Age within Slovenia and the Posavje region (Gabrovec 1975, 56), it was decided that, initially, this work should attempt to place the site within its extended landscape context. The lack of information on Eneolithic settlement patterns also dictated that we must attempt to avoid preconceptions about the settlement pattern and attempt to work at the larger geographical level (Pahic 1975). The considerable amount of ploughed and open land within the adjacent valley (see table 1) meant that a surface survey designed to provide this information could be carried out very easily. Consequently, during 
December 1987, it was decided to carry out an investigative survey over a period of 5 days in order to gauge the potential of the land for further and more extensive survey. The results from this work, which are discussed below, were very encouraging and indicate that this type of landscape is capable of producing quantitative data on land use in a way which hitherto has been very rare within Slovenia.

Table 1 Land use within the Sedem area

$\begin{array}{llr}\text { Land Use } & \text { Area in Hectares } & \text { Percent } \\ \text { Grassland } & 3.875 & 33.7 \\ \text { Stubble } & 0.65 & 5.7 \\ \text { Forest } & 0.725 & 6.3 \\ \text { Vineyard } & 0.075 & 0.7 \\ \text { Wheat } & 6.175 & 53.7\end{array}$

\subsection{THE SURVEY METHODOLOGY}

From the very beginning of the survey, it was decided that it was essential that all survey work should be carried out within a grid which would provide precise and quantifiable data on the levels of artefact densities across the landscape. It was felt that such an approach would not only provide information on the location of early settlement within the environs of Sv. Jakob, but it would also give important information on the distribution of non-site material. Such "non-site or "off-site" survey techniques have been used in a variety of situations and have demonstrable potential to produce very powerful models for the interpretation of past land use. This sort of information can rarely be produced by surveys whose techniques are either non-quantifiable or based simply upon site location (Thomas 1975, Foley 1981). Although the development of quantifiable survey methodologies has proceeded at a rapid rate in North America, and in some parts of Europe, their adoption has been relatively slow within Yugoslavia itself (but see Chapman and Shiel, Bintliff and Gaffney, this volume; Bankoff et al. 1981).

The technique adopted was a development of one which was originally used to document lithic distributions associated with Bronze Age barrows and prehistoric landscapes in England (Woodward 1978, Richards 1985). The area chosen for survey was gridded into continuous hectare divisions using 1:5,000 cadastral maps. Within each hectare square, a series of traverses were walked at 10-metre intervals, in a south to north direction. For collection purposes, each 100-metre traverse was further subdivided into 4 $x 25$ metre parts. All material found within the grid could therefore be pinpointed to a 10 x 25 metre traverse within a fixed and replaceable grid. Within each 10 × 25 metre collection unit archaeological material relating to all chronological periods was collected and placed within a plastic bag. This bag was given a unique reference number. Information relating to ground visibility within each traverse sub-unit was also collected. The initial area chosen for survey was a sample transect, 3 hectares wide and 6 hectares long, which was designed to run from the top 
of the Sv. Jakob gradisce, north across Loka, the area of arable fields associated with the village of Sedem, and eventually to sedem itself, the maximum area to be covered being 18 hectares. However, the very poor weather conditions in early December meant that an area of only 11.5 hectares was eventually covered using the technique described above (Figure 14.3, Plate 14.1). This information was then used to plot the collected material spatially.

One area was omitted from the above collection procedure. This was the area that lay to the south of the site, between the gradisce and a stream running east to west. This area included the vineyards in which very high densities of archaeological material had been found, and which prompted the survey. Whilst it was desirable that this area should also be surveyed, the very extreme gradient in this area prevented the use of a strict hectare grid for such a purpose. Consequently the area (a further 1.05 hectares), was surveyed using 10 metre spaced transects within the field boundaries. Although the use of such a technique prevented the use of this data for direct comparative work with that carried out within the hectare grid, some useful comparison could be made by expressing both sets of data in terms of densities per square metre (see below).

During the period when surface collection was carried out on the area around the hillfort, a resistivity survey was also carried out over the top of the hillfort itself. An area of 2,000 square metres was surveyed using a Geoscan Mark 4 resistance meter. Hilltop sites such as Sv. Jakob are not regarded as the optimum environment for such surveys, whilst the site has also been subject to a number of extensive post-prehistoric disturbances, including the building of a church and a cess pit. However, a number of prehistoric features were noted. These include a linear low resistance feature, interpreted as a possible ditched enclosure within the gradisce itself.

\subsection{THE DISTRIBUTION OF LITHIC MATERIAL}

Perhaps the most interesting results of the Sv. Jakob survey lay in the distribution of lithic materials. The distribution of lithic material clearly shows the existence of a concentration, or "scatter", of material towards the centre of the area surveyed (Figure 14.4). A second minor concentration may also be seen to the extreme north of the grid. It should be said at this time that these scatters represent a relatively low level of material discard. In total, only 178 pieced of flint debitage were recovered. All these artefacts were manufactured from a very poor black and grey flint. However, since the material does not occur naturally within the survey area, the presence of the material can only be explained with reference to the activity of prehistoric man. The assemblage is mainly composed of very small "spalls" of flint, and only 52 pieces could be identified as tools or specific flint reduction forms. Table 2 gives a breakdown of the identifiable flint types. Figure 14.5 shows the spatial distribution of these artefact types. 
Table 2 Flint Artefacts found during the Sv. Jakob survey

$\begin{array}{lr}\text { Artefact type } & \text { Number } \\ \text { Unretouched flakes } & 14 \\ \text { Retouched flakes } & 10 \\ \text { Scrapers } & 5 \\ \text { Blades } & 1 \\ \text { Other Implements } & 11 \\ \text { Cores } & 7 \\ \text { Broken Cores } & 4 \\ \text { TOTAL } & 52\end{array}$

Quantitatively, the lithic assemblage associated with these foci appears to differ from that associated with the gradisce itself. This can be shown by contrasting the lithic assemblage from the northern grid collection area with that from the southern side of the gradisce, an area where we may be looking at material directly associated with hilltop settlement activity. Figure 14.6 compares these areas by reducing the data to the form of densities of artefact per metre square. The wide variety of lithic types within the valley flint scatter is not reflected in the assemblage from the gradisce. The interpretation of such a pattern is problematic; the difference may be functional or chronological. only further and more extensive work will solve this problem.

\subsection{THE DISTRIBUTION OF PREHISTORIC POTTERY}

The distribution of prehistoric pottery found during the survey provides a radically different picture from that provided by the flint (Figure 14.7). Of the 129 sherds of prehistoric pottery found, 69 were found within the most southerly hectare unit. This unit actually lies on the top of the hill and within the gradisce itself. This concentration may also be associated with the position of the ditched enclosure located by the resistance survey carried out on the top of the hillfort.

\subsection{DISCUSSION}

Although the survey at Sv. Jakob was carried out over a small area, the results are very interesting and provoke a number of points of discussion. Initially, it can be said that the quantitative approach to the surface data was validated through the identification of several lithic artefact foci. Whilst we cannot state with certainty any opinions on the status of lithic scatters, the isolation of such phenomena is a very significant achievement. In providing evidence for such entities at Sv. Jakob, we must begin to question the continuing bias of prehistoric site locations within caves or on hilitops. We must begin to consider the situation in which prehistoric valley-based activity may, in some cases, only be represented by very low density artefact scatters. The Sv. Jakob survey is not, of course, the first work within Slovenia to provide evidence for such archaeological features. A similar scatter was located on the Ljubljana Barje by Turk and Vuga (1984). However, these isolated examples 
do indicate that it is possible that lithic scatters may represent a widespread and hitherto largely undiscovered indication of archaeological activity. If this is the case, the continuing reliance on non-quantitative, site-based topographic survey within Yugoslav archaeology may well result in a continuation of the present landscape bias in favour of the most obvious landscape features (e. g., gradiśce). We should consider that some elements of the settlement hierarchy in certain periods may be almost entirely missing and that, if we wish to ensure that our regional archaeological data base is representative, more money and effort must be invested in analytical and quantitative field survey.

The Sv. Jakob pottery data is equally significant, if somewhat more complex. There would seem to be no corresponding concentration of pottery with the lithic scatter discussed above. However, we cannot be sure that this disparity is a reflection of the original archaeological distribution. It is possible that this disparity is a reflection of the intensity of ploughing within the valley. In those cases where data are available (e. g., the Bishops Canning Down site in England), it can be shown that such a process can seriously deplete the topsoil pottery reservoir (Gingell and Schadla-Hall 1980), and therefore, potentially, bias the surface data. However, if the pattern proves to be real, we must begin to consider the implications for slovenian survey. The figures indicate that about half of the prehistoric pottery collected within the grid survey lay outside the area of the gradisce. Given the area involved, it would seem illogical to associate this material directly with extra-mural settlement activity. The very low levels of the recovered pottery may also argue against this. This can, perhaps, be illustrated by comparing the difference between the density of pottery from the southern grid collection area with that from the northern side of the gradisce, an area where we may be looking at site density pottery levels. Figure 14.8 compares these areas by reducing the data to the form of densities of artefact per metre square. The contrast between site and non-site pottery densities is very great, and it is difficult to argue that both areas should simply reflect areas of "settlement". If this material eventually proves not to be indicative of an extended settlement area, how then should we begin to interpret it? Analogy with surveys in area of the Mediterranean zone suggests that we should consider that many sites should be surrounded with an halo of material associated with agricultural and other off-site activities. The published material provided by the Boeotia survey provides examples of such rings of detritus (Bintliff 1985:figure 6). It is also significant that, in some cases, such information has been used to define site territory and off site agricultural and behavioural practices (Gaffney et al. 1985). It is intriguing to think that we may be beginning to isolate evidence for such activity at Sv. Jakob. 


\subsection{CONCLUSIONS}

In conclusion, we must restate that the results presented here are both preliminary and limited, both in area and inferential potential. Without doubt, a larger area around the site should be surveyed, and some comparative work should also be carried out on other significant local sites (e. g., Veliki Kamen or Marsive Lozice). However, the results so far have provided a tantalising glimpse of the nature of surface archaeology at Sv. Jakob. It is sufficient to say that, at this point, the first results are extremely exciting and that further work may well provide a clearer picture both of past land use associated with the Sv. Jakob site, but also of the biases and potential of field survey work within Slovenia.

\subsection{ACKNOWLEDGEMENTS}

I would like to thank the Posavski Musej Brē̄ice for providing funding for the work at Sveti Jakob. Special thanks go to my colleagues who actually did the fieldwork. Peter Cerce translated the paper into English. Many thanks to Vince Gaffney for discussions of the methodology and the text. 


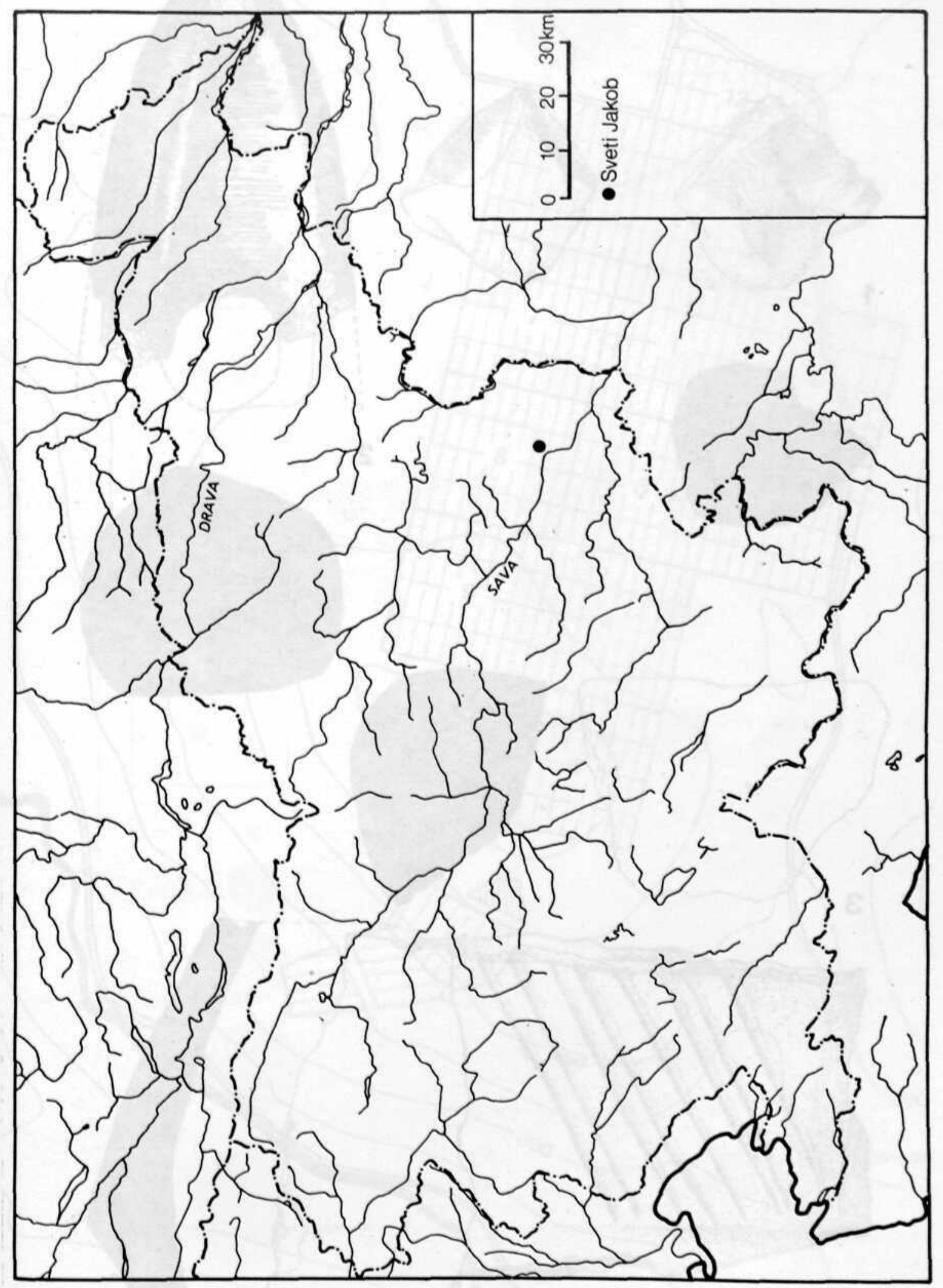

Figure 14.1 Slovenia and the position of Sveti Jakob. 


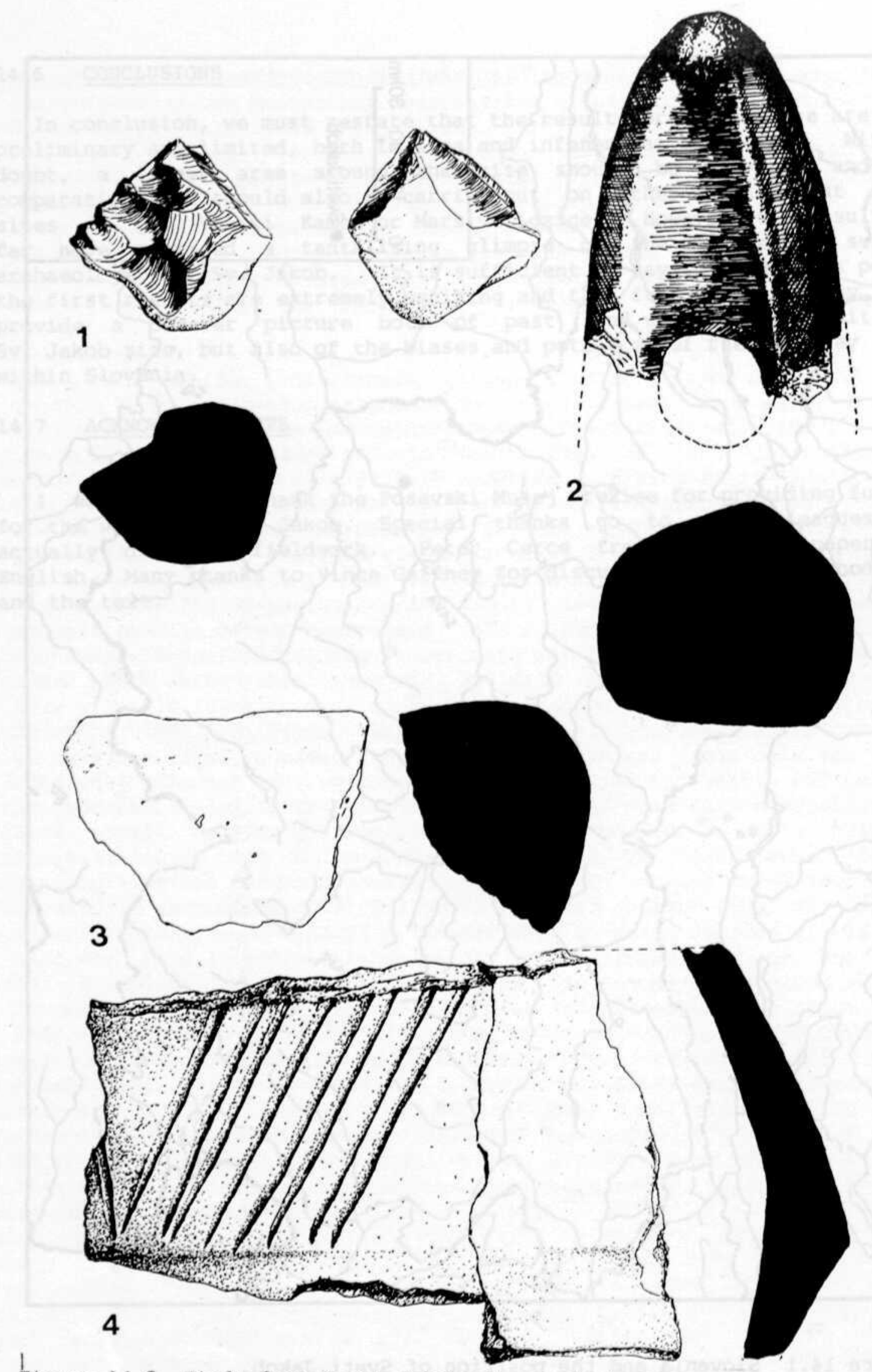

Figure 14.2 Finds from Sveti Jakob: 1 - worked cores

2 - serpentine axe 3-4 - Eneolithic pottery. 


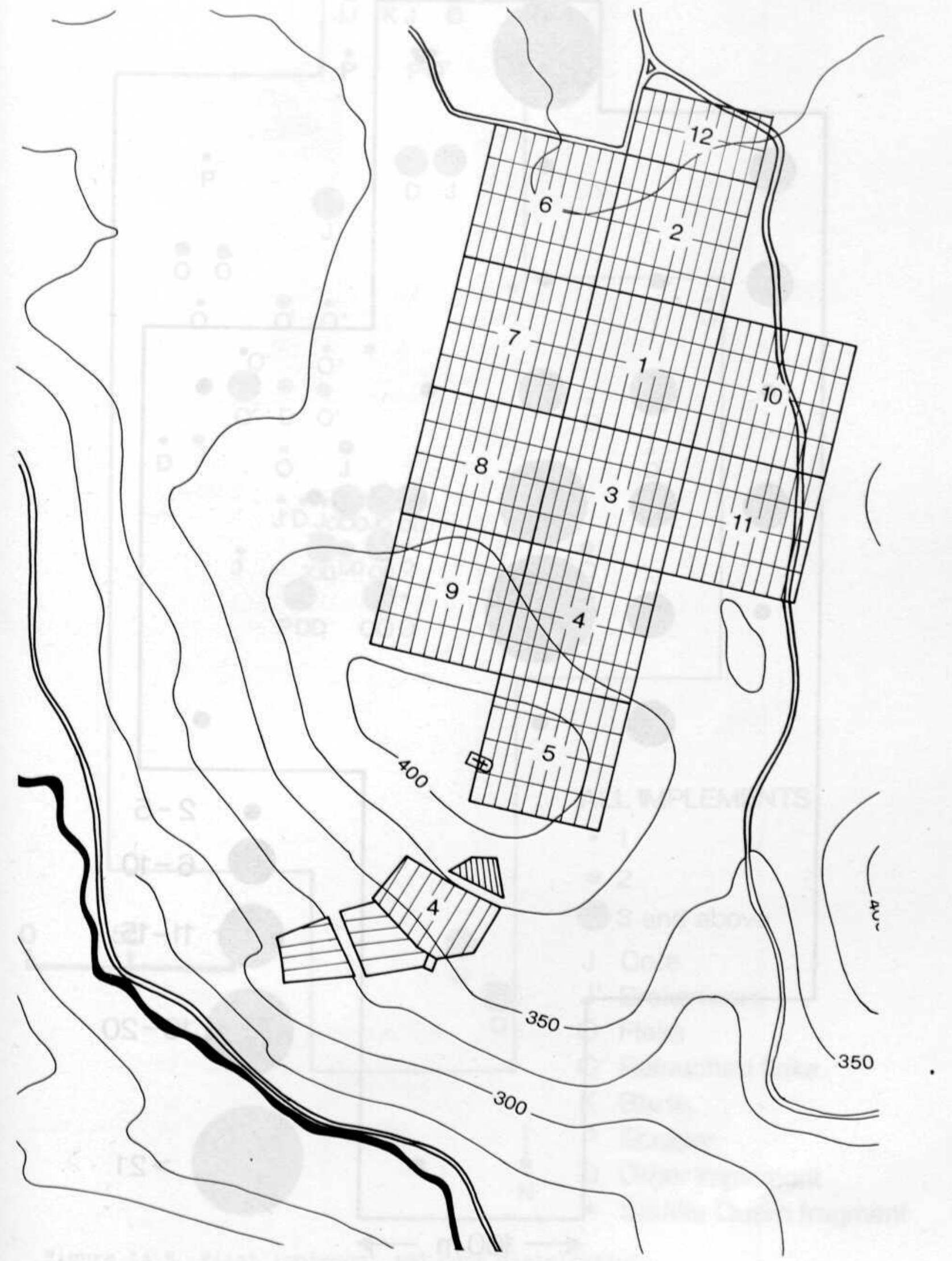

Figure 14.3 The location of the extensive surface collection grid. 


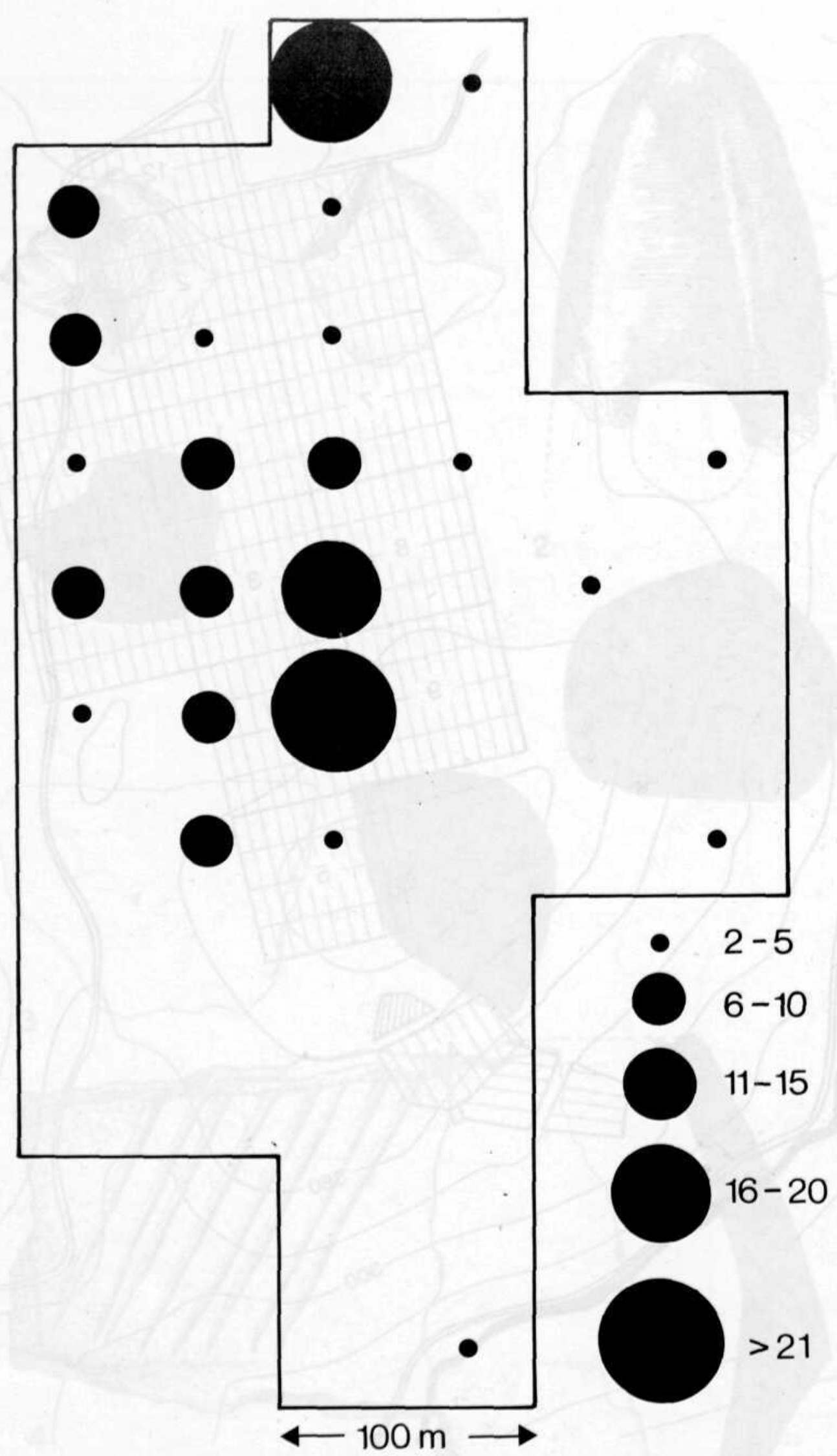

Figure 14.4 The distribution of all flints collected within the extensive collection grid. 


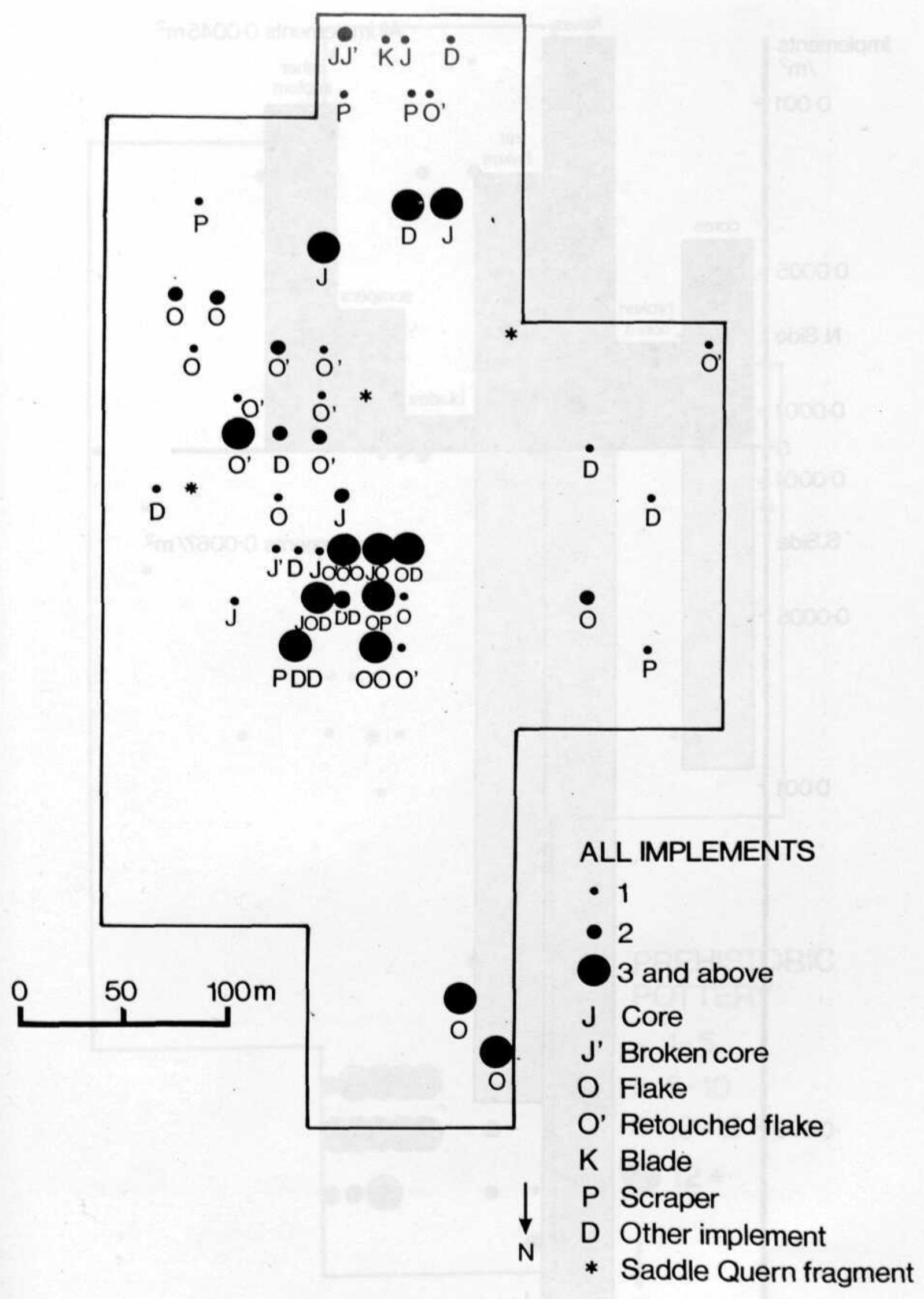

Figure 14.5 Flint implement and core distribution. 


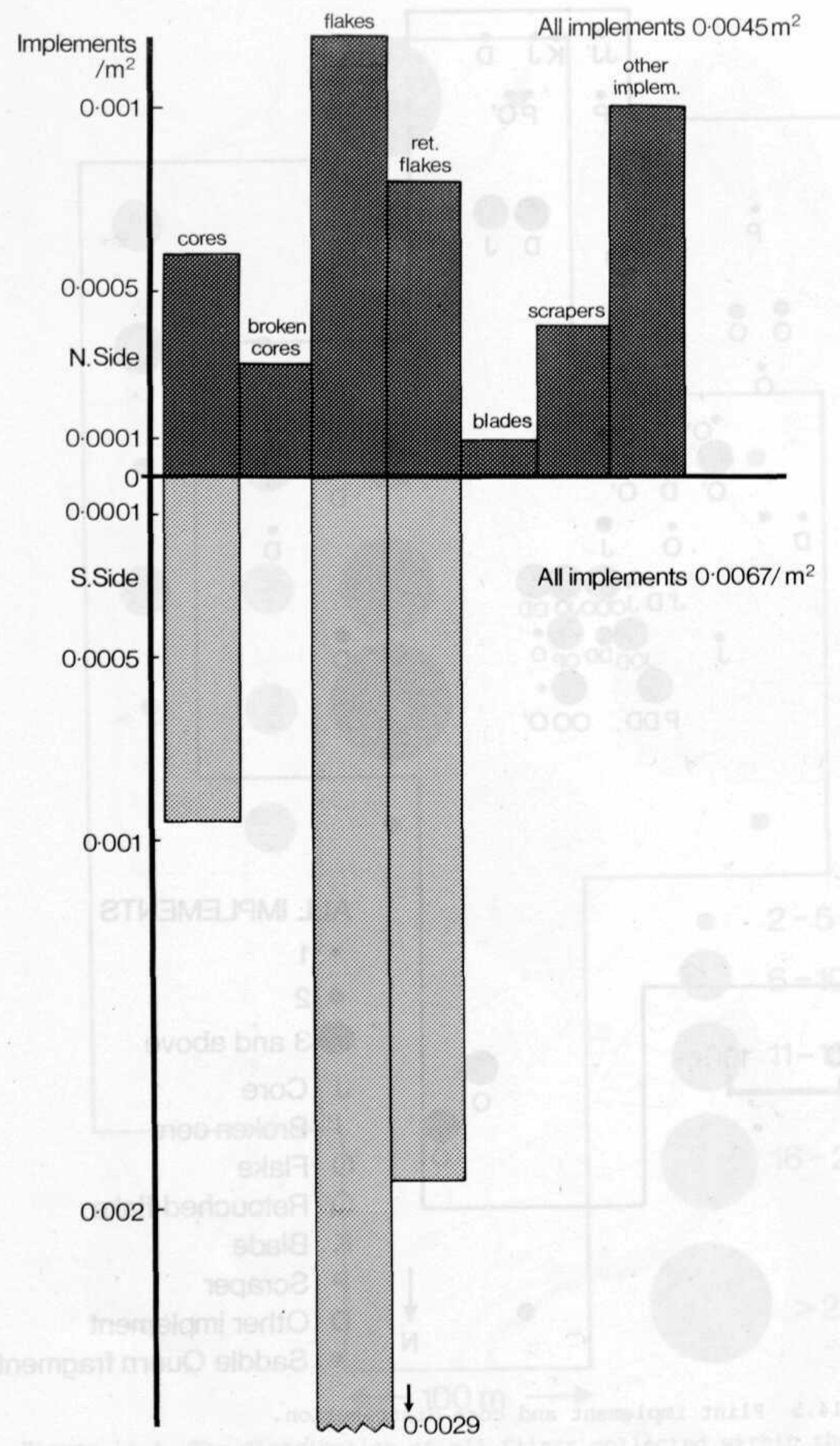

Figure 14.6 Flint artifact types : densities per square metre. 


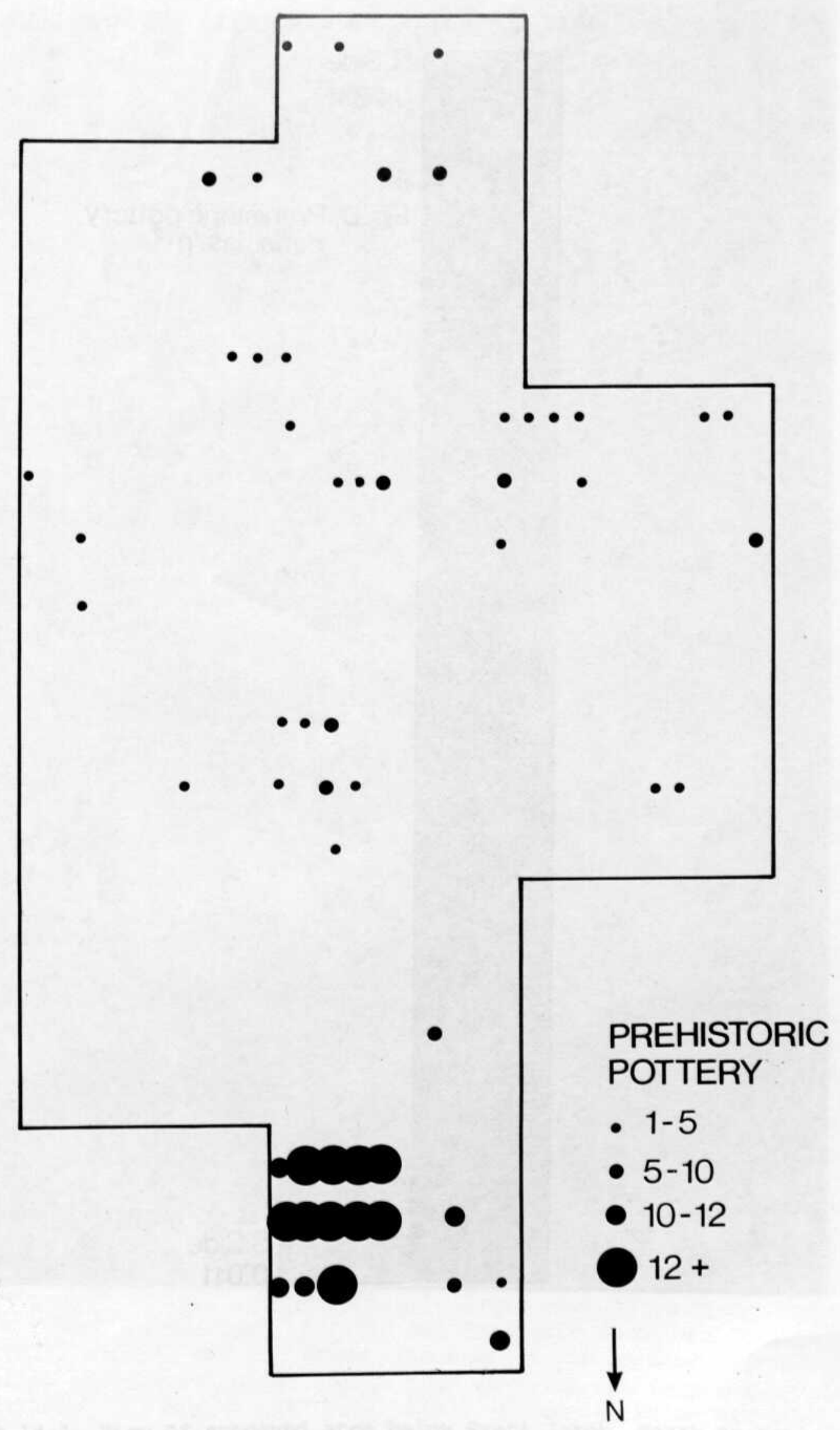

Figure 14.7 The distribution of all prehistoric pottery within the extensive collection grid. 


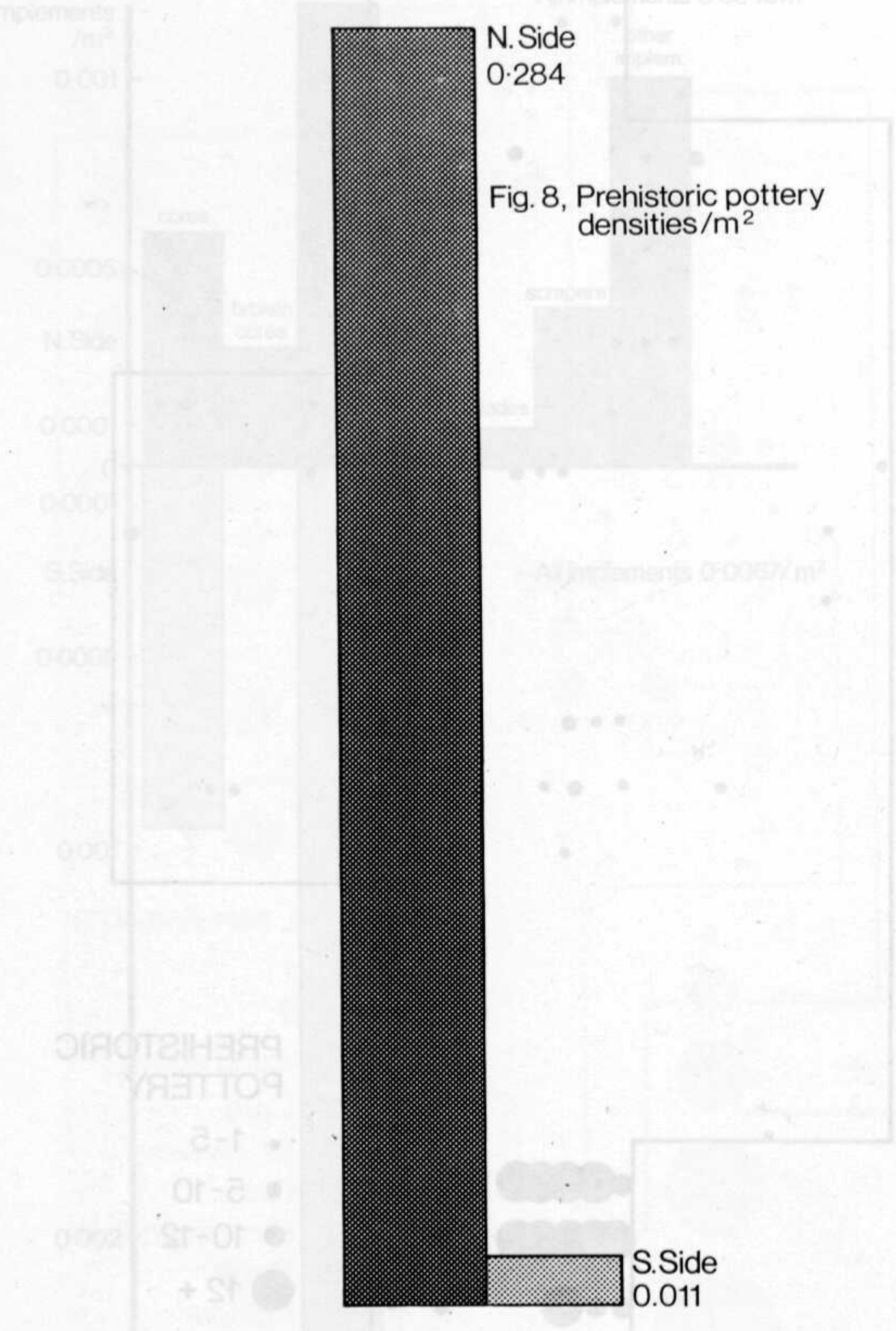

Figure 14.8 Prehistoric pottery densities per square metre. 


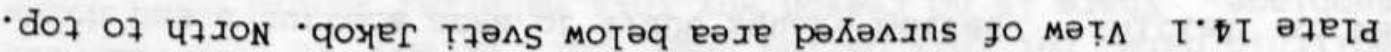

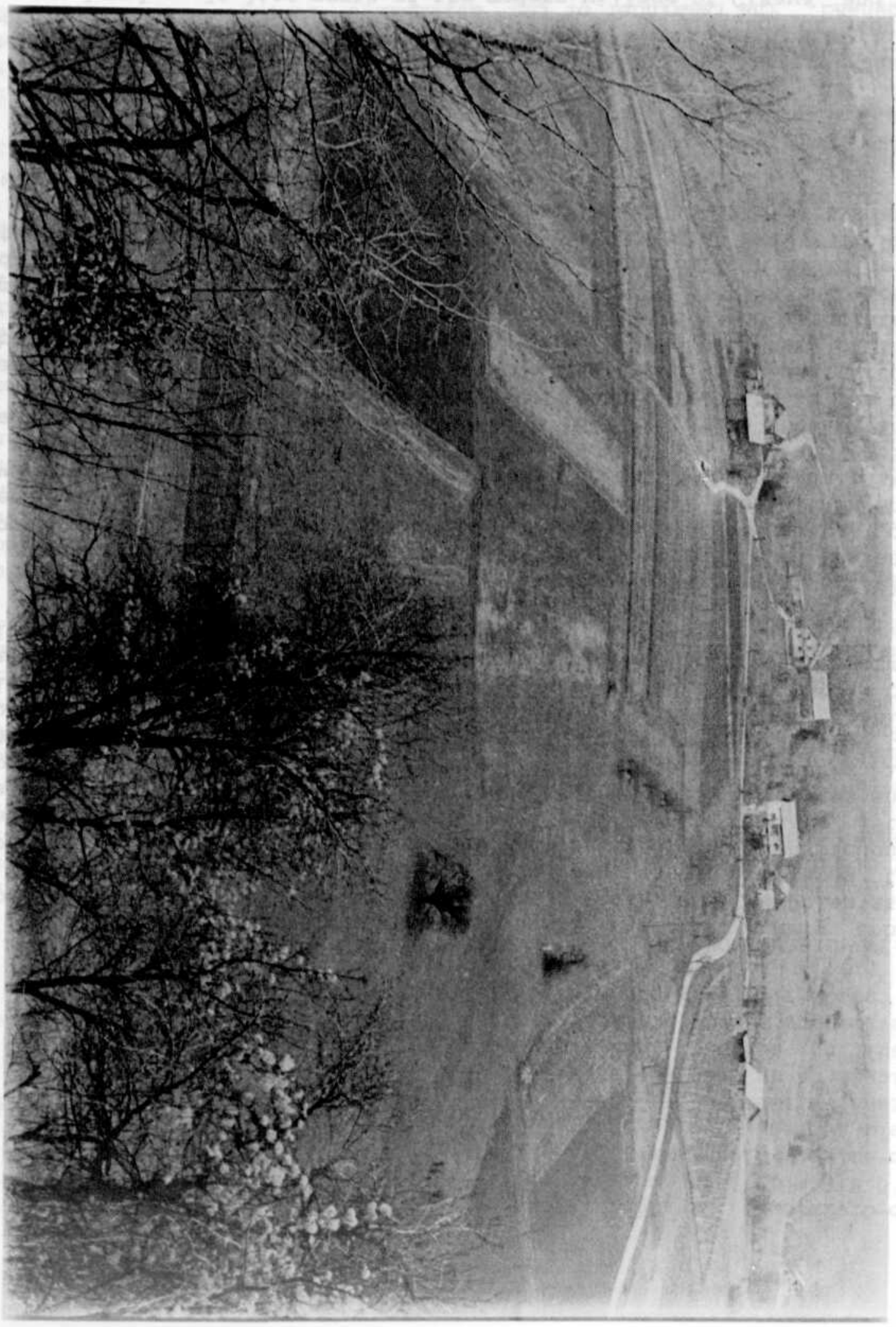


COMING DOWN FROM THE HILLS

A PREL IMINARY REPORT ON THE INTENSIVE SURFACE COLLECTION OF

A LOWLAND EARLY IRON AGE ACTIVITY AREA IN SLOVENIA

PHIL MASON

As the title of this short article suggests, until recently, early iron age lowland settlement both within Slovenia as a whole, and the Dolenjska region in particular, was almost unknown. Settlement studies related to this period appear to have been trapped within a paradigm of conspicuous defended upland settlement, much of which was identified in the late 19th and early 20th centuries. The importance of these hillfort sites and their potential functions as central places and population centres is undeniable, although recent work has begun to shift academic attention to the study of extensive, if sometimes discrete, lowland areas within Slovenia and Yugoslavia in general, and has emphasised the potential of these areas to contain further and hitherto unknown settlement forms (Batović and Chapman 1985; Bavec, this volume).

The results contained within this paper arise from a small-scale field survey project conducted within the Grosuplje basin, a restricted lowland area approximately 15 kilometres south east of Ljubljana, the capital of the republic of Slovenia (Figure 15.1). This area lies within the putative territory of the hillfort and mortuary complex of Magdalenska gora, the cemeteries of which were excavated in the late 19 th and early 20th centuries and are relatively well known in the literature (Dular and Gus̄tin 1974, Hencken 1978, Hvala and Kocuvan 1982). The site is one of the classic centres of the early iron age Dolenjska group, but, apart from a number of smaller hillfort settlements on the upland periphery of the basin, of which none has been excavated, the site territory and associated settlement hierarchy are an archaeological lacuna. It was therefore decided that a more realistic picture of the settlement pattern could best be established through a field survey of the surrounding area. It was during this survey that the example of the hypothesised lowland settlement sites which is discussed below was discovered.

\subsection{SITE LOCATION}

The site is situated on an old gravel terrace, $750 \mathrm{~m}$ south of the hillfort settlement of Magdalenska gora, and lies at an altitude of $340 \mathrm{~m}$ above sea level. It lies north of the modern village of Cikava, and is separated from the lower slopes of the hill of Magdalenska gora by the narrow marshy valley of a seasonal water course (Figure 15.2). The initial discovery of the site was made during extensive surface collection of a well-weathered ploughed field (MGE 88, Field 10, Cadastral no. $460 / 2$ ), which has a surface area of 4,000 square metres. Initial survey was carried out using traverses with a $25 \mathrm{~m}$ separation and $10 \mathrm{~m}$ collection 
sub-divisions. During this extensive work, early iron age sherd densities of 0.5 sherds per square metre were identified within two traverse sub-units, along with an extensive distribution of iron slag across the field surface. Following discovery it was felt necessary to carry out an intensive surface collection of the field surface using an arbitrary grid, aligned on an east-west axis and using a $5 \times 5 \mathrm{~m}$ collection unit. The resulting ceramic densities are presented below (Figure 15.3). The preliminary nature of this report unfortunately precludes the presentation of the on-site slag and lithic distribution.

\subsection{DISCUSSION}

The survey at Magdalenska gora was carried out over a very small area, but clearly shows a discrete distribution of early iron age ceramics which trends from south west to north east. There is a distinct fall-off of material on the north west and south east sides of the scatter. Isolated low-density sherd distributions occur within the fall-off zone and probably result from off-site activity or movement related to modern ploughing (Figure 15.3). The densities of ceramics are low, but there are a number of reasons for identifying the scatter with settlement activity, e.g. this can also be demonstrated through comparison with survey results from another recently discovered lowland early iron age site situated at Trebnje-Benec̄ija.

The site of Trebnje-Benec̄ija was located during the geophysical survey of a large Roman settlement. Complementary intensive surface collection of the area associated with buildings located through resistivity survey has revealed similar low-level early iron age artefact densities. Again there is a marked fall-off in ceramic densities away from the areas of the structures, which are aligned north to south, and iron slag also forms a major component of the surface assemblage. The larger pieces of slag are found together with the concentrations of early iron age ceramics, smaller pieces forming part of the halo (Bres̄çak, Kris̄ and Waters pers. com.). It should be stressed that the site at Trebnje is at present unexcavated; consequently, it is unclear whether the survey results indicate industrial or settlement activity. The distribution of the slag at Cikava has not been fully quantified, but does appear to present a similar picture. Of course, as geophysical survey has not yet been conducted at Cikava, no structures have been identified.

Low densities of lithic material have also been recorded at the Cikava site. This material appears to have a random distribution across the field and forms no coherent or discrete scatter. Lithic densities range between one and two pieces per $25 \mathrm{sq} \mathrm{m}$ and only two identifiable tools occur within the assemblage: an end-retouched blade and a notched tool or arrowhead. The remainder of the assemblage consists of waste flakes, chips or unworked lumps. The raw material, a poor quality flint, does not occur naturally within the region.

The identifiable lithic pieces may well be of Late Neolithic or Eneolithic date, but this dating need not extend to the rest of the assemblage. There is no reason why this material should not relate to the 
early iron age activity on the site, particularly when it is considered in the light of the excavated lithics from Cvinger at Dolenjske Toplice (Kris pers. com.; Terz̄an 1976, T. 92:38).

The topographical situation of the site makes it unlikely that it is a extra-mural settlement directly associated with the hillfort of Magdalenska gora, or that the artefact assemblage is derived from there by post-depositional erosion processes. Indeed, its location on the edge of the floodplain is similar to that of Trebnje-Benec̄ija, which lies on the edge of the river Temenica. This has important implications for future research on site location in the Grosuplje basin and the Dolenjska region as a whole. These sites suggest that another tier of settlement outside hillforts may exist and that they may be expected to occupy similar first-terrace sites.

The low surface densities of ceramics at Cikava may be explained by reference to the nature of modern agricultural activity within the Grosuplje basin. Deep ploughing has only begun in the last four or five years in some areas. As a result, the Cikava site cannot be expected to produce surface material in the same densities as prehistoric sites in many parts of southern Britain which may have been ploughed for several decades. This observation also applies to Trebnje-Benec̄ija, which may suggest that the early iron age sites in question are less damaged in comparison with sites in southern Britain, (e. g., Bishops Canning Down:Gingell and Schadla-Hall 1980). A further factor affecting artefact densities concerns the nature of the ceramics themselves. These are largely poorly fired coarse wares with an organic temper. Observations in the field, and from other sites (Bavec, this volume, Gingell and Schadla-Hall op. cit.), suggest that such material breaks down rapidly through weathering and continued ploughing, and so would be unlikely to remain within the ploughsoil for any great length of time. This may also suggest that ceramics which have recently entered the ploughsoil are unlikely to represent prehistoric agricultural practices, particularly manuring.

The ceramics from the Cikava site differ from those recovered by grab sampling from the Magdalenska gora hillfort. It is true that both types seem to represent coarse wares, quite distinct from the fine wares which are usually found in mortuary contexts (Dular 1982). The production techniques are also similar from sampled settlement sites. The ceramics are coil-built and show evidence for differential firing, probably as a consequence of the use of clamp kilns. However, the ceramic inclusions do exhibit significant differences. The hillfort ceramics contain large crushed limestone inclusions, whilst the Cikava ceramics largely exhibit organic tempering. Available data is not sufficient to assess a chronological explanation, but the complementary spatial distributions of ceramic types tends to refute the derivation of the lowland ceramics from upland off-site activity. 


\subsection{CONCLUSIONS}

In conclusion, it is necessary to emphasise the interim nature of this report. A clearer picture regarding settlement pattern and hierarchy can only be drawn from the field survey of a larger area within the Grosuplje basin, and in comparable areas of Dolenjska and Slovenia as a whole. Naturally, it would be inadvisable to concentrate on sampling only first-terrace areas, as researchers would run the risk of being trapped within yet another restrictive paradigm, no better than that resulting from the previous concentration on upland settlement. There is clearly a need for stratified sampling designs in further work in order to sample all available environments. The significance of this preliminary work is considerable. First, it demonstrates the potential for lowland early iron age activity and settlement sites in Dolenjska and Slovenia. Comparative studies are needed to extend this. It is not enough to assume that this research will merely recover the lower social tier of settlement. There is a need to re-examine the social context of hillfort settlement. Although hillforts are conspicuous monuments and of ten have associated barrow cemeteries, this does not mean they are elite centres. Lowland elite centres are known in other areas of Europe within regions of hillfort settlement (Härke 1979, Bradley 1986, 114-127, 138-144, Gaffney pers. com.). While there is no suggestion that the Cikava site was an elite settlement, fine wares have been found in the surface collection at Trebnje-Benec̄ija, and not all barrows are directly associated with hillfort sites. Thus there is the likelihood that further field survey will supply important data relating to all aspects of early iron age settlement, off-site activity and land use in Slovenia.

\subsection{ACKNOWLEDGEMENTS}

I would like to thank the British Council that provided funding which has enabled me to carry out field work in Slovenia. The staff of the archaeological department of Ljubljana University, especially Dr. B. Terz̄an and Dr. B. Slaps̄ak, have been supportive, supplying me with field equipment and processing facilities throughout the period of field survey. Credit must go to the students from Ljubljana University and to Dr. D. Davidson, who took part in the surface collection. I would like to thank the editors for accepting this paper at such short notice. Finally, special thanks must go to 'Vince Gaffney and Andy Waters for discussion of the methodology employed and comments on the text. 


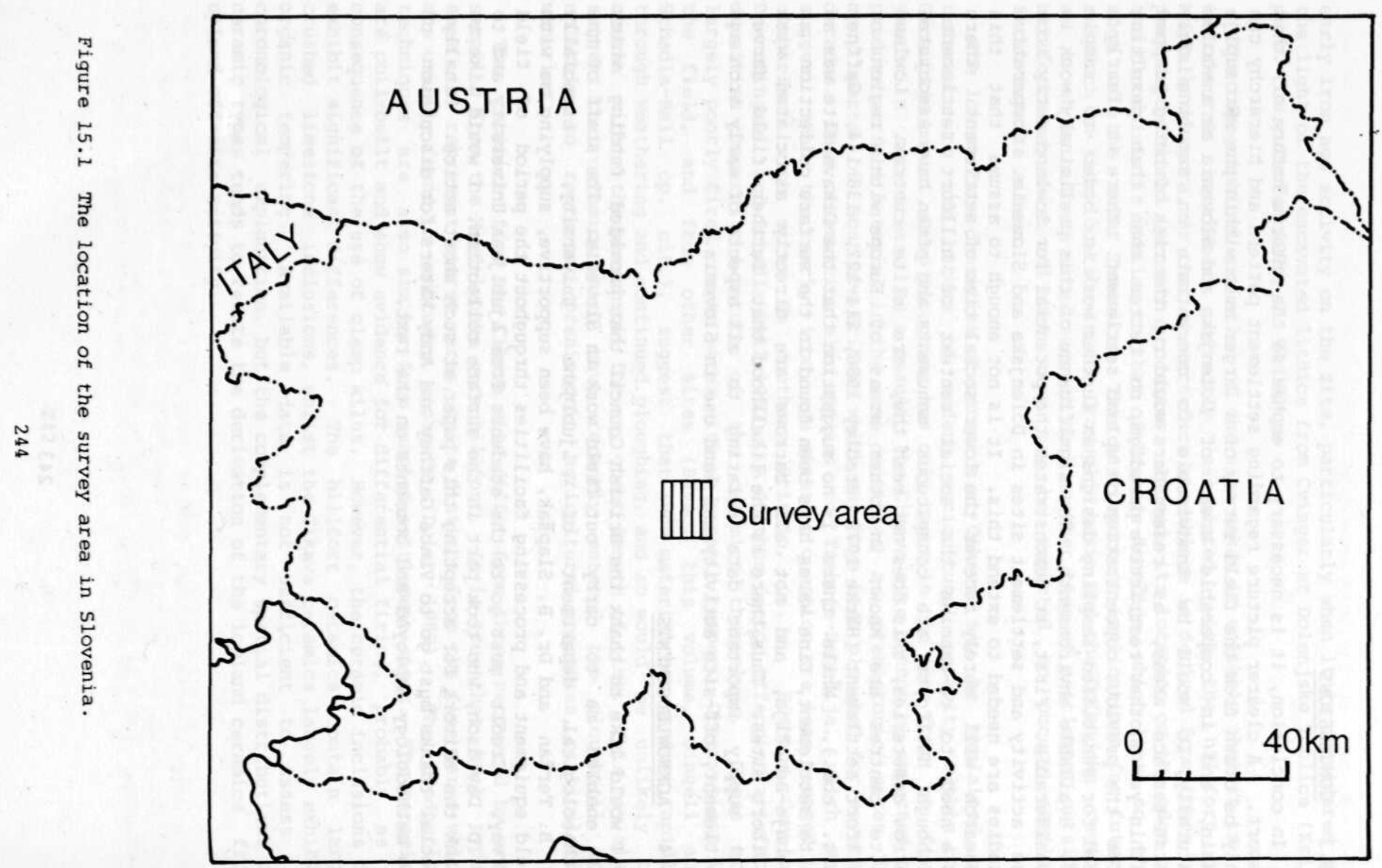




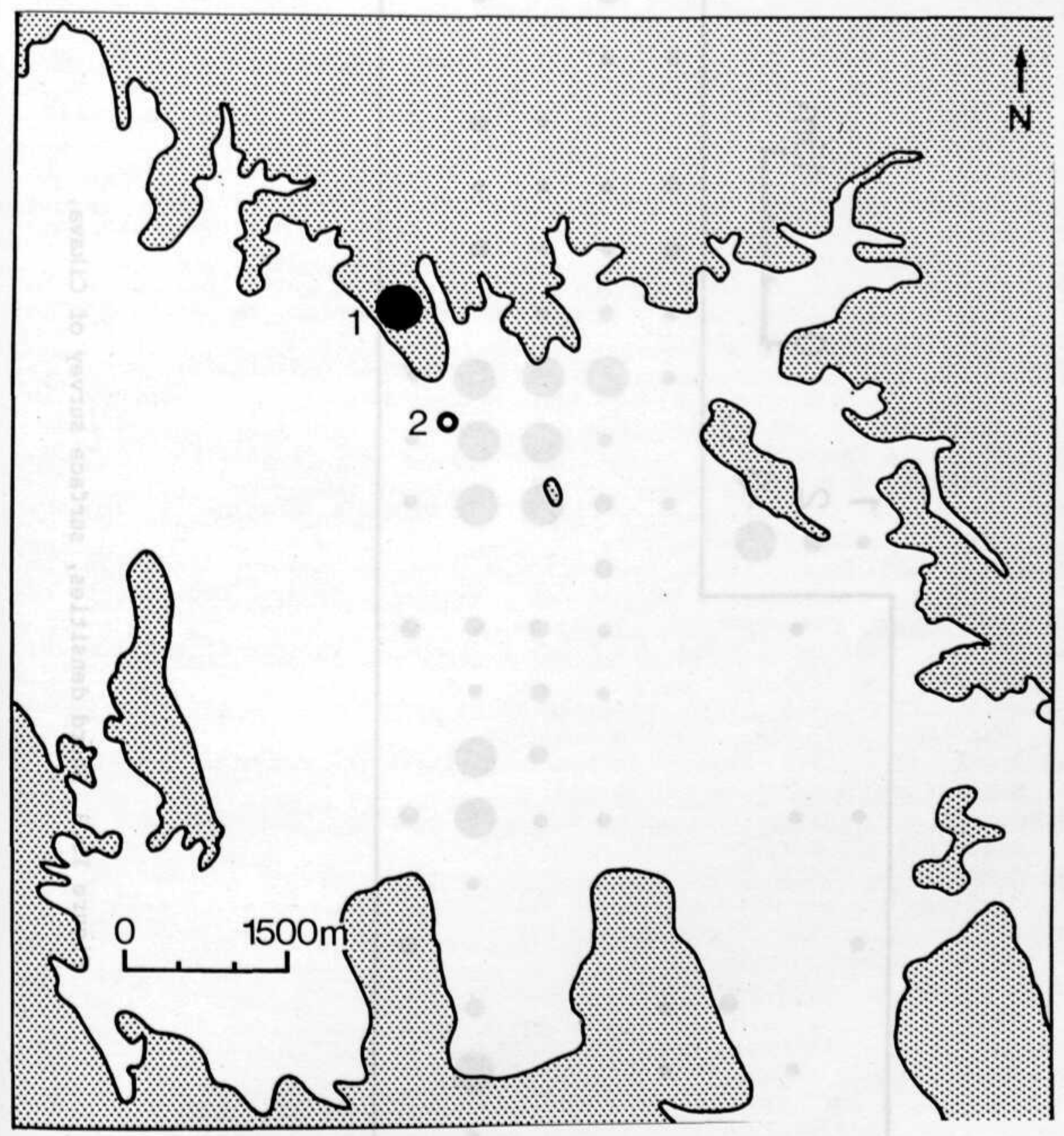

Figure 15.2 Site locations in the survey area: (1) Magdalenska gora; (2) Cikava. Stippled areas above $400 \mathrm{~m}$ asl. 


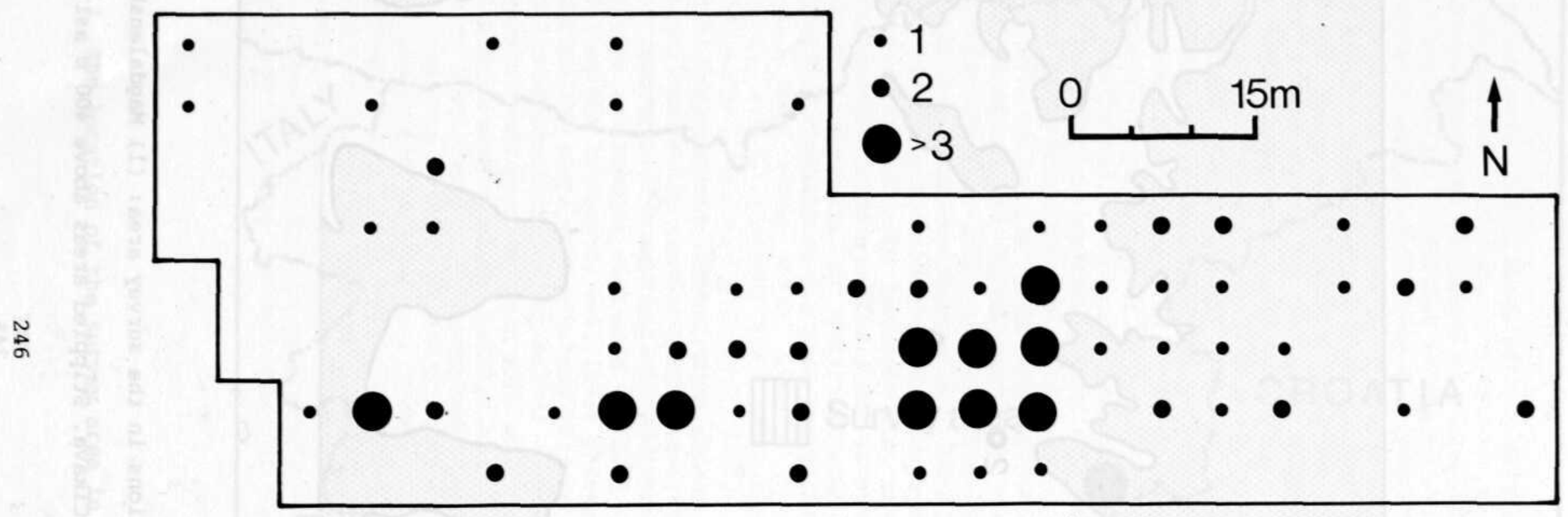

Figure 15.3 Sherd densities, surface survey of Cikava. 
Adams J. P., 1982 L'architecture militaire grecque. Paris:Picard.

Arnold D. , 1985 Ceramic theory and culture process. Cambridge:Cambridge University Press.

Askew G. , Payton R. \& Shiel R. S. , 1985 Upland soils and land clearance in Britain during the second millennium BC. In Spratt D. \& Burgess C. (eds) Upland settlement in Brìtain. British Series B-143. Oxford: BAR: 5-33.

Bankoff H. A., Winter F. \& Greenfield H. , 1980 Archaeological Survey in the lower Morava Valley. Current Anthropology 21:286-287.

Barker G. , 1985 Prehistoric farming in Europe. Cambridge:Cambridge University Press.

Batović S. , 1977 Caractéristiques des agglomérations fortifiées dans la région des Liburniens. Godis̄njak xvi (Centar za Balkanolos̄ka Ispitivanja knj. 14):45-60.

Batović S. \& Chapman J. C. , 1985 The Neothermal Dalmatia Project. In Macready S. \& Thompson F. H. (eds) Archaeological Field Survey in Britain and Abroad. London:Society of Antiquaries of London:158-195.

Batović S. \& Chapman J. C. , 1986 Bukovič-Lastvine. Eneolitsko naselje. Arheolos̄ki Pregled 24:52-53.

Batović S. , \& Chapman J. C. , 1987 Istraz̄ivanje Gradine u Nadinu. Obavijesti (Zagreb) xIX:28-31.

Bavec U. , 1985 Sveti Jakob nad Dovskim novo arheolosko najdis̄c̄e na področju Senovega. Unpublished seminar paper, Department of Archaeology, University of Ljubljana.

Bavec U. , 1986 Sveti Jakob nad Dovskim, Senovo. Varstvo Spomenikov 28, 243-244.

Belosevic J. , 1962 Slavenska Keramika iz ranosrednjovjekovne nekropole 'Materiza' kraj Nin. Diadora 2:237-249.

Belos̄evič J. , 1972 Stanje Istrazivanja Slavenske keramike na podruc̄ju Dalmacije. Materijali IX:125-138.

Belos̄ević J. , 1973 Starohrvatska Nekropola iz Humak 'Materiza' kod Nina. Diadora $6: 221-244$.

Beloševič J. , 1974 Die ersten slawischen Urnengraber auf dem Gebiete Jugoslawiens aus dem Dorfe Kasić bei Zadar. Balcanoslavica 1:73-86.

Belos̄ević J. , 1975 Starohrvatska nekropola u selu Biljanima Donjim kod Zadra. Diadora 8:103-110.

Belos̄ević J. , 1980 Materijalna Kultura Hrvata od 7 do 9 stoljeća. Zagreb.

Belos̃evič J. , 1985 Starohrvatska nekropola u Stankovcima kod Benkovca. Radovi Filozofski Fakultet u Zadru 24:73-97.

Beuermann A. , 1967 Fernerweidewirtschaft in Sudosteuropa. Braunschweig.

Bintliff J. , 1977 Natural environment and human settlement in prehistoric Greece. International Series S-28. Oxford:BAR.

Bintliff J. , 1985 The Boeotia Survey. In Macready S. \& Thompson F. H. (eds) Archaeological Field Survey in Britain and Abroad. London:Society of Antiquaries of London:196-216.

Bintliff J., n.d. Extracting meaning from the past. Oxford:Oxbow Books. Bintliff J. ,, Gaffney V. \& Slapsak B. , n.d. The Hvar Survey Project, 
site formation processes and the villa Jeże. In Schofield J. (ed) Interpreting artifact scatters.

Boyd D. T. , \& Jameson M. H. , 1981 Urban and rural land division in ancient Greece. Hesperia 50/4:327-342.

Bracewell w. , n.d. Zadar's mainland territory in the sixteenth and seventeenth centuries. Newcastle upon Tyne:Neothermal Dalmatia Project.

Bradford J. , 1957 Ancient landscapes. London:Bell.

Bradley R. J. , 1982 The social foundations of prehistoric Britain. London: Longmans .

British Admiralty Handbook, 1944 Jugoslavia. Vol. I. Naval Intelligence Handbook. London: HMSO.

Chapman J. C., 1981 The value of Dalmatian museum collections to Dalmatian settlement studies. In Cantwell A-M., Griffin J. B. \& Rothschild N. A. (eds) The research potential of anthropological museum collections. New York:Annals of New York Academy of Science $376: 529-555$.

Chapman J. c., n.d. Archaeological field survey in Yugoslavia.

Chapman J. C., \& Batović S. , 1985 The Neothermal-Dalmatia Project - Third (1984) Season. Archaeological Reports for 1984:8-11. Durham:Universities of Durham \& Newcastle upon Tyne.

Chapman J. C., \& Shiel R. S. , Settlement, soils and societies in Dalmatia. To appear in Barker G. (ed) Roman Agrarian Structure in the Mediterranean. London:British School in Rome.

Chapman J. C., Shiel R. S. \& Batovié S. , 1987 Settlement patterns and land use in Neothermal Dalmatia, Yugoslavia: 1983-1984 seasons. Journal of Field Archaeology 14:123-146.

Chevallier R. , 1957 La centurazione romana dell'Istria è della Dalmazia. Bolletino di Geodesia è Scienze Affini 167-177.

C̈irić M. ' \& Filipović G. ' 1969 Soils of Yugoslavia. Beograd:Jugoslovensko Društvo za Proučanvanje Zemljišta.

Coles J. M., \& Harding A. F. , 1979 The Bronze Age in Europe. London: Methuen and Co.

Crompton E. , 1966 Soils of the Preston District of Lancashire. Memoirs of the Soil Survey of Great Britain: England and Wales. Harpenden: HMSO.

Darwin C. , 1881 The formation of vegetable mould through the action of earthworms. London:J. Murray.

Dobiat C. , 1980 Das hallstattzeitlichen Gräberfeld von Klein-Klein und seine keramik. Beiheft I Graz:Schild von Steifer.

Drucker P. , 1939 Rank, wealth and kinship in Northwest Coast Society. American Anthropologist 41, 55-65.

Drucker P. , 1955 Indians of the Northwest Coast. New York:McGraw-Hill.

Duboković-Nadalini N. , 1962 Ager Pharensis, arheolos̄ke biljes̄ke. Vjesnik za arheologiju $i$ historiju dalmatinsku 63-64:91-96.

Dular J. , 1973 Bela Krajina v starohalstatskem obdobju (Bela krajina in der frühen Hallstattzeit). Arheolos̄ki Vestnik 24 (Ljubljana 1975), 544-591.

Dular J. , 1979 Zarno grobis̄c̄e na Borstku v Metliki (Das Urnengraberfeld von Metlika-Borstek). Arheoloski Vestnik 30 (Ljubljana), 65-100

Eibner A. , 1980 Darstellungsinhalte in der Kunst der Hallstatt-kultur. in: Die Hallstattkultur: Symposium Steyr (Linz 1981), 261-296. 
Eisner J. , 1966 Rukovet Slovenske Archeologie. Praha.

Faber A. , 1976 Prilog kronologiji fortifikacija u primorsku Iliriku. Jadranska obala u protohistoriji. Zagreb:Sveuc̄ilista u Zagrebu:227-246.

Feinman G. M. , Upham S. \& Lightfoot K. G. , 1981 The Production Step Measure: An ordinal index of labour input in ceramic manufacture. American Antiquity $46(4): 871-884$.

Foley R., 1981 off Site Archaeology and Human Adaptation in Eastern Kenya. Cambridge Monographs in African Archaeology 3. International Series S-97. Oxford:BAR.

Forenbauer S. , \& Vranjićan P. , 1982 Pé́ina u Pazjanic̄ama - V. Paklenica. Senjski Zbornik IX:5-14.

Gabrovec S. , 1960 Grob z oklepom iz Novega mesta (Das Panzer grab von Novo mesto). Situla I (Ljubljana), 27-80.

Gabrovec S. , 1966 Zur Hallstattzeit in Slowenien. Germania 44, 1-48.

Gabrovec S. , 1968 Grob s Trinozkom iz Novega mesta (Das Dreifuss-grab aus Novo mesto). Arheolos̄ki Vestnik 19 (Ljubljana), 157-188.

Gabrovec S. , 1970 Dvozankaste Ločne Fibule (Die zweischleifigen Bogenfibeln). Godis̄njak 8 (Sarajevo), 5-65.

Gabrovec S. , 1973 Zacetek halstatskega obdobja v Sloveniji (Der Beginn der Hallstattzeit in Slowenien). Arheolos̄ki Vestnik 24 (Ljubljana 1975), 338-385.

Gabrovec S. , 1981 Die Verbindungen zwischen den Sudostalpen und dem jugoslawischen Donaugebiet in der älteren Eisenzeit. Materijali 19 (Novi Sad), 155-178.

Gabrovec S. , 1975 Naselitvena zgodovina Slovenije v halstatskem obdobju, Arheološka najdis̄ça, Slovenije. Slovenska Akademia znanosti in umetnosti, Institut za arheologijo, Ljubljana:55-60.

Gaffney C. , , Gaffney V. \& Tingle M. , 1985 Settlement, Economy or Behaviour? Micro-regional Land Use Models and the interpretation of Surface Artefact Patterns. In Haselgrove C. Millett M. and Smith I. (eds) Archaeology from the ploughsoil. Sheffield:Academic Press: 95-108.

Gavazzi M. , 1965 Lonc̄ari s otoka iz̄a, etnolos̄ki zavod filozofskog faculteta, Zagreb.

Gingell C. J., \& Schadla-Hall R. T. , 1980 Excavations at Bishops Cannings Down, 1976. In Hinchcliffe J. and Schadla-Hall R. T. (eds) The past under the plough. Directorate of Ancient Monuments and Historic Buildings, Occasional Papers 3, London: 109-113.

Glavic̄ić A. , 1983 Prilog istrā̄ivanju starohrvatske sakralne arhitekture na primorskim padinama Velebita i Velike Kapele. Senjski zbornik $\mathrm{x}: 8-16$.

Glavičić A. , 1983 Nalazi kamenih gromila na Velebitu. Senjski Zbornik $\mathrm{x}: 17-27$.

Glentworth R. , \& Muir J.W. , 1963 The soils of the county round Aberdeen. Inverurie and Fraserburgh. Memoir of the Soil Survey of Great Britain:Scotland. Edinburgh:HMSO.

Gould R. , 1966 The wealth quest among the Tolowa Indians of northwestern California. Proceedings of the American Philosophical Society 110 (I), 67-89.

Gregory-Warden P. , 1984 The Colline Metallifere: Prolegomena to the study of mineral exploitation in Central Italy. In Hackens $\mathrm{T}$, Holloway 
N. D. \& Holloway R. D. (eds) Crossroads of the Mediterranean. Archaeologica Transatlantica II (Louvain-la-Neuve), 349-364.

Gus̄tin M. , 1976 Libna. Posavski Musej, Brez̄ice.

Helms M. W., 1979 Ancient Panama: Chiefs in Search of Power. University of Texas Press.

Holleyman G. A., 1948 Tiree Craggans, Antiquity XX, 205-211.

Horvat J. , 1983 Prazgodovinske naselbinske najdbe pri Farni cerkvi v Kranju (Vorgeschichtliche Siedlungsfunde bei der Pfarrkirche in Kranj). Arheolos̄ki Vestnik 34 (Ljubljana 1984), 140-218.

Howell J. , 1983 Settlement and economy in Neolithic Northern France. International Series S-157.0xford:BAR.

Ilakovac B. , 1965 Pećina buta. Diadora 1:27-36.

Jelovina D. , 1968 Ranosrednjovjekovna nekropola na 'Razbojinama' u selu Kasić kraj Zadra. Starohrvatska Prosvjeta series III, 10:23-51.

Kalmeta A. , 1954 o seljac̄kom lonc̄arstvu u zapadnoj i srednjoj Bosni, Glasnik Zemaljskog Muzeja u Sarajevu (Istorija i etnografija) IX:

Keay S. , Late Roman rural settlement in eastern Spain. To appear in Barker G. (ed) Roman Agrarian Structure in the Mediterranean. London:British School in Rome.

Kirigin B. , 1987 Maslinovik - zaboravljena grc̄ka kula u starigradskom polju na otoku Hvaru. Obavijesti (Zagreb) 1:21-24.

Kirigin B. , n.d. Greeks in Central Dalmatia - some new evidence. Proceedings of the First Australian Congress for Classical Archaeology. Oxford:Oxford University Press.

Kirigin B. , \& Slaps̄ak B. , 1986 Starigradsko polje na otoku Hvaru. Arheolos̄ki Pregled 207-208.

Klaić N. , 1976 Zadar u srednjem vijeku. Zadar:Filozofski Fakultet Zadar.

Knez T. , 1966 Zarno Grobis̄ce v Novem mestu (Urnengraberfeld Novo mesto). Arheoloski Vestnik 17 (Ljubljana), 51-101.

Knez T. , 1967 Zarni grobovi v Brsljinu (Gräber der Urnenfelderzeit in Brsljin). Arheolos̄ki Vestnik 18 (Ljubljana), 155-161.

Knez T. , 1972 Novo mesto $v$ davnini (Novo mesto in der Vorzeit). Zalosba Obzorja, Maribor.

Knez T. , 1984 Zarno Grobis̄c̄e v Novem mestu: zac̄asno Poroc̄ilo o Raziskovanje $v$ Letu 1982 (Das Urnengräberfeld in Novo mesto: Vorbericht der Grabung 1982). Arheolos̄ki Vestnik 35 (Ljubljana), 119-133.

Levy J. , 1982 Social and Religious Organisation in Bronze Age Denmark. Supplementray Series 124 Oxford:BAR.

Lockwood J. C. , 1974 World climatology. London:Edward Arnold.

Loebert H. W., 1984 Types of potter's wheels and the spread of the spindle-wheel in German, in Van der Leeuw S. E. and Pritchard A. C. (eds) The Many Dimensions of Pottery. Amsterdam:Cingula VII : 203-226.

Love J. R., 1977 A Multivariate Analysis of Lithological coloration within the Catskill formation. Unpublished M. Sc. degree thesis, Pennsylvania State University.

Malez M. 1975 Tragovi paleolitika u Lici i susjednim oblastima. Arheolos̄ka problematika Like. Split:Hrvatsko Arheolos̄ko Drus̄tvo:9-18.

Malinowski T. , 1982 L'Ambre jaune Baltique et le problème de son Exportation' pendant les premières périodes de l'Âge du Fer. Savaria 16 (Szombathely 1983), 113-123. 
Mann M. , 1986 The sources of social power. Volume 1. A history of power from the beginning to $A D$ 1760. London:Cambridge University Press.

Marshall J. R., 1987 Clastic Particles - Scanning Electron Microscopy and Shape Analysis of Sedimentary and Volcanic Clasts. New York:Van Nostrand Reinhold.

Millett M. , 1986 Field survey calibration: a contribution. In Haselgrove C., Millett M. \& Smith I. (eds) Archaeology from the ploughsoil. Sheffield:Dept. of Archaeology \& Prehistory:31-37.

Millett M. , n.d. Pottery: population or supply pattern in the Ager Tarraconensis. To appear in Barker G. (ed) Roman Agrarian Structure in the Mediterranean. London:British School in Rome.

Muhly J. D., 1973 Copper and Tin - The Distribution of Mineral Resources and the nature of the Metals Trade in the Bronze Age. Transactions of the Connecticut Academy of Arts and Sciences, 43 (New Haven):155-535.

Muhly J. D., 1976 Supplement to Copper and Tin: The Distribution of Mineral Resources and the nature of the Metals Trade in the Bronze Age. Transactions of the Connecticut Academy of Arts and Sciences 46 (New Haven) : 77-136.

Müller-Karpe H. , 1959 Beitrăge zur Chronologie der Urnenfelderzeit nordlich und südlich der Alpen, I. Römisch-Germanisch Forschungen 22 (Berlin).

Museum of London Department of Urban Archaeology, 1984 Pottery Archive Users' Handbook. Extract from DUA Finds Processing Manual. London:Museum of London Department of Urban Archaeology.

Nandris J. G., 1984 La Civilisation de Cucuteni en Contexte Européen, Bibliotheca Archaeologica Iassiensis 1, Universitaţe Iași:201-222.

Nandris J. G., 1985 The Stina and the Katun: foundations of a research design in highland zone ethnoarchaeology. World Archaeology $17 / 2: 256-268$.

Orme B., 1981 Anthropology for Archaeologists: An Introduction, Duckworth, London.

Osterc v. , 1986 Mineralogija Keramike iz Ajdovske Jame 1. Proc̄ilo 0 Raziskovanyu Paleolita, Neolita in Eneolitica v Sloveniji Vol XIV. Universa Edvarda Kardelja, Ljubljana, 97-110.

Ostrić 0. , 1978 Narodno Lonc̄arstvo. Zadar:Etnografski Musej Zadar.

Pahić S. , 1973 Najdišča staresjse z̄elezne dobe v Podravju. Arheolos̄ki Vestnik 24 (Ljubljana 1975), 521-543.

Pahić S. , 1975 Neolitsko in eneolitsko obdobje, Arheolos̄ka najdis̄̄̃a Slovenije. Slovenska Akademia znanosti in umetnosti, Institut za arheologijo, Ljubljana, 43-49.

Pahić S. ' 1981 Brinjeva gora 1953. Arheolos̄ki Vestnik 32 (Ljubljana), 71-143.

Pahić v. , 1983 Zakopna najda iz Pekla pri Mariboru (Vergrabungsfund aus Pekel bei Maribor). Arheolos̄ki Vestnik 34 (Ljubljana 1984), 106-128.

Parker-Pearson M. , 1982 Mortuary practices, society and ideology: an ethnoarchaeological study. In Hodder I. (ed) Symbolic and structural archaeology. Cambridge:Cambridge University Press.

Patsch K. , 1900 Die Lika in Römischer Zeit. Schriften der Balkankommission:Antiquarische Abteilung I. Wien:Kaiserliche Akademie der Wissenschaften.

Pavelić R. , 1973 Bunjevci. unpub. ms. Zagreb.

Peacock D. P. S., 1970 The Scientific Analysis of Ancient Ceramics: 
Review. World Archaeology 1, 375-389.

Peacock D. P. S., 1981 Archaeology, Ethnology and Ceramic Distribution. In Howard H. and Morris E. L. (eds.), Production and Distribution: A Ceramic Viewpoint. International Series S-120:0xford:BAR:187-194.

Peacock D. P. S., 1982 Pottery in the Roman World: An Ethnoarchaeological approach. London: Longmans .

Perry B. T., 1969 Iron Age enclosures and settlements on the Hampshire chalklands. Archaeological Journal 126:29-43.

Petrić N. , 1975 Arheolos̄ka istrażivanja otoka Hvara. Hvarski Zbornik $3: 243-268$.

Pettijohn F. J., 1975 Sedimentary Rocks. Harper and Row, London, Third edition.

Petz B. , 1985 Osnovne Statistic̄ke metode za Nematematic̄are. Sveuc̄ilista Naklada Liber, Zagreb, Second Edition.

Pittioni R. , 1954 Urgeschichte des österreichischen Raumes. Wien:Franz Deuticke.

Pope K. O. , \& van Andel T. H. , 1984 Late Quaternary alluviation and soil formation in the southern Argolid: its history, causes and archaeological implications. Journal of Archaeological Science $11: 281-306$.

Popović C. D., 1959 Tekhnika Primitivnog Lonc̄arstva Jugoslaviji, Glasnika Zemaljskog Muzeja u Sarajevu 14:25-59.

Popović C. D., 1960 Narodnog Lonc̄arstva, Pregled, Beograd.

Poulik J. , 1950 Jizni Morava zeme davnych Slovanu. Brno.

Pounds N. J. G. , 1969 Eastern Europe. London:Longmans.

Price B. J. , 1984 Competition, Productive Intensification and Ranked Society: Speculations from Evolutionary Theory. In Ferguson R. B. (eds) Warfare, culture and environment. London:Academic Press:209-240.

Pus̄ I. , 1971 Zarnogrobis̄ēna nekropola na dvoriscu SAZU v Ljubljani. Razprave I, razprave SAZU $7 / 1$ (L jubljana).

Pus I. , 1973 Pomen ljubljanskega prostora v starejsi z̄elezni dobi (The significance of the Ljubljana Region in the Early Iron Age). Arheolos̄ki Vestnik 24 (Ljubljana 1975), 386-396.

Pus̄ I. , 1982 Prazgodovinsko zarno grobis̄̄ée v Ljubljani. Razprave I, razprave SAZU $3 / 2$ (L jubljana).

Pus̄ I. , 1984 Prazgodovinski Molnik (Das vorgeschichtliche Molnik). Arheolos̄ki Vestnik 35 (Ljubljana), 134-162.

Raukar T. , 1977 Zadar u XV stoljeću. Ekonomski razvoj i drus̄tveni odnosi. Zagreb:Sveuciliste u Zagrebu, Institut za hrvatsku povijest.

Rice P. M., 1984 Change and Conservatism in Pottery-producing Systems, in Van der Leeuw S. E. and Pritchard H. E. (eds) The Many Dimensions of Pottery, Amsterdam:Cingula vII:231-288.

Richards J., 1985 Scouring the surface: Approaches to the Ploughsoil in the Stonehenge Environs. Archaeological Review from Cambridge 4, 27-42.

Richards J. , 1987 The significance of Form and Decoration of Anglo-Saxon Cremation Urns. Oxford.

Rowlands M. , 1980 Kinship, alliance and exchange in the European Bronze Age. In Barrett J. C. and Bradley R. J. (eds.) Settlement and society in the later British Bronze Age. British Series B-83. Oxford:BAR: $1-45$. 
Runnels C. N., \& Hansen J. , 1986 The olive in the prehistoric Aegean: the evidence for domestication in the Early Bronze Age. Oxford Journal of Archaeology $5 / 3: 29$.

Russu I. I. , 1958 Din trecutul pastoritului Romînesc. Anuarul Muzeului Etnografic al Transîlvaniei (Cluj) 1957-8:135-156.

Rutter J. , 1983 Some thoughts on the analysis of ceramic data generated by site surveys. In Keller D. R. \& Rupp D. W. (eds) Archaeological survey in the Mediterranean area. International Series I-155. Oxford:BAR: $137-142$.

Salviat F. , \& Vatin C. , 1974 Le cadastre de Larissa. Bulletin de Correspondance Hellénique 98:247-262.

S̄as̄el J. , 1977 Strabo, Ocra and Archaeology. In Markotić v. ; (ed.). Ancient Europe and the Mediterranean. Warminster:Aris \& Phillips: $157-160$.

Shennan S. J., 1985 Experiments in the collection and analysis of archaeological survey data: the East Hampshire Survey. Sheffield:Dept. of Archaeology \& Prehistory.

Sherratt A., 1979 Plough and pastoralism: aspects of the secondary products revolution. In Hodder I., Hammond N. \& Isaac G., (eds) Patterns in the past. Cambridge:Cambridge University Press:261-305.

Slovenska Akademija Nauka, 1975 Arheolos̄ka najdis̄ča Slovenije Ljubljana:Slovenska Akademija Nauka.

Staré F. , 1954 Ilirske najdbe żelezne dobe v Ljubljani. Dela I, razprave SAZU (L jubljana).

Staré F. , 1955 Vac̄e. Arheolos̄ki Katalogi Slovenije Ljubljana

Streeten A. D. F., 1980 Textural Analysis: an Approach to the characterisation of Sand Tempered ceramics. In Freestone I. , Jones C. and Potter T. (eds.). Current Research in Ceramics - Thin Section Studies. British Museum Occasional Papers, Vol. 32, London.

Strnc̄nik-Gulić M. , 1979 Prazgodovinske gomile na Legnu pri Slovenj Gradcu (Vorgeschichtliche Grabhugel auf dem Legen bei Slovenj Gradec). Arheološki Vestnik 30 (Ljubljana), 101-150.

Suić M. , 1974 Antic̄ki grad na istoc̄nom Jadranu. Zagreb:Jugoslavenska Akademija Znanosti i Umjetnosti.

Thomas D. H., 1975 Non Site Sampling in Archaeology: up the Creek without a Site. In Mueller J. w. (ed) Sampling in Archaeology.Tucson:University of Arizona Press:61-81.

Tomić E. , 1983 Grnc̄arstvo u Srbiji. Beograd:Etnografski Musej u Beograd. Trenz A. , 1985 Prazgodovinske najdbe iz Velikega Kamna. Internal paper number 7, Posavski musej Brez̄ice, 16-18.

Tringham R. , 1971 Hunters, fishers and farmers of Eastern Europe, $6000-$ 3000 BC. London:Hutchinson.

Trošelj M. , 1981 Mirile. Senjski zbornik IX:115-148.

van Andel T. H. , Runnels C. N. \& Pope K. O., 1986 Five thousand years of land use and abuse in the southern Argolid, Greece. Hesperia $55: 103-128$.

van As A. , 1984 Reconstructing the Potter's Craft, in Van der Leeuw S. E. and Pritchard H. E. (eds) The Many Dimensions of Pottery. Amsterdam:Cingula VII:129-160.

van der Leeuw S. E., 1984 Dust to Dust: A Transformational View of the Ceramic Cycle, in Van der Leeuw S. E. and Pritchard H. E. (eds) The Many Dimensions of Pottery. Amsterdam:Cingula VII:707-774. 
Vinsc̄ak T. , 1983 Transhumantno stoc̄arstvo na Velebitu. Etnolos̄ki Pregled (Sarajevo) 18:101-105.

Vuga D. , \& Turk I. , 1984 Zamedvedica pri Plesivci. Novo eneolitsko naselje na Ljubljanskem barju. Arheolos̄ki Vestnik xxxv, 76-89.

Whittle A. , 1985 Neolithic Europe. A survey. Cambidge:Cambridge University Press.

Wilkes J. J., 1969 Dalmatia. London:Routledge \& Kegan Paul.

Woodward P. J. , 1978 Flint Distribution, ring ditches and Bronze Age settlement patterns in the Great Ouse Valley: the problem, a field survey technique and some preliminary results. Archaeological Journal $135,32-56$.

Zaninović M. , 1982 Nalazi sa Tora kod Jelse kao prilog njegovoj kronologiji. Opuscula archaeologica 7:61-76.

Zaninović M. , 1983 Greek land division at Pharos. Archaeologica Iugoslavica $\mathrm{xx}: 20-21$.

Zaninović M. , 1984 New contributions to the archaeology of Pharos. Vjesnik za arheologiju i historiju dalmatinsku 77:93-101. 